
«ЛЕЧЕНИЕ ОЖИРЕНИЯ И КОМОРБИДНЫХ ЗАБОЛЕВАНИЙЖ

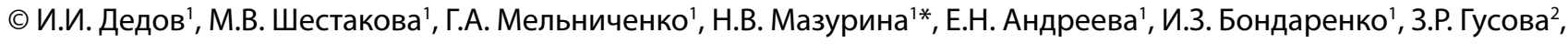
Ф.Х. Дзгоева ${ }^{1}$, М.С. Елисеев ${ }^{3}$, Е.В. Ершова' ${ }^{1}$, М.В. Журавлева ${ }^{4}$, Т.А. Захарчук' ${ }^{1}$ В.А. Исаков ${ }^{5}$, М.В. Клепикова ${ }^{6}$,

К.А. Комшилова' , В.С. Крысанова7, С.В. Недогода ${ }^{8}$, А.М. Новикова ${ }^{3}$, О.Д. Остроумова ${ }^{6}$, А.П. Переверзев ${ }^{6}$, Р.В. Роживанов ${ }^{1}$, Т.И. Романцова7, Л.А. Руяткина ${ }^{9}$, А.С. Саласюк ${ }^{8}$, А.Н. Сасунова ${ }^{5}$, С.А. Сметанина ${ }^{10}$, А.В. Стародубова ${ }^{5}$, Л.А. Суплотова ${ }^{10}$, О.Н. Ткачева" ${ }^{11}$, Е.А. Трошина', М.Б. Хамошина ${ }^{12}$, С.М. Чечельницкая ${ }^{13}$, Е.А. Шестакова' , Е.В. Шереметьева'

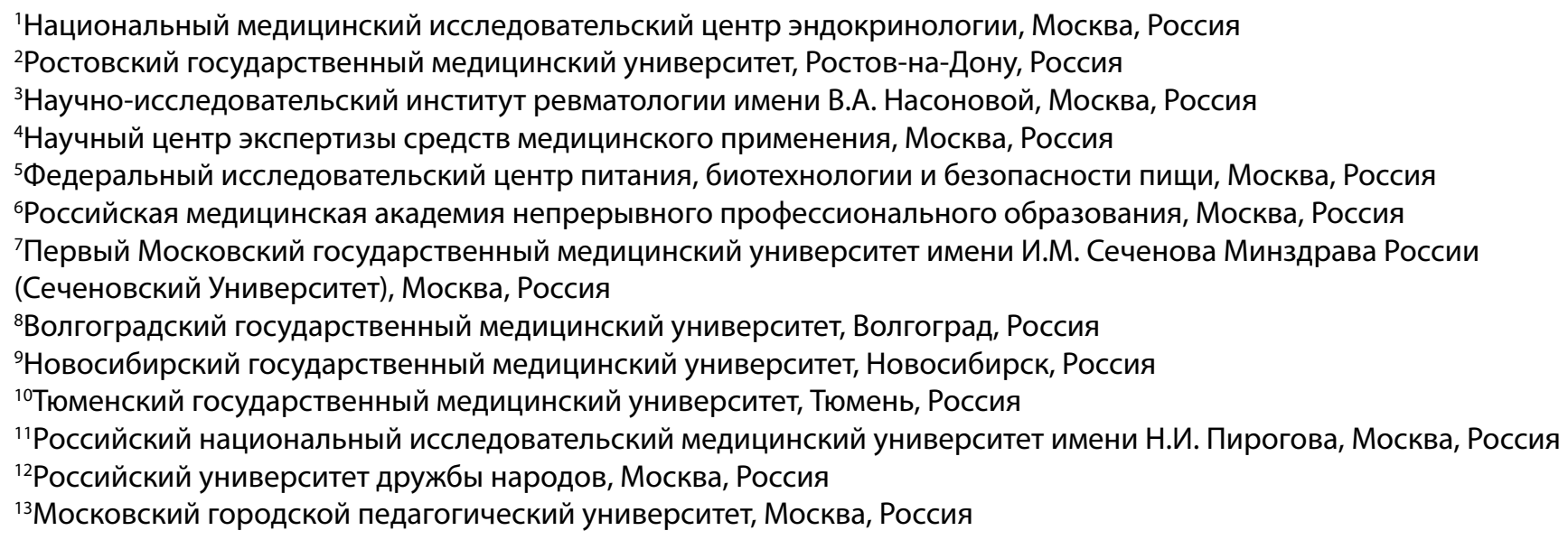

Клинические рекомендации уже давно вошли в число рабочих инструментов современного врача, помогая ему быстро ориентироваться в наиболее эффективных доказанных методах лечения и профилактики различных заболеваний, а также адаптировать эти методы к конкретным задачам своих больных и добиваться максимальной персонализации лечения. Клинические рекомендации составляются профессиональными некоммерческими ассоциациями и одобряются научным советом МЗ РФ, при этом нередко одна рекомендация готовится двумя или даже тремя ассоциациями. Особенность предлагаемых вашему вниманию рекомендаций в том, что в профилактику и лечение ожирения вовлекаются не только эндокринологи, но и терапевты, кардиологи, гинекологи, гастроэнтерологи и врачи многих других специальностей. Мультидисциплинарная рабочая группа представляет этот проект в многопрофильном журнале с целью объединения усилий нескольких профессиональных ассоциаций, что связано с необходимостью уделить внимание не только самому ожирению, но и коморбидным состояниям. Мы надеемся на конструктивную критику и разностороннее обсуждение проблемы на страницах нашего журнала.

КЛЮЧЕВЫЕ СЛОВА: кЛинические рекомендации, артериальная гипертензия, бандажирование желудка, бариатрическая / метаболическая хирургия, билиопанкреатическое шунтирование, гипокалорийное питание, желудочное шунтирование, лираглутид, морбидное ожирение, ожирение, орлистат, рукавная гастрэктомия, сахарный диабет 2 типа, сибутрамин, обструктивное апноэ сна, физическая активность, постменопауза, неалкогольная жировая болезнь печени, гиперурикемия, подагра.

\title{
ЦИТИРОВАТЬ:
}

Дедов И.И., Шестакова М.В., Мельниченко Г.А., Мазурина Н.В., Андреева Е.Н., Бондаренко И.З., Гусова 3.Р., Дзгоева Ф.Х., Елисеев М.С., Ершова Е.В., Журавлева М.В., Захарчук Т.А., Исаков В.А., Клепикова М.В., Комшилова К.А., Крысанова В.С., Недогода С.В., Новикова А.М., Остроумова О.Д., Переверзев А.П., Роживанов Р.В., Романцова Т.И., Руяткина Л.А., Саласюк А.С., Сасунова А.Н., Сметанина С.А., Стародубова А.В., Суплотова Л.А., Ткачева О.Н., Трошина Е.А., Хамошина М.Б., Чечельницкая С.М., Шестакова Е.А., Шереметьева Е.В. Междисциплинарные клинические рекомендации «Лечение ожирения и коморбидных заболеваний» // Ожирение и метаболизм. — 2021. — Т. 18. — №1. - С. 5-99. doi: https://doi.org/10.14341/omet12714 


\section{INTERDISCIPLINARY CLINICAL PRACTICE GUIDELINES "MANAGEMENT OF OBESITY AND ITS COMORBIDITIES"}

() Ivan I. Dedov', Marina V. Shestakova', Galina A. Melnichenko', Natalia V. Mazurina'*, Elena N. Andreeva', Irina Z. Bondarenko', Zalina R. Gusova², Fatima K. Dzgoeva', Maksim S. Eliseev', Ekaterina V. Ershova', Marina V. Zhuravleva4, Tatyana A. Zakharchuk', Vasilii A. Isakov', Mariya V. Klepikova ${ }^{6}$, Kseniya A. Komshilova', Vera S. Krysanova ${ }^{7}$, Sergei V. Nedogoda ${ }^{8}$, Aleksandra M. Novikova ${ }^{3}$, Olga D. Ostroumova ${ }^{6}$, Anton P. Pereverzev ${ }^{6}$, Roman V. Rozhivanov' Tatyana I. Romantsova ${ }^{7}$, Lyudmila A. Ruyatkina ${ }^{9}$, Alla S. Salasyuk ${ }^{8}$, Armida N. Sasunova ${ }^{5}$, Svetlana A. Smetanina ${ }^{10}$, Antonina V. Starodubova ${ }^{5}$, Lyudmila A. Suplotova ${ }^{10}$, Olga N. Tkacheva ${ }^{11}$, Ekaterina A. Troshina', Marina B. Khamoshina ${ }^{12}$, Serafima M. Chechelnitskaya ${ }^{13}$, Ekaterina A. Shestakova', Ekaterina V. Sheremet'eva'

'Endocrinology Research Centre, Moscow, Russia

${ }^{2}$ Rostov State Medical University, Rostov-on-Don, Russia

${ }^{3}$ Research Institute of Rheumatogy named after V.A. Nasonova, Moscow, Russia

${ }^{4}$ Scientific Centre for Expert Evaluation of Medicinal Products, Moscow, Russia

${ }^{5}$ Federal Research Center of Nutrition, Biotechnology and Food Safety, Moscow, Russia

${ }^{6}$ Russian Medical Academy of Continuous Professional Education, Moscow, Russia

${ }^{7}$ Sechenov First Moscow State Medical University, Moscow, Russia

${ }^{8}$ Volgograd State Medical University, Volgograd, Russia

${ }^{9}$ Novosibirsk State Medical University, Novosibirsk, Russia

${ }^{10}$ Tyumen State Medical University, Tyumen, Russia

${ }^{1}$ Russian National Research Medical University named after N.I. Pirogov, Moscow, Russia

${ }^{12}$ Peoples' Friendship University of Russia, Moscow, Russia

${ }^{13}$ Moscow City University, Moscow, Russia

Clinical guidelines have long been one of the working tools of the modern doctor, helping him quickly navigate the most effective proven methods of treatment and prevention of various diseases, and also to adapt these methods to the specific tasks of their patients and to achieve maximum personalization of treatment. Clinical practice guidelines are drawn up by professional non-profit associations and are approved by the Scientific Council of the Ministry of Health of the Russian Federation, while often one recommendation is prepared by two or even three associations. The peculiarity of the recommendations offered to your attention is that not only endocrinologists, but also therapists, cardiologists, gynecologists, gastroenterologists, and experts of many other specialties are involved in the prevention and treatment of obesity. The Multidisciplinary Working Group presents this a project in a multidisciplinary journal to bring together the efforts of several professional associations that associated with the need to pay attention not only to obesity itself but also to comorbid conditions. We are looking forward to constructive criticism and a comprehensive discussion of the problem on the pages of our journal.

KEYWORDS: guidelines, arterial hypertension, gastric banding, bariatric / metabolic surgery, biliopancreatic diversion (BPD), hypocaloric nutrition, gastric bypass, liraglutide, morbid obesity, obesity, orlistat, sleeve gastrectomy, type 2 diabetes, sibutramin, obstructive sleep apnoe, physical activity, postmenopause, non-alcoholic fatty liver disease, hyperuricemia, gout.

\section{TO CITE THIS ARTICLE:}

Dedov II, Shestakova MV, Melnichenko GA, Mazurina NV, Andreeva EN, Bondarenko IZ, Gusova ZR, Dzgoeva FK, Eliseev MS, Ershova EV, Zhuravleva MV, Zakharchuk TA, Isakov VA, Klepikova MV, Komshilova KA, Krysanova VS, Nedogoda SV, Novikova AM, Ostroumova OD, Pereverzev AP, Rozhivanov RV, Romantsova TI, Ruyatkina LA, Salasyuk AS, Sasunova AN, Smetanina SA, Starodubova AV, Suplotova LA, Tkacheva ON, Troshina EA, Khamoshina MB, Chechelnitskay SM, Shestakova EA, Sheremet'eva EV. Interdisciplinary Clinical Practice Guidelines "Management of obesity and its comorbidities". Obesity and metabolism. 2021;18(1):5-99. doi: https://doi.org/10.14341/omet12714 
Мазурина Н.В., Суплотова Л.А., Сметанина С.А., Руяткина Л.А.

\section{ОПРЕДЕЛЕНИЕ}

Ожирение - это хроническое заболевание, характеризующееся избыточным накоплением жировой ткани в организме, представляющим угрозу здоровью, и являющееся основным фактором риска ряда других хронических заболеваний, включая сахарный диабет 2 типа (СД2) и сердечно-сосудистые заболевания (СС3) [1-3].

\section{ДИАГНОСТИКА ОЖИРЕНИЯ}

Диагностику ожирения в клинической практике следует проводить в три этапа: на первом этапе установить диагноз ожирения на основании антропометрических параметров, на втором - выявить осложнения, ассоциированные с ожирением, на третьем - провести дифференциальную диагностику для исключения вторичного ожирения, связанного с эндокринной или синдромальной патологией.

1.1. В качестве первого этапа диагностики и скрининга ожирения для лиц старше 18 лет рекомендуется определение антропометрических показателей - измерение массы тела, роста и окружности талии (уровень достоверности доказательств (УДД) 1, уровень убедительности рекомендаций (УУР) А).

1.2. Для диагностики ожирения и определения его степени рекомендуется расчет индекса массы тела (индекс Кетле), который представляет собой показатель, равный массе тела пациента в килограммах, разделенной на рост в метрах в квадрате (УДД 1, УУР А):

Индекс массы тела (ИМт) $=\frac{\text { Масса тела (кг) }}{\text { Рост }\left(\mathrm{M}^{2}\right)}$

При оценке ИМТ у лиц европеоидной расы нормальная масса тела соответствует значению ИМТ 18,5-24,9 кг/м².

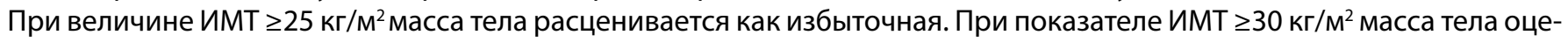
нивается как ожирение (табл. 1) [4].

Таблица 1. Классификация ожирения по индексу массы тела (ВО3, 1995 г. с дополнениями) [4]

\begin{tabular}{|c|c|c|c|}
\hline Масса тела & $\begin{array}{c}\text { ИМт, кг/м² } \\
\text { у лиц европеоидной } \\
\text { расы }\end{array}$ & 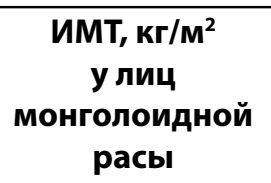 & Риск сопутствующих заболеваний \\
\hline Дефицит массы тела & $<18,5$ & $<18,5$ & Низкий (повышен риск других заболеваний) \\
\hline Нормальная масса тела & $18,5-24,9$ & $18,5-22,9$ & Обычный \\
\hline Избыточная масса тела & $25,0-29,9$ & $23,0-27,4$ & Повышенный \\
\hline Ожирение I степени & $30,0-34,9$ & $27,5-32,4$ & Высокий \\
\hline Ожирение II степени & $35,0-39,9$ & $32,5-37,4$ & Очень высокий \\
\hline Ожирение III степени & $\geq 40,0$ & $\geq 37,5$ & Чрезвычайно высокий \\
\hline
\end{tabular}

1.3. У пациентов европеоидной расы для оценки риска осложнений, ассоциированных с ожирением, в клинической практике рекомендуется использовать классификацию ожирения по ИМТ (ВО3, 1997): ожире-

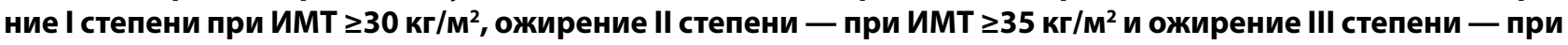
ИМТ $\geq 40$ кг/м² (УДД 1, УУР А) (табл. 1).

1.4. ИМТ не рекомендуется использовать для диагностики ожирения у пожилых людей, спортсменов, у лиц с чрезмерно развитой мускулатурой, беременных женщин, лиц с ампутированными конечностями, с выраженными отеками, поскольку данный показатель не является достоверно отражающим содержание жировой ткани в организме (УДД 1, УУР А).

Комментарии. ИМТ (индекс Кетле) позволяет косвенно судить о количестве жировой ткани в организме и диагностировать наличие низкой, нормальной, избыточной массы тела или ожирения [5-7]. Учитывая, что ИМТ $\geq 30$ кг/м² у лиц европеоидной расы и ИМТ $\geq 25,0$ кг/м² у лиц монголоидной расы в большинстве случаев ассоциирован с высоким содержанием жировой ткани в организме и, следовательно, является информативным и простым индикатором ожирения, достаточным в рутинной клинической практике в качестве первого этапа диагностики.

1.5. Другие методы оценки количества жировой ткани в организме, такие как биоэлектрический импеданс, плетизмография, двухэнергетическая рентгеновская абсорбциометрия, магнитно-резонансная томография и компьютерная томография могут использоваться в клинической практике в особых ситуациях, например, при наличии чрезмерно развитой мускулатуры, отеков, больших образований, низкорослости, после ампутаций конечностей, при саркопении, у пожилых лиц (УДД 3, УУР С). 
Комментарии. Клиническая значимость таких методов определения содержания жировой ткани в организме, как биоэлектрический импеданс, плетизмография, двухэнергетическая рентгеновская абсорбциометрия, ограничивается наличием, стоимостью и отсутствием исходных данных для валидированных точек. Золотым стандартом оценки количества подкожного и висцерального жира является магнитно-резонансная или компьютерная томография [7, 8]. Однако данные методы диагностики не подходят для рутинной клинической практики, так как они достаточно трудоемкие, дорогостоящие и вредны для здоровья при частом использовании. В настоящее время не получено убедительных данных, демонстрирующих, что более сложные методы диагностики ожирения более эффективны в работе с пациентами с ожирением.

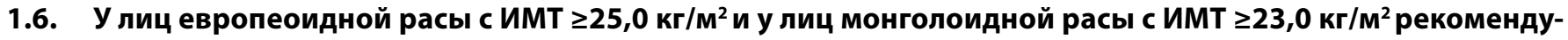
ется измерение окружности талии в качестве простого и информативного метода диагностики абдоминального ожирения (УДД 1, УУР А). Значения ОТ $\geq 80$ см у женщин и ОТ $\geq 94$ см у мужчин соответствуют абдоминальному ожирению и повышенному риску сердечно-сосудистых событий (УДД 1, УУР А) $[4,9-13]$.

Комментарии. Высокий показатель ОТ у лиц с ИМТ $\geq 25$ кг/м² связан с риском развития сахарного 2 типа, дислипидемии, артериальной гипертонии и сердечно-сосудистых заболеваний [13-15]. ОТ - уникальный индикатор распределения жировой ткани, который коррелирует с количеством абдоминального жира, является простым и недорогим методом для диагностики абдоминального ожирения [13-15]. Определение ОТ позволяет в рутинной клинической практике выявлять пациентов с высоким кардиометаболическим риском в большей степени, чем ИМТ [13-15].

В соответствии с протоколом Всемирной организации здравоохранения измерение ОТ должно производиться стоя без обуви, при плавном выдохе, при упоре на обе стопы и с руками, свободно вытянутыми вдоль туловища в средней точке между нижним краем последнего прощупываемого ребра и верхней частью гребня подвздошной кости. Измерительная лента должна быть изготовлена из материала, не поддающегося легкому растяжению. Лента должна располагаться перпендикулярно длинной оси тела и параллельно полу и иметь достаточное натяжение для обеспечения точности измерения. Измерения, как правило, выполняют два раза и регистрируются с точностью до $0,1 \mathrm{~cm}[4]$.

Другие антропометрические индексы ожирения (например, коэффициент отношения ОТ к росту, индекс «продукта накопления липидов», индекс висцерального ожирения и прочие) не рекомендуются к применению в рутинной клинической практике в связи с отсутствием достоверных данных о связи с абдоминальным ожирением и кардиоваскулярными событиями, а также из-за отсутствия крупномасштабных исследований по их оценке среди взрослых в Российской популяции.

\section{ОСОБЕННОСТИ ДИАГНОСТИКИ ОЖИРЕНИЯ В АЗИАТСКОЙ ПОПУЛЯЦИИ}

1.7. При интерпретации ИМТ у лиц монголоидной расы ИМТ 18,5-22,9 кг/м² расценивается как нормальный

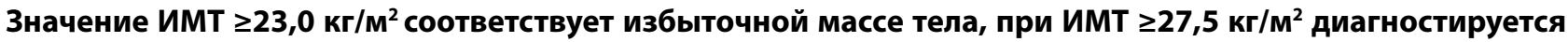
ожирение (УДД 1, УУР А).

1.8. Для лиц монголоидной расы с целью оценки риска развития осложнений, связанных с ожирением, рекомендуется использовать классификацию ожирения по ИМТ (ВО3, 1997 с дополнениями): ожирение 1-й степени при ИМТ $\geq 27,5$ кг/м², ожирение 2-й степени при ИМТ $\geq 32,5$ кг/м² и ожирение 3-й степени при ИМТ $\geq 37,5$ кг/м² (УДД 1, УУР А) (табл. 1).

1.9. У женщин монголоидной расы абдоминальное ожирение и наличие кардиометаболического риска следует устанавливать при значении ОТ $\geq 80$ см, у мужчин монголоидной расы абдоминальному ожирению и повышенному риску сердечно-сосудистых событий соответствует ОТ $\geq 90$ см (УДД 2, УУР В).

Комментарии. В Российской Федерации доля населения, относящего к различным типам монголоидной расы и к смешанным формам между монголоидной и европеоидной расой, составляет около 9\%. Если в европейской части территории России подавляющая часть населения относится к европеоидной расе, то в азиатской части страны доля представителей монголоидной расы значительно возрастает.

В последнее время отмечается устойчивая тенденция к увеличению распространенности ожирения в странах с азиатским населением, что обусловлено несбалансированностью питания и низкой физической активностью. Ожирение в азиатских популяциях имеет свои особенности: более высокий уровень жира в организме и меньшую массу скелетных мышц при том же или более низком значении ИМТ по сравнению с европеоидами, что послужило основанием для выделения особого фенотипа, сочетающего высокий уровень жира в организме, нормальный ИМТ и низкую мышечную массу. При этом отмечается избыточное накопление жира в брюшной полости и печени (неалкогольная жировая болезнь печени), что тесно связано с кардиометаболическим риском и ухудшением прогноза по заболеваемости и смертности [16-23].

Под кардиометаболическим риском понимают повышенную склонность к сердечно-сосудистым событиям, включая инсульт, инфаркт миокарда и заболевания периферических артерий, а также к обменным нарушениям, таким как сахарный диабет 2 типа, что продемонстрировано и в азиатских популяциях. По сути, концепция кардиометаболического риска акцентирует прогностическую роль метаболического синдрома. 
Именно более высокий кардиометаболический риск у лиц азиатских популяций потребовал изменения критериев диагностики избыточной массы тела и ожирения, отличных от неазиатского населения [18-23]. Известно, что прогностическое значение ОТ в отношении наличия метаболического синдрома выше, чем значение ИМт. Однако ОТ не включает измерение роста и, следовательно, может иметь ограничения в прогнозировании факторов риска ССЗ для высоких и низкорослых групп населения.

В ходе исследований азиатских популяций отмечалось, что ОТ имеет существенную вариабельность и ряд ограничений. В качестве альтернативы было предложено измерение окружности шеи (ОШ) как простой и надежной антропометрический маркер [24]. Сделаны попытки определить половые количественные показатели ОШ на основании перекрестного обсервационного исследования в Бангладеш с высокой корреляцией с содержанием висцерального жира [25].

В то же время, хотя ИМТ отражает содержание как мышечной, так и жировой массы тела, но имеет важные преимущества: ИМТ легко измерить, что существенно в учреждениях первичной медицинской помощи. Среди разных этнических групп в Азии процентное содержание жира в организме при равном ИМТ может варьировать. Однако в целом у азиатов кардиометаболический риск выше, чем у неазиатской популяции в одинаковом диапазоне ИМТ. Поэтому именно этот антропометрический индекс используют для диагностики избыточной массы тела/ожирения в азиатских популяциях $[18,19]$.

Общепринято, что пороговые значения ИМТ для определения избыточного веса и ожирения должны быть ниже для азиатов. Эти критерии обсуждаются, и в разных странах с различными этническими особенностями азиатских популяций могут отличаться. В 2019 г. ADA (American Diabetes Association) в стандартах медицинской помощи в лечении сахарного диабета в разделе «Ведение ожирения» дают отрезные точки ИМТ, разработанные для азиатских популяций американцев [26]. На территории Российской Федерации проживают представители различных азиатских этносов (буряты, якуты и др.), в связи с чем встает вопрос о том, какую классификацию применить.

Кроме того, в этих же регионах для диагностики абдоминального ожирения и оценки риска заболеваний, связанных с ним, некоторыми авторами предложено использовать региональные и этнические значения пороговых значений ОТ: для мужчин от 85 см и для женщин от 74 до 80 см.

\section{ДИАГНОСТИКА ОСЛОЖНЕНИЙ ОЖИРЕНИЯ}

1.10. На втором этапе обследования всем лицам с ожирением, подтвержденным антропометрическими критериями, рекомендуется проводить диагностику осложнений, ассоциированных с избыточным содержанием жировой ткани в организме (УДД 2, УУР В).

1.11. У лиц с ожирением в рутинной клинической практике рекомендуется определение клинических и биохимических параметров, являющихся факторами риска развития сахарного диабета и сердечно-сосудистых заболеваний (УДД 3, УУР С).

Комментарии. К факторам сердечно-сосудистого риска относятся: артериальная гипертензия (АГ) (АД $\geq 130 / 85$ мм рт.ст.), повышение уровня триглицеридов (ТГ) ( $\geq 1,7$ ммоль/л), снижение уровня холестерина липопротеидов высокой плотности (ХС ЛПВП) (<1,0 ммоль/л у мужчин; <1,2 ммоль/л уженщин), повышение уровня холестерина липопротеидов низкой плотности (ХС ЛПНП) (>3,0 ммоль/л), гипергликемия натощак (глюкоза в плазме крови натощак $\geq 6,1$ ммоль/л), нарушение толерантности к глюкозе (глюкоза в плазме крови через 2 ч после нагрузки глюкозой в пределах $\geq 7,8$ и $\leq 11,1$ ммоль/л).

1.12. Для диагностики нарушений углеводного обмена (предиабет, сахарный диабет 2 типа) в качестве скрининга всем пациентам с ожирением рекомендовано определить глюкозу плазмы натощак (УДД 3, УУР С), или провести тест толерантности к глюкозе (УДД 1, УУР 1), и/или определить уровень гликированного гемоглобина (НВА1с) (УДД 5, УУР С).

Комментарии. При наличии ожирения и других факторов риска следует провести исследование глюкозы плазмы натощак, тест толерантности к глюкозе и/или определить уровень гликированного гемоглобина [27, 28]. Определение базального и стимулированного иммунореактивного инсулина в рутинной клинической практике не рекомендуется в связи с высокой вариабельностью и низкой информативностью. Согласно «Алгоритмам специализированной медицинской помощи больным сахарным диабетом» 2019 г., для диагностики нарушений углеводного обмена следует использовать критерии ВОЗ, представленные в главе 3 [29].

1.13. Для диагностики нарушений липидного обмена всем пациентам с ожирением рекомендуется определение липидного профиля, включая общий холестерин, ТГ, лПВП, лПНП (УДД 1, УУР А).

Комментарии. Для диагностики нарушений липидного обмена у лиц с ожирением следует использовать диагностические критерии, рекомендованные ВОЗ, Европейским обществом кардиологов (ЕОК) и Европейским обществом атеросклероза (EOA) по диагностике и лечению дислипидемий, представленные в главе 8.

1.14. Для диагностики артериальной гипертензии у всех пациентов с ожирением в качестве скрининга рекомендовано измерение артериального давления (УДД 1, УУР А).

Комментарии. При уровне АД $\geq 135 / 85$ мм рт.ст. для дополнительного обследования следует провести суточное мониторирование АД [30]. Измерение АД проводит врач или медсестра в амбулаторных условиях или в стационаре. 
Соблюдение правил измерения АД необходимо для точной диагностики артериальной гипертензии и определения степени тяжести.

Правила измерения АД: выполняется в положении исследуемого сидя в удобной позе; рука на столе, находится на уровне сердца; манжета накладывается на плечо, нижний край ее на 2 см выше локтевого сгиба.

Условия измерения АД: исключается употребление кофе и крепкого чая в течение 1 ч перед исследованием, рекомендуется не курить в течение 30 мин до измерения АД, отменяется прием симпатомиметиков, включая назальные и глазные капли. АД измеряется в покое после 5-минутного отдыха; в случае если процедуре измерения АД предшествовала значительная физическая или эмоциональная нагрузка, период отдыха следует продлить до 15-30 мин.

Оснащение для измерения АД: размер манжеты должен соответствовать размеру руки: резиновая раздуваемая часть манжеты должна охватывать не менее 80\% окружности плеча, для плеча окружностью 27-34 см - манжета $13 \times 30$ см; для плеча окружностью 35-44 см - манжета 16 × 38 см; для плеча окружностью 45-52 см - манжета $20 \times 42$ см. Таким образом, для многих пациентов, страдающих ожирением, манжеты стандартного размера могут быть недостаточными для получения достоверных результатов измерения АД. Столбик ртути или стрелка тонометра перед началом измерения должны находиться на нулевой отметке [31].

Для диагностики артериальной гипертензии у лиц с ожирением следует использовать критерии, представленные в главе 7, согласно Клиническим рекомендациям по диагностике и лечению артериальной гипертонии у взрослых Российского кардиологического общества и Российского медицинского общества по артериальной гипертонии.

1.15. Для диагностики неалкогольной жировой болезни печени (НАЖБП) всем пациентам с ожирением рекомендуется проведение ультразвукового исследования печени и определение уровня аланинаминотрансферазы (АлАТ), аспаргинаминотрансферазы (АсАТ) и гамма-глутамилтранспептидазы (ГГТ) (УДД 2, УУР В).

Комментарии. Для диагностики НАЖБП у лиц с ожирением следует использовать критерии, рекомендованные Российским обществом по изучению печени и Российской гастроэнтерологической ассоциацией, представленные в главе 10.

1.16. Для диагностики гиперурикемии всем пациентам с ожирением рекомендуется исследование уровня мочевой кислоты в сыворотке крови (УДД 2, УУР В).

Подробные рекомендации по диагностике и лечению нарушений обмена мочевой кислоты представлены в главе 14.

1.17. Все пациентки с ожирением и нарушениями менструального цикла, бесплодием или симптомами гиперандрогении (акне, гирсутизм или андрогенная алопеция) должны быть обследованы для исключения синдрома поликистозных яичников (СПКЯ) (УДД 2, УУР В).

Комментарии. Диагностика синдрома поликистозных яичников основана на регистрации клинических и лабораторных проявлений гиперандрогении, оценке менструальной, овуляторной функции, а также морфологии яичников с помощью ультрасонографии. У женщин с ожирением наличие СПКЯ должно быть установлено в соответствии с Роттердамским консенсусом, который требует наличия двух из трех критериев, включая гиперандрогению, хроническую ановуляцию и поликистоз яичников, которые оцениваются с помощью ультразвукового исследования [32]. В соответствии с согласованными критериями ASRM/ESHRE, принятыми в Роттердаме (2003), для диагностики поликистозных яичников при ультрасонографии необходимо наличие в яичнике 12 и более фолликулов, имеющих диаметр 2-9 мм, и/или увеличение овариального объема более 10 мл. Увеличение овариального объема считается более надежным критерием диагностики СПКЯ, чем количество фолликулов.

1.18. У всех пациентов с ожирением рекомендуется выявлять симптомы, характерные для обструктивного апноэ сна (OAC), и при их наличии для скрининга синдрома ОАС рекомендуется проведение ночной пульсоксиметрии в качестве неинвазивного метода измерения процентного содержания оксигемоглобина в артериальной крови (SpO $)$ (УДД 3, УУР C).

Комментарии. При выявлении комплекса ОАС, циклически повторяющихся эпизодов значительного снижения сатурации крови кислородом более чем на 4\% от базальной по данным пульсоксиметрии показано проведение полисомнографического исследования. Пациенты с диагностированным ОАС направляются в специализированное лечебное учреждение [33].

1.19. Все пациенты с ожирением должны быть обследованы путем опроса и физикального осмотра с целью диагностики остеоартрита и остеоартроза коленного и других крупных суставов (УДД 3, уУР С).

1.20. Пациенты с ожирением и симптомами гастроэзофагеальной рефлюксной болезни должны быть обследованы путем проведения эзофагогастродуоденоскопии (УДД 3, УУР С).

1.21. При выявлении симптомов депрессии пациенты с ожирением должны направляться на консультацию психиатра (УДД 3, УУР С).

Рекомендации по диагностике и лечению психосоматических расстройств у пациентов с ожирением в клинической практике представлены в главе 14. 


\section{ДИФФЕРЕНЦИАЛЬНАЯ ДИАГНОСТИКА ОЖИРЕНИЯ}

На третьем этапе для постановки диагноза «Ожирение, обусловленное избыточным поступлением энергетических ресурсов» (код по МКБ-10 Е66.0), или первичное ожирение, следует провести дифференциальную диагностику с целью исключения или подтверждения вторичного ожирения, вызванного эндокринной или синдромальной патологией.

1.22. Всем пациентам с ожирением рекомендуется определение уровня тиреотропного гормона (TTГ) в сыворотке крови для диагностики гипотиреоза с использованием тех же референсных значений уровня ТТГ, что и для лиц с нормальной массой тела (УДД 3, УУР С).

Комментарии. Распространенность гипотиреоза среди лиц с ожирением, по данным метаанализа 19 исследований, составляет 14\% (95\% доверительный интервал (ДИ) 9,7-18,9) [34, 35]. Некомпенсированный гипотиреоз может способствовать увеличению массы тела и развитию осложнений у лиц ожирением, а также снижать эффективность мероприятий, направленных на снижение массы тела. Диагностику гипотиреоза у пациентов с ожирением следует проводить согласно критериям диагностики, представленным в клинических рекомендациях Российской ассоциации эндокринологов.

1.23. Пациентам с ожирением, имеющим характерные клинические проявления (остеопороз, низкотравматичные переломы, спонтанные экхимозы, истончение кожи, наличие багровых стрий), рекомендуется обследование для исключения эндогенного гиперкортицизма (УДД 3, УУР С).

Комментарии. Частота эндогенного гиперкортицизма среди больных ожирением составляет около 1\% (0,9\%, 95\% ДИ 0,3-1,6) [36-38]. Принимая во внимание высокую распространенность ожирения, его многофакторную этиологию и низкую распространенность эндогенного гиперкортицизма, в настоящее время в рутинной клинической практике не рекомендуется проведение скрининга на эндогенный гиперкортицизм у всех пациентов с ожирением. Следовательно, скрининг для исключения гиперкортицизма следует проводить у пациентов, у которых, помимо ожирения, проявляются другие специфические симптомы гиперкортицизма.

Обследование для исключения эндогенного гиперкортицизма рекомендовано в следующих группах пациентов [36-42]: молодые люди с необычными для их возраста проявлениями (например, остеопороз с низкотравматическими переломами, сахарный диабет и ожирение, артериальная гипертензия, аменорея у женщин и снижение полового влечения у мужчин, быстрая прибавка массы тела в сочетании с выраженной общей и мышечной слабостью), пациенты с характерными изменениями внешности и множеством разнообразных клинических проявлений гиперкортицизма, пациенты со случайно выявленным новообразованием надпочечника, пациенты любого возраста с плохо контролируемым сахарным диабетом и/или гипертензией в сочетании с ожирением или быстрой прибавкой массы тела; пациенты с переломами тел позвонков, особенно множественными переломами в возрасте до 65 лет.

\subsection{4. Всем пациентам, являющимся кандидатами на бариатрические операции, рекомендовано исключение} эндогенного гиперкортицизма (УДД З, УУР С).

Комментарии. Несмотря на то что гиперкортицизм является достаточно редким заболеванием, в случае хирургического лечения ожирения данное состояние может стать причиной серьезных осложнений. Такие клинические черты, присущие гиперкортицизму, как гиперкоагуляция и высокий риск ССЗ, могут стать причиной серьезных осложнений как в раннем, так и позднем послеоперационном периоде [43, 44].

Ночной подавляющий тест с 1 мг дексаметазона может рассматриваться как тест первой линии. Риск ложноположительных результатов при морбидном ожирении несколько повышается, однако специфичность теста остается высокой и составляет 92\%. Недавние исследования показали, что увеличениедозы дексаметазона до 2 мг при ожирении не повышает чувствительности теста. При неадекватном подавлении уровня кортизола в ходе ночного подавляющего теста требуется проведение второго теста: определение кортизола слюны вечером или определение кортизола суточной мочи [45].

1.25. У мужчин с ожирением при наличии характерных жалоб и клинических проявлений гипогонадизма рекомендуется определение общего тестостерона, секс-стероидсвязывающего глобулина, расчет свободного тестостерона, исследование лютеинизирующего (ЛГ) и фолликулостимулирующего гормонов (ФСГ) (УДД 2, УУР В).

Комментарии. При диагностике гипогонадизма в рутинной клинической практике следует ориентироваться на три основных признака: снижение либидо и сексуальной активности, снижение числа утренних эрекций, снижение адекватных эрекций [46]. При диагностике гипогонадизма у лиц с ожирением следует использовать критерии, представленные в главе 6.

1.26. Исследование уровня пролактина при ожирении рекомендуется проводить у женщин с нарушениями менструального цикла, бесплодием и при наличии лактореи, а также у мужчин с гипогонадизмом, подтвержденным данными лабораторных исследований (УДД З, УУР С).

Комментарии. Вне зависимости от причины гиперпролактинемии, избыточная секреция пролактина приводит к нарушениям пульсаторного выброса ЛГ, ФСГ и, как следствие, к гипогонадизму и бесплодию [47]. Со стороны репродуктивной системы наблюдаются галакторея, нарушения менструального цикла (аменорея, олиго/опсоменорея, ановуляторные циклы, недостаточность лютеиновой фазы), бесплодие, снижение полового влечения, фригидность. У мужчин проявлениями гиперпролактинемии могут быть снижение или отсутствие либидо и потенции, уменьшение вторичных половых признаков, бесплодие вследствие олигоспермии, гинекомастия. Пациентов с макропролактиномами могут беспокоить жалобы, связанные с наличием объемного образования, — головная боль, повышение внутричерепного 
давления, сужение полей зрения. Основным диагностическим критерием гиперпролактинемии служит определение уровня пролактина в сыворотке крови. Сложность интерпретации показателей базального уровня пролактина обусловлена не только транзиторным повышением гормона при стрессах или чрезмерных физических нагрузках, но и существенной вариабельностью показателей у одного и того же больного при соблюдении всех рекомендаций по сбору крови. Большинство российских экспертов придерживаются мнения о необходимости как минимум двукратного проведения лабораторного анализа. Как правило, микроаденомы ассоциированы с уровнем более 5000 мЕд/л (250 мг/л), макроаденомы — более 10000 мЕд/л (500 мг/л), при этом уровень пролактина менее 2000 мЕд/л (100 мг/л) более характерен для гиперпролактинемии неопухолевого генеза [47].

\subsection{7. Пациентам с ожирением, прогрессирующим увеличением массы тела и клиническими признаками ги- погликемических состояний рекомендуется проведение обследования для исключения органического гиперинсулинизма (УДД 3, УУР С).}

Комментарии. Триада Уиппла остается фундаментом диагностики органического гиперинсулинизма. Триада представлена симптомами гипогликемии, снижением уровня глюкозы в плазме, исчезновением симптомов гипогликемии после введения глюкозы [48]. Общепринято, что диагноз инсулиномы должен быть лабораторно подтвержден, для чего используются следующие 6 критериев: документированное снижение уровня глюкозы в плазме $\leq 2,5$ ммоль/л, сопутствующий гипогликемии уровень инсулина $\geq 3,0$ мкЕД/мл, уровень С-пептида $\geq 0,6$ нг/мл; уровень проинсулина $\geq 5,0$ пмоль/л, уровень $\beta$-гидроксибутирата $\leq 2,7$ ммоль/л, отсутствие субстанций сахароснижающих препаратов в плазме и/или моче. При отсутствии возможности забора крови на фоне спонтанной гипогликемии проводится тест с голоданием, длительность которого может достигать 72 ч [48].

\subsection{8. Пациентам с ожирением, манифестировавшим в детском возрасте, и имеющим фенотипические осо- бенности рекомендуется провести диагностику для исключения несиндромального моногенного ожи- рения и синдромальных форм ожирения (УДД 3, УУР С).}

Комментарии. Моногенные формы ожирения обусловлены мутациями одного гена с высокой пенетрантностью. К моногенным формам ожирения относят: мутации гена лептина, гена рецептора лептина, гена прогормона конвертазы 1, гена проопиомеланокортина, гена рецептора меланокортина-4, гена рецептора нейротропной тирозиновой киназы 2-го типа. Следует отметить, что моногенные формы ожирения встречаются крайне редко [49].

Синдромальные формы ожирения наблюдаются при хромосомных и других генетических синдромах и отличаются широким клиническим полиморфизмом. При подозрении на синдромальное или моногенное ожирение рекомендуется проведение молекулярно-генетического или цитогенетического исследования [49].

Синдром Прадера-Вилли: самый часто встречаемый вариант синдромального ожирения. Характерны мышечная гипотония при рождении, задержка нервно-психического развития, прогрессирующее ожирение со 2-го года жизни, гипогонадизм, низкорослость, отставание в умственном развитии, косоглазие, сколиоз.

ROHHAD-синдром: редкий синдром, основными компонентами которого являются ожирение в сочетании с гипоталамической дисфункцией, гиповентиляцией и дисрегуляцией автономной нервной системы.

Синдром Альстрёма: ожирение с детского возраста, дислипидемия, низкий рост, дилатационная кардиомиопатия, сахарный диабет, нистагм, светобоязнь, нейросенсорная тугоухость, задержка умственного развития, уронефрологические нарушения, бесплодие.

Синдром Барде-Бидля: ожирение с первого года жизни, пигментный ретинит, низкий рост, задержка умственного развития, полидактилия, синдактилия, врожденный порок сердца, нефрогенный несахарный диабет.

Синдром Коэна: основными признаками являются мышечная гипотония, умственная отсталость и ожирение. Характерны микроцефалия, большие уши, гипоплазия верней челюсти.

Синдром Карпентера: акроцефалия (высокий башенный череп), краниосиностоз и ожирение, синдактилия II-V пальцев рук, полидактилия и синдактилия пальцев ног, увеличение нижней челюсти, пороки сердца, умеренная умственная отсталость.

\section{СПИСОК ЛИТЕРАТУРЫ | REFERENCES}

Must A. The Disease Burden Associated With Overweight and Obesity. JAMA. 1999;282(16):1523. doi: https://doi.org/10.1001/jama.282.16.1523 Guh DP, Zhang W, Bansback N, Amarsi Z, Birmingham CL, Anis AH. The incidence of co-morbidities related to obesity and overweight: A systematic review and meta-analysis. BMC Public Health. 2009;9(1):88. doi: https://doi.org/10.1186/1471-2458-9-88

3. Lenz M, Richter T, Mühlhauser I. The Morbidity and Mortality Associated With Overweight and Obesity in Adulthood. Dtsch Aerzteblatt Online. 2009;106:641-648. doi: https://doi.org/10.3238/arztebl.2009.0641

4. Physical status: the use and interpretation of anthropometry. Report of a WHO Expert Committee. World Health Organ Tech Rep Ser. 1995. doi: https://doi.org/10.1002/(sici)1520-6300(1996)8:6<786:aidajhb11 $>3.0$. co; $^{2}-\mathrm{i}$

Forbes GB, Reina JC. Adult lean body mass declines with age: Some longitudinal observations. Metabolism. 1970;19(9):653-663. doi: https://doi.org/10.1016/0026-0495(70)90062-4
6. Rolland-Cachera MF et al. Body mass index variations — centiles from birth to 87 years. European Journal of Clinical Nutrition. 1991;45:13-21.

7. Ross R, Shaw KD, Rissanen J, et al. Sex differences in lean and adipose tissue distribution by magnetic resonance imaging: anthropometric relationships. Am J Clin Nutr. 1994;59(6):1277-1285. doi: https://doi.org/10.1093/ajcn/59.6.1277

8. Shen W, Wang Z, Punyanita M, et al. Adipose Tissue Quantification by Imaging Methods: A Proposed Classification. Obes Res. 2003;11(1):5-16. doi: https://doi.org/10.1038/oby.2003.3

9. Alberti KGMM, Zimmet P, Shaw J. The metabolic syndrome-anewworldwidedefinition.Lancet.2005;366(9491):1059-1062. doi: https://doi.org/10.1016/S0140-6736(05)67402-8

10. https://www.who.int/en/news-room/fact-sheets/detail/obesity-andoverweight

11. Lean MEJ, Han TS, Morrison CE. Waist circumference as a measure for indicating need for weight management. BMJ. 1995;311(6998):158-161 doi: https://doi.org/10.1136/bmj.311.6998.158 
12. Han TS et al. Waist circumference relates to intra-abdominal fat mass better than waist:hip ratio in women. Proceedings of the Nutrition Society. 1995:54:152A.

13. Pouliot M-C, Després J-P, Lemieux S, et al. Waist circumference and abdominal sagittal diameter: Best simple anthropometric indexes of abdominal visceral adipose tissue accumulation and related cardiovascular risk in men and women. Am J Cardiol. 1994;73(7):460-468. doi: https://doi.org/10.1016/0002-9149(94)90676-9

14. Wormser $D$, et al. Separate and combined associations of body-mass index and abdominal adiposity with cardiovascular disease: collaborative analysis of 58 prospective studies. Lancet. 2011;377(9771):1085-1095. doi: https://doi.org/10.1016/S0140-6736(11)60105-0

15. Fox CS, Massaro JM, Hoffmann U, et al. Abdominal Visceral and Subcutaneous Adipose Tissue Compartments. Circulation. 2007;116(1):39-48. doi: https://doi.org/10.1161/CIRCULATIONAHA.106.675355

16. Misra A, Jayawardena R, Anoop S. Obesity in South Asia: Phenotype, Morbidities, and Mitigation. Curr Obes Rep. 2019;8(1):43-52. doi: https://doi.org/10.1007/s13679-019-0328-0

17. Cheng L, Yan W, Zhu L, et al. Comparative analysis of IDF, ATPIII and CDS in the diagnosis of metabolic syndrome among adult inhabitants in Jiangxi Province, China. PLoS One. 2017;12(12):e0189046. doi: https://doi.org/10.1371/journal.pone.0189046

18. Nishida C, Barba C, Cavalli-Sforza T, et al. Appropriate bodymass index for Asian populations and its implications for policy and intervention strategies. Lancet. 2004;363(9403):157-163. doi: https://doi.org/10.1016/S0140-6736(03)15268-3

19. Pan W-H, Yeh W-T. How to define obesity? Evidence-based multiple action points for public awareness, screening, and treatment: an extension of Asian-Pacific recommendations. Asia Pac J Clin Nutr. 2008. doi: https://doi.org/10.6133/apjcn.2008.17.3.02

20. Nam GE, Park HS. Perspective on Diagnostic Criteria for Obesity and Abdominal Obesity in Korean Adults. J Obes Metab Syndr. 2018;27(3):134-142. doi: https://doi.org/10.7570/jomes.2018.27.3.134

21. Zeng Q, He Y, Dong S, et al. Optimal cut-off values of BMI, waist circumference and waist:height ratio for defining obesity in Chinese adults. Br J Nutr. 2014;112(10):1735-1744. doi: https://doi.org/10.1017/S0007114514002657

22. Jih J, Mukherjea A, Vittinghoff E, et al. Using appropriate body mass index cut points for overweight and obesity among Asian Americans. Prev Med (Baltim). 2014;65:1-6. doi: https://doi.org/10.1016/j.ypmed.2014.04.010

23. Garvey WT, Mechanick Jl, Brett EM, et al. Reviewers of the AACE/ACE Obesity Clinical Practice Guidelines. American association of clinical endocrinologists and American college of endocrinology comprehensive clinical practice guidelines for medical care of patients with obesity. EndocrPract. 2016;22(3):1-203. doi: https://doi.org/10.4158/EP161365

24. Anothaisintawee T, Sansanayudh N, Thamakaison S, et al. Neck Circumference as an Anthropometric Indicator of Central Obesity in Patients with Prediabetes: A Cross-Sectional Study. Biomed Res Int. 2019;2019:1-8. doi: https://doi.org/10.1155/2019/4808541

25. Qureshi N, Hossain T, Hassan M, et al. Neck circumference as a marker of overweight and obesity and cutoff values for Bangladeshi adults. Indian J Endocrinol Metab. 2017;21(6):803. doi: https://doi.org/10.4103/ijem.IJEM_196_17

26. ADA. Standarts of medical care in diabetes-2019. Diabetes Care. 2019;24(1):s1-s187.

27. WHO. Definition and Diagnosis of Diabetes Mellitus and Intermediate Hyperglycemia: Report of a WHO/IDF Consultation; 2006.

28. Дедов И.И., Шестакова М.В., Майоров А.Ю., и др. Алгоритмы специализированной медицинской помощи больным сахарным диабетом: Клинические рекомендации (Вып. 9) // Сахарный диабет. - 2019. - T. 22. — №S1. — C. 1-144. [Dedov II, Shestakova MV, Mayorov AYu, et al. Standards of specialized diabetes care. Diabetes Mellitus. 2019;22(S1):1-144 (In Russ.)] doi: https://doi.org/10.14341/DM221S1

29. Piepoli MF, Hoes AW, Agewall S, et al. ESC Scientific Document Group. 2016 European Guidelines on cardiovascular disease prevention in clinical practice: The Sixth Joint Task Force of the European Society of Cardiology and Other Societies on Cardiovascular Disease Prevention in Clinical Practice (constituted by representatives of 10 societies and by invited experts) Developed with the special contribution of the European. Association for Cardiovascular Prevention \& Rehabilitation (EACPR). Eur Heart J. 2016;37:2315-2381.
30. Российское медицинское общество по артериальной гипертонии. Рекомендации по ведению больных артериальной гипертонией с метаболическими нарушениями и сахарным диабетом 2-го типа // Cистемные гипертензии. - 2020. - Т. 17. - №1. - С. 7-45. [Chazova IE, Shestakova MV, Zhernakova YV, et al. Guidelines on treatment of patients with arterial hypertension comorbid with metabolic disorders and diabetes mellitus type 2. Syst Hypertens. 2020;17(1):7-45. (In Russ.)]. doi: https://doi.org/10.26442/2075082X.2020.1.200051

31. Chazova IE, Shestakova MV, Zhernakova YV, et al. Revised 2003 consensus on diagnostic criteria and long-term health risks related to polycystic ovary syndrome (PCOS). Hum Reprod. 2004;19(1):41-47. doi: https://doi.org/10.1093/humrep/deh098

32. Kapur VK, Auckley DH, Chowdhuri S, et al. Clinical Practice Guideline for Diagnostic Testing for Adult Obstructive Sleep Apnea: An American Academy of Sleep Medicine Clinical Practice Guideline. J Clin Sleep Med. 2017;13(03):479-504. doi: https://doi.org/10.5664/jcsm.6506

33. Garmendia Madariaga A, Santos Palacios S, Guillén-Grima F, Galofré JC. The Incidence and Prevalence of Thyroid Dysfunction in Europe: A Meta-Analysis. J Clin Endocrinol Metab. 2014;99(3):923-931. doi: https://doi.org/10.1210/jc.2013-2409

34. Michalaki MA, Vagenakis AG, Leonardou AS, et al. Thyroid Function in Humans with Morbid Obesity. Thyroid. 2006;16(1):73-78. doi: https://doi.org/10.1089/thy.2006.16.73

35. Tiryakioglu O, Ugurlu S, Yalin S, et al. Screening for Cushing's syndrome in obese patients. Clinics. 2010;65(1):9-13. doi: https://doi.org/10.1590/S1807-59322010000100003

36. Lammert A, Nittka S, Otto M, et al. Performance of the $1 \mathrm{mg}$ dexamethasone suppression test in patients with severe obesity. Obesity. 2016;24(4):850-855. doi: https://doi.org/10.1002/oby.21442

37. Janković $\mathrm{D}$, Wolf $\mathrm{P}$, Anderwald $\mathrm{C}-\mathrm{H}$, et al. Prevalence of Endocrine Disorders in Morbidly Obese Patients and the Effects of Bariatric Surgery on Endocrine and Metabolic Parameters. Obes Surg. 2012;22(1):62-69. doi: https://doi.org/10.1007/s11695-011-0545-4

38. Catargi B, Rigalleau V, Poussin A, et al. Occult Cushing's Syndrome in Type-2 Diabetes. J Clin Endocrinol Metab. 2003;88(12):5808-5813. doi: https://doi.org/10.1210/jc.2003-030254

39. Leibowitz G, Tsur A, Chayen SD, et al. Pre-clinical Cushing's syndrome: an unexpected frequent cause of poor glycaemic control in obese diabetic patients. Clin Endocrinol (Oxf). 1996;44(6):717-722. doi: https://doi.org/10.1046/j.1365-2265.1996.737558.x

40. Steffensen C, Pereira AM, Dekkers OM, Jørgensen JOL. Diagnosis of endocrine disease: Prevalence of hypercortisolism in type 2 diabetes patients: a systematic review and meta-analysis. Eur J Endocrinol. 2016;175(6):R247-R253. doi: https://doi.org/10.1530/EJE-16-0434

41. Caetano MSS, Silva RDC, Kater CE. Increased diagnostic probability of subclinical cushing's syndrome in a population sample of overweight adult patients with type 2 diabetes mellitus. Arq Bras Endocrinol Metabol. 2007;51(7):1118-1127. doi: https://doi.org/10.1590/S0004-27302007000700015

42. Fleseriu M, Ludlam WH, Teh SH, Yedinak CG, Deveney C, Sheppard BC. Cushing's syndrome might be underappreciated in patients seeking bariatric surgery: a plea for screening. Surg Obes Relat Dis. 2009:5(1):116-119. doi: https://doi.org/10.1016/j.soard.2008.09.011

43. Savastano S, Pivonello R, Colao A. Bariatric surgery for obesity and hidden Cushing syndrome. Surg Obes Relat Dis. 2009;5(1):121-122. doi: https://doi.org/10.1016/j.soard.2008.07.006

44. Loriaux DL. Diagnosis and Differential Diagnosis of Cushing's Syndrome. N Engl J Med. 2017;376(15):1451-1459. doi: https://doi.org/10.1056/NEJMra1505550

45. Dhindsa S, Ghanim H, Batra M, Dandona P. Hypogonadotropic Hypogonadism in Men With Diabesity. Diabetes Care. 2018;41(7):1516-1525. doi: https://doi.org/10.2337/dc17-2510

46. Auriemma RS, De Alcubierre D, Pirchio R, et al. The effects of hyperprolactinemia and its control on metabolic diseases. Expert Rev Endocrinol Metab. 2018;13(2):99-106. doi: https://doi.org/10.1080/17446651.2018.1434412

47. Evaluation and Management of Adult Hypoglycemic Disorders: An Endocrine Society Clinical Practice Guideline. Journal of Clinical Endocrinology \& Metabolism. 2009;94(3):709-728.

48. van der Klaauw AA, Faroogi IS. The Hunger Genes: Pathways to Obesity. Cell. 2015;161(1):119-132. doi: https://doi.org/10.1016/j.cell.2015.03.008

49. Koves $\mathrm{H}$, Roth C. Genetic and Syndromic Causes of Obesity and its Management. Indian J Pediatr. 2018:85(6):478-485. doi: https://doi.org/10.1007/s12098-017-2502-2 


\title{
ГЛАВА 2. ЛЕЧЕНИЕ НЕОСЛОЖНЕННОГО ОЖИРЕНИЯ
}

\section{1. ОСНОВНЫЕ ПРИНЦИПЫ ЛЕЧЕНИЯ}

\author{
Ершова Е.В., Комшилова К.А.
}

Снижение массы тела показано всем пациентам, имеющим ожирение, а также пациентам с избыточной массой тела и наличием одного и более факторов риска ССЗ или с наличием сопутствующих заболеваний, течение которых ассоциировано с ожирением. Пациентам с избыточной массой тела, у которых нет сопутствующих заболеваний, течение которых ассоциировано с ожирением, или факторов риска СС3, рекомендуется не допускать дальнейшего увеличения массы тела. Целями лечения ожирения являются снижение массы тела до такого уровня, при котором достигаются максимально возможное уменьшение риска для здоровья и улучшение течения заболеваний, ассоциированных с ожирением; поддержание достигнутого результата; улучшение качества жизни больных.

2.1. Рекомендуется снижение массы тела на 5-10\% за 3-6 мес терапии и удержание результата в течение года, что позволяет уменьшить риски для здоровья, а также улучшить течение заболеваний, ассоциированных с ожирением. Большую (15-20\% и более) потерю массы тела можно рекомендовать для пациентов с ИМТ $\geq 35$ кг/М² при наличии коморбидных заболеваний [1-7] (УДД 5, УУР С).

Комментарии. С учетом того, что ожирение является хроническим заболеванием, контроль над ним необходимо осуществлять на протяжении всей жизни под постоянным наблюдением для предотвращения восстановления потерянной массы тела, а также для мониторинга рисков коморбидных заболеваний или их лечения (например, СД2, СС3).

2.2. Пациентам, достигшим клинически значимого снижения массы тела ( $\geq 5 \%$ от исходной), рекомендуется удержание веса в течение 1-2 лет [2-7] (УДД 2, УУР В).

2.3. На этапе удержания массы тела рекомендуются ежемесячное консультирование со специалистом (очное или дистанционное), регулярный контроль массы тела (взвешивание не реже 1 раза в неделю), сохранение или расширение режима аэробных физических нагрузок, эукалорийное сбалансированное питание [1-14] (УДД 5, УУР С).

\section{НЕМЕДИКАМЕНТОЗНАЯ ТЕРАПИЯ}

2.4. Немедикаментозная терапия (изменение образа жизни посредством коррекции питания и расширения объема физических нагрузок в объеме, безопасном с точки зрения сердечно-сосудистой системы) является основой лечения ожирения и рекомендуется как первый, обязательный и постоянный этап лечения ожирения [1, 7-9] (УДД 2, УУР В).

2.5. Для снижения массы тела рекомендуется гипокалорийная диета (дефицит 500-700 ккал от физиологической потребности с учетом массы тела, возраста и пола), сбалансированная по пищевым ингредиентам; на этапе поддержания достигнутой массы тела - сбалансированная по пищевым ингредиентам эукалорийная диета. Голодание не рекомендуется в связи с отсутствием данных о его эффективности и безопасности в лечении ожирения в долгосрочном прогнозе [10-14] (УДД 2, УУР А).

Комментарии. Снижение калорийности питания на 500-1000 ккал в сутки от расчетного приводит куменьшению массы тела на 0,5-1,0 кг в неделю. Такие темпы снижения массы тела сохраняются в течение 3-6 мес. В дальнейшем умеренное снижение массы тела приводит к уменьшению энергозатрат на 16 ккал/кг в сутки у мужчин и на 12 ккал/кг в сутки у женщин за счет уменьшения тощей массы, в результате чего потеря массы тела приостанавливается. Большинство различных типов диет являются равноэффективными при соблюдении принципа ограничения общей калорийности рациона. Основной предиктор успеха диеты - систематическое следование данной диете.

2.6. Рекомендуется терапевтическое обучение пациентов, направленное на изменение образа жизни, квалифицированным медицинским специалистом по структурированной программе в групповом или индивидуальном порядке [15-17] (УДД 3, УУР С).

2.7. Физическая активность рекомендуется как неотъемлемая часть лечения ожирения и поддержания достигнутой в процессе лечения массы тела. Всем лицам с избыточной массой тела и ожирением показаны регулярные аэробные физические упражнения продолжительностью не менее 150 мин в неделю [18-22] (УДД 2, УУР В).

Комментарии. Увеличение физической активности уменьшает количество висцерального жира и увеличивает мышечную массу, в то же время ослабляя вызванное потерей массы тела снижение расхода энергии в покое, снижает АД, повышает толерантность к глюкозе, чувствительность к инсулину, улучшает липидный профиль, положительно влияет на длительное поддержание массы тела. Увеличение уровня физической активности (преимущественно аэробной) $\geq 150$ мин в неделю (что эквивалентно $\geq 30$ мин в большинство из дней) рекомендовано на этапе снижения массы тела; более интенсивные физические нагрузки (от 200 до 300 мин в неделю) могут быть рекомендованы для удержания веса в долгосрочной перспективе. Комбинированное изменение образа жизни (изменение питания в дополнение к физическим упражнениям) приводит к более значимому снижению массы тела по сравнению с «монотерапией» (диетой или физическими нагрузками). 


\section{СПИСОК ЛИТЕРАТУРЫ | REFERENCES}

1. Must A. Reduction in the Incidence of Type 2 Diabetes with Lifestyle Intervention or Metformin. N Engl J Med. 2002;346(6):393-403. doi: https://doi.org/10.1056/NEJMoa012512

2. Blundell JE, Dulloo AG, Salvador J, Frühbeck G. Beyond BMI Phenotyping the Obesities. Obes Facts. 2014;7(5):322-328. doi: https://doi.org/10.1159/000368783

3. Schwarz P, Lindström J, Kissimova-Scarbeck K, et al. The European Perspective of Type 2 Diabetes Prevention: Diabetes in Europe Prevention Using Lifestyle, Physical Activity and Nutritional Intervention (DE-PLAN) Project. Exp Clin Endocrinol Diabetes. 2008;1 16(03):167-172. doi: https://doi.org/10.1055/s-2007-992115

4. Hainer V, Toplak H, Mitrakou A. Treatment Modalities of Obesity: What fits whom? Diabetes Care. 2008;31(2):S269-S277. doi: https://doi.org/10.2337/dc08-s265.

5. Sampsel S, May J. Assessment and Management of Obesity and Comorbid Conditions. Dis Manag. 2007;10(5):252-265. doi: https://doi.org/10.1089/dis.2007.105712

6. Jensen MD, Ryan DH, Apovian CM, et al. 2013 AHA/ACC/TOS Guideline for the Management of Overweight and Obesity in Adults. J Am Coll Cardiol. 2014;63(25):2985-3023. doi: https://doi.org/10.1016/j.jacc.2013.11.004

7. World Health Organization: Obesity: Preventing and Managing the Global Epidemic. Report of a WHO Consultation (WHO Technical Report Series 894). [Internet]. Geneva: 1998. www.who.int/nutrition/publications/obesity/WHO_TRS_894/en/ (cited: 2015 November 30).

8. Cefalu WT, Bray GA, Home PD, et al. Advances in the Science, Treatment, and Prevention of the Disease of Obesity: Reflections From a Diabetes Care Editors' Expert Forum. Diabetes Care. 2015;38(8):1567-1582. doi: https://doi.org/10.2337/dc15-1081

9. Garvey WT, Mechanick JI, Brett EM, et al. American Association of Clinical Endocrinologists and American College of Endocrinology Comprehensive Clinical Practice Guidelines Formedical Care of Patients with Obesity. Endocr Pract. 2016;22:1-203. doi: https://doi.org/10.4158/EP161365.GL

10. Shai I, Schwarzfuchs D, Henkin Y, et al. Weight Loss with a LowCarbohydrate, Mediterranean, or Low-Fat Diet. N Eng/ J Med. 2008;359(3):229-241. doi: https://doi.org/10.1056/NEJMoa0708681

11. Dernini S, Berry EM. Mediterranean Diet: From a Healthy Diet to a Sustainable Dietary Pattern. Front Nutr. 2015;2. doi: https://doi.org/10.3389/fnut.2015.00015
12. Estruch R, Ros E, Salas-Salvadó J, et al. Primary Prevention of Cardiovascular Disease with a Mediterranean Diet Supplemented with Extra-Virgin Olive Oil or Nuts. N Engl J Med. 2018;378(25):e34. doi: https://doi.org/10.1056/NEJMoa1800389.

13. Avenell A, Brown TJ, McGee MA, et al. What are the long-term benefits of weight reducing diets in adults? A systematic review of randomized controlled trials. J Hum Nutr Diet. 2004;17(4):317-335. doi: https://doi.org/10.1111/j.1365-277X.2004.00531.x

14. Dansinger ML, Gleason JA, Griffith JL, Selker HP, Schaefer EJ. Comparison of the Atkins, Ornish, Weight Watchers, and Zone Diets for Weight Loss and Heart Disease Risk Reduction. JAMA. 2005;293(1):43. doi: https://doi.org/10.1001/jama.293.1.43

15. Sharma M. Behavioural interventions for preventing and treating obesity in adults. Obes Rev. 2007:8(5):441-449. doi: https://doi.org/10.1111/j.1467-789X.2007.00351.x

16. Lang A, Froelicher ES. Management of Overweight and Obesity in Adults: Behavioral Intervention for Long-Term Weight Loss and Maintenance. Eur J Cardiovasc Nurs. 2006;5(2):102-114. doi: https://doi.org/10.1016/j.ejcnurse.2005.11.002

17. Moffitt R, Haynes A, Mohr P. Treatment Beliefs and Preferences for Psychological Therapies for Weight Management. J Clin Psychol. 2015;71(6):584-596. doi: https://doi.org/10.1002/jclp.22157

18. Willis LH, Slentz CA, Bateman LA, et al. Effects of aerobic and/ or resistance training on body mass and fat mass in overweight or obese adults. J Appl Physiol. 2012;113(12):1831-1837. doi: https://doi.org/10.1152/japplphysiol.01370.2011

19. Geliebter A, Christopher N, Ochner CN, et al. Obesity-related hormones and metabolic risk factors: a randomized trial of diet plus either strength or aerobic training versus diet alone in overweight participants. J Diabetes Obes. 2015;1:1-7.

20. Poirier P, Després J-P. Exercise in weight management of obesity. Cardiol Clin. 2001;19(3):459-470. doi: https://doi.org/10.1016/S0733-8651(05)70229-0

21. Chin S-H., Kahathuduwa CN, Binks M. Physical activity and obesity: what we know and what we need to know*. Obes Rev. 2016;17(12):1226-1244. doi: https://doi.org/10.1111/obr.12460

22. K. Stephens S, J. Cobiac L, Veerman JL. Improving diet and physical activity to reduce population prevalence of overweight and obesity: An overview of current evidence. Prev Med (Baltim). 2014;62:167-178. doi: https://doi.org/10.1016/j.ypmed.2014.02.008 


\title{
2.2. НЕМЕДИКАМЕНТОЗНЫЕ МЕТОДЫ ЛЕЧЕНИЯ
}

\author{
Дзгоева Ф.X.
}

Здоровое питание играет важную роль в снижении веса. Концепция, согласно которой дисфункция жировой ткани играет основную роль в возникновении метаболических нарушений, в настоящее время является общепризнанной [1]. Таким образом, основное внимание при консультировании по вопросам питания при избыточной массе весе или ожирении уделяется снижению риска различных состояний и заболеваний, ассоциированных с ожирением.

Пищевое поведение взрослых основано на опыте из детства. Важно учитывать роль семьи, так как целый ряд факторов домашней обстановки определяют стиль питания: например, наличие определенных продуктов в домашних хозяйствах, их доступность [2].

Окружающая среда и особенно семья являются основными факторами формирования пищевого поведения. Так, моделирование здорового рациона родителями и более частое совместное семейное питание могут способствовать формированию полезных пищевых привычек среди детей и подростков. Стиль питания родителей и потребление овощей в семье также влияют на потребление фруктов и овощей среди молодежи [3]. Нерациональная практика родителей в области питания детей, такая как ограничение пищи, принуждение детей к еде или использование продуктов питания в качестве вознаграждения, могут способствовать нарушениям пищевого поведения. Кроме того, имеются данные о том, что семейные социально-экономические и демографические факторы могут способствовать ожирению у молодежи. К таким факторам относятся неполноценная семья (воспитание одним из родителей), плохие условия жизни, низкий доход семьи, низкий социальный и образовательный статус родителей.

Питание в ресторанах и фастфудах, большие порции, употребление алкоголя, ночное питание, частые перекусы между приемами пищи, добавление сахара - все это увеличивает потребление энергии и связано с избыточным весом и ожирением. С другой стороны, потребление продуктов с низкой энергетической ценностью (то есть фруктов и овощей) снижает потребление энергии, что помогает потере или поддержанию веса [4].

\section{ОБЩИЕ РЕКОМЕНДАЦИИ ДЛЯ ЗДОРОВОГО ПИТАНИЯ И ПРОФИЛАКТИКИ ЗАБОЛЕВАНИЙ}

\section{8. Рекомендуется с момента начала лечения ожирения каждый пациент должен получить инструкции по здоровому питанию и правильному планированию приема пищи у квалифицированных медицин- ских работников (УУР А, УДД 1).}

Комментарии. Занятия по изменению поведенческих модификаций по лечению проходят по структурированной учебной программе, которая начинается с обзора продуктов питания и активности участников. Медицинский работник помогает участникам определить стратегии, позволяющие справиться с выявленными проблемами, и тем самым повысить их приверженность предписанным планам питания и мероприятий. Выполнение еженедельных домашних заданий является важным компонентом изменения образа жизни. Завершение пациентами ежедневных записей о еде является последовательным предиктором начальной потери веса [5].

\section{9. Рекомендуется ежедневно вести учет продуктов питания и физической активности, чтобы помочь па-} циентам достичь наилучших результатов (УУР А, УДД 1).

Комментарии. Ежедневный самоконтроль питания включает в себя наблюдение и запись потребления калорий, а также других, связанных с этим, аспектов пищевого поведения (время, место, эмоции и т. д.). Самоконтроль может помочь пациентам определить неадаптивные аспекты их пищевого поведения, которые часто являются побочным продуктом целого ряда экологических стимулов. Например, с помощью самоконтроля пациент может выявить привычку к чрезмерным перекусам во время вечернего просмотра телевизора. В результате стратегия изменения поведения, направленная на формирование более здорового пищевого поведения, будет заключаться в том, чтобы исключить прием пищи перед телевизором. Для решения других поведенческих и эмоциональных проблем часто используются более когнитивные интервенционные стратегии, которые нацелены на неадекватные мысли пациента о еде и поведении в отношении еды [6].

\subsection{0. Рекомендуется пациентам с избыточной массой тела и ожирением ограничение калорийности суточно- го рациона с целью снижения массы тела (УУР А, УДД 1).}

Комментарии. На этапе снижения массы тела важно создание отрицательного энергетического баланса за счет соблюдения низкокалорийного рациона питания на определенный промежуток времени (создание дефицита энергии 500-1000 ккал в сутки), следует уделять внимание поддержанию плана здорового питания и рекомендовать избегать причудливых диет. Рацион с дефицитом от 500 до 700 ккал в день должен быть неотъемлемой частью любой программы, направленной на достижение общего показателя снижения веса от 0,5 до 1 кг в неделю. Такой рацион обычно начинается с 1200 ккал в день; норма 1000 ккал в день должна с осторожностью использоваться у детей, пожилых и неактивных людей. В отношении микронутриентов: например, употребление рекомендуемого количества кальция от 1000 до 1500 мг в день особенно важно для женщин, которые подвержены риску остеопороза, женщинам детородного возраста необходимо адекватное потребление фолатов в пищевых продуктах, а также фолиевой кислоты (400 мкг/день) из обогащенных пищевых продуктов и/или добавок, чтобы избежать риска дефектов нервной трубки у плода. 
Для успешной коррекции избыточного веса с помощью диетотерапии до начала снижения калорийности питания пациента важно оценить его исходную энергоемкость. В случае высокой исходной калорийности ( $\geq 1,5$ нормы, необходимой для поддержания стабильной массы тела) рекомендуется постепенно уменьшать калорийность до рекомендуемого показателя: по 300-600 ккал в течение 3-4 нед. Минимальная суточная калорийность рациона для мужчин составляет 1500 ккал, для женщин - 1200 ккал. Рекомендуемую калорийность следует распределить на 3-4 приема пищи; основной объем приходится на первую половину дня, а на ужин - лишь 15-20\% рассчитанного количества. Ужинать следует за 3-4 ч до отхода ко сну.

\section{МЕТОДЫ ОЦЕНКИ ЭНЕРГЕТИЧЕСКОГО БАЛАНСА}

Общий расход энергии (ОРЭ) определяет количеством калорий, затраченных в следующих направлениях.

1. Физическая активность: составляет примерно от 20 до $30 \%$ ОРЭ.

2. Основная потребность организма в покое: скорость метаболизма в покое составляет от 65 до $75 \%$ ОРЭ.

3. Термогенез: энергия, расходуемая организмом на переработку потребляемой пищи, составляет от 10 до $15 \%$ ОРЭ.

Измерение метаболизма в состоянии покоя (МСП) теперь также возможно и практично с помощью офисного портативного медицинского устройства. МСП можно измерить с помощью ручных мониторов потребления кислорода. Оптимальные условия тестирования бывают утром, когда пациент отдыхает. Перед тестированием пациент должен воздержаться от еды и напитков (кроме воды в течение 4 ч), не иметь физической активности в течение 4 ч, не употреблять никотин за 1 ч до теста и за 10 мин до начала теста отдохнуть. Результат теста покажет количество растрачиваемой энергии МСП, которое обычно на 10\% превышает основные затраты энергии [7].

Таким образом, рекомендуется просто рассчитать общий расход энергии, используя стандартизованную формулу. Дополнительная оценка преднамеренной физической активности усредняется за неделю и добавляется для оценки общих затрат калорий в день.

Формула расчета основного обмена — самого важного и преобладающего компонента затрат энергии — такова:

- для женщин:

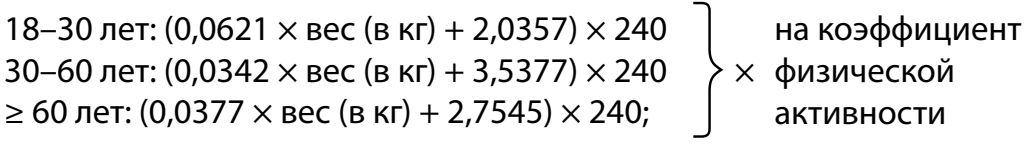

- для мужчин:

\begin{tabular}{|c|c|}
\hline & на коэффициент \\
\hline $\begin{array}{l}-60 \text { лет: }(0,0484 \times \text { вес (в кг) + 3,6534) × } 240 \\
60 \text { лет: }(0,0491 \times \text { вес (в кг)+24587) × } 240\end{array}$ & \\
\hline
\end{tabular}

При низком уровне физической активности пациента (умственная, сидячая, домашняя работа) полученный результат умножается на коэффициент 1,1; при умеренной физической активности (ходьба не менее 60 мин в день, регулярные занятия спортом 2-3 раза в неделю) - на 1,3; при высокой физической активности (тяжелая физическая работа, профессиональные занятия спортом) результат умножается на коэффициент 1,5.

Наиболее простой способ расчета калорийности для пациентов с различной физической активностью с помощью учета половой и возрастной принадлежности указан в таблице 2.

«Сидячий» означает образ жизни, который включает только легкую физическую активность, связанную с повседневной жизнью.

«Активный» - образ жизни, включающий физическую активность, эквивалентную ходьбе более 5 км в день со скоростью 5-6 км/ч, в дополнение к легкой физической активности, в обычной повседневной жизни.

Таблица 2. Диапазон калорий для отдельных лиц каждой возрастной/половой принадлежности, с различными уровнями физической активности

\section{Пациенты/Образ жизни}

\section{Калорийность}

Сидячий Активный

\begin{tabular}{lll}
\hline Дети & & 1400 \\
\hline $2-3$ года & 1000 & 1800 \\
\hline Женщины & 1200 & 2200 \\
\hline $4-8$ лет & 1600 & 2400 \\
\hline $9-13$ лет & 1800 & 2400 \\
\hline $14-18$ лет & 2000 & 2200 \\
\hline $19-30$ лет & 1800 & 2200 \\
\hline $31-50$ лет & 1600 & \\
\hline 51 год и старше & & \\
\hline
\end{tabular}


Пациенты/Образ жизни
Калорийность

Сидячий Активный

\begin{tabular}{lll}
\hline Мужчины & & 2000 \\
\hline $4-8$ лет & 1400 & 2600 \\
\hline $9-13$ лет & 1800 & 3200 \\
\hline $14-18$ лет & 2200 & 3000 \\
\hline $19-30$ лет & 2400 & 3000 \\
\hline $31-50$ лет & 2200 & 2800 \\
\hline 51 год и старше & 2200 & \\
\hline
\end{tabular}

Дискреционная норма калорий - это оставшееся количество калорий, которое может использоваться после учета вышеперечисленных групп. Это количество лучше использовать за счет продуктов, не содержащих жира или с низким процентом жирности, без добавления сахара.

\section{РЕКОМЕНДОВАННЫЙ ПЛАН ПИТАНИЯ}

Пациентам следует потреблять не более 6-8 порций углеводов в день (одна порция = 15 г углеводов), при этом 3-4 порции должны состоять из цельнозерновых продуктов с высоким содержанием клетчатки [8]. Ежедневное потребление фруктов (особенно ягод) и овощей (особенно сырых) ( $\geq 4,5$ чашки в день) увеличивает поступление клетчатки, фитонутриентов и облегчает контроль над энергоемкостью пищи. И особое внимание должно уделяться потреблению цельнозерновых продуктов вместо рафинированных, так как они в большей степени обеспечивают микроэлементами, пищевыми волокнами и помогают снизить артериальное давление (АД). План питания должен включать максимум 170 г в день животного белка с пониженным содержанием жира. Основным источником животных белков должны служить молочные продукты (2-3 порций в день), поскольку они помогают снизить вес и являются не только источником белка, но и микронутриентов (кальций). Особое внимание при формировании суточного рациона необходимо уделять растительным белкам (бобы, чечевица, орехи, брокколи, капуста, шпинат) - они обладают многими полезными свойствами, которые способны улучшить показатели липидного обмена (ЛПВП, ЛПНП) и снизить уровень АД [4]. Натуральные продукты с содержанием мононенасыщенных жиров, такие как оливковое масло в средиземноморском рационе питания, должны употребляться чаще, поскольку это тесно связано с улучшением состояния здоровья. Если пациенты сосредотачиваются на снижении углеводов, а не на снижении калорий и/или жиров, это может быть успешной краткосрочной стратегией для некоторых людей. Снижение потребления углеводов более чем на $35 \%$ потребляемой энергоемкости приводит к снижению потребления энергии и связано с большей потерей веса и жира в течение первых 6 мес. Эти результаты не были значимыми через один год [9]. Использование низкоуглеводных планов питания следует контролировать у пациентов с остеопорозом, заболеваниями почек и пациентов с повышенным уровнем ХС ЛПНП [10].

План питания с низким гликемическим индексом не рекомендуется для уменьшения массы тела или поддержания веса. Тем не менее актуальны общие рекомендации: есть больше свежих фруктов и овощей и меньше обработанных пищевых продуктов, в основном крахмалов и сахара; сократить потребление продуктов с высоким гликемическим индексом. 3-4 порции нежирных молочных продуктов должны быть включены в ежедневный рацион [11].

Порционный контроль должен быть включен в комплексную программу управления весом.

Общее потребление калорий должно быть распределено в течение дня на 3-4 приема пищи/закусок, включая завтрак. Большее потребление энергии днем предпочтительнее, чем вечернее чрезмерное потребление пищи и, тем более, - ночное переедание.

2.11. Рекомендуется очень низкокалорийный рацион питания в случае необходимости интенсивного снижения массы тела пациентам с ИМТ >30 кг/м², у которых есть серьезные сопутствующие заболевания, или которые потерпели неудачу в других диетологических подходах в снижении веса (УУР В, УДД 2). На это время рекомендуется постоянное наблюдение медицинского персонала за состоянием электролитного баланса, активностью печеночных трансаминаз, желчевыводящей системы и контроля, дополнительное назначение недостающих макро- и микроэлементов (УУР А, УДД 1).

2.12. Рекомендуется основные макро- и микронутриенты, клетчатка, вода должны поступать с правильно подобранными продуктами и напитками, которые являются образцом здорового питания. Макронутриенты следует рекомендовать в рамках общей энергоемкости пищи, контролируемой суточным калоражем (УУР А, УДД 1).

2.13. Рекомендуется энергоемкость пищи необходимо распределить по основным макронутриентам (белкам, жирам и углеводам) на основе актуального образца питания и метаболических целей. На долю белков животного и растительного происхождения приходится примерно 15-35\% калорийности (Уур А, УДД 1), углеводов - 45-55\% - 6-8 порций углеводсодержащей пищи по 15 г, половина из которых должны составлять углеводы, обогащенные пищевыми волокнами (УУР А, УДД 1), и жиров - 25-35\% В основном из источников растительного происхождения для снижения риска ССЗ (УУР А, УДД 1). 
Комментарии по расчету потребления макронутриентов.

\section{- Углеводы.}

При формировании рационального питания на долю углеводов следует выделять от 45 до $65 \%$ поступления энергии от суточной нормы (оптимальное потребление 50-55\%), за счет ограничения легкоусвояемых углеводов или продуктов с высоким гликемическим индексом (ГИ). Независимо от состава макронутриентов, суточная норма калорий рассчитывается индивидуально, с учетом пола, возраста и антропометрических параметров [12].

\section{- Белки.}

В зависимости от суточной нормы белки должны обеспечивать от 15 до 35\% калорий. Однако их следует рекомендовать только тем пациентам, у которых отсутствует непереносимость или аллергия на лактозу, в случае дефицита мышечной массы у пациента целесообразно на долю белков выделять максимально допустимый процент калорийности или рассчитать его, умножив показатель массы тела на коэффициент от 1,1 до 1,5 - в зависимости от индивидуальных характеристик.

\section{- Жиры.}

Суточная норма потребления жиров должна укладываться в диапазоне 25-35\% общих калорий, так как она способствует уменьшению риска развития ССЗ. В структуре потребления жиров следует рекомендовать употреблять ненасыщенные жиры, входящие в состав рыбы, жидких нерафинированных растительных масел, семян, орехов, вместо продуктов с высоким содержанием насыщенных жиров (сливочное масло и животные жиры). Еженедельно в рационе должно быть не менее 2 порций рыбы (например, лосося или скумбрии) из-за содержания большого количества эйкозапентаеновой кислоты (ЭПК) и докозагексаеновой кислоты (ДГК). Часто наибольшие трудности возникают в соблюдении нормы жиров, так как при гипокалорийном питании их допустимое количество должно быть эквивалентно скрытому содержанию жиров в низкожирных продуктах.

2.14. Рекомендуется для управления избыточной массой тела и ожирением требуется мультидисциплинарный подход к их лечению (УУР А, УДД 1). В долгосрочных программах по похудению и удержанию достигнутых результатов имеет важное значение постоянное поддержание поведенческой терапии, включающее сочетание рационального питания и адекватных физических нагрузок (УУР А, УДД 1). Доказана эффективность участия пациентов в группах по управлению массой тела (УУР В, УДД 2) и постоянного учета потребляемой пищей в виде контроля над порциями (УУР А, УДД 1) [13-19].

Комментарии: ежедневный расчет нутриентов из каждой группы при заданной калорийности представлен в таблице 3.

Таблица 3. Ежедневный расчет нутриентов из каждой группы при заданной калорийности

\begin{tabular}{|c|c|c|c|c|c|c|c|c|c|c|c|c|}
\hline $\begin{array}{l}\text { Уровень } \\
\text { калорий }\end{array}$ & 1000 & 1200 & 1400 & 1600 & 1800 & 2000 & 2200 & 2400 & 2600 & 2800 & 3000 & 3200 \\
\hline Фрукты & $\begin{array}{l}1 \\
\text { чашка }\end{array}$ & $\begin{array}{l}1 \\
\text { чашка }\end{array}$ & $\begin{array}{l}1,5 \\
\text { чашки }\end{array}$ & $\begin{array}{l}1,5 \\
\text { чашки }\end{array}$ & $\begin{array}{l}1,5 \\
\text { чашки }\end{array}$ & $\begin{array}{l}2 \\
\text { чашки }\end{array}$ & $\begin{array}{l}2 \\
\text { чашки }\end{array}$ & $\begin{array}{l}2 \\
\text { чашки }\end{array}$ & $\begin{array}{l}2 \\
\text { чашки }\end{array}$ & $\begin{array}{l}2,5 \\
\text { чашки }\end{array}$ & $\begin{array}{l}2,5 \\
\text { чашки }\end{array}$ & $\begin{array}{l}2,5 \\
\text { чашки }\end{array}$ \\
\hline Овощи & $\begin{array}{l}1 \\
\text { чашка }\end{array}$ & $\begin{array}{l}1,5 \\
\text { чашки }\end{array}$ & $\begin{array}{l}1,5 \\
\text { чашки }\end{array}$ & $\begin{array}{l}2 \\
\text { чашки }\end{array}$ & $\begin{array}{l}2,5 \\
\text { чашки }\end{array}$ & $\begin{array}{l}2,5 \\
\text { чашки }\end{array}$ & $\begin{array}{l}3 \\
\text { чашки }\end{array}$ & $\begin{array}{l}3 \\
\text { чашки }\end{array}$ & $\begin{array}{l}, 5 \\
\text { чашки }\end{array}$ & $\begin{array}{l}, 5 \\
\text { чашки }\end{array}$ & $\begin{array}{l}4 \\
\text { чашки }\end{array}$ & $\begin{array}{l}4 \\
\text { чашки }\end{array}$ \\
\hline Зерновые & $85 r$ & $115 r$ & $140 r$ & $140 r$ & $170 r$ & 170 r & 198 r & 227 r & $255 r$ & $285 r$ & $285 r$ & 285 г \\
\hline $\begin{array}{l}\text { Мясо } \\
\text { и бобы }\end{array}$ & $57 г$ & $85 r$ & 115 г & 140 г & 140 г & 155 г & 170 г & 185 г & 185 г & 198 г & 198 г & 198 г \\
\hline Молоко & $\begin{array}{l}2 \\
\text { чашки }\end{array}$ & $\begin{array}{l}2 \\
\text { чашки }\end{array}$ & $\begin{array}{l}2 \\
\text { чашки }\end{array}$ & $\begin{array}{l}3 \\
\text { чашки }\end{array}$ & $\begin{array}{l}3 \\
\text { чашки }\end{array}$ & $\begin{array}{l}3 \\
\text { чашки }\end{array}$ & $\begin{array}{l}3 \\
\text { чашки }\end{array}$ & $\begin{array}{l}3 \\
\text { чашки }\end{array}$ & $\begin{array}{l}3 \\
\text { чашки }\end{array}$ & $\begin{array}{l}3 \\
\text { чашки }\end{array}$ & $\begin{array}{l}3 \\
\text { чашки }\end{array}$ & $\begin{array}{l}3 \\
\text { чашки }\end{array}$ \\
\hline Масла & 3 ч.л. & 4 ч.л. & 4 ч.л. & 5 ч.л. & 5 ч.л. & 6 ч.л. & 6 ч.л. & 7 ч.л. & 8 ч.л. & 8 ч.л. & 10 ч.л. & 11 ч.л. \\
\hline $\begin{array}{l}\text { Дискреци- } \\
\text { онная } \\
\text { норма } \\
\text { калорий }\end{array}$ & 165 & 171 & 171 & 132 & 195 & 267 & 290 & 362 & 410 & 426 & 512 & 648 \\
\hline
\end{tabular}

Группа «фрукты» включает в себя все свежие, замороженные, консервированные, сушеные фрукты и фруктовые соки. Как правило, одна чашка фруктов или 100\% фруктового сока или полчашки сухофруктов могут рассматриваться как одна чашка.

Группа «овощи» включает в себя все свежие, замороженные, консервированные, сушеные овощи и овощные соки. Как правило, одна чашка сырых или приготовленных овощей, или овощного сока, или две чашки сырой листовой зелени можно рассматривать как одну чашку из группы овощей.

Группа «зерновых» включает в себя следующие продукты: пшеницу, рис, овес, кукурузную или ячменную муку. В виде хлеба, макарон, овсянки, хлопьев для завтрака, лепешек и крупы. Как правило, 28 г могут еще и рассматриваться как один стакан готовых к употреблению хлопьев или половины чашки приготовленного риса, макаронных изделий, хлопьев. По крайней мере половина всех потребляемых зерен должны быть цельными. 
Группа «мясо и бобы» в целом, 28 г, может состоять из постного мяса, птицы, рыбы, одного яйца, одной столовой ложки арахисового масла, четверти чашки приготовленных сухих бобов или 14 г орехов или семян.

Группа «молоко» включает в себя все жидкие продукты, изготовленные из молока с сохранением содержания кальция, а также творог и сыр. Пищевые продукты с низким содержанием кальция, приготовленные из молока, например, сливочный сыр, сливки и масло, не входят в группу. Большинство продуктов из этой группы должны содержать низкий процент жирности или вовсе быть обезжиренными.

Группа «масла» - все растительные жиры, такие как рапсовое, кукурузное, оливковое, соевое и подсолнечное масла. Некоторые продукты с высоким содержанием масла: орехи, оливки, авокадо, любая рыба.

\section{СПИСОК ЛИТЕРАТУРЫ | REFERENCES}

1. Bays HE, González-Campoy JM, Bray GA, et al. Pathogenic potential of adipose tissue and metabolic consequences of adipocyte hypertrophy and increased visceral adiposity. Expert Rev Cardiovasc Ther. 2008;6(3):343-368. doi: https://doi.org/10.1586/14779072.6.3.343

2. Cullen KW, Baranowski T, Owens E, Marsh T, Rittenberry L, de Moor C Availability, Accessibility, and Preferences for Fruit, 100\% Fruit Juice, and Vegetables Influence Children's Dietary Behavior. Heal Educ Behav. 2003;30(5):615-626. doi: https://doi.org/10.1177/1090198103257254

3. Hanson NI, Neumark-Sztainer D, Eisenberg ME, et al. Associations between parental report of the home food environment and adolescent intakes of fruits, vegetables and dairy foods. Public Health Nutr. 2005;8(1):77-85. doi: https://doi.org/10.1079/PHN2005661

4. Duffey KJ, Gordon-Larsen P, Jacobs DR, et al. Differential associations of fast food and restaurant food consumption with $3-y$ change in body mass index: the Coronary Artery Risk Development in Young Adults Study. Am J Clin Nutr. 2007;85(1):201-208. doi: https://doi.org/10.1093/ajcn/85.1.201

5. Wing RR, Tate DF, Gorin AA, et al. A Self-Regulation Program for Maintenance of Weight Loss. N Eng/ J Med. 2006;355(15):1563-1571. doi: https://doi.org/10.1056/NEJMoa061883

6. Schmidt ME, Haines J, O'Brien A, et al. Systematic Review of Effective Strategies for Reducing Screen Time Among Young Children. Obesity. 2012;20(7):1338-1354. doi: https://doi.org/10.1038/oby.2011.348

7. Gonzalez-Campoy JM, Castorino K, Ebrahim A, et al. Clinical Practice Guidelines for Healthy Eating for the Prevention and Treatment of Metabolic and Endocrine Diseases in Adults: Cosponsored by the American Association of Clinical Endocrinologists/ The American College of Endocrinology and the Obesity Soci. Endocr Pract. 2013;19(15):1-82. doi: https://doi.org/10.4158/EP13155.GL

8. AACE/ACE Obesity Task Force. AACE/ACE Position Statement on the Prevention, Diagnosis, and Treatment of Obesity. Endocr Pract. 1998;4:297-350.

9. Seagle HM, Strain GW, Makris A, Reeves RS. Position of the American Dietetic Association: Weight Management. J Am Diet Assoc. 2009;109(2):330-346. doi: https://doi.org/10.1016/j.jada.2008.11.041

10. 2006 Adult Weight Management EvidenceBased Nutrition Practice Guideline. Available at: https://www.andeal.org/topic..fm?cat=2798\&auth=1.2009
11. Afshin A, Sur PJ, Fay KA, et al. Health effects of dietary risks in 195 countries, 1990-2017: a systematic analysis for the Global Burden of Disease Study 2017. Lancet. 2019;393(10184):1958-1972. doi: https://doi.org/10.1016/S0140-6736(19)30041-8

12. Yancy WS, Olsen MK, Guyton JR, Bakst RP, Westman EC. A LowCarbohydrate, Ketogenic Diet versus a Low-Fat Diet To Treat Obesity and Hyperlipidemia. Ann Intern Med. 2004;140(10):769. doi: https://doi.org/10.7326/0003-4819-140-10-200405180-00006

13. Wadden TA, West DS, Neiberg RH, et al. One-year Weight Losses in the Look AHEAD Study: Factors Associated With Success. Obesity. 2009;17(4):713-722. doi: https://doi.org/10.1038/oby.2008.637

14. Wadden TA, Butryn ML, Byrne KJ. Efficacy of Lifestyle Modification for Long-Term Weight Control. Obes Res. 2004;12(S12):151S-162S. doi: https://doi.org/10.1038/oby.2004.282

15. Gonzalez-Campoy JM, Castorino K, Ebrahim A, et al. The Diabetes Prevention Program (DPP): Description of lifestyle intervention. Diabetes Care. 2002;25(12):2165-2171. doi: https://doi.org/10.2337/diacare.25.12.2165

16. Perri MG, McAllister DA, Gange JJ, et al. Effects of four maintenance programs on the long-term management of obesity. J Consult Clin Psychol. 1988;56(4):529-534. doi: https://doi.org/10.1037/0022-006X.56.4.529

17. Sbrocco T, Nedegaard RC, Stone JM, Lewis EL. Behavioral choice treatment promotes continuing weight loss: Preliminary results of a cognitive-behavioral decision-based treatment for obesity. J Consult Clin Psychol. 1999;67(2):260-266. doi: https://doi.org/10.1037/0022-006X.67.2.260

18. The Practical Guide : Identification, Evaluation, and Treatment of Overweight and Obesity in Adults. [Bethesda, Md.] :National Institutes of Health, National Heart, Lung, and Blood Institute, NHLBI Obesity Education Initiative, North American Association for the Study of Obesity, 2000.

19. NHLBI Obesity Education Initiative Expert Panel on the Identification, Evaluation, and Treatment of Obesity in Adults (US). Clinical Guidelines on the Identification, Evaluation, and Treatment of Overweight and Obesity in Adults: The Evidence Report. Bethesda (MD): National Heart, Lung, and Blood Institute; $1998 \mathrm{Sep}$. Available from: https://www.ncbi.nlm.nih.gov/books/NBK2003/ 


\section{3. ФАРМАКОТЕРАПИЯ ОЖИРЕНИЯ}

Трошина Е.А., Ершова Е.В., Комшилова К.А.

2.15. Назначение препаратов, зарегистрированных в качестве лекарственных средств для лечения ожирения, рекомендовано пациентам, которые не могут достичь в течение 3-6 мес клинически значимого снижения массы тела на 5-10\% на фоне немедикаментозных методов лечения и/или на этапе удержания достигнутого результата. При этом при наличии хотя бы одного коморбидного состояния, ассоциированного с ожирением, с целью снижения риска развития осложнений назначение фармакотерапии показано сразу на фоне немедикаментозных методов лечения [1-4] (УУР С, УДД 5).

2.16. Назначение лекарственных средств для терапии ожирения рекомендовано при ИМТ $\geq 30$ кг/м² или при ИМТ $\geq 27$ кг/м² при наличии коморбидных заболеваний [1-4] (УУР С, УДД 5).

2.17. Оценку эффективности лекарственной терапии ожирения рекомендуется проводить спустя 3 мес после начала лечения. Неэффективным может считаться снижение массы тела менее чем на 5\% от исходной в течение 3 мес [1-4] (УУР С, УДД 5).

2.18. Оценку безопасности терапии рекомендуется проводить спустя 1-3 мес от момента назначения препарата и не реже чем раз в 3 мес в дальнейшем [1-4] (УУР С, УДД 5).

2.19. Лечение заболеваний, ассоциированных с ожирением, проводится в рамках соответствующих стандартов в соответствии с клиническими рекомендациями. При этом рекомендуется назначение лекарственных препаратов, не влияющих на массу тела, или лекарственных препаратов, способствующих ее снижению [1-4] (УУР С, УДД 3).

2.20. Не рекомендуется назначение пищевых добавок или биологически активных добавок в связи с отсутствием данных об их эффективности и безопасности в лечении ожирения [5-10] (УУР А, УДД 2).

Комментарии. Алгоритм ведения пациента с экзогенно-конституциональным ожирением представлен на рисунке 1.

В настоящее время на территории Российской Федерации зарегистрированы следующие препараты для лечения ожирения: орлистат, сибутрамин, в том числе сибутрамин + микрокристаллическая целлюлоза (МКЦ), сибутрамин + метформин, лираглутид. Алгоритм выбора препаратов для фармакотерапии ожирения представлен в таблице 4.

2.21. Орлистат (А08АВ01) - препарат для лечения ожирения периферического действия, рекомендуется па-

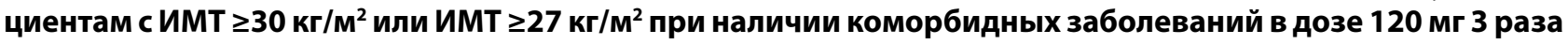
В сутки во время еды или не позже 1 ч после нее для снижения массы тела. Разрешенная максимальная длительность лечения составляет 4 года [9, 12-18] (УУР А, УДД 1).

Комментарии. Орлистат, будучи специфическим, длительно действующим ингибитором желудочно-кишечной липазы, оказывает терапевтический эффект в пределах ЖКТ и не обладает системными эффектами: препятствует расщеплению и последующему всасыванию жиров, поступающих с пищей (около 30\%), создавая тем самым дефицит энергии, что приводит к снижению массы тела. Орлистат способствует также снижению гиперхолестеринемии, причем независимо от степени снижения массы тела. Если прием пищи пропускают или пища не содержит жира, то прием препарата можно пропустить. Применение орлистата у больных ожирением позволяет существенно улучшить профиль факторов риска СД2, СС3 и других заболеваний, ассоциированных с ожирением, что может благоприятно влиять на прогноз жизни у этой категории больных. Данных, позволяющих судить о влиянии орлистата на общую смертность или смертность от СС3, в настоящее время нет. Важным преимуществом препарата является его периферическое действие только в пределах ЖКТ и отсутствие системных эффектов. Орлистат противопоказан при острых панкреатитах и заболеваниях, сопровождающихся диареей, синдромом хронической мальабсорбции, холестазом. Орлистат повышает вероятность образования камней в желчном пузыре, однако рациональное потребление жиров не приводит к снижению моторикижелчного пузыря. С учетом механизма действия, к числу побочных эффектов препарата относятся жирный стул, маслянистые выделения из прямой кишки, императивные позывы на дефекацию, учащение дефекации и недержание кала, боли в животе, выделение газов с некоторым количеством отделяемого. Выраженность и продолжительность побочных эффектов напрямую зависят от приверженности пациентов лечению и соблюдения рекомендаций по ограничению жиров в пище. Если рекомендованы поливитамины, их следует принимать не ранее чем через 2 ч после приема орлистата или перед сном.

2.22. Сибутрамин (А08АА 10)*, сибутрамин+МКЦ - препарат для лечения ожирения центрального действия,

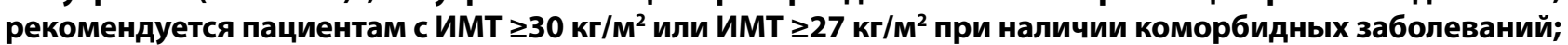
в качестве начальной дозы сибутрамина, в т.ч. сибутрамина + МКЦ, рекомендуется 10 мг утром, ежедневно, независимо от приема пищи. Если масса тела за первый месяц лечения снизилась менее чем на 2 кг, рекомендуется увеличить дозу до 15 мг сибутрамина при условии хорошей его переносимости. Если за 3 мес приема масса тела уменьшилась менее чем на 5\% исходной, лечение считается неэффективным. Разрешенная максимальная длительность лечения составляет 1 год [9, 11-13, 19-21]. При необходимости возможно возобновление терапии через 3-6 месяцев. (УУР А, УДД 1).

Комментарии. Сибутрамин, будучи ингибитором обратного захвата серотонина, норадреналина и, в меньшей степени, допамина, в синапсах ЦНС, в том числе в комбинации с МКЦ, имеет двойной механизм действия: с одной 
стороны, он ускоряет чувство насыщения, снижая количество потребляемой пищи, с другой - увеличивает энергозатраты организма, что в совокупности приводит к отрицательному балансу энергии. Сибутрамин обеспечивает эффективное снижение массы тела вне зависимости от пола, возраста и наличия сопутствующих заболеваний. Чем выше исходный ИМТ, тем более интенсивного снижения массы тела можно ожидать. Сибутрамин обеспечивает эффективную и устойчивую потерю массы тела, улучшает метаболические показатели: достоверно снижает уровень ТГ, ОХС, ЛПНП, увеличивает количество антиатерогенных ЛПВП, уменьшает содержание мочевой кислоты в плазме крови, снижает уровень гликированного гемоглобина.

МКЦ является энтеросорбентом, обладает сорбционными свойствами и неспецифическим дезинтоксикационным действием. Связывает и выводит продукты жизнедеятельности микроорганизмов, токсины экзогенной и эндогенной природы, аллергены, ксенобиотики, а также избыток некоторых продуктов обмена веществ и метаболитов, ответственных за развитие эндогенного токсикоза.

Лечение ожирения сибутрамином требует обязательного врачебного наблюдения. Контроль АДи пульса необходим у всех больных до начала лечения, далее с 1-го по 3-й месяц лечения - каждые 2 нед, с 4-го по 6-й месяц - ежемесячно, с 6-го по 12-й месяц — каждые 3 мес. Препарат отменяют при двукратном учащении пульса более чем на 10 ударов в минуту, повышении АД более чем на 10 мм рт.ст., а также в случае, если оно при двух повторных измерениях превышает 140/90 мм рт.ст. при ранее компенсированной АГ. Препарат не может быть назначен пациентам с неконтролируемой АГ (АД выше 145/90 мм рт.ст.), ИБС, декомпенсацией хронической сердечной недостаточности, нарушением ритма сердца, цереброваскулярными заболеваниями (инсультом, транзиторными нарушениями мозгового кровообращения), окклюзионными заболеваниями периферических артерий, в возрасте старше 65 лет, при тяжелых поражениях печени и почек, которые могут встречаться при ожирении, в случае одновременного приема или спустя менее 2 нед после отмены ингибиторов моноаминоксидазы или других препаратов, действующих на ЦНС (в т.ч. антидепрессантов), при серьезных нарушениях питания и психических заболеваниях, тиреотоксикозе, феохромоцитоме, закрытоугольной глаукоме, доброкачественной гиперплазии предстательной железы. Такие побочные действия, как тошнота, потеря аппетита, запор, сухость во рту, изменение вкуса, бессонница, головная боль, возбуждение, потливость, обычно слабо выражены, отмечаются лишь в начале лечения, имеют преходящий характер и, как правило, не требуют отмены терапии.

2.23. Сибутрамин (АО8АA10) В комбинации с метформином (А10ВА02) рекомендуется пациентам

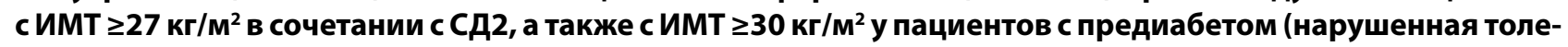
рантность к глюкозе (НТГ), нарушение гликемии натощак (НГН) или их сочетание) для снижения массы тела. Рекомендуется принимать препарат в начальной дозе 1 таблетка, содержащая 10 мг сибутрамина и 850 мг метформина в сутки. Препарат следует принимать утром, не разжевывая и запивая достаточным количеством жидкости как натощак, так и в сочетании с приемом пищи. Если в течение 4 нед от начала лечения не достигнуто снижение массы тела на 5\% и более, то доза увеличивается до 15 мг сибутрамина + 850 мг метформина. Лечение не должно продолжаться более 3 мес у пациентов, которым не удалось за этот период добиться снижения массы тела на 5\% от исходного уровня. Длительность лечения не более 1 года [20-22]. При необходимости возможно возобновление терапии через 3-6 месяцев (УУР В, УДД 1).

Комментарии. Совместное применение сибутрамина с метформином повышает терапевтическую эффективность используемой комбинации у пациентов с избыточной массой тела и нарушениями углеводного обмена. Препарат не следует принимать при наличии диабетического кетоацидоза, нарушении функции печени и почек (клиренс креатинина менее 45 мл/мин), а также при наличии противопоказаний к приему сибутрамина или метформина. Во время приема препарата следует избегать приема алкоголя, а также лекарственных средств, содержащих этанол.

2.24. Лираглутид (А10ВЈ02) - аналог человеческого глюкагоноподобного пептида-1 (ГПП-1), рекомендуется

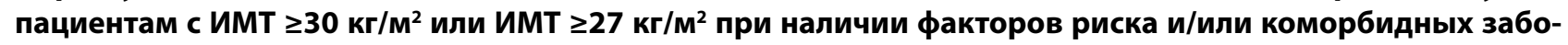
леваний; начальная доза составляет 0,6 мг подкожно 1 раз в сутки, с последующей стандартной титрацией (доза увеличивается на 0,6 мг с интервалами не менее 1 нед для улучшения желудочно-кишечной переносимости до достижения терапевтической - 3,0 мг в сутки). При отсутствии снижения массы тела на 5\% и более от исходной за 3 мес применения лираглутида в суточной дозе 3,0 мг лечение прекращают [23-27] (УУР А, УДД 1).

Комментарии. Лираглутид регулирует аппетит с помощью усиления чувства наполнения желудка и насыщения, одновременно ослабляя чувство голода и уменьшая предполагаемое потребление пищи. Лираглутид не увеличивает 24-часовой расход энергии. Лираглутид 3,0 мг обеспечивает эффективную и устойчивую потерю массы тела, положительно влияет на динамику кардиометаболических факторов риска на фоне снижения массы тела. Лираглутид 3,0 мг может рассматриваться как предпочтительный вариант для пациентов с ожирением и наличием сопутствующих СС3 в связи с доказанным снижением сердечно-сосудистых рисков, устойчивым снижением массы тела в течение трех лет терапии, снижением тяжести ночного апноэ, значительным снижением риска развития СД2 и благоприятным профилем безопасности и переносимости. Препарат противопоказан при медуллярном раке щитовидной железы в анамнезе, в т.ч. семейном, множественной эндокринной неоплазии II типа, тяжелой депрессии, суицидальных мыслях или поведении, в т.ч. В анамнезе, почечной и печеночной недостаточности тяжелой степени, хронической сердечной недостаточности IV функционального класса (в соответствии с классификацией NYHA, 
у пациентов в возрасте $\geq 75$ лет). Применение лираглутида у пациентов с воспалительными заболеваниями кишечника и диабетическим парезом желудка не рекомендуется, поскольку оно связано с транзиторными нежелательными реакциями со стороны ЖКТ, включая тошноту, рвоту и диарею. С осторожностью - прием препарата у пациентов с печеночной недостаточностью легкой и средней степени тяжести, заболеваниями щитовидной железы и наличием острого панкреатита в анамнезе.

2.25. При наличии у пациента с ожирением нарушений углеводного обмена, в том числе состояний, ассоциированных с инсулинорезистентностью (НГН, НТГ), с целью снижения риска развития СД2 или увеличения периода до его манифестации рекомендуется назначение метформина, лираглутида или комбинации метформина и сибутрамина, в том числе фиксированной [20-22, 24] (УУР В, УДД 2).

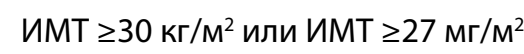
при наличии ассоциированных заболеваний
ИМТ $\geq 30$ кг/м² при наличии ассоциированных заболеваний

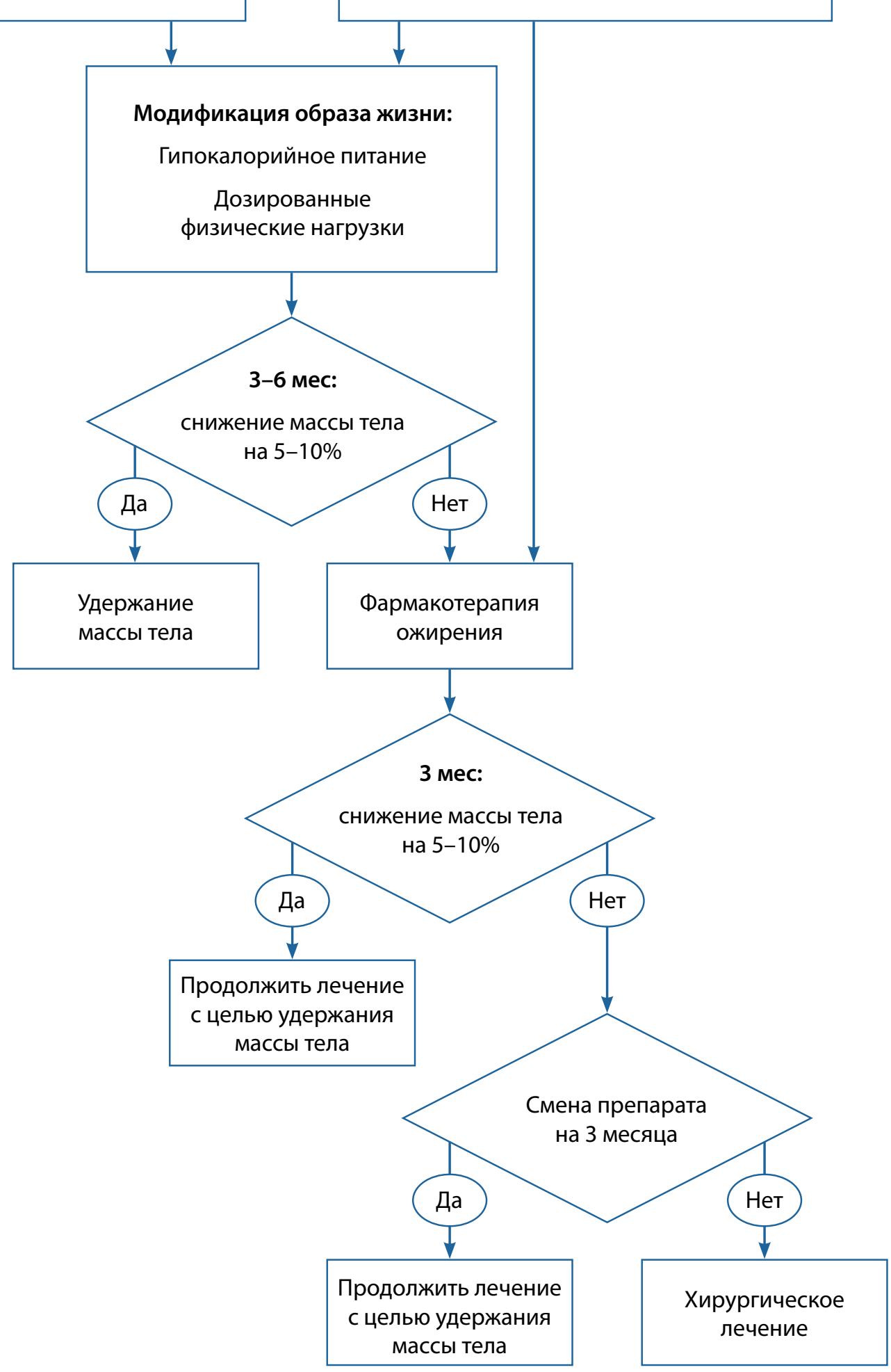

Рисунок 1. Алгоритм ведения пациента с экзогенно-конституциональным ожирением 
Таблица 4. Алгоритм выбора препаратов для фармакотерапии ожирения

\begin{tabular}{|c|c|c|c|}
\hline & Орлистат & $\begin{array}{c}\text { Сибутрамин, } \\
\text { Сибутрамин + МКЦ, } \\
\text { Сибутрамин + метформин }\end{array}$ & Лираглутид 3 мг \\
\hline Артериальная гипертензия & + & $+/-$ & + \\
\hline $\begin{array}{l}\text { ИБС, цереброваскулярная } \\
\text { болезнь }\end{array}$ & + & - & + \\
\hline $\mathrm{XCH}$ & + & - & + \\
\hline Панкреатиты & + & + & $+/-$ \\
\hline Медуллярный рак ЩЖ & + & + & - \\
\hline Желчнокаменная болезнь & $+/-$ & + & $+/-$ \\
\hline Холестаз & - & + & + \\
\hline $\begin{array}{l}\text { Заболевания ЖКТ, } \\
\text { сопровождающиеся диареей }\end{array}$ & - & + & $+/-$ \\
\hline Предиабет & + & + & + \\
\hline
\end{tabular}

\section{СПИСОК ЛИТЕРАТУРЫ | REFERENCES}

1. Biddle SJH, Bengoechea García E, Pedisic Z, et al. Screen Time, Other Sedentary Behaviours, and Obesity Risk in Adults: A Review of Reviews. Curr Obes Rep. 2017;6(2):134-147. doi: https://doi.org/10.1007/s13679-017-0256-9

2. Heymsfield SB, Wadden TA. Mechanisms, Pathophysiology, and Management of Obesity. Longo DL, ed. N Engl J Med. 2017;376(3):254-266. doi: https://doi.org/10.1056/NEJMra1514009

3. Guh DP, Zhang W, Bansback N, et al. The incidence of comorbidities related to obesity and overweight: A systematic review and meta-analysis. BMC Public Health. 2009;9:88. doi: https://doi.org/10.1186/1471-2458-9-88

4. Lenz M, Richter T, Mühlhauser I. The Morbidity and Mortality Associated With Overweight and Obesity in Adulthood. Dtsch Aerzteblatt Online. 2009;106:641-648. doi: https://doi.org/10.3238/arztebl.2009.0641

5. Avenell A, Brown TJ, McGee MA, et al. What are the long-term benefits of weight reducing diets in adults? A systematic review of randomized controlled trials. J Hum Nutr Diet. 2004;17(4):317-335. doi: https://doi.org/10.1111/j.1365-277X.2004.00531.x

6. Dansinger ML, Gleason JA, Griffith JL. et al. Comparison of the Atkins, Ornish, Weight Watchers, and Zone Diets for Weight Loss and Heart Disease Risk ReductionA Randomized Trial. JAMA. 2005;293(1):43-53. doi: https://doi.org/10.1001/jama.293.1.43

7. Stephens SK, Cobiac LJ, Veerman JL. Improving diet and physical activity to reduce population prevalence of overweight and obesity: An overview of current evidence. Prev Med (Baltim). 2014;62:167-178. doi: https://doi.org/10.1016/j.ypmed.2014.02.008

8. Garvey WT, Mechanick JI, Brett EM, et al. American Association of Clinical Endocrinologists and American College of Endocrinology Comprehensive Clinical Practice Guidelines Formedical
Care of Patients with Obesity. Endocr Pract. 2016;22:1-203. doi: https://doi.org/10.4158/EP161365.GL

9. Rucker D, Padwal R, Li SK, et al. Long term pharmacotherapy for obesity and overweight: updated meta-analysis. BMJ. 2007;335(7631):1194-1199. doi: https://doi.org/10.1136/bmj.39385.413113.25

10. Avenell A, Broom J, Brown T, et al. Systematic review of the longterm effects and economic consequences of treatments for obesity and implications for health improvement. Health Technol Assess (Rockv). 2004;8(21). doi: https://doi.org/10.3310/hta8210.

11. Garvey WT, Mechanick JI, Brett EM, et al. American Association of Clinical Endocrinologists and American College of Endocrinology Comprehensive Clinical Practice Guidelines Formedical Care of Patients with Obesity. Endocr Pract. 2016;22(3):1-203. doi: https://doi.org/10.4158/EP161365.GL

12. Jensen MD, Ryan DH, Apovian CM, et al. 2013 AHA/ACC/TOS Guideline for the Management of Overweight and Obesity in Adults. J Am Coll Cardiol. 2014;63(25):2985-3023. doi: https://doi.org/10.1016/j.jacc.2013.11.004

13. Jensen MD, Ryan DH, Apovian CM, et al. 2013 AHA/ACC/TOS Guideline for the Management of Overweight and Obesity in Adults. Circulation. 2014;129(25 suppl 2):S102-S138. doi: https://doi.org/10.1161/01.cir.0000437739.71477.ee

14. Bray GA. Medical treatment of obesity: The past, the present and the future. Best Pract Res Clin Gastroenterol. 2014;28(4):665-684. doi: https://doi.org/10.1016/j.bpg.2014.07.015

15. Pucci A, Finer N. New Medications for Treatment of Obesity: Metabolic and Cardiovascular Effects. Can J Cardiol. 2015;31(2):142-152. doi: https://doi.org/10.1016/j.cjca.2014.11.010 
16. Torgerson JS, Hauptman J, Boldrin MN, Sjostrom L. XENical in the Prevention of Diabetes in Obese Subjects (XENDOS) Study: A randomized study of orlistat as an adjunct to lifestyle changes for the prevention of type 2 diabetes in obese patients. Diabetes Care. 2004;27(1):155-161. doi: https://doi.org/10.2337/diacare.27.1.155

17. Toplak H, Ziegler O, Keller U, et al. X-PERT: weight reduction with orlistat in obese subjects receiving a mildly or moderately reduced-energy diet. Early response to treatment predicts weight maintenance. Diabetes, Obes Metab. 2005;7(6):699-708. doi: https://doi.org/10.1111/j.1463-1326.2005.00483.x

18. Williamson DF, Pamuk E, Thun M, et al. Prospective Study of Intentional Weight Loss and Mortality in Overweight White Men Aged 40-64 Years. Am J Epidemiol. 1999;149(6):491-503. doi: https://doi.org/10.1093/oxfordjournals.aje.a009843

19. James WPT, Astrup A, Finer N, et al. Effect of sibutramine on weight maintenance after weight loss: a randomised trial. Lancet. 2000;356(9248):2119-2125. doi: https://doi.org/10.1016/S0140-6736(00)03491-7

20. Dedov II, Melnichenko GA, Troshina EA, et al. Body Weight Reduction Associated with the Sibutramine Treatment: Overall Results of the PRIMAVERA Primary Health Care Trial. Obes Facts. 2018;11(4):335-343. doi: https://doi.org/10.1159/000488880

21. Дедов И.И., Мельниченко Г.А., Романцова Т.И. Стратегия управления ожирением: итоги Всероссийской наблюдательной программы «ПримаВера» // Ожирение и метаболизм. 2016. — T.13 - №1. - C. 36-44. [Dedov II, Mel'nichenko GA,
Romantsova TI. The strategy of obesity management: the results of All-Russian observational program "Primavera." Obesity and metabolism. 2016;13(1):36-44. (In Russ.)]. doi: https://doi.org/10.14341/omet2016136-44

22. Knowler WC, Barrett-Connor E, Fowler SE, et al. Diabetes Prevention Program Research Group: Reduction in the incidence of type 2 diabetes with lifestyle intervention or metformin. N Engl J Med. 2002; 346:393-403. doi: https://doi.org/10.1056/NEJMoa012512

23. Pi-Sunyer $X$, Astrup A, Fujioka K, et al. A Randomized, Controlled Trial of $3.0 \mathrm{mg}$ of Liraglutide in Weight Management. N Eng/ J Med. 2015;373(1):11-22. doi: https://doi.org/10.1056/NEJMoa1411892

24. le Roux CW, Astrup A, Fujioka K, et al. 3 years of liraglutide versus placebo for type 2 diabetes risk reduction and weight management in individuals with prediabetes: a randomised, double-blind trial. Lancet. 2017;389(10077):1399-1409. doi: https://doi.org/10.1016/s0140-6736(17)30069-7

25. Blackman A, Foster GD, Zammit G, et al. Effect of liraglutide $3.0 \mathrm{mg}$ in individuals with obesity and moderate or severe obstructive sleep apnea: the SCALE Sleep Apnea randomized clinical trial. Int J Obes (Lond). 2016;40(8):1310-1319. doi: https://doi.org/10.1038/ij 0.2016.52

26. Wadden TA, Hollander P, Klein S et al. Weight maintenance and additional weight loss with liraglutide after low-calorie-diet-induced weight Ioss: The SCALE Maintenance randomized study. International Journal of Obesity. 2013; 37:1443-1451. doi: https://doi.org/10.1038/ijo.2013.120

27. Marso SP, Daniels GH, Brown-Frandsen K, et al. Liraglutide and cardiovascular outcomes in type 2 diabetes. N Engl J Med. 2016;375(4):311-22. doi: https://doi.org/10.1056/NEJMoa1603827 


\section{4. ПРИНЦИПЫ УДЕРЖАНИЯ СНИЖЕННОГО ВЕСА}

Романцова Т.И.

\section{ПОВТОРНЫЙ НАБОР МАССЫ ТЕЛА ПОСЛЕ ЕЕ СНИЖЕНИЯ, ПРИЧИНЫ РЕЦИДИВА ЗАБОЛЕВАНИЯ}

Ожирение - хроническое, рецидивирующее, прогрессирующее заболевание [1]. Снижение массы тела на 5-10\% существенно снижает кардиометаболический риск. Многим больным не удается сохранить уже достигнутые на фоне лечения показатели динамики массы тела [2, 3]. В среднем через 4-6 мес после начального, результативного этапа снижения массы тела, как правило, развивается период плато, который у ряда больных существенно снижает мотивацию к дальнейшему продолжению лечения. Период плато нередко переходит в фазу повторного увеличения массы тела. Повторный набор массы тела отмечается вне зависимости от вида применяемой терапии - на фоне изменения образа жизни, при использовании фармакотерапии, оперативного лечения. До половины потерянной массы тела вновь прибавляется уже в течение первого года терапии, в последующем масса тела может достичь исходных значений либо даже превзойти их $[3,4]$. В развитии рецидива заболевания важную роль играет как субъективный, психологический фактор (снижение приверженности к лечению, «дезингибирование» самоконтроля), так и объективная, биологически обусловленная адаптация к снижению массы тела. В биологической адаптации задействовано множество механизмов. Отрицательный энергобаланс оказывает стрессорное воздействие на адипоциты, что приводит к резкому, диспропорциональному в отношении достигнутого снижения массы тела уменьшению выработки лептина [5]. Снижается содержание других анорексигенных гормонов: глюкагоноподобного пептида-1, пептида YY; холецистокинина, амилина, повышается содержание грелина. В ответ на периферические сигналы в дугообразных ядрах гипоталамуса повышается выработка анаболических нейромедиаторов - нейропептида Ү и агути-подобного белка; снижается синтез катаболических нейромедиаторов проопиомеланокортина и кокаин-амфетамин-регулируемого транскрипта $[6,7,8]$. Данные преобразования лежат в основе повышения аппетита. В адипоцитах развивается резистентность к катехоламин-индуцированному липолизу [9]. Снижение массы тела происходит за счет как жировой ткани, так и уменьшения массы «тощих» тканей, прежде всего скелетной мускулатуры [10]. Дефицит энергии приводит к метаболической адаптации энергозатрат. Отмечается снижение основного обмена, а также энергозатрат, обусловленных двигательной активностью и термическим динамическим действием пищи [11]. Таким образом, метаболическая адаптация обусловлена реорганизацией механизмов регуляции энергобаланса с целью максимального сохранения энергии в условиях ее критического дефицита. Характерные изменения содержания гормонов и снижение энергозатрат могут сохраняться свыше года после окончания периода снижения массы тела, в том числе даже после полного восстановления исходных значений ИМТ [8, 12]. В настоящее время не существует единых общепринятых критериев успешного снижения массы тела. В большинстве исследовательских работ успешные респондеры характеризуются как пациенты, снизившие массу тела на 10\% и сохраняющие этот результат не менее года [13].

\section{РЕКОМЕНДАЦИИ}

2.26. Рекомендуется постановка реалистичных целей перед началом терапии, т.е. снижение массы тела на 5-10\% за 6 мес, что сопровождается существенным улучшением показателей метаболического здоровья [2] (УДД 1, УУР А).

Комментарии. Нереалистичные цели (снижение массы тела на 30\% и более за короткий промежуток времени) в последующем могут послужить причиной разочарования пациентов в эффективности лечения, снижении приверженности к терапии $[14,15]$. При быстром снижении массы тела отмечаются более выраженные потери мышечной ткани, что негативно отражается на показателях энергозатрат [16].

2.27. Рекомендуется сохранение режима гипокалорийного питания. Состав макронутриентов основывается на индивидуальных предпочтениях больного и состоянии его здоровья [17, 18] (УДД 1, УУР А).

Комментарии. Успешное долгосрочное поддержание массы тела отмечается: 1) на фоне низкого содержания жиров в рационе; 2) при рационе, обогащенном пищевыми волокнами, источниками которых являются овощи и фрукты; 3) на фоне высокобелковой диетотерапии [17-19]. Повышение содержания белка (до 25-30\% от суточной калорийности) способствует быстрому насыщению (предположительно, за счет активации секреции анорексигенных гормонов пептида YY и глюкагоноподобного пептида-1), а также характеризуется более высоким термическим эффектом [19, 20].

2.28. Рекомендуется сохранение режима повышенной физической активности: аэробная физическая активность (например, быстрая ходьба) от 200 до 300 мин в неделю, общие энергозатраты $\approx 2500$ ккал в неделю [17] (УДД 2, УУР В).

Комментарии. Отмечается отрицательная зависимость между объемом физической активности и риском повторного набора массы тела. Расширение физической активности обеспечивает сохранность «тощих» тканей, уменьшает адаптивный термогенез. Успешные респондеры уделяют больше времени умеренной либо интенсивной физической активности по сравнению с нереспондерами при сопоставимых показателях массы тела [21, 22].

2.29. Рекомендуется назначение фармакотерапии при неэффективности немедикаментозных методов лечения или смена препаратов при неэффективности предшествующей медикаментозной терапии (выбор препаратов - орлистат, сибутрамин (в т.ч. сибутрамин+метформин), лираглутид) (УДД 1, УУР А). 
Комментарии. Применение указанных препаратов в сочетании с изменением образа жизни позволяет обеспечить более стойкое длительное поддержание массы тела по сравнению с плацебо [23-25]. Нецелесообразно продолжение приема ранее назначенного препарата для лечения ожирения при отсутствии клинически значимого снижения массы тела на 5-10\% после 3-4 мес фармакотерапии.

\subsection{0. Рекомендуется наблюдение пациента в процессе лечения не реже чем раз в месяц [26] (УДД 1, УУР А).}

Комментарии. Консультации проводятся либо во время визита пациента в лечебное учреждение, либо дистанционно (по телефону, электронной почте). В ходе консультаций уточняется динамика массы тела, состояние здоровья с учетом ассоциированных заболеваний, мотивация к продолжению лечения, при необходимости - смена тактики терапии $[26,27]$.

2.31. Рекомендуется постоянный самостоятельный мониторинг массы тела, ведение дневника питания и контроля физических нагрузок: ежедневное (предпочтительно) либо еженедельное взвешивание. Мониторинг приема пищи - размера порций, суточного калоража. Мониторинг физической активности $[20,27,28,29]$ (УДД 1, УУР А).

\section{СПИСОК ЛИТЕРАТУРЫ | REFERENCES}

1. Bray GA, Kim KK, Wilding JPH, et al. Obesity: a chronic relapsing progressive disease process. A position statement of the World Obesity Federation. Obes Rev. 2017;18(7):715-723. doi: https://doi.org/10.1111/obr.12551.

2. Magkos F, Fraterrigo G, Yoshino J. et al. Effects of Moderate and Subsequent Progressive Weight Loss on Metabolic Function and Adipose Tissue Biology in Humans with Obesity. Cell Metab, 2016;23:1-11. doi: https://doi.org/10.1016/j.cmet.2016.02.005

3. McGuire MT, Wing RR, Hill JO. The prevalence of weight loss maintenance among American adults. Int J Obes Relat Metab Disord. 1999;23:1314-1319. doi: https://doi.org/10.1038/sj.ijo.0801075

4. Dulloo AG, Jacquet J, Girardier L. Poststarvation hyperphagia and body fat overshooting in humans: a role for feedback signals from lean and fat tissues. Am J Clin Nutr. 1997;65(3):717-723. doi: https://doi.org/10.1093/ajcn/65.3.717

5. Roumans NJT, Vink RG, Bouwman FG, et al. Weight-loss stress in subcutaneous adipose tissue is related to weight regain. Int J Obes (Lond). 2017;41(6):894-901. doi: https://doi.org/10.1038/ijo.2016.221

6. Crujeiras AB, Goyenechea E, Abete l, et al. Weight Regain after a Diet-Induced Loss Is Predicted by Higher Baseline Leptin and Lower Ghrelin Plasma Levels. J Clin Endocrinol Metab. 2010;95(11):5037-5044. doi: https://doi.org/10.1210/jc.2009-2566

7. Hinkle W, Cordell M, Leibel R, et al. Effects of reduced weight maintenance and leptin repletion on functional connectivity of the hypothalamus in obese humans. PLoS One. 2013;8:e59114. doi: https://doi.org/10.1371/journal.pone.0059114.

8. Sumithran P, Prendergast LA, Delbridge E, et al. Long-term persistence of hormonal adaptations to weight loss. N Engl J Med 2011;365:1597-1604. doi: https://doi.org/10.1056/NEJMoa1 105816

9. Kasher-Meron M, Youn DY, Zong H, Pessin JE. Lipolysis defect in white adipose tissue and rapid weight regain. Am J Physiol Metab. 2019;317(2):E185-E193. doi: https://doi.org/10.1152/ajpendo.00542.2018

10. Sparti A, DeLany JP, de la Bretonne JA, et al. Relationship between resting metabolic rate and the composition of the fat-free mass. Metabolism. 1997:46:1225-1230. doi: https://doi.org/10.1016/S0026-0495(97)90222-5

11. Leibel RL, Rosenbaum M, Hirsch J. Changes in Energy Expenditure Resulting from Altered Body Weight. N Engl J Med. 1995;332(10):621628. doi: https://doi.org/10.1056/NEJM199503093321001

12. Rosenbaum M, Hirsch J, Gallagher DA, Leibel RL. Long-term persistence of adaptive thermogenesis in subjects who have maintained a reduced body weight. Am J Clin Nutr. 2008;88:906-912. doi: https://doi.org/10.1093/ajcn/88.4.906

13. Wing RR, Hill JO. Successful weight loss maintenance. Annu Rev Nutr 2001;21:323-341. doi: https://doi.org/10.1146/annurev.nutr.21.1.323

14. DeJesus RS, Bauer KW, Bradley DP, et al. Experience and expectations of patients on weight loss: The Learning Health system Network experience. Obesity Science \& Practice. 2019;5(5):479-486. doi: https://doi.org/10.1002/osp4.364

15. Preuss $H$, Leister $L$, Pinnow $M$, Legenbauer $T$. Inhibitory control pathway to disinhibited eating: A matter of perspective? Appetite. 2019;141(2):104297. doi: https://doi.org/10.1016/j.appet.2019.05.028
16. Vink RG, Roumans NJT, Arkenbosch LAJ, et al. The effect of rate of weight loss on long-term weight regain in adults with overweight and obesity. Obesity. 2016;24(2):321-327. doi: https://doi.org/10.1002/oby.21346

17. Jensen MD, Ryan DH, Apovian CM, et al. 2013 AHA/ACC/TOS Guideline for the Management of Overweight and Obesity in Adults. Circulation. 2014;129(25 suppl 2):S102-S138. doi: https://doi.org/10.1161/01.cir.0000437739.71477.ee

18. Bray GA, Heisel WE, Afshin A, et al. The Science of Obesity Management: An Endocrine Society Scientific Statement. Endocr Rev. 2018;39(2):79-132. doi: https://doi.org/10.1210/er.2017-00253

19. Aller EE, Larsen $T M, C l a u s ~ H$, et al. Weight loss maintenance in overweight subjects on ad libitum diets with high or low protein content and glycemic index: the DIOGENES trial 12-month results. Int. J. Obes. (Lond.). 2014;38:1511-1517 doi: https://doi.org/10.1038/ijo.2014.52

20. Varkevisser RDM, van Stralen MM, Kroeze W, et al. Determinants of weight loss maintenance: a systematic review. Obes Rev. 2019;20(2):171-211. doi: https://doi.org/10.1111/obr.12772

21. Schoeller DA, Shay K, Kushner RF. et al. How much physical activity is needed to minimize weight gain in previously obese women? Am J Clin Nutr. 1997;66(3):551-556. doi: https://doi.org/10.1093/ajcn/66.3.551.

22. Ostendorf DM, Caldwell AE, Creasy SA, et al. Physical Activity Energy Expenditure and Total Daily Energy Expenditure in Successful Weight Loss Maintainers. Obesity (Silver Spring). 2019;27(3):496-504 doi: https://doi.org/10.1002/oby.22373

23. James WTP, Astrup A, Finer N, et al. The STORM Study Group. Effect of sibutramine on weight maintenance after weight loss: a randomised trial. Lancet. 2000;356:2119-2125. doi: https://doi.org/10.1016/S0140-6736(00)03491-7

24. Richelsen B, Tonstad S, Rössner S, et al. Effect of orlistat on weight regain and cardiovascular risk factors following a very-lowenergy diet in abdominally obese patients: a 3-year randomized, placebo-controlled study. Diabetes Care. 2007;30(1):27-32. doi: https://doi.org/10.2337/dc06-0210

25. Wadden TA, Hollander P, Klein S, et al. Weight maintenance and additional weight loss with liraglutide after lowcalorie-diet-induced weight loss: the SCALE Maintenance randomized study. Int J Obes (Lond). 2013;37(11):1443-51 doi: https://doi.org/10.1038/ijo.2013.120

26. Dutton GR, Gowey MA, Tan F. Comparison of an alternative schedule of extended care contacts to a self-directed control: a randomized trial of weight loss maintenance. Int J Behav Nutr Phys Act. 2017;14(1):107. doi: https://doi.org/10.1186/s12966-017-0564-1

27. Wing RR, Tate DF, Gorin AA, et al. A Self-Regulation Program for Maintenance of Weight Loss. N Engl J Med. 2006;355(15):1563-1571. doi: https://doi.org/10.1056/NEJMoa061883

28. Ostendorf DM, Lyden K, Pan Z, et al. Objectively measured physical activity and sedentary behavior in successful weight loss maintainers. Obesity (Silver Spring). 2018;26(1):53-60. doi: https://doi.org/10.1002/oby.22052

29. Crain AL, Sherwood NE, Martinson BC, Jeffery RW. Mediators of Weight Loss Maintenance in the Keep It Off Trial. Ann Behav Med. 2018;52(1):9-18. doi: https://doi.org/10.1007/s12160-017-9917-x 


\section{5. ФИЗИЧЕСКАЯ РЕАБИЛИТАЦИЯ И ДВИГАТЕЛЬНАЯ АКТИВНОСТЬ ПАЦИЕНТОВ С ОЖИРЕНИЕМ}

Чечельницкая С.M.

\section{ФИЗИЧЕСКАЯ РЕАБИЛИТАЦИЯ И ДВИГАТЕЛЬНАЯ АКТИВНОСТЬ ПАЦИЕНТОВ С ОЖИРЕНИЕМ}

Физическая терапия пациентов с ожирением складывается из двух взаимосвязанных и взаимопотенцирующих направлений: оптимизация двигательной активности и физическая реабилитация.

Цель оптимизации двигательной активности - увеличение расходов энергии для постепенного монотонного снижения веса пациента (5-10\% в год) до оптимального для него уровня и удержание достигаемых результатов на длительный период. Она достигается за счет определения объемов, интенсивности, характера и режима нагрузок.

Цель физической реабилитации - обеспечить пациенту возможность активно двигаться за счет устранения нарушений, препятствующих выполнению физических нагрузок и адекватной двигательной активности (хронические кардиологические заболевания, контрактуры суставов, выраженные нарушения ходьбы, дистрофия скелетных мышц, низкая переносимость физических нагрузок и т.д.).

Задачи физической реабилитации:

- уменьшение болевых ощущений;

- улучшение функционирования сердечно-сосудистой и дыхательной систем;

- повышение мышечной силы;

- улучшение качества движения;

- повышение гибкости и улучшение осанки;

- повышение уровня двигательной активности.

Ведущие принципы физической реабилитации:

- деятельность строится на холистическом подходе - реабилитационные задачи формулируются совместно пациентом, лечащим врачом, реабилитологом и психологом;

- методы, средства и режим реабилитации выбираются на основе результатов современной инструментальной диагностики;

- персональные реабилитационные программы составляются с учетом личных предпочтений пациента, возможности пациента и его ближайшего окружения обеспечить их выполнение самостоятельно;

- неотъемлемой частью реабилитационной программы являются инструменты контроля полноты и качества выполнения требований, этапного контроля эффективности;

- реабилитационный процесс ведется длительное время (1,5-2 года) в смешанном режиме: очные сессии, дистанционная поддержка в межгоспитальный период.

\section{РЕКОМЕНДАЦИИ}

\section{Сроки и целевые ориентиры}

2.32. Рекомендуемая продолжительность программ физической реабилитации должна составлять не менее 12 нед (УДД 1, УУР А).

Комментарии. По данным ряда исследований, при продолжительности занятий 12 нед и более значимо снижаются показатели веса, ИМТ, окружность талии и содержание жировой ткани в организме. Продолжительность курса 12 нед и оказывает существенное влияние на липидный профиль пациентов, приводя к снижению уровня ЛПВП [1]. Менее продолжительные курсы не дают подобного эффекта.

Максимальное снижение массы тела отмечено при продолжительности тренировок в течение 16 нед (4 мес).

2.33. Двигательная активность в программах реабилитации пациентов с ожирением носит вспомогательный характер и не рекомендуется как монотерапия. Клиническая эффективность комплексных программ поведенческого контроля веса, по сравнению с однокомпонентными программами (диетотерапии или физическая активность), выше (УДД 1, УУР А).

Комментарии. Систематический обзор А. Thorogood и соавт. показал, что ценность физических упражнений как самостоятельного средства снижения веса для групп с избыточным весом и ожирением ограничена [2]. В то же время аэробные упражнения обеспечивают снижение риска сердечно-сосудистых заболеваний и уровня липидов и могут иметь ценность как часть комплексной программы, включающей диетотерапию.

В краткосрочной перспективе потеря веса одинакова для диетических и комбинированных программ, но в долгосрочной перспективе потеря веса увеличивается при сочетании диеты и физической активности. Программы, основанные только на физической активности, менее эффективны, чем комбинированные как в краткосрочной, так и в долгосрочной перспективе [3].

Физические упражнения являются обязательной частью лечения ожирения, так как улучшают кардиореспираторную подготовку и состояние скелетных мышц, что помогает предотвратить саркопеническое ожирение [4]. Систематический обзор Conn V.S. и соавт. показал, что одним из наиболее важных преимуществ двигательной активности может быть предотвращение увеличения веса [5]. 
2.34. Не рекомендуется ставить перед пациентом с ожирением цель доведения веса до половозрастной нормы, так как она недостижима. Снижение веса у пациентов должно происходить постепенно, оптимальный целевой показатель 1-й ступени - снижение веса на 5\% в течение 6 мес с удержанием этого показателя в последующий период (УДД 2, УУР В).

Комментарии. В наблюдательных исследованиях (9 лет) Fildes A. и соавт. наблюдали, как правило, циклическое изменение веса в категории патологического ожирения. Ряд авторов сообщали о большей нестабильности результатов среди пациентов с более высоким ИМТ. Циклическое изменение веса сопровождается более высоким риском заболеваемости и смертности, чем стабильное ожирение, хотя доказательства причинной связи остаются неубедительными [6]. Было показано, что не менее 50\% пациентов, потерявших 5\% массы тела, вернули этот вес в течение 2 лет. Ранее сообщалось, что примерно 80\% людей, которые намеренно достигают потери веса на 10\% или более от своего веса, восстанавливают эту потерю. В связи с этим в материалах ВОЗ говорится, что «здоровая потеря веса - это не просто «диета» или «программа». Речь идет о постоянном образе жизни, который включает в себя долгосрочные изменения в ежедневных привычках питания и физических упражнениях».

\subsection{5. В отношении пациентов с ожирением не рекомендуется применять универсальный подход при опре-} делении целевых показателей снижения веса (УДД 2, УУР В).

Комментарии. Снижение веса не является самоцелью при реабилитации пациентов с ожирением. Физическая реабилитация в большей степени направлена на предупреждение заболеваний сердечно-сосудистой, дыхательной и костно-мышечной систем, вызываемых ожирением. Существуют убедительные доказательства того, что у пациентов с сердечно-сосудистыми заболеваниями избыточный вес и умеренное ожирение (т.е. ИМТ <35 кг/м²) защищают от новых сердечно-сосудистых заболеваний, что было названо парадоксом ожирения. Идеальной долгосрочной целью было бы доведение пациентов с тяжелым ожирением до избыточного веса или легкой степени ожирения с помощью здорового питания, двигательной активности и улучшения кардиореспираторной подготовки [7].

\section{Оптимизация двигательной активности}

По определению ВО3, физическая (двигательная) активность - это какое-либо движение тела, производимое скелетными мышцами, которое требует расхода энергии. Термин «физическая активность» относится к любым видам движений, в том числе во время отдыха, поездок в какие-либо места и обратно или во время работы.

2.36. При расчете объемов двигательной активности для пациентов, лечащихся от ожирения, рекомендуется учитывать все виды физических действий (УДД 2, УУР А).

Комментарии. В обзоре А. Данна (2009 г.) анализируется концепция, согласно которой, образ жизни имеет такую же эффективность в контроле веса, как и структурированные программы упражнений. Сделан вывод, что вмешательства в образ жизни обладают способностью улучшать исходы СС3, хотя отмечается краткосрочный характер многих исследований, подтверждающих этот вывод, и важность будущих исследований, направленных на поддержание такого образа жизни [8]. По мнению Р. Кушнера, консультирование по снижению веса должно поощрять как структурированные упражнения, так и физическую активность, связанную с образом жизни, как часть лечения ожирения [9].

2.37. Рекомендовано, чтобы большая часть ежедневной двигательной активности приходилась на аэробные физические нагрузки, то есть соответствовала нагрузке умеренной интенсивности (УДД 1, УУР А).

Комментарии. Интенсивность физических нагрузок - понятие индивидуальное, зависящее от физической подготовленности пациента. Она определяется по реакции сердечно-сосудистой системы на нагрузку. При нагрузке низкой интенсивности пульс достигает 50-60\% максимального. Для физической активности умеренной интенсивности целевая частота пульса должна составлять от 64 до 76\% максимальной частоты пульса. Для физической активности с высокой интенсивностью целевая частота пульса - от 77 до 93\% максимальной частоты пульса. Максимальную частоту сердечных сокращений можно рассчитать по формуле Карванена (220 - возраст).

Для индивидуального использования во время тренировок можно применять более простой способ измерения относительной интенсивности - тест разговора. Если упражнения средней интенсивности, пациент может говорить, но не петь во время упражнения. Если упражнения более интенсивны, он не сможет сказать больше нескольких слов, не делая паузу для дыхания. Для измерения уровня интенсивности физической активности также широко применяется тест-рейтинг воспринимаемого напряжения Борга. Он основан на физических ощущениях, которые испытывает человек, включая учащенное сердцебиение, учащенное дыхание или одышку, повышенное потоотделение и мышечную усталость. Каждая позиция шкалы оценивается в баллах от 6 (полное отсутствие усилий) до 20 (максимальное усилие). Практики, как правило, соглашаются с тем, что воспринимаемые уровни нагрузки от 12 до 14 по шкале Борга предполагают, что физическая активность выполняется с умеренным уровнем интенсивности, более 14 - с высоким уровнем.

2.38. При физической реабилитации пациентов с ожирением важно обеспечить адекватный недельный объем двигательной активности, обеспечивающий опережающий расход энергии по отношению к энергии, поступающей с пищей (УДД 2, УУР А).

Комментарии. При планировании объемов двигательной активности целесообразно использовать метрическую единицу для универсальной оценки физических затрат - MET (метаболический эквивалент физической деятельности). МЕТ — количество кислорода, поглощаемого человеком в покое за 1 мин в пересчете на 1 кг его веса. На основе 
многочисленных измерений для взрослых людей принято считать $1 \mathrm{MET}=3,5$ мл О $/$ кг/мин. Во время любой деятельности, включая компьютерные игры и домашнюю работу, человек затрачивает количество кислорода, кратное 1 МЕТ. Например, при выполнении гимнастических упражнений человек тратит 2,7 МЕТ в минуту. Если он занимался активно в течение 30 мин, потратил 81 МЕТ. Наиболее распространенной рекомендацией по объему энергетических затрат является уровень 3000-4000 МЕТ в неделю.

Для различных видов активности разработана градация по интенсивности нагрузок в MET:

- крайне низкой интенсивности (сидячие), например, компьютерные игры лежа, - до 1,5 MET;

- н низкой интенсивности, например, письмо от руки, складывание белья, подметание пола, - от 1,5 до 3 MET;

- средней интенсивности, например, быстрая ходьба по земле, - от 3 до 6 MET;

- высокой интенсивности, например, игра в баскетбол, бег на скорость, - более 6 MET.

Для подсчета недельных энергетических затрат удобно пользоваться справочниками, в которых приводятся усредненные энергозатраты на измеренные виды активности. Примером такого источника является Компендиум Arizona State University and National Cancer Institute (https://sites.google.com/site/compendiumofphysicalactivities/ home). В том случае, если специалист или пациент не нашел необходимый ему вид активности, рекомендуется подбирать аналогичное по интенсивности занятие и ориентироваться на его энергетическую стоимость. Например, спокойная ходьба вверх по лестнице, по сути, является кардиореспираторной тренировкой с умеренной интенсивностью.

Суммарные энергетические затраты складываются из затрат на повседневные дела, работу, передвижения, прогулки и т.д.

На этом принципе построены многочисленные анкеты самоконтроля и профессиональной супервизии, например, International physical activity questionnaire (IPAQ). На сайте https://sites.google.com/site/theipaq/ paзмещены опросники IPAQ на многих языках мира, при заполнении которых онлайн-программа выдает результат недельной активности в МЕT.

После заполнения опросника суммируются все часы и минуты активности из первых 4 частей по умеренным нагрузкам и умножаются на средние цифры МЕТ умеренной нагрузки:

$[($ часы $\times 60$ мин $)+$ минуты $] \times$ кол-во дней в неделю $\times$ 4,5 (средняя цена за умеренную нагрузку в MET) = MET в неделю.

Так же вычисляется затраты на интенсивную физическую нагрузку:

$[($ часы $\times 60$ мин $)+$ минуты $] \times$ кол-во дней в неделю $\times 8$ (средняя цена за интенсивную нагрузку в MET) = MET в неделю.

Для оценки энергии, затраченной маломобильными пациентами, дополнительно существует 5-я часть, которая анализирует нагрузки низкой интенсивности - до 3 МЕТ. Принцип подсчета прежний.

Сумма МЕТ легкой, умеренной и интенсивной нагрузок определяет среднюю физическую активность в неделю.

Подобный подход обеспечивает высокую вариативность двигательного режима. Пациент с низкой переносимостью физических нагрузок или в период интеркуррентного заболевания, плохого самочувствия может составить свой двигательный рацион из более длительных низкоинтенсивных занятий. При хорошем самочувствии желательно повысить интенсивность нагрузок, сократив при этом их время.

\section{Физические упражнения}

2.39. Поскольку у многих людей с ожирением снижена кардиореспираторная подготовка, они не знакомы с физическими упражнениями и имеют повышенный риск травм опорно-двигательного аппарата из-за избыточной массы тела и нарушений постуральной устойчивости, важно назначать упражнения, которые безопасны и позволяют им чувствовать себя комфортно, тем самым обеспечивая соблюдение программы тренировок. Рекомендуется, чтобы упражнения проводились под контролем специализированного тренера, по крайней мере, в начальный период (УДД 2, УУР В).

Комментарии. Тип упражнения - это параметр, который следует учитывать при лечении ожирения. Упражнения на выносливость являются самым популярным и эффективным видом упражнений для похудания, так как они легко применимы для людей с ожирением и обеспечивают высокий расход энергии. Упражнения с отягощениями и периодические упражнения также могут быть включены в программу управления весом, предлагая разнообразие и дополнительные положительные эффекты на показатели здоровья и физической формы. Они могут влиять на массу тела, увеличивая безжировую массу, что повышает скорость метаболизма в состоянии покоя. Однако поскольку упражнение с отягощениями включает длительные интервалы отдыха, его расход энергии низок по сравнению с непрерывными упражнениями на выносливость.

Упражнения с сопротивлением также улучшают мышечную силу, что может привести к более высокой физической активности и, следовательно, к увеличению общих суточных затрат энергии, хотя следует соблюдать осторожность из-за повышенного риска мышечно-скелетных травм, связанных с этим видом упражнений.

Интервальная тренировка высокой интенсивности (ИТВИ) характеризуется короткими сериями упражнений высокой интенсивности, чередующимися с периодами отдыха или упражнениями низкой интенсивности. ИТВИ в последнее время стала популярной стратегией похудания среди населения в целом [10]. Также было показано, что такой режим тренировки хорошо переносится людьми с ожирением. Согласно метаанализу Джеллеймана 
и соавт. [11], ИТВИ вызвала значительное снижение массы тела, на 1,3 кг, по сравнению с контрольными группами без упражнений, но не по сравнению с непрерывными тренировками средней интенсивности. По-видимому, оба этих вида тренировок одинаково эффективны в снижении жировых отложений даже при отсутствии изменений массы тела у тучных людей. Преимуществом является то, что ИТВИ требует примерно на $40 \%$ меньше времени [12]. Метаанализ, проведенный Тюрком и соавт. [13], показал значительное снижение процентного содержания жира в организме при ИТВИ по сравнению с «традиционными» упражнениями, но при этом не показано выраженного снижения веса, ИМТ или уменьшения ОТ.

Согласно Р. Де Фео (2013), большое значение имеет постепенное увеличение физической нагрузки в процессе выполнения упражнений [14]. Наиболее эффективный режим повышения нагрузок для людей с ожирением - это начинать с умеренной интенсивности и увеличивать ее на 5\% каждые шесть тренировок, до 65\% от максимальной нагрузки. После того, как будет достигнута достаточная адаптация, лучше добавить короткие повторения интервальных тренировок с субмаксимальной интенсивностью.

\subsection{0. Выполнение физических упражнений является частью двигательной активности и должно учитывать- ся в общей недельной нагрузке. Продолжительность занятий физическими упражнениями должна превышать рекомендованную для здоровых лиц в 1,5-2 раза (УДД 2, УУР С).}

Комментарии. Рекомендуемые для общей популяции минимальные уровни физической активности (примерно 150 мин упражнений средней интенсивности в неделю) без ограничений в питании могут вызвать умеренную потерю веса (около 2-3 кг), но недостаточны для клинически значимой потери веса ( $\geq 5 \%$ ). Для похудания и успешного долгосрочного контроля веса необходимо больше физических нагрузок (от 225 до 420 мин упражнений в неделю) [15]. Подсчитано, что каждые 50 мин физических упражнений в неделю приводят к потере около 1 кг за 6-месячный период. Итак, если заниматься по 250 мин каждую неделю, можно ожидать потери 5 кг за 6 мес (то есть только от упражнений).

Разделение ежедневного расписания упражнений на несколько коротких периодов, по данным исследователей, является таким же эффективным в управлении весом, как выполнение упражнений в одно занятие [16].

\subsection{1. Для пациентов с ожирением должны разрабатываться персональные программы физических упраж- нений, учитывающие физические характеристики пациента, его ограничения, связанные с ожирением, осложнениями и сопутствующими заболеваниями (УДД 2, УУР В).}

Комментарии. Персональная программа физических упражнений должна составляться на основе результатов диагностики функционального состояния релевантных органов и систем пациента.

Диагностика физического статуса пациента позволяет одновременно получить необходимую информацию для разработки персональной программы физической реабилитации и разработать перечень показателей для оценки эффективности и действенности предпринимаемых мер. Соответственно, она включает достаточно широкий спектр процедур, перечисленных ниже.

Физикальное обследование, фиксация антропометрических показателей: масса тела, длина тела, окружности талии, бедер, голеней и плеч. С целью выявления саркопенического ожирения проводится исследование компонентного состава тела методом биоимпедансометрии. Определяется процент жировой, тощей и мышечной масс. По итогам обследования проводится консилиум команды специалистов с участием пациента: лечащий врач, реабилитолог, методист лечебной физической культуры (ЛФК), психолог.

Роли участников консилиума распределяются следующим образом:

- лечащий врач информирует об особенностях течения заболевания у пациента, осложнениях и коморбидных заболеваниях, функциональном состоянии сердечно-сосудистой и дыхательной систем;

- пациент рассказывает о существующих ограничениях в физическом функционировании и опыте занятий физической культурой, спортом, предъявляет актуальные жалобы, принимает решение о выборе средств и методов физической реабилитации из числа предлагаемых специалистами;

- реабилитолог анализирует результаты проведенных диагностических мероприятий, информацию от лечащего врача и пациента и формулирует реабилитационные задачи, определяя последовательность их решения;

- методист ЛФК предлагает средства и методы адаптивной физической культуры, двигательной активности и лечебной гимнастики, позволяющие решать поставленные задачи.

При составлении персональной программы физической реабилитации может использоваться широкий спектр методик ЛФК, которые применяются для решения конкретных задач восстановления функций сердечно-сосудистой и легочной систем, периферической нервной системы и опорно-двигательного аппарата (кардиотренировки, дыхательные упражнения, стрейчинг, суставная гимнастика, ушу, элементы йоги, изометрические силовые упражнения, упражнения с отягощением, работа на тренажерах с собственным весом, лечебная гимнастика, кинезитерапия, аквакинезитерапия и т.д. и т.п.).

Тренировки должны проводиться на регулярной основе, не реже 3 раз в неделю. Тренировки низкой или умеренной интенсивности должны занимать в совокупности не менее 5 ч в неделю, тренировки высокой интенсивности - не менее 3 ч.

Во все комплексы облигатно, желательно в разминочной части, должны включаться упражнения кардиологической и респираторной направленности. Неотъемлемой составляющей основной части занятия должны быть упражнения, направленные на повышение силовой выносливости скелетных мышц и объемов движений в отдельных 
суставах, укрепление костей. Основная часть должна наполняться упражнениями с учетом всех известных персональных особенностей пациента.

Обязательная часть персональной программы физической реабилитации - контроль эффективности и действенности. Необходимо предусмотреть текущий контроль в виде заполнения самоотчетов по выполняемым нагрузкам и простым, но информативным тестам. Этапный контроль должен включать проведение инструментального обследования по диагностическому протоколу, который применялся в подготовительный период.

Занятия могут проводиться как в очной, так и в заочной форме при информационной поддержке врача-реабилитолога и методиста ЛФК. Очные занятия признаются более эффективными, но даже дистанционное сопровождение пациента обеспечивает достаточный эффект.

\section{СПИСОК ЛИТЕРАТУРЫ | REFERENCES}

1. Kim K-B, Kim K, Kim C, et al. Effects of Exercise on the Body Composition and Lipid Profile of Individuals with Obesity: A Systematic Review and Meta-Analysis. J Obes Metab Syndr. 2019;28(4):278-294. doi: https://doi.org/10.7570/jomes.2019.28.4.278

2. Thorogood A, Mottillo S, Shimony A, et al. Isolated Aerobic Exercise and Weight Loss: A Systematic Review and Meta-Analysis of Randomized Controlled Trials. Am J Med. 2011;124(8):747-755. doi: https://doi.org/10.1016/j.amjmed.2011.02.037

3. Johns DJ, Hartmann-Boyce J, Jebb SA, Aveyard P. Diet or Exercise Interventions vs Combined Behavioral Weight Management Programs: A Systematic Review and Meta-Analysis of Direct Comparisons. J Acad Nutr Diet. 2014;1 14(10):1557-1568. doi: https://doi.org/10.1016/j.jand.2014.07.005

4. Hamasaki H. Physical Activity and Obesity in Adults. In: Adiposity Epidemiology and Treatment Modalities. Vol 13. InTech; 2017:36-44. doi: https://doi.org/10.5772/64672

5. Conn VS, Hafdahl A, Phillips LJ, et al. Impact of Physical Activity Interventions on Anthropometric Outcomes: Systematic Review and Meta-Analysis. J Prim Prev. 2014;35(4):203-215. doi: https://doi.org/10.1007/s10935-014-0352-5

6. Fildes A, Charlton J, Rudisill C, et al. Probability of an Obese Person Attaining Normal Body Weight: Cohort Study Using Electronic Health Records. Am J Public Health. 2015;105(9):e54-e59. doi: https://doi.org/10.2105/AJPH.2015.302773

7. Ortega FB, Lavie CJ, Blair SN. Obesity and Cardiovascular Disease. Circ Res. 2016;118(11):1752-1770. doi: https://doi.org/10.1161/CIRCRESAHA.115.306883

8. Dunn AL. Effectiveness of Lifestyle Physical Activity Interventions to Reduce Cardiovascular Disease. Am J Lifestyle Med. 2009;3(1):1 1S-18S. doi: https://doi.org/10.1177/1559827609336067
9. Kushner RF. Weight Loss Strategies for Treatment of Obesity. Prog Cardiovasc Dis. 2014;56(4):465-472. doi: https://doi.org/10.1016/j.pcad.2013.09.005

10. Obert J, Pearlman M, Obert L, Chapin S. Popular Weight Loss Strategies: a Review of Four Weight Loss Techniques. Curr Gastroenterol Rep. 2017;19(12):61. doi: https://doi.org/10.1007/s11894-017-0603-8

11. Jelleyman C, Yates T, O'Donovan G, et al. The effects of highintensity interval training on glucose regulation and insulin resistance: a meta-analysis. Obes Rev. 2015;16(11):942-961. doi: https://doi.org/10.1111/obr.12317

12. Wewege $M$, van den Berg R, Ward RE, Keech A. The effects of highintensity interval training vs. moderate-intensity continuous training on body composition in overweight and obese adults: a systematic review and meta-analysis. Obes Rev. 2017;18(6):635-646. doi: https://doi.org/10.1111/obr.12532

13. Türk Y, Theel W, Kasteleyn MJ, et al. High intensity training in obesity: a Meta-analysis. Obes Sci Pract. 2017;3(3):258-271. doi: https://doi.org/10.1002/osp4.109

14. De Feo P. Is high-intensity exercise better than moderate-intensity exercise for weight loss? Nutr Metab Cardiovasc Dis. 2013;23(11):1037-1042. doi: https://doi.org/10.1016/j.numecd.2013.06.002

15. Sword DO. Exercise as a Management Strategy for the Overweight and Obese. Strength Cond J. 2012;34(5):47-55. doi: https://doi.org/10.1519/SSC.0b013e31826d9403

16. Fogelholm M, Stallknecht B, Van Baak M. ECSS position statement: Exercise and obesity. Eur J Sport Sci. 2006;6:15-24. doi: https://doi.org/10.1080/17461390600563085 


\title{
ГЛАВА З. ОЖИРЕНИЕ И НАРУШЕНИЯ УГЛЕВОДНОГО ОБМЕНА
}

\author{
Шестакова М.В., Шестакова Е.А.
}

Наличие сопутствующей патологии зачастую изменяет подход к терапии основного заболевания. Как наличие ожирения у пациента с СД2, так и наличие СД2 у пациента с ожирением будет видоизменять тактику лечения.

\section{ВЛИЯНИЕ ОЖИРЕНИЯ НА ВЫБОР ТАКТИКИ ЛЕЧЕНИЯ СД2}

Выбор терапии пациентов с СД2 происходит в несколько этапов: постановка адекватной цели терапии, старт сахароснижающей терапии, своевременная интенсификация терапии, коррекция терапии в зависимости от эффективности лечения/наличия сопутствующих заболеваний/побочных эффектов и т.д.

Выбор целей лечения СД2 не зависит от наличия у пациента избыточной массы тела или ожирения. Целью терапии пациентов с СД является определенный врачом уровень гликированного гемоглобина (HbA 1 ) в диапазоне от 6,5\% до 8,5\% [1]. На целевой уровень НbА функциональная зависимость, наличие атеросклеротических сердечно-сосудистых заболеваний, риск тяжелой гипогликемии.

В то же время выбор сахароснижающего агента будет во многом определяться наличием у пациента ожирения. Среди сахароснижающих препаратов есть группы как снижающих, так и увеличивающих массу тела.

\section{ВЛИЯНИЕ СД2 НА ВЫБОР ТАКТИКИ ЛЕЧЕНИЯ ПРИ ОЖИРЕНИИ}

Терапия пациентов с ожирением состоит из трех компонентов: немедикаментозный подход, лекарственная терапия и хирургическое лечение. Наличие у пациента с ожирением Сд2 будет влиять на выбор режима питания, интенсивности физической нагрузки, а также определять более скорый переход к хирургическому лечению ожирения.

Немедикаментозный подход, или изменение образа жизни, в лечении ожирения является первоочередным и базируется на двух принципах: диетотерапии и увеличении режима физических упражнений. При неэффективности данного подхода возможно назначение медикаментозного и хирургического методов лечения, особенности которых будут рассмотрены в соответствующих разделах.

\section{РЕКОМЕНДАЦИИ}

\section{Диагностика нарушений углеводного обмена при ожирении}

\section{1. Диагностические критерии нарушений углеводного обмена (ВО3, 1999-2013) одинаковы для всех паци- ентов вне зависимости от наличия избыточной массы тела или ожирения (УДД 1, УУР А).}

Комментарии. Диагностические критерии нарушений углеводного обмена (СД и предиабетических состояний) одинаковы при ожирении и нормальной массе тела. Согласно «Алгоритмам специализированной медицинской помощи больным сахарным диабетом» 2019 г., для диагностики нарушений углеводного обмена следует использовать критерии ВОЗ [1] (табл. 5). В 2011 г. ВОЗ одобрила возможность использования НbА диагностического критерия СД выбран уровень $\mathrm{HbA}_{1 c} \geq 6,5 \%$ (48 ммоль/моль). Данный уровень гликированного гемоглобина используется как критерий диагностики СД и у лиц с ожирением.

Нормальным считается уровень $\mathrm{HbA}_{1 с}$ до 6,0\% (42 ммоль/моль). Согласно рекомендациям ВО3, уровень НbA1c 6,0-6,4\% (42-47 ммоль/моль) сам по себе не позволяет ставить какие-либо диагнозы, но не исключает возможности диагностики СД по уровню глюкозы крови [2].

3.2. Лицам с избыточной массой тела и ожирением при наличии одного или более дополнительных факторов риска развития СД2 рекомендуется проведение скрининга нарушений углеводного обмена 1 раз В 3 года; при наличии у пациента с избыточной массой тела или ожирением предиабетических состояний рекомендуется проводить скрининг ежегодно (УДД 3, УУР В).

Комментарии. При отсутствии нарушений углеводного обмена у лиц с избыточной массой тела и ожирением необходимо помнить о необходимости систематического проведения скрининга СД. При превышении ИМТ $\geq 25$ кг/м² и наличии одного дополнительного фактора риска СД2 (табл. 6) скрининг проводится 1 раз в 3 года; в том случае, когда при исследовании глюкозы плазмы натощак/перорального глюкозотолерантного теста (ПГТТ)/ гликированного гемоглобина было выявлено предиабетическое нарушение углеводного обмена, то последующие скрининги проводятся с частотой 1 раз в год [1]. Несмотря на то что исследования, посвященные оценке снижения смертности от проведения скрининга, имеют противоречивые результаты [3, 4], скрининг может способствовать снижению затрат на лечение пациентов с СД2 [5].

Ожирение является одним из ключевых факторов риска развития СД2, для пациентов с СД1 выраженное ожирение нехарактерно; тем не менее, эпидемия ожирения приводит к росту ИМТ и среди больных с СД1 [6]. Поэтому наличие избыточной массы тела или ожирения у пациента не позволяет исключить диагноз СД1. 
Справочный материал

Таблица 5. Диагностические критерии сахарного диабета и других нарушений гликемии (ВОЗ, 1999-2013)

\begin{tabular}{|c|c|c|}
\hline \multirow{2}{*}{ Время определения } & \multicolumn{2}{|c|}{ Концентрация глюкозы, ммоль/л } \\
\hline & Цельная капиллярная кровь & Венозная плазма \\
\hline \multicolumn{3}{|c|}{ HOPMA } \\
\hline \multirow{2}{*}{$\begin{array}{l}\text { Натощак } \\
\text { и через } 2 \text { ч после ПГТТ }\end{array}$} & $<5,6$ & $<6,1$ \\
\hline & $<7,8$ & $<7,8$ \\
\hline \multicolumn{3}{|c|}{ Сахарный диабет } \\
\hline \multirow{3}{*}{$\begin{array}{l}\text { Натощак, } \\
\text { или через } 2 \text { ч после ПГТТ, } \\
\text { или случайное определение }\end{array}$} & $\geq 6,1$ & $\geq 7,0$ \\
\hline & $\geq 11,1$ & $\geq 11,1$ \\
\hline & $\geq 11,1$ & $\geq 11,1$ \\
\hline \multicolumn{3}{|c|}{ Нарушенная толерантность к глюкозе } \\
\hline \multirow{2}{*}{$\begin{array}{l}\text { Натощак } \\
\text { через } 2 \text { ч после ПГТТ }\end{array}$} & $<6,1$ & $<7,0$ \\
\hline & $\geq 7,8$ и $<11,1$ & $\geq 7,8$ и $<11,1$ \\
\hline \multicolumn{3}{|c|}{ Нарушенная гликемия натощак } \\
\hline \multirow{2}{*}{$\begin{array}{l}\text { Натощак и } \\
\text { через } 2 \text { ч после ПГТТ }\end{array}$} & $\geq 5,6$ и $<6,1$ & $\geq 6,1$ и $<7,0$ \\
\hline & $<7,8$ & $<7,8$ \\
\hline \multicolumn{3}{|c|}{ Норма у беременных } \\
\hline \multirow{3}{*}{$\begin{array}{l}\text { Натощак, } \\
\text { и через } 1 \text { ч после ПГТТ, } \\
\text { и через } 2 \text { ч после ПГТТ }\end{array}$} & & $<5,1$ \\
\hline & & $<10,0$ \\
\hline & & $<8,5$ \\
\hline \multicolumn{3}{|c|}{ Гестационный сахарный диабет } \\
\hline \multirow{3}{*}{$\begin{array}{l}\text { Натощак } \\
\text { или через } 1 \text { ч после ПгТТ }\end{array}$} & & $\geq 5,1$ и $<7,0$ \\
\hline & & $\geq 10,0$ \\
\hline & & $\geq 8,5$ и $<11,1$ \\
\hline
\end{tabular}

Таблица 6. Факторы риска развития сахарного диабета 2 типа

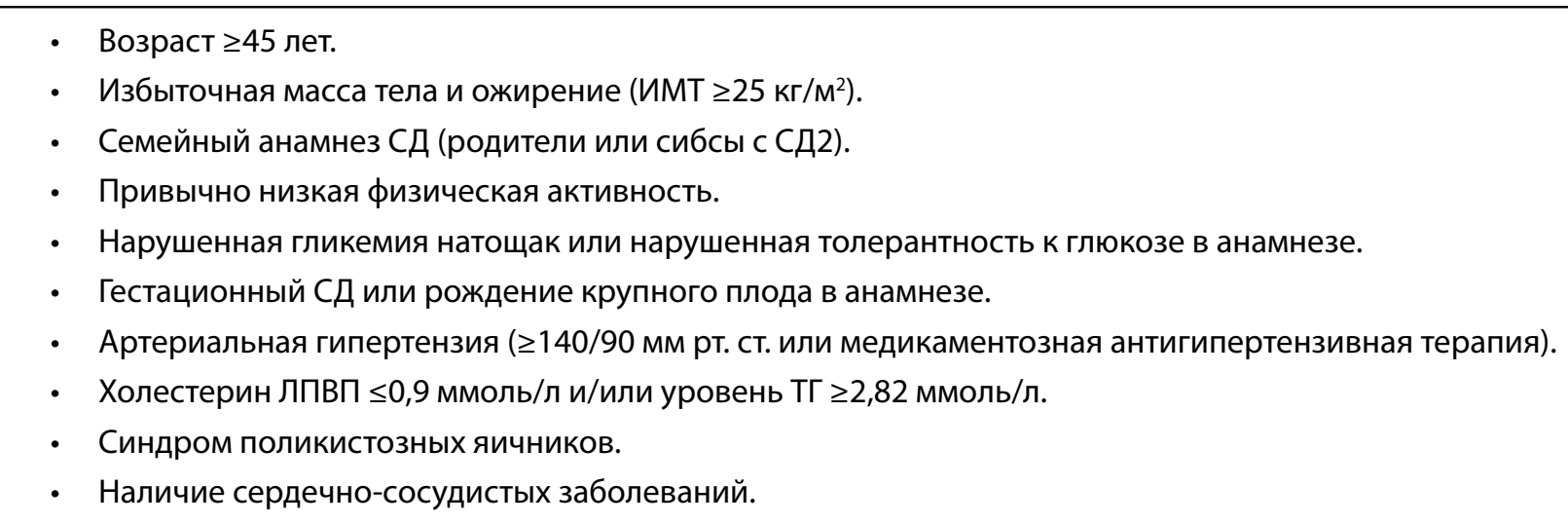

\section{Выбор тактики лечения при ожирении и Сд2}

3.3. Пациентам с ожирением и сопутствующим СД2 рекомендуется достигать цели по снижению массы тела минимум на 5\% исходной в течение 6 мес для улучшения компенсации углеводного обмена (УДД 2, УУР A).

Комментарии. Цель консервативной терапии ожирения как у пациентов с СД2, так и без нарушений углеводного обмена заключается в снижении массы тела на 5-10\% исходного веса в течение 6 мес лечения и поддержании достигнутого результата [7]. Изменение образа жизни является основой в лечении ожирения и рекомендуется как первый и постоянный этап лечения ожирения. Анализ результатов исследования Look AHEAD, проведенного среди пациентов с СД2, показал, что снижение веса $5 \%$ и более позволило достичь значимого снижения уровня НbА ${ }_{1 c^{\prime}} \mathrm{AД}$ ТГ и увеличения концентрации ЛПВП [8]. 


\section{Особенности немедикаментозного подхода у пациентов с ожирением при нарушениях углеводного обмена}

\section{4. Для снижения массы тела пациентам с ожирением и нарушениями углеводного обмена рекомендуется создание условий дефицита суточного потребления энергии за счет снижения суточной калорийности рациона и/или увеличения расхода энергии на 500-700 ккал/сут (УДД 2, УУР А).}

Комментарии. На текущий момент не существует доказательной базы, демонстрирующей превосходство того или иного режима питания в снижении и удержании веса. По данным метаанализа 48 клинических исследований с участием 7286 пациентов с избыточной массой тела и ожирением, не было показано преимущества ограничения жиров или углеводов для снижения массы тела [9]. Иными словами, задача диетотерапии сводится к ограничению общей калорийности рациона при соблюдении его сбалансированности. При ожирении без нарушений углеводного обмена одним из ключевых предикторов успеха диетотерапии является приверженность пациента данной диете, а не ограничение определенного вида макронутриентов [10].

3.5. Пациентов с СД1 и с СД2 на болюсной инсулинотерапии рекомендуется обучать правилам подсчета количества углеводов с целью определения дозы болюсного инсулина перед приемами пищи (УДД 1, УУР В).

Комментарии. В том случае, когда пациенту с ожирением и СД2 для достижения целевых значений НbA1c необходимо назначение болюсной инсулинотерапии (инсулинов короткого и ультракороткого действия), важным становится подсчет количества продуктов, содержащих углеводы [11]. При этом стоит задача не полного ограничения углеводов, а строгого контроля их потребления, так как доза инсулина рассчитывается в том числе из расчета съеденных углеводов. Для пациентов, принимающих пероральные сахароснижающие препараты (ПССП) рекомендации по рациону питания схожи с рекомендациями для лиц с ожирением без нарушений углеводного обмена: снижение массы тела у таких пациентов обеспечивает положительный эффект в отношении гликемического контроля, липидного спектра и артериального давления.

3.6. Пациентам с ожирением, СД2 или предиабетическими состояниями рекомендуется средиземноморский тип питания для улучшения контроля гликемии и коррекции факторов риска сердечно-сосудистых заболеваний (УДД 1, УУР А).

Комментарии. Типом питания, положительно влияющим не только на метаболические исходы, но и смертность пациентов с ожирением как при наличии, так и в отсутствие нарушений углеводного обмена, является средиземноморский тип питания. Средиземноморская диета подразумевает достаточное использование оливкового масла; частое употребление растительной пищи (фрукты, овощи, бобовые, злаки, орехи и семена); умеренное потребление вина (особенно красного) с приемами пищи; умеренное потребление рыбы, морепродуктов, ферментированных молочных продуктов (йогурт и сыр), птицы и яиц; редкое потребление красного и обработанного мяса и сладостей [12]. Влияние такого типа питания на сердечно-сосудистые исходы было изучено в исследовании PREDIMED [13]. Cреди 7447 включенных пациентов более 90\% имели избыточную массу тела и ожирение, около половины страдали СД2. Участники исследования были разделены на 3 группы: 1) средиземноморская диета с добавлением оливкового масла; 2) средиземноморская диета с добавлением орехов; 3) контрольная группа, придерживающаяся низкожировой диеты. Через 4,8 года наблюдения в обеих группах, следовавших средиземноморской диете, наблюдалось снижение риска сердечно-сосудистых исходов (нефатального инфаркта миокарда, нефатального инсульта, сердечно-сосудистой смерти) на 30\% по сравнению с контрольной группой. Также пациенты без исходных нарушений углеводного обмена реже заболевали СД2 на средиземноморской диете. Результаты исследования PREDIMED говорят о более благоприятном кардиопротективном эффекте питания с высоким содержанием полиненасыщенных жиров по сравнению с питанием с ограничением жиров. Средиземноморский тип питания рекомендован пациентам с ожирением и СД2 для улучшения сердечно-сосудистого прогноза [14].

3.7. Большинству пациентов с ожирением и СД2 рекомендуется умеренная аэробная физическая активность 3-4 раза в неделю (суммарно не менее 150 мин в неделю) как неотъемлемая часть лечения для поддержания достигнутой в процессе лечения массы тела, контроля гликемии и коррекции факторов риска сердечно-сосудистых заболеваний (УДД 2, УУР В).

Комментарии. Важной составной частью изменения образа жизни является расширение объема физических нагрузок. У лиц с ожирением физическая активность рекомендуется как неотъемлемая часть лечения ожирения и поддержания достигнутой в процессе лечения массы тела. Присоединение к диетотерапии физических нагрузок позволяет достичь ряда неоспоримых преимуществ, таких как увеличение мышечной массы и профилактика саркопенического ожирения.

Основной целью является выполнение аэробной физической активности в течение 150 мин в неделю, что эквивалентно ходьбе со скоростью 5-6 км/ч [15]. Ходьба остается лучшим видом физических нагрузок по многим причинам: не требует специального оборудования, оплаты, места проведения и т.д. Для снижения выраженности висцерального ожирения и увеличения мышечной массы необходимо присоединение анаэробных (силовых) упражнений 3 раза в неделю. Помимо учета времени физической активности, важным компонентом изменения образа жизни является снижение периодов неактивности (сидячего состояния), что достигается благодаря ежедневному выполнению домашних и рабочих дел (уборка, выгуливание домашних животных, подъем по лестнице вместо использования лифта, выход из общественного транспорта за 2-3 остановки раньше и т.п.). Продолжительность непрерывного сидячего положения не должна превышать 1 ч. 
3.8. Интенсивная физическая нагрузка не рекомендуется пациентам с ожирением и СД2 с высоким риском гипогликемий, поздними стадиями микрососудистых осложнений СД2, сопутствующими заболеваниями, требующими ограничения физических нагрузок (УДД 4, УУР С). Рекомендуется временно ограничить физическую нагрузку пациентам с выраженной декомпенсацией углеводного обмена (УДД 4, УУР С).

Комментарии. Сложность быстрого наращивания физической активности у всех лиц с ожирением вне зависимости от наличия нарушений углеводного обмена заключается в том, что для ряда пациентов расширение режима физической активности невозможно в связи с наличием патологии опорно-двигательного аппарата, сердечной или дыхательной недостаточности. Поэтому для лиц с ожирением рекомендовано плавное увеличение физических нагрузок.

У пациентов с ожирением и СД2 имеются особенности интенсификации физической активности. Во-первых, пациенты с СД2 имеют больший риск ИБС, в связи с чем планирование физических нагрузок часто будет требовать предварительного выполнения нагрузочного стресс-теста. Во-вторых, некоторые ПССП и все виды препаратов инсулина повышают риск развития гипогликемий, в связи с чем лица, получающие данные препараты, должны соблюдать меры предосторожности во время выполнения физических нагрузок. Физическая активность способствует снижению гликемии во время и после нагрузок, поэтому основным принципом борьбы с гипогликемиями является их профилактика. При кратковременной нагрузке (до 2 ч) профилактика гипогликемии заключается в дополнительном приеме 10-20 г углеводов при нормальном исходном значении гликемии; при длительных физических нагрузках профилактика гипогликемий осуществляется за счет снижения доз препаратов инсулина накануне и в день активности. Особенную осторожность необходимо соблюдать во время занятий видами спорта, при которых трудно купировать гипогликемию, таких как подводное плавание, дельтапланеризм, серфинг. Таким образом, первостепенным фактором, способным обеспечить безопасность физической активности у пациентов с ожирением и СД2 на препаратах с высоким риском гипогликемий, является запланированность физической нагрузки.

Третья особенность планирования физической активности у лиц с ожирением и наличием Сд2 заключается в необходимости учитывать наличие микрососудистых осложнений. Дистальная нейропатия приводит к потере чувствительности и может служить источником травматизма; вегетативная нейропатия опасна риском возникновения ортостатической гипотензии; диабетическая ретинопатия на поздних стадиях при нагрузках высокой интенсивности чревата развитием отслойки сетчатки из-за резкого повышения уровня АД.

Наконец, для пациентов с выраженной декомпенсацией углеводного обмена физическая активность должна быть временно ограничена. В большинстве случаев к временным противопоказаниям к физическим нагрузкам относится стойкое превышение уровня глюкозы плазмы выше 13 ммоль/л в сочетании с кетонурией или выше 16 ммоль/л без кетонурии. Это противопоказание объясняется тем, что в условиях дефицита инсулина физическая активность будет усиливать гипергликемию [1].

Особенности медикаментозной терапии у пациентов с ожирением при нарушениях углеводного обмена. Лекарственные взаимодействия

3.9. Пациентам с избыточной массой тела и нарушениями углеводного обмена рекомендуется назначать фармакологические препараты для лечения ожирения в сочетании с умеренно гипокалорийной диетой, начиная с ИМТ $\geq 27$ кг/м² (УДД 1, УУР А).

Комментарии. Назначение фармакологических препаратов для лечения ожирения рекомендуется в сочета-

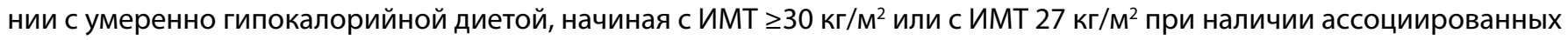
с ожирением заболеваний [7].

3.10. Не рекомендуется продолжение приема препаратов для лечения ожирения при отсутствии снижения веса на 5\% после 3-4 мес фармакотерапии (УДД 1, УУР А).

Комментарии. Медикаментозная терапия ожирения направлена на ускорение снижения массы тела. По данным исследований, при отсутствии эффекта снижения массы тела на 5\% за первые 3-4 мес терапии дальнейшее использование лекарственных препаратов для лечения ожирения не приводило к снижению веса в дальнейшем, поэтому являлось нецелесообразным.

3.11. Пациентам с избыточной массой тела или ожирением и сопутствующим Сд2 рекомендуется назначение сахароснижающих препаратов, способствующих снижению массы тела, таких как агонисты рецепторов глюкагоноподобного пептида 1 типа (ГПП-1) и ингибиторы натрий-глюкозных ко-транспортеров 2 типа (иНГЛТ-2) (УДД 2, УУР А).

Комментарии. Согласно российским клиническим рекомендациям по лечению больных СД2 [1], выбор назначаемых сахароснижающих препаратов зависит от доминирующей клинической проблемы: наличия атеросклеротических сердечно-сосудистых заболеваний или факторов риска, сердечной недостаточности, хронической болезни почек (ХБП), ожирения или высокого риска гипогликемий. При сопутствующем СД2 ожирении препаратами выбора будут являться агонисты рецепторов ГПП-1, ингибиторы натрий-глюкозного ко-транспортера 2 типа (иНГЛТ-2), а также метформин. Акарбоза и ингибиторы дипептидилпептидазы (иДПП-4) нейтральны в отношении веса; прибавке массы 
тела способствует назначение препаратов с высоким риском гипогликемий - производных сульфонилмочевины, препаратов инсулина. Тиазолидиндионы (ТЗД) также приводят к увеличению массы тела.

В клинической практике метформин является стартовым препаратом для лечения пациентов с СД2, он повышает чувствительность периферических рецепторов к инсулину и утилизацию глюкозы клетками. С целью снижения массы тела и контроля гликемии к метформину на втором этапе могут быть добавлены агонисты рецепторов ГПП-1 или иНГЛт-2. Данные препараты также могут применяться в тройной комбинации.

Важным аспектом, который необходимо учитывать при назначении лекарственной терапии пациентам с СД2, является более высокий риск развития хронической болезни почек (ХБП), чем в общей популяции, в связи с чем требуется оценка функции почек при назначении любого медикамента и последующий ее мониторинг.

3.12. Пациентам с ожирением и СД2, принимающим лекарственную терапию по поводу ожирения, рекомендуется корректировать дозы сахароснижающих препаратов для профилактики гипогликемии (УДД 2, УУР А).

Комментарии. Прием всех препаратов, зарегистрированных для лечения ожирения, может приводить к увеличению чувствительности к инсулину. Совместный прием данной группы препаратов с производными сульфонилмочевины или инсулинами несет повышенный риск развития гипогликемий.

Лираглутид в дозе 3,0 мг в сутки зарегистрирован для лечения ожирения, в дозе до 1,8 мг в сутки - для лечения СД2. В монотерапии лираглутид обладает низким риском гипогликемий благодаря глюкозозависимому действию, однако в комбинациях с другими ПССП имеется риск гипогликемий. При добавлении лираглутида к производным сульфонилмочевины/инсулинам рекомендуется снизить дозу последних с последующим контролем гликемии.

\section{Хирургическое лечение пациентов с ожирением и СД2}

3.13. Метаболическая хирургия рекомендуется для лечения СД2 у взрослых пациентов с ИМТ $\geq 35$ кг/м² ( $\geq 32,5$ кг/м² для азиатской популяции), не достигших контроля гликемии после нескольких попыток нехирургического лечения ожирения (изменения образа жизни и медикаментозной терапии). Метаболи-

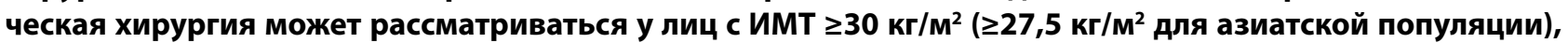
не достигших снижения массы тела и контроля гликемии на фоне нехирургического лечения (УДД 1, УУР А).

Комментарии. Показания к хирургическому лечению пациентов с ожирением возникают при неэффективности немедикаментозных и фармакологических методов лечения. У пациентов с ожирением принято использовать термин «бариатрические вмешательства», у пациентов с метаболическими осложнениями, в первую очередь при СД2 «метаболические вмешательства».

Для пациентов с ожирением показанием к выполнению бариатрических операций является ИМТ более 40 кг/м². При наличии СД2 пациенту может быть рекомендована метаболическая операция при меньшей выраженности ожирения, начиная с ИМТ более 35 кг/м². У ряда пациентов возможно рассмотреть хирургический метод лечения при ИМТ $\geq 30 \mathrm{Kг} / \mathrm{M}^{2}$.

Российские рекомендации согласуются с международными данными, в которых решение о переходе к хирургическому этапу лечения СД2 основывается не только на величине ИМТ, но и на возможности достижения компенсации углеводного обмена в предыдущие этапы лечения [16].

При выборе оперативного вмешательства у пациентов с ожирением и нарушениями углеводного обмена следует полагаться на частоту достижения компенсации углеводного обмена после той или иной операции. Более выраженным сахароснижающим эффектом обладают шунтирующие операции, менее выраженным - рестриктивные. Вероятность компенсации углеводного обмена в послеоперационном периоде преимущественно зависит от длительности СД2, количества сахароснижающих препаратов, получения инсулинотерапии и качества дооперационного контроля гликемии [17].

3.14. В послеоперационном периоде пациентам рекомендуется частый контроль гликемии с коррекцией доз сахароснижающих препаратов для снижения риска развития гипогликемии (УДД З, УУР В).

Комментарии. В раннем послеоперационном периоде рекомендуется частый мониторинг гликемии (не менее 2 раз в день) для решения вопроса о коррекции сахароснижающей терапии [18]. При возникновении гипогликемии на фоне исходной сахароснижающей терапии рекомендуется постепенная отмена препаратов. Потребность в самоконтроле гликемии у пациентов после метаболического вмешательства остается длительно, частота самоконтроля индивидуальна и зависит от типа сахароснижающих препаратов и темпов снижения массы тела.

\subsection{5. Хирургическое лечение СД1 не рекомендовано, за исключением пациентов с ИМт $\geq 40$ кг/м² (УДД 1, УУР А).}

Комментарии. Метаболическая хирургия не показана пациентам с СД1, так как она не воздействует на патогенез данного заболевания. Однако у пациентов с ИМТ> 40 кг/м² эффект метаболической хирургии может проявлять в снижении доз инсулинотерапии, а также в коррекции других метаболических заболеваний [19]. 


\section{СПИСОК ЛИТЕРАТУРЫ | REFERENCES}

1. Дедов И.И., Шестакова М.В., Майоров А.Ю. и др. Алгоритмы специализированной медицинской помощи больным сахарным диабетом: Клинические рекомендации (Вып. 9) // Сахарный диабет. - 2019. - T. 22. - №S1. - C. 1-144. [Dedov II, Shestakova MV, Mayorov AYu et al. Standards of specialized diabetes care. Diabetes Mellitus. 2019;22(S1):1-144 (In Russ.)]. doi: https://doi.org/10.14341/DM221S1

2. Gabir MM, Hanson RL, Dabelea D, et al. The 1997 American Diabetes Association and 1999 World Health Organization criteria for hyperglycemia in the diagnosis and prediction of diabetes. Diabetes Care. 2000;23(8):1108-1112. doi: https://doi.org/10.2337/diacare.23.8.1108

3. Simmons RK, Griffin SJ, Witte DR et al. Effect of population screening for type 2 diabetes and cardiovascular risk factors on mortality rate and cardiovascular events: a controlled trial among 1,912,392 Danish adults. Diabetologia. 2017;60(11):2183-2191. doi: https://doi.org/10.1007/s00125-017-4323-2

4. Simmons RK, Griffin SJ, Lauritzen T, Sandbæk A. Effect of screening for type 2 diabetes on risk of cardiovascular disease and mortality: a controlled trial among 139,075 individuals diagnosed with diabetes in Denmark between 2001 and 2009. Diabetologia. 2017;60(11):2192-2199. doi: https://doi.org/10.1007/s00125-017-4299-y

5. Sorts $\varnothing$ C, Komkova A, Sandbæk A, et al. Effect of screening for type 2 diabetes on healthcare costs: a register-based study among 139,075 individuals diagnosed with diabetes in Denmark between 2001 and 2009. Diabetologia. 2018;61:1306. doi: https://doi.org/10.1007/s00125-018-4594-2

6. Mottalib A, Kasetty M, Mar JY, et al. Weight Management in Patients with Type 1 Diabetes and Obesity. Curr Diab Rep. 2017;17:92. doi: https://doi.org/10.1007/s11892-017-0918-8

7. Дедов И.И., Мельниченко Г.А., Шестакова М.В., и др. Лечение морбидного ожирения у взрослых // Ожирение и метаболизм. - 2018. - Т. 15. - №1. — C. 53-70. [Dedov II, Mel'nichenko GA, Shestakova MV, et al. Russian national clinical recommendations for morbid obesity treatment in adults. 3rd revision (Morbid obesity treatment in adults). Obesity and metabolism. 2018;15(1):53-70. (In Russ.)]. doi: https://doi.org/10.14341/omet2018153-70

8. Wing RR, Lang W, Wadden TA, et al. Benefits of Modest Weight Loss in Improving Cardiovascular Risk Factors in Overweight and Obese Individuals With Type 2 Diabetes. Diabetes Care. 2011;34(7):1481-1486. doi: https://doi.org/10.2337/dc10-2415
9. Johnston BC, Kanters S, Bandayrel K, et al. Comparison of Weight Loss Among Named Diet Programs in Overweight and Obese Adults. A Meta-analysis. JAMA. 2014;312(9):923-933. doi: https://doi.org/10.1001/jama.2014.10397

10. Sacks FM, Bray GA, Carey VJ, et al. Comparison of Weight-Loss Diets with Different Compositions of Fat, Protein, and Carbohydrates. N Engl J Med. 2009;360(9):859-873. doi: https://doi.org/10.1056/NEJMoa0804748

11. Bell KJ, Barclay AW, Petocz P, et al. Efficacy of carbohydrate counting in type 1 diabetes: a systematic review and metaanalysis. Lancet Diabetes Endocrinol. 2014;2(2):133-140. doi: https://doi.org/10.1016/S2213-8587(13)70144-X

12. D'Alessandro A, De Pergola G. Mediterranean Diet Pyramid: A Proposal for Italian People. Nutrients. 2014;6:4302-4316. doi: https://doi.org/10.3390/nu6104302.

13. Estruch $R$, Ros E, Salas-Salvadó J, et al. Primary Prevention of Cardiovascular Disease with a Mediterranean Diet Supplemented with Extra-Virgin Olive Oil or Nuts. N Engl J Med. 2018;378(25):e34. doi: https://doi.org/10.1056/NEJMoa1800389

14. Esposito K, Maiorino Ml, Bellastella G, et al. A journey into a Mediterranean diet and type 2 diabetes: a systematic review with meta-analyses. BMJ Open. 2015;5(8):e008222. doi: https://doi.org/10.1136/bmjopen-2015-008222

15. Durrer Schutz D, Busetto L, Dicker D, et al. European Practical and Patient-Centred Guidelines for Adult Obesity Management in Primary Care. Obes Facts. 2019;12(1):40-66. doi: https://doi.org/10.1159/000496183

16. Rubino F, Nathan DM, Eckel RH, et al. Metabolic Surgery in the Treatment Algorithm for Type 2 Diabetes: A Joint Statement by International Diabetes Organizations. Diabetes Care. 2016;39(6):861-877. doi: https://doi.org/10.2337/dc16-0236

17. Aminian A, Brethauer SA, Andalib A? et al. Individualized Metabolic Surgery Score: Procedure Selection Based on Diabetes Severity. Ann Surg. 2017;266(4):650-657. doi: https://doi.org/10.1097/SLA.0000000000002407

18. Busetto L, Dicker D, Azran C, et al. Practical Recommendations of the Obesity Management Task Force of the European Association for the Study of Obesity for the Post-Bariatric Surgery Medical Management. Obes Facts. 2017;10(6):597-632. doi: https://doi.org/10.1159/000481825

19. Hussain A. The effect of metabolic surgery on type 1 diabetes: meta-analysis. Arch Endocrinol Metab. 2018;62(2):172-178. doi: https://doi.org/10.20945/2359-3997000000021 


\title{
ГЛАВА 4. ОЖИРЕНИЕ И РЕПРОДУКТИВНОЕ ЗДОРОВЬЕ ЖЕНЩИНЫ
}

\author{
Андреева Е.Н., Шереметьева Е.В.
}

\section{эПИДЕМИоЛОГИЯ}

Количество женщин с ожирением в возрасте старше 18 лет в России, по данным ВОЗ, составляет 31\% [1].

\section{ВЛИЯНИЕ ОЖИРЕНИЯ НА РЕПРОДУКТИВНОЕ ЗДОРОВЬЕ ЖЕНЩИНЫ}

Ожирение оказывает отрицательное влияние на гипоталамо-гипофизарно-яичниковую ось, нарушает ритм и соотношение гонадотропных гормонов, снижает интенсивность фолликулогенеза и провоцирует снижение уровня прогестерона [2-7].

\section{Ожирение и регулярность менструального цикла}

4.1. Рекомендовано всем женщинам в репродуктивном периоде с избыточной массой тела или ожирением оценивать регулярность менструального цикла (например, по данным менструального календаря, который ведет сама женщина) (УУР А, УДД 3) [8-14].

Комментарии. Нарушения менструального цикла встречаются чаще у женщин с ожирением и прогрессируют (вплоть до аменореи) по мере увеличения ИМТ [7, 8]. Однако следует помнить о женщинах с высоким ИМТ, у которых менструальные циклы овуляторные, но с течением времени и при некомпенсации ожирения фертильность пациентки будет снижаться. Риск развитии нарушений менструального цикла зависит не только от ИМТ, но и от величины ОТ. Женщины репродуктивного возраста с ОТ более 80 см чаще имеют синдром хронической ановуляции в сравнении с теми, у которых такой же ИМТ, но ОТ менее 80 см $[9,10]$.

\section{2. Для диагностики избыточной массы тела и ожирения (и оценки его степени) всем женщинам репродук-} тивного периода на этапе прегравидарной подготовки рекомендовано определение ИМТ (УУР А, УДД З) [15-18].

Комментарии. Повышенный ИМТ у матери может быть фактором риска патологического течения беременности.

Ожирение уженщины репродуктивного возраста является фактором риска потери беременности на малом сроке $[17,18]$. Ожирение у матери до беременности увеличивает как общую, так и тяжелую материнскую заболеваемость во время беременности [17]. Повышенный ИМТ у матери может быть фактором риска патологического течения беременности.

Высокий риск типичных акушерских осложнений при ожирении:

$>$ угрожающий выкидыш (в 2,5 раза чаще у беременных с ожирением, чем у здоровых беременных женщин);

$>$ замершая беременность;

> преждевременные роды;

> гестационный диабет;

> макросомия плода;

$>$ задержка роста плода;

> преэклампсия;

$>$ эклампсия;

> гипогалактия.

Беременные с ожирением чаще нуждаются в абдоминальном родоразрешении и применении оперативных пособий $[17,18]$.

У женщин с ожирением риск рождения ребенка с макросомией или врожденной аномалией развития повышен. Тяжелые перинатальные исходы чаще встречаются в группе женщин с ожирением, чем с нормальной массой тела (табл. 7) $[19,20]$.

Таблица 7. Антенатальные потери, мертворождение, перинатальные и неонатальные потери, младенческая смертность в зависимости от ИМТ матери

\begin{tabular}{lccr}
\hline & \multicolumn{2}{c}{ ИМт до беременности, кг/м² } \\
\cline { 2 - 4 } & $\mathbf{2 0}$ & $\mathbf{2 5}$ & $\mathbf{3 0}$ \\
\cline { 2 - 4 } & \multicolumn{2}{c}{ Абсолютный риск (95\% ДИ), данные представлены на 10 000 беременностей } \\
\hline Антенатальные потери & 76 & 82 & 102 \\
\hline Мертворождение & 40 & 48 & 59 \\
\hline Перинатальные потери & 66 & 73 & 86 \\
\hline Неонатальные потери & 20 & 21 & 24 \\
\hline Младенческая смертность & 33 & 37 & 43 \\
\hline
\end{tabular}


Допустимая прибавка массы тела относительно ИМТ на момент зачатия [21] (табл. 8).

Таблица 8. Рекомендации по прибавке массы тела во время беременности

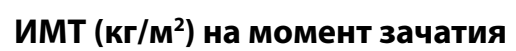
Прибавка массы тела
за беременность, кг
Скорость увеличения массы тела во II и III триместре (кг/неделя)

\begin{tabular}{ccc}
\hline$<18,5$ & $12,5-18,0$ & $0,51(0,44-0,58)$ \\
$18,5-24,9$ & $11,5-16,0$ & $0,42(0,35-0,50)$ \\
$25,0-29,9$ & $7,0-11,5$ & $0,28(0,23-0,33)$ \\
$\geq 30$ & $5,0-9,0$ & $0,22(0,17-0,27)$ \\
\hline
\end{tabular}

Ожирение матери связано с риском развития у детей нарушений нервной системы: синдрома гиперактивности/ дефицита внимания и аутических расстройств. Высокий ИМТ до беременности в значительной степени связан с повышенным риском антенатальной депрессии и тревоги у матери [22, 23].

\section{Ожирение и преконцепционный период/беременность/послеродовый период}

Ожирение у женщины репродуктивного возраста оказывает отрицательное влияние на течение преконцепционного периода, беременности и послеродового периода.

4.3. Рекомендовано всем женщинам репродуктивного периода с ожирением и бесплодием оценивать овуляторную функцию яичников с помощью проведения доступных методов оценки овуляции: определение уровня прогестерона в крови (за 7 дней до менструации), и/или проведение мочевого теста на овуляцию, и/или ультразвуковой мониторинг овуляции, который позволяет оценить рост и созревание фолликулов, произошедшую овуляцию, формирование желтого тела (УУР А, УДД З) $[24,25]$.

Комментарии. Ожирение является фактором риска бесплодия. Основная причина - формирование синдрома хронической ановуляции. Риск развития заболеваний репродуктивной системы напрямую ассоциирован с ИМТ женщины репродуктивного возраста.

> Избыточная масса тела (25-29,9 кг/м²) - повышенный риск нарушений репродуктивной системы.

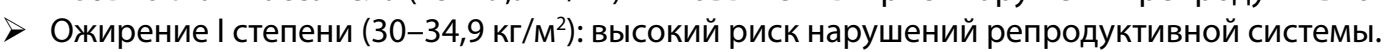

> Ожирение II степени (30-34,9 кг/м²): очень высокий риск нарушений репродуктивной системы.

$>$ Ожирение III степени ( $\geq 40$ кг/M²): крайне высокая степень риска нарушений репродуктивной системы [15].

\section{Ожирение и ВРТ}

4.4. Для диагностики избыточной массы тела и ожирения (и оценки его степени) всем женщинам репродуктивного периода, вступающим в протокол вспомогательных репродуктивных технологий (ВРТ), рекомендовано определение ИМТ с целью оценки возможных рисков осложнений протокола (УУР В, УДД 3) [26-29].

Комментарии. Ожирение снижает частоту наступления биохимической и клинической беременности во время BPT: имплантация, частота биохимической беременности и частота клинической беременности обратно пропорциональны увеличению ИМТ в протоколе ВРТ. Осложнениями протоколов ВРТ и особенностями течения беременности у женщин с ожирением являются:

$>$ синдром гиперстимуляции яичников;

$>$ многоплодная беременность;

> эктопическая беременность;

$>$ гестационный диабет;

> увеличение частоты оперативного родоразрешения;

$>$ малый гестационный возраст [26-29].

Ожирение и сексуальное здоровье женщины

4.5. Всем женщинам репродуктивного периода с ожирением при наличии половой жизни в рамках первичного скрининга синдрома сексуальной дисфункции рекомендуется задать вопросы об удовлетворенности сексуальной жизнью (УУР В, УДД 4).

Комментарии. Ожирение - самостоятельный фактор риска сексуальной дисфункции. У каждой 2-й пациентки с ожирением нет удовлетворения сексуальной жизнью, а это, в свою очередь, может приводить к нарушению психологического статуса женщины и быть фактором ненаступления беременности (уменьшение частоты половых контактов, снижение сексуального влечения) [30, 31]. 
Ожирение и синдром поликистозных яичников.

Одной из частых патологий репродуктивного периода женщины является синдром поликистозных яичников (СПЯ), при котором повышение ИМТ встречается чаще, чем в общей популяции [32], что в 4 раза увеличивает риск СД2 в этой популяции [33].

4.6. Всем женщинам репродуктивного периода с СПЯ рекомендовано определение ИМТ с целью диагностики избыточной массы тела и ожирения (и оценки его степени) (УУР В, УДД 4).

Комментарии. Ожирение при СПЯ - это:

> дополнительный фактор риска сердечно-сосудистых заболеваний;

> фактор риска рака эндометрия (который встречается в 2-6 раза чаще в сравнении с женщинами без СПЯ);

$>$ усугубляющий фактор риска депрессивных и тревожных состояний;

$>$ фактор, влияющий на процент рождаемости, фактор, влияющий на восстановление репродуктивной функции, исходы беременности, процент рождаемости [25].

\section{Ожирение и патология эндометрия}

4.7. Всем женщинам репродуктивного периода с патологией эндометрия рекомендовано определение ИМТ с целью диагностики избыточной массы тела и ожирения (и оценки его степени) (УУР А, УДД 3) [34].

Комментарии. Ожирение - фактор риска патологии эндометрия, в т.ч. рака эндометрия. Причинами можно считать:

$>$ дефицит прогестерона;

$>$ хроническую ановуляцию, сопровождающую женщину с ожирением;

$>$ увеличение периферической гиперэстрогении [35-38].

Также есть данные, что ожирение может оказывать влияние на экспрессию генов эндометрия во время периода имплантации как в естественном цикле, так и в циклах ВРТ, в т.ч. даже при процедуре донорской яйцеклетки уженщины с ожирением [39].

\section{Ожирение и патология молочной железы}

4.8. Всем женщинам репродуктивного периода с патологией молочной железы рекомендовано определение ИМТ с целью диагностики избыточной массы тела и ожирения (и оценки его степени) (УУР А, УДД 2) [40-41].

Комментарии. Ожирение - фактор риска патологии молочной железы, в т.ч. рака молочной железы.

\section{ЛЕЧЕНИЕ}

Терапевтическая тактика у женщин с ожирением репродуктивного периода

4.9. Всем женщинам репродуктивного возраста с избыточной массой тела или ожирением при планировании беременности рекомендовано умеренное по интенсивности снижение веса на фоне модификации образа жизни для улучшения метаболического профиля (УУР А, УДД 3).

Комментарии. Женщинам с избыточным весом и ожирением рекомендовано снизить вес на 5-10\% в течение 3-6 мес до зачатия $[15,25]$.

4.10. Всем женщинам репродуктивного возраста с бесплодием и избыточной массой тела или ожирением рекомендовано снижение массы тела с целью снижения риска осложнений во время беременности (УУР А, УДД З).

Комментарии. По рекомендациям ВО3, снижение веса у женщины с ожирением и ненаступлением беременности - первая ступень терапии бесплодия [1, 2].

4.11. Всем женщинам репродуктивного периода с бесплодием и избыточной массой тела или ожирением, вступающим в протокол вспомогательных репродуктивных технологий, рекомендовано уменьшение массы тела для снижения риска осложнений во время протокола и улучшения его исходов (УУР В, УДД 3). [26-29]

Комментарии. Особенности женщин с ожирением в рамках протокола ВРТ:

- у уенщин с ожирением во время протокола ВРТ отмечается меньшее количество яйцеклеток;

- чем выше ИМТ, тем хуже имплантация, ниже частота клинической беременности и рождаемости;

- д до 24 нед беременности у женщин с ожирением риск потери беременности увеличивается с увеличением ИМТ;

- рождаемость снижается приблизительно на 0,3-0,4\% на каждые 1 кг/м² увеличения ИМт;

- женщинам с ожирением, использующим донора яйцеклеток, следует рекомендовать снижение веса до вступления в протокол ВРТ;

- ожирение - это фактор риска осложнений во время процедуры пункции фолликулов яичника [26-29]. 
4.12. Всем женщинам репродуктивного периода с патологией эндометрия (гиперпластические процессы эндометрия, рак эндометрия) и избыточной массой тела или ожирением рекомендовано снижение массы тела для снижения частоты рецидивов (УУР В, УДД 3).

Комментарии. Одной из профилактических мер по снижению риска рака эндометрия является снижение массы тела [34-39].

4.13. Всем небеременным женщинам репродуктивного периода и беременным с избыточной массой тела или ожирением рекомендовано изменение образа жизни посредством коррекции питания и расширения объема физических нагрузок (при отсутствии противопоказаний) как 1-я линия терапевтической тактики (УУР А, УДД 4) [42-46].

Комментарии. Рекомендовано учитывать особенности питания пациентки (религия, привычки в семье, особенности соматического статуса и т.д.).

Питание должно быть разнообразным, полноценным с включением овощей, фруктов, зерновых, постного мяса, молочных продуктов, а также рекомендуется пить достаточное количество жидкости. Ограничить потребление продуктов и напитков, содержащих насыщенные жиры, большое количество соли, сахара.

Всем беременным, не имеющим акушерских и медицинских противопоказаний, рекомендуется следовать тем же принципам, что и небеременным, то есть заниматься аэробными и силовыми упражнениями с умеренной интенсивностью не менее 20-30 мин в день в большинстве дней недели [21].

Интенсивность каждого сеанса упражнений должна быть индивидуализирована и может контролироваться с помощью шкалы оценки воспринимаемого напряжения (RPE) - шкала Борга (минимальный балл 6 (очень легкое напряжение), максимум 20 (очень тяжелое напряжение)).

Согласно рекомендациям Американского общества акушеров-гинекологов (ACOG), беременные женщины должны тренироваться с умеренной интенсивностью. Более практичным методом, рекомендованным ACOG для наблюдения за интенсивностью упражнений, является тест на «разговор» — до тех пор, пока человек может во время занятий спокойно и комфортно разговаривать, он не перенапрягается.

Женщины должны тренироваться в комфортных условиях, поддерживать гидратацию, предотвращать воздействие влажности и температуры, а также голодание или гипогликемию. Упражнения следует прекратить, если у беременной женщины появились какие-либо предупредительные признаки или симптомы (вагинальное кровотечение, регулярные или болезненные сокращения, подтекание амниотической жидкости, затрудненное дыхание, головокружение, головная боль, боль в груди, мышечная слабость, влияющая на равновесие, боль в икрах или отеки). Силовая аэробная тренировка с более чем 90\% HRmax' не рекомендуется. Следует также избегать бега на длинные дистанции и частого подъема тяжелых весов (или интенсивных изометрических упражнений). Со II триместра до родов также следует избегать упражнений, выполняемых в положении лежа на спине. Положение лежа на спине может спровоцировать аортокавальную компрессию, которая, в свою очередь, вызывает гипотензию и снижает сердечный выброс, что потенциально снижает кровоснабжение плода.

Абсолютными противопоказаниями к аэробным физическим нагрузкам во время беременности являются гемодинамически значимые заболевания сердца, рестриктивные дыхательные нарушения, истмико-цервикальная недостаточность или состояние после наложения швов на шейку матки, многоплодная беременность с повышенным риском преждевременных родов, сохраняющиеся кровянистые выделения во II или III триместре, предлежание плаценты после 26 нед беременности, угроза преждевременных родов во время текущей беременности, разрыв околоплодных оболочек, преэклампсия или индуцированная беременностью артериальная гипертензия, а также тяжелая анемия [42-46].

4.14. Беременным женщинам не рекомендованы диеты с резким ограничением каких-либо макронутриентов с целью снижения веса (УУР В, УДД 3) [21, 45].

Комментарии. С пациенткой с избыточной массой тела/ожирением рекомендовано обсуждать принципы питания, направленные на снижение массы тела и профилактику осложнений, ассоциированных с ИМТ во время беременности. При возможности рекомендована консультация диетолога.

4.15. Всем беременным рекомендовано следить за увеличением массы тела во время беременности с учетом ИМТ женщины на момент зачатия (УУР С, УДД 4) [21, 45].

Комментарии. Общая прибавка веса за время беременности с учетом ИМТ на момент зачатия:

- ИМТ менее $18,5 \mathrm{kr} / \mathrm{M}^{2}-12,5-18 \mathrm{kr} ;$

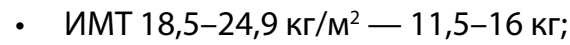

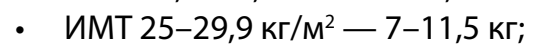

- ИМТ более $30 \mathrm{kr} / \mathrm{M}^{2}-5-9 \mathrm{kr}$.

Скорость набора веса во II и III триместрах беременности с учетом ИМТ на момент зачатия:

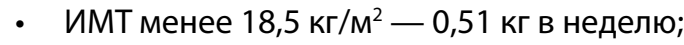

- нормальный ИМТ - 0,32 кг в неделю;

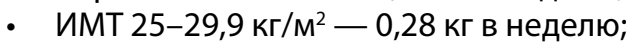

- ИМТ более $30 \mathrm{kг} / \mathrm{M}^{2}-0,22$ кг в неделю.

4.16. Женщинам репродуктивного возраста с ожирением, которые не могут достичь клинически значимого снижения веса на фоне немедикаментозных методов в течение 3 мес, рекомендовано назначение препаратов, зарегистрированных в качестве лекарственных средств для лечения ожирения (УУР А, УДД 3) [42].

Комментарии. Лекарственная терапия ожирения - см. главу 2.2

HRmax = максимальная частота сердечных сокращений (ЧСС), определяется по формуле «220 минус возраст». 
4.17. Женщинам репродуктивного возраста с ожирением, получающим препараты, зарегистрированные в качестве лекарственных средств для лечения ожирения, рекомендовано соблюдать доступные им методы контрацепции для предохранения от беременности (УУР А, УДД 3) [42].

Комментарии. Все препараты, зарегистрированные в качестве лекарственных средств для лечения ожирения, не имеют значимых весомых заключений, подтверждающих отсутствие тератогенного эффекта препаратов у человека.

4.18. Женщинам в репродуктивном периоде с морбидным ожирением при неэффективности ранее проводимой терапии рекомендовано хирургическое лечение ожирения (УУР В, УДД 3) [42, 47].

Комментарии. Планирование беременности после проведения бариатрической операции возможно только через 1-2 года [47]. Женщины после бариатрической операции имеют более высокие риски малого гестационного возраста, но более низкие риски макросомии плода, гестационного диабета и гипертонии [47].

\section{Терапевтическая тактика лечения пациенток с СПЯ и ожирением}

4.19. Всем пациенткам с СПЯ репродуктивного возраста рекомендована модификация образа жизни (включая снижение массы тела при избыточной массе тела или ожирении) для снижения риска развития кардиометаболических заболеваний (УУР А, УДД 2) [25, 43].

4.20. Всем пациенткам с СПЯ репродуктивного возраста на этапе планирования беременности рекомендована модификация образа жизни (включая снижение массы тела при избыточной массе тела или ожирении) для снижения риска развития осложнений во время беременности (УУР А, УДД 2) [25, 43].

Комментарии. Снижение массы тела на этапе планирования беременности - профилактика осложнений гестации, родового акта и улучшение перинатального прогноза [28].

4.21. Женщинам репродуктивного возраста с СПЯ и метаболическим синдромом рекомендовано назначение сенситайзера к инсулину - метформина для улучшения гормональных и метаболических исходов (УУР С, УдД 4) [25, 48].

Комментарии. Согласно международным клиническим рекомендациям по ведению пациенток с СПЯ, метформин показан:
$>$ женщинам с СПЯ для снижения веса, улучшения гормональных и метаболических исходов;

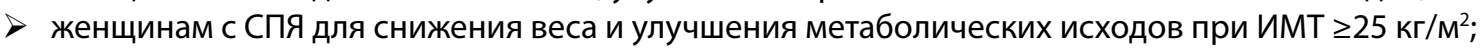
$>$ в группах повышенного риска развития нарушений углеводного обмена [48].

4.22. Женщинам с СПЯ, которые не могут достичь клинически значимого снижения веса на фоне немедикаментозных методов лечения в течение 3 мес, рекомендовано назначение препаратов, зарегистрированных в качестве лекарственных средств для лечения ожирения, при ИМт $\geq 30$ кг/м² или при ИМТ $\geq 27$ кг/м² при наличии факторов риска и/или коморбидных заболеваний (УУР А, УДД 2) [48].

4.23. Все препараты, зарегистрированные в качестве лекарственных средств для лечения ожирения, могут быть рекомендованы для лечения ожирения у женщин с СПЯ (УУР А, УДД 2) [48].

Комментарии. Обязательно консультирование в отношении контрацепции в течение приема всехлекарственных препаратов, зарегистрированных для лечения ожирения.

4.24. Не рекомендуется назначение пищевых добавок или биологически активных добавок в связи с отсутствием данных об их эффективности и безопасности в лечении ожирения у женщин репродуктивного возраста с СПЯ (УУР 2, УДД 2) [49, 50].

\section{СПИСОК ЛИТЕРАТУРЫ | REFERENCES}

World Health Organization. Noncommunicable Diseases Country Profiles 2018. Russian Federation. Available at: https://www.who.int/nmh/countries/2018/rus_en.pdf?ua=1

2. Norman JE. The adverse effects of obesity on reproduction. Reproduction. 2010;140(3):343-345 doi: https://doi.org/10.1530/REP-10-0297

3. Pasquali R, Gambineri A, Pagotto U. Review article: The impact of obesity on reproduction in women with polycystic ovary syndrome. BJOG An Int J Obstet Gynaecol. 2006;113(10):11481159. doi: https://doi.org/10.1111/j.1471-0528.2006.00990.x

4. Pasquali R, Gambineri A. Metabolic effects of obesity on reproduction. Reprod Biomed Online. 2006;12(5):542551. doi: https://doi.org/10.1016/S1472-6483(10)61179-0

5. Pasquali R. Obesity and reproductive disorders in women. Hum Reprod Update. 2003;9(4):359-372. doi: https://doi.org/10.1093/humupd/dmg024

6. Jain A, Polotsky AJ, Rochester D, et al. Pulsatile Luteinizing Hormone Amplitude and Progesterone Metabolite Excretion Are Reduced in Obese Women. J Clin Endocrinol Metab. 2007;92(7):2468-2473. doi: https://doi.org/10.1210/jc.2006-2274
Castillo-Martínez L, López-Alvarenga JC, Villa AR, González-Barranco J. Menstrual cycle length disorders in 18- to 40-y-old obese women. Nutrition. 2003;19(4):317-320. doi: https://doi.org/10.1016/S0899-9007(02)00998-X

8. Polotsky AJ, Hailpern SM, Skurnick JH, et al. Association of adolescent obesity and lifetime nulliparity-The Study of Women's Health Across the Nation (SWAN). Fertil Steril. 2010;93(6):2004-2011. doi: https://doi.org/10.1016/j.fertnstert.2008.12.059

9. Kuchenbecker WKH, Groen H, Zijlstra TM, et al. The Subcutaneous Abdominal Fat and Not the Intraabdominal Fat Compartment Is Associated with Anovulation in Women with Obesity and Infertility. J Clin Endocrino/ Metab. 2010;95(5):2107-2112. doi: https://doi.org/10.1210/jc.2009-1915

10. Morán C, Hernández E, Ruíz JE, et al. Upper Body Obesity and Hyperinsulinemia Are Associated with Anovulation. Gynecol Obstet Invest. 1999;47(1):1-5. doi: https://doi.org/10.1159/000010052

11. Gesink Law DC, Maclehose RF, Longnecker MP. Obesity and time to pregnancy. Hum Reprod. 2006;22(2):414-420. doi: https://doi.org/10.1093/humrep/del400 
12. Jensen TK, Scheike T, Keiding N, Schaumburg I, Grandjean P. Fecundability in Relation to Body Mass and Menstrual Cycle Patterns. Epidemiology. 1999;10(4):422-428. doi: https://doi.org/10.1097/00001648-199907000-00014

13. Zaadstra BM, Seidell JC, Van Noord PA, et al. Fat and female fecundity: prospective study of effect of body fat distribution on conception rates. BMJ. 1993;306(6876):484-487. doi: https://doi.org/10.1136/bmj.306.6876.484

14. Rich-Edwards JW, Spiegelman D, Garland M, et al. Physical Activity, Body Mass Index, and Ovulatory Disorder Infertility. Epidemiology. 2002;13(2):184-190 doi: https://doi.org/10.1097/00001648-200203000-00013

15. Clinical Guidelines on the Identification, Evaluation, and Treatment of Overweight and Obesity in Adults - The Evidence Report. National Institutes of Health. Obesity research. 1998;6(Suppl 2):51S-2095.

16. Selter J, Wen T, Palmerola KL, et al. Life-threatening complications among women with severe ovarian hyperstimulation syndrome. Am J Obstet Gynecol. 2019;220(6):575.e1-575.e11. doi: https://doi.org/10.1016/j.ajog.2019.02.009

17. Siddiqui A, Azria E, Howell EA, et al. Associations between maternal obesity and severe maternal morbidity: Findings from the French EPIMOMS population-based study. Paediatr Perinat Epidemiol. 2019;33(1):7-16. doi: https://doi.org/10.1111/ppe.12522

18. Белицина Л.В. Ожирение и репродуктивное здоровье (обзорная статья) // Журнал ассочиачии спеииалистов в области репродуктивного здоровья. — 2012. — №3. — C. 3-25. [Belitsina L.V. Ozhirenie i reproduktivnoe zdorov'e (obzornaya stat'ya). Zhurnal assotsiatsii spetsialistov voblasti reproduktivnogo zdorov'ya. 2012;(3):3-25. (In Russ.)].

19. Подзолкова Н.М., Агеева М.И., Скворцова М.Ю., и др. Течение беременности и перинатальные исходы у женщин с нарушениями жирового обмена // Акушерство и Гинекология. — 2011. — №6. C. 86-92. [Podzolkova N.M., Ageeva M.I., Skvortsova M.Yu., et al. Techenie beremennosti i perinatal'nye iskhody u zhenshchin s narusheniyami zhirovogo obmena. Akusherstvo i Ginekologiya. 2011;(6):86-92. (In Russ.)].

20. Gaudet L, Ferraro ZM, Wen SW, Walker M. Maternal Obesity and Occurrence of Fetal Macrosomia: A Systematic Review and Meta-Analysis. Biomed Res Int. 2014;2014:1-22. doi: https://doi.org/10.1155/2014/640291

21. Institute of Medicine and National Research Council. 2009. Weight Gain During Pregnancy: Reexamining the Guidelines. Washington, DC: The National Academies Press. doi: https://doi.org/10.17226/12584

22. Mahutte N, Kamga-Ngande C, Sharma A, Sylvestre C. Obesity and Reproduction. J Obstet Gynaecol Canada. 2018;40(7):950-966. doi: https://doi.org/10.1016/j.jogc.2018.04.030

23. Holton S, Fisher J, Nguyen H, et al. Pre-pregnancy body mass index and the risk of antenatal depression and anxiety. Women and Birth. 2019;32(6):e508-e514. doi: https://doi.org/10.1016/j.wombi.2019.01.007

24. Broughton DE, Moley KH. Obesity and female infertility: potential mediators of obesity's impact. Fertil Steril. 2017;107(4):840-847. doi: https://doi.org/10.1016/j.fertnstert.2017.01.017

25. Teede H, Misso M, Costello M, et al. International Evidence-Based Guideline for the Assessment and Management of Polycystic Ovary Syndrome 2018. Available at: https://www.monash.edu/_data/assets/ pdf_file/0004/1412644/PCOS_Evidence-Based-Guidelines_20181009.pdf

26. Maged AM, Fahmy RM, Rashwan $\mathrm{H}$, et al. Effect of body mass index on the outcome of IVF cycles among patients with poor ovarian response. Int J Gynecol Obstet. 2019;144(2):161-166. doi: https://doi.org/10.1002/ijgo.12706

27. Koning $\mathrm{AMH}$, Mutsaerts MAQ, Kuchenbecher WKH, et al. Complications and outcome of assisted reproduction technologies in overweight and obese women. Hum Reprod. 2012;27(2):457-467. doi: https://doi.org/10.1093/humrep/der416

28. Banker M, Sorathiya D, Shah S. Effect of Body Mass Index on the Outcome of In-Vitro Fertilization/Intracytoplasmic Sperm Injection in Women. J Hum Reprod Sci. 2017;10(1):37-43. doi: https://doi.org/10.4103/jhrs.JHRS_75_16

29. Frankenthal D, Hirsh-Yechezkel G, Boyko V, et al. The effect of body mass index (BMI) and gestational weight gain on adverse obstetrical outcomes in pregnancies following assisted reproductive technology as compared to spontaneously conceived pregnancies. Obes Res Clin Pract. 2019;13(2):150-155. doi: https://doi.org/10.1016/j.orcp.2018.11.239

30. Kolotkin RL, Zunker C, Østbye T. Sexual Functioning and Obesity: A Review. Obesity. 2012;20(12):2325-2333. doi: https://doi.org/10.1038/oby.2012.104
31. Steffen KJ, King WC, White GE, et al. Changes in Sexual Functioning in Women and Men in the 5 Years After Bariatric Surgery. JAMA Surg. 2019;154(6):487. doi: https://doi.org/10.1001/jamasurg.2018.1162

32. Yao K, Bian C, Zhao X. Association of polycystic ovary syndrome with metabolic syndrome and gestational diabetes: Aggravated complication of pregnancy. Exp Ther Med. 2017;14(2):1271-1276. doi: https://doi.org/10.3892/etm.2017.4642

33. Rodgers R, Avery J, Moore V, et al. Complex diseases and co-morbidities: polycystic ovary syndrome and type 2 diabetes mellitus. Endocr Connect. February 2019. doi: https://doi.org/10.1530/EC-18-0502

34. MacKintosh ML, Crosbie EJ. Prevention Strategies in Endometrial Carcinoma. Curr Oncol Rep. 2018;20(12):101. doi: https://doi.org/10.1007/s11912-018-0747-1

35. Benedetto C, Salvagno F, Canuto EM, Gennarelli G. Obesity and female malignancies. Best Pract Res Clin Obstet Gynaecol. 2015;29(4):528-540. doi: https://doi.org/10.1016/j.bpobgyn.2015.01.003

36. Yang S, Thiel KW, Leslie KK. Progesterone: the ultimate endometrial tumor suppressor. Trends Endocrinol Metab. 2011;22(4):145-152. doi: https://doi.org/10.1016/j.tem.2011.01.005

37. Gottschau M, Kjaer SK, Jensen A, et al. Risk of cancer among women with polycystic ovary syndrome: A Danish cohort study. Gynecol Oncol. 2015;136(1):99-103. doi: https://doi.org/10.1016/j.ygyno.2014.11.012

38. Wise MR, Jordan V, Lagas A, et al. Obesity and endometrial hyperplasia and cancer in premenopausal women: A systematic review. Am J Obstet Gynecol. 2016;214(6):689.e1-689.e17. doi: https://doi.org/10.1016/j.ajog.2016.01.175

39. Bellver J, Martínez-Conejero JA, Labarta E, et al. Endometrial gene expression in the window of implantation is altered in obese women especially in association with polycystic ovary syndrome. Fertil Steril. 2011;95(7):2335-2341.e8. doi: https://doi.org/10.1016/j.fertnstert.2011.03.021

40. Hillers-Ziemer LE, Arendt LM. Weighing the Risk: effects of Obesity on the Mammary Gland and Breast Cancer Risk. J Mammary Gland Biol Neoplasia. 2020;25(2):115-131. doi: https://doi.org/10.1007/s10911-020-09452-5

41. Belardi V, Gallagher EJ, Novosyadlyy R, LeRoith D. Insulin and IGFs in Obesity-Related Breast Cancer. J Mammary Gland Biol Neoplasia. 2013;18(3-4):277-289. doi: https://doi.org/10.1007/s10911-013-9303-7

42. Клинические рекомендации Российской ассоциации эндокринологов и Российского общества бариатрических хирургов «Лечение ожирения у взрослых», 2020 [Klinicheskie rekomendatsii Rossiiskoi assotsiatsii endokrinologov i Rossiiskogo obshchestva bariatricheskikh khirurgov «Lechenie ozhireniya u vzroslykh», 2020 (In Russ.)]. Available at: http://cr.rosminzdrav.ru/schema/28

43. Morgante G, Massaro MG, Di Sabatino A, et al. Therapeutic approach for metabolic disorders and infertility in women with PCOS. Gynecol Endocrinol. 2018;34(1):4-9. doi: https://doi.org/10.1080/09513590.2017.1370644

44. Committee Opinion No. 650. Physical Activity and Exercise During Pregnancy and the Postpartum Period. Obstet Gynecol. 2015;126(6):e135-e142. doi: https://doi.org/10.1097/AOG.0000000000001214

45. Muktabhant B, Lawrie TA, Lumbiganon P, Laopaiboon M. Diet or exercise, or both, for preventing excessive weight gain in pregnancy. Cochrane Database Syst Rev. 2015;(6). doi: https://doi.org/10.1002/14651858.CD007145.pub3

46. Artal R. Guidelines of the American College of Obstetricians and Gynecologists for exercise during pregnancy and the postpartum period. Br J Sports Med. 2003;37(1):6-12. doi: https://doi.org/10.1136/bjsm.37.1.6

47. National Institute for Health and Clinical Excellence. NICE public health guidance 27: weight management before, during and after pregnancy. London, United Kingdom: NICE, 2010. Available at: https://www.nice.org.uk/guidance/ph27

48. Teede HJ, Misso ML, Costello MF, et al. Recommendations from the international evidence-based guideline for the assessment and management of polycystic ovary syndrome. Fertil Steril. 2018;110(3):364-379. doi: https://doi.org/10.1016/j.fertnstert.2018.05.004

49. Arentz S, Smith CA, Abbott J, Bensoussan A. Nutritional supplements and herbal medicines for women with polycystic ovary syndrome; a systematic review and meta-analysis. BMC Complement Altern Med. 2017;17(1):500. doi: https://doi.org/10.1186/s12906-017-2011-x

50. Kwon C-Y, Lee B, Park KS. Oriental herbal medicine and moxibustion for polycystic ovary syndrome. Medicine (Baltimore). 2018;97(43):e12942. doi: https://doi.org/10.1097/MD.0000000000012942 


\section{ГЛАВА 5. ОЖИРЕНИЕ И ПОСТМЕНОПАУЗА}

Андреева Е.Н., Хамошина М.Б.

\section{ОПРЕДЕЛЕНИЕ}

Менопауза - это стойкое прекращение менструаций, последняя самостоятельная менструация, обусловленная возрастным снижением гормональной и «выключением» репродуктивной функции яичников. Дата оценивается ретроспективно: спустя 12 мес отсутствия менструации. Постменопауза - период после наступления менопаузы, длящийся до конца жизни [1].

\section{этиология}

Постменопаузальный статус является фактором, предрасполагающим к развитию у женщин «возрастного» ожирения и метаболического синдрома [2]. Доказана взаимосвязь между вазомоторными симптомами и инсулинорезистентностью (ИР), эндотелиальной дисфункцией, повышением кальцификации аорты и толщиной интимы-медиа сонной артерии, уровнем маркеров коагуляции и воспаления [3-6].

\section{КЛАССИФИКАЦИЯ}

Выделяют «менопаузальное» ожирение и «менопаузальный» метаболический синдром [7, 8]. Заболевание проявляется быстрой (5-10 кг и более за 6-12 мес и менее) прибавкой массы тела с формированием абдоминального ожирения, ИР и дислипидемии и/или АГ в период менопаузального перехода или ранней постменопаузы. Триггером служат дефицит и нарушение обмена половых стероидов [7, 8].

\section{ДИАГНОСТИКА}

5.1. Для верификации «менопаузального» ожирения у всех женщин в пери- и постменопаузе рекомендуется (УУР В, УДД 3) [9-11]:

- измерение окружности талии (ОТ) как ключевого фактора висцерального ожирения;

- определение веса, роста и вычисление ИМТ как важного фактора риска метаболических нарушений;

- измерение уровня артериального давления (АД) как важного фактора риска сердечно-сосудистых нарушений;

- проведение перорального глюкозотолерантного теста при подозрении на наличие нарушений углеводного обмена [9-11].

\section{ОСОБЕННОСТИ ДИЕТОТЕРАПИИ ОЖИРЕНИЯ В ПОСТМЕНОПАУЗЕ}

5.2. Всем женщинам в постменопаузе рекомендовано соблюдение терапевтической модификации образа жизни (ТМОЖ), предусматривающей регулярную умеренную физическую активность, отказ от курения, следование принципам здорового питания (УУР В, УДД 3) [3, 12-14].

Комментарии. В отличие от лиц среднего возраста, в пожилом и старческом возрасте критерии необходимости снижения веса могут отличаться - повышение у пожилых ИМТ до 25-29,9 кг/м² по сравнению с более низкими значениями ассоциировано со снижением, а не повышением риска смерти. Более высокая масса тела ассоциирована с большей минеральной плотностью костной ткани (МПКТ), меньшим риском остеопороза и перелома бедренной кости.

Приоритет следует отдавать потреблению пищевых продуктов с низкой энергетической ценностью, прекращению употребления пищевых продуктов быстрого приготовления и продукции сетей быстрого питания. Необходимы несколько порций фруктов и овощей в день, потребление цельных злаков, рыбы дважды в неделю и низкое общее потребление жиров, рекомендуется отдавать предпочтение оливковому или соевому маслу. Потребление соли должно быть ограничено, также ограничено потребление алкоголя до 10 г.

Для контроля за пищевым поведением следует рекомендовать нормализацию ночного сна, уменьшение каждой порции пищи на треть, тщательное пережевывание пищи (не менее 20 раз).

5.3. Рекомендовано учитывать, что для расчета суточного калоража у пациенток старше 60 лет используется формула с другими коэффициентами (УУР С, УДД 3) [15, 16].

Комментарии. Для пациенток пожилого возраста важное значение в рационе питания имеет достаточное потребление белка (не менее 1,0 г/кг веса), дополнительный прием препаратов витамина D [16].

\section{ОСОБЕННОСТИ ФИЗИЧЕСКОЙ АКТИВНОСТИ}

5.4. Всем женщинам в постменопаузе рекомендована регулярная физическая активность для улучшения качества жизни, снижения смертности от сердечно-сосудистых заболеваний и общей смертности, профилактики когнитивных нарушений (УУР В, УДД 4) [3, 10, 17].

Комментарии. Для профилактики «менопаузального» ожирения и гиподинамии, а также с целью снижения риска сердечно-сосудистых осложнений взрослым необходимо по крайне мере 150 мин (2 ч 30 мин) в неделю аэробной 
физической активности умеренной интенсивности или 75 мин (1 ч 15 мин) в неделю аэробной физической активности высокой интенсивности $[18,19]$.

\section{5. Рекомендовано персонализировать программы физических занятий с учетом возраста (физическое состояние у пожилых людей определяет интенсивность аэробной активности), степени ожирения и на- грузки на суставы (приоритетны физические упражнения в воде - плавание, аквааэробика) (УУР С, УдД 4) [19].}

Комментарии. Для пожилого возраста характерно развитие саркопенического ожирения с уменьшением мышечной массы. Саркопения лежит в основе развития старческой астении. Физическая активность способна отдалить развитие старческой астении и/или замедлить ее прогрессирование. Для снижения риска ранней смерти у пожилых женщин достаточно делать около 5000 шагов в день, а не 10 000, как считалось ранее - после 7500 шагов дополнительное преимущество от долгой прогулки может быть сведено к нулю. В то же время максимальные показатели по количеству шагов могут хорошо сказаться на самом качестве жизни.

Пациенткам с ожирением и избыточной массой тела рекомендуется 225-300 мин в неделю физической активности умеренной интенсивности или 150 мин в неделю аэробной физической активности высокой интенсивности, что эквивалентно тратам в 1800-2500 ккал в неделю [1 1]. Физические нагрузки должны включать упражнения для гибкости, растяжки, баланса и выносливости [11].

\section{ОСОБЕННОСТИ МЕДИКАМЕНТОЗНОЙ ТЕРАПИИ}

Фармакокинетика сибутрамина у пожилых здоровых лиц (средний возраст - 70 лет) аналогична таковой у молодых [20]. Применение сибутрамина + МКЦ ограничено индивидуальным риском сердечно-сосудистых событий, особенно у пациенток старше 60 лет. В отечественной практике имеется положительный опыт эффективности терапии сибутрамином, сибутрамином + МКЦ и орлистатом при «менопаузальном» метаболическом синдроме [7, 20]. С учетом положительных эффектов метформина в отношении коррекции метаболических нарушений стоит ожидать повышения эффективности терапии при комбинированном применении сибутрамина и метформина у рассматриваемой группы пациенток.

- Особенностью пациенток в постменопаузе является применение менопаузальной гормонотерапии (МГТ) препаратами половых стероидов. Ожирение является одним из факторов риска вазомоторных симптомов $[21,22]$. МГТ включает широкий спектр гормональных препаратов и путей введения, которые потенциально имеют различные риски и преимущества. Например, дроспиренон обладает подтвержденной способностью снижать уровень АД [1].

Следует придерживаться так называемой «временной гипотезы»: начинать МГТ в возрасте моложе 60 лет или при длительности постменопаузы менее 10 лет [1]. В этом случае может быть реализован присущий ей профилактический эффект в отношении метаболического синдрома в постменопаузе (прибавки массы тела, абдоминального ожирения, ИР, АГ, нарушения обмена липидов) у исходно здоровых лиц [8]. В первые два года после манифестации «менопаузального» метаболического синдрома раннее начало МГТ препаратами, в состав которых входят метаболически нейтральные прогестагены (дидрогестерон, дроспиренон), может способствовать его обратному развитию. Снижения массы тела лишь на 5-10\% достаточно для коррекции многих нарушений, ассоциированных с синдромом инсулинорезистентности.

Упациенток с ожирением и метаболическим синдромом при назначении МГТ трансдермальное введение эстрогенов [3, 9-11, 23] необходимо при наличии:

- болезней печени, поджелудочной железы, нарушений всасываемости в желудочно-кишечном тракте;

- расстройств коагуляции, высокого риска развития венозного тромбоза;

- гипертриглицеридемии;

- АГ (>170/100 мм рт. ст.), гиперинсулинемии;

- повышенного риска образования камней в желчных путях;

- мигренозной головной боли;

- приверженности к табакокурению.

При трансдермальном пути введения эстрогенов защита эндометрия у пациенток с ожирением может быть обеспечена путем введения левоноргестрел-выделяющей внутриматочной системы либо интравагинальным введением микронизированного прогестерона. Возможен прием дидрогестерона внутрь.

\section{ЛЕКАРСТВЕННЫЕ ВЗАИМОДЕЙСТВИЯ}

У пациенток с ожирением, получающих МГТ, необходимо учитывать, что эстрадиол повышает эффективность гиполипидемических средств и ослабляет эффект гипогликемических, диуретических, гипотензивных препаратов и антикоагулянтов.

Нет данных о клинически значимом взаимодействии сибутрамина, орлистата и лираглутида с препаратами половых стероидов.

Подробная информация по взаимодействию лекарственных средств при лечении ожирения и коморбидных заболеваний представлена в главе 13. 


\section{СПИСОК ЛИТЕРАТУРЫ | REFERENCES}

1. Российское общество акушеров-гинекологов Российская ассоциация по менопаузе. Менопауза и климактерическое состояние у женщины. Клинические рекомендации, 2016 [Menopauza i klimaktericheskoe sostoyanie u zhenshchiny. Klinicheskie rekomendatsii MZ RF, 2016 (In Russ.)].

2. Рекомендации по ведению больных с метаболическим синдромом МЗ РФ, 2013. [Rekomendatsii po vedeniyu bol'nykh s metabolicheskim sindromom MZ RF, 2013 (In Russ.)].

3. Сухих Г.Т., Сметник В.П., Андреева Е.Н., и др. Менопаузальная гормонотерапия и сохранение здоровья женщин в зрелом возрасте. Клинические рекомендации (протокол лечения), Москва, 2016 г. [Sukhikh GT, Smetnik VP, Andreeva EN, et al. Menopauzal'naya gormonoterapiya i sokhranenie zdorov'ya zhenshchin v zrelom vozraste. Klinicheskie rekomendatsii (protokol lecheniya), Moskva, 2016. (In Russ.)].

4. Lambrinoudaki I, Augoulea A, Armeni E, et al. Menopausal symptoms are associated with subclinical atherosclerosis in healthy recently postmenopausal women. Climacteric. 2012;15(4):350-357. doi: https://doi.org/10.3109/13697137.2011.618564

5. Lee SW, Jo HH, Kim MR, Kwon DJ, You YO, Kim JH. Association between menopausal symptoms and metabolic syndrome in postmenopausal women. Arch Gynecol Obstet. 2012;285(2):541-548. doi: https://doi.org/10.1007/s00404-011-2016-5

6. Андреева Е.Н., Григорян О.Р. Менопауза при ожирении. Научнопрактическое руководство (под ред. Академика РАН Дедова И.И.). M.: 2018, c. 11 [Andreeva EN, Grigoryan OR, Menopauza pri ozhirenii/ Nauchno- prakticheskoe rukovodstvo (pod red. Akademika RAN Dedova I.I.). M.: 2018. S11 (In Russ.)].

7. Сметник В.П. Медицина климактерия. Ярославль: Литера, 2006. 848 c. [Smetnik VP. Medicina klimakterija. Jaroslavl': Litera, 2006. S. 848. (in Russ.)]

8. Lobo RA, Davis SR, De Villiers TJ, et al. Prevention of diseases after menopause. Climacteric. 2014;17(5):540-556. doi: https://doi.org/10.3109/13697137.2014.933411

9. Baber RJ, Panay N, Fenton A. 2016 IMS Recommendations on women's midlife health and menopause hormone therapy. Climacteric. 2016;19(2):109-150. doi: https://doi.org/10.3109/13697137.2015.1129166

10. Neves-e-Castro M, Birkhauser M, Samsioe G, et al. EMAS position statement: The ten point guide to the integral management of menopausal health. Maturitas. 2015;81(1):88-92. doi: https://doi.org/10.1016/j.maturitas.2015.02.003

11. National Institute for Health and Clinical Excellence. Menopause: Diagnosis and Management (NG23) 2015. Available at: https://www.nice.org.uk/guidance/ng23/resources/menopausediagnosis-andmanagement-1837330217413

12. Howe M, Leidal A, Montgomery D, Jackson E. Role of Cigarette Smoking and Gender in Acute Coronary Syndrome Events. Am J Cardiol. 2011;108(10):1382-1386. doi: https://doi.org/10.1016/j.amjcard.2011.06.059
13. Luo J, Rossouw J, Margolis KL. Smoking Cessation, Weight Change, and Coronary Heart Disease Among Postmenopausal Women With and Without Diabetes. JAMA. 2013;310(1):94. doi: https://doi.org/10.1001/jama.2013.6871

14. Kline J, Tang A, Levin B. Smoking, alcohol and caffeine in relation to two hormonal indicators of ovarian age during the reproductive years. Maturitas. 2016;92:115-122. doi: https://doi.org/10.1016/j.maturitas.2016.07.010

15. WHO Consultation on Obesity (1997: Geneva S, Diseases WHOD of N, World Health Organization. Programme of Nutrition F and $\mathrm{RH}$. Obesity: preventing and managing the global epidemic : report of a WHO Consultation on Obesity, Geneva, 3-5 June 1997. https://apps.who.int/iris/handle/10665/63854

16. Stallings DT, Kraenzle Schneider J. Motivational Interviewing and Fat Consumption in Older Adults: A Meta-Analysis. J Geronto/ Nurs. 2018:44(11):33-43. doi: https://doi.org/10.3928/00989134-20180817-01

17. Eckel RH, Jakicic JM, Ard JD, et al. 2013 AHA/ACC Guideline on Lifestyle Management to Reduce Cardiovascular Risk. Circulation. 2014;129(25 suppl 2):S76-S99. doi: https://doi.org/10.1161/01.cir.0000437740.48606.d1

18. Ladabaum U, Mannalithara A, Myer PA, Singh G. Obesity, Abdominal Obesity, Physical Activity, and Caloric Intake in US Adults: 1988 to 2010. Am J Med. 2014;127(8):717-727.e12 doi: https://doi.org/10.1016/j.amjmed.2014.02.026

19. U.S. Department of Health and Human Services. 2008 Physical activity guidelines for Americans: Be Active, Healthy and Happy! US Dep Heal Hum Serv. 2008. Available at: https://health.gov/our-work/physical-activity/current-guidelines

20. Эффективность терапии Редуксином пациенток с ожирением старше 40 лет при наличии сопутствующих гинекологических заболеваний. Клинический отчет, программа Примавера, 2016. [Effektivnost' terapii Reduksinom patsientok s ozhireniem starshe 40 let pri nalichii soputstvuyushchikh ginekologicheskikh zabolevanii. Klinicheskii otchet, programma Primavera, 2016. (In Russ.)]

21. Freeman EW, Sammel MD, Sanders RJ. Risk of long-term hot flashes after natural menopause. Menopause. 2014;21(9):924-932. doi: https://doi.org/10.1097/GME.0000000000000196

22. Костромина А.А., Радзинский В.Е., Хамошина М.Б., и др. Факторы риска развития климактерического синдрома тяжелой степени: клиникостатистическое исследование // Доктор.Ру. - 2017. - №9 (138). - C. 12-16. [Kostromina AA, Radzinskii VE, Khamoshina MB, et al. Faktory riska razvitiya klimaktericheskogo sindroma tyazheloi stepeni: klinikostatisticheskoe issledovanie. Doktor.Ru. 2017.9(138):12-16. (In Russ.)].

23. Stuenkel CA, Davis SR, Gompel A, et al. Treatment of Symptoms of the Menopause: An Endocrine Society Clinical Practice Guideline. J Clin Endocrinol Metab. 2015;100(11):3975-4011. doi: https://doi.org/10.1210/jc.2015-2236 


\section{ГЛАВА 6. ОСОБЕННОСТИ ДИАГНОСТИКИ И ЛЕЧЕНИЯ ОЖИРЕНИЯ У МУЖЧИН}

\section{Гусова 3.Р., Роживанов Р.В.}

Современные эпидемиологические данные указывают на повсеместный катастрофически быстрый рост заболеваемости ожирением среди мужчин. Во многих странах за последние 20 лет количество лиц мужского пола с избыточной массой тела и ожирением возросло в 1,5-2,3 раза [1-3].

Анализ современных крупномасштабных исследований наглядно продемонстрировал, что ожирение у мужчин является важнейшим фактором риска развития СД2, атеросклероза и артериальной гипертензии - заболеваний, сопровождающихся развитием тяжелых осложнений, существенно повышающих риски развития сердечно-сосудистых катастроф, инвалидизации и высокой смертности пациентов [3, 4].

При этом многие эксперты считают, что клиническая значимость ожирения у лиц мужского пола значительно выше, чем у женщин, т.к. часто заболевание диагностируется поздно, труднее поддается лечению, сопровождается быстрым развитием и прогрессированием традиционных осложнений, приводя к уменьшению средней продолжительности жизни у мужчин на 8-12 лет по сравнению с женщинами [5-7].

Эти особенности обусловлены рядом закономерностей. Так, генетически у мужчин формируется абдоминальный тип ожирения, характеризующийся преобладанием висцерального компонента, метаболическая активность которого является пусковым фактором развития метаболического синдрома, иммуноопосредованных заболеваний и онкологической патологии $[8,9]$.

На сегодняшний день установлено, что именно висцеральная жировая ткань является фактором высокого риска развития не только сопутствующей соматической патологии, но и сексуальной дисфункции у мужчин [10, 11]. В ряде клинических исследований показано, что у пациентов с ожирением уровень тестостерона, как правило, ниже популяционного $[12,13]$. В поисках патогенетической основы данного феномена было обнаружено, что в жировой ткани присутствует фермент ароматаза, под влиянием которого происходит конверсия андрогенов в эстрогены. С увеличением массы адипоцитов концентрация циркулирующих эстрогенов существенно возрастает. Длительно существующий избыток эстрогенов у мужчин приводит к подавлению выработки ЛГ и гиперпродукции пролактина, которые, в свою очередь, вызывают сбой центральных регуляторных механизмов стероидогенеза в яичках. Формируется так называемый нормогонадотропный гипогонадизм с нарушением отрицательной обратной связи гипоталамус-гипофиз-гонады [5, 14, 15].

Одновременно гиперэстрогения является и фактором стимуляции репликации висцеральных преадипоцитов в зрелые адипоциты и процесса формирования их гиперплазии. Становится очевидным, что за счет снижения уровня тестостерона в крови в организме мужчины создаются дополнительные условия для прогрессирующего набора массы висцеральной жировой ткани. Замыкается своего рода порочный круг, ведущий к усугублению имеющихся поражений органов и систем и обусловливающий неэффективность лечебных мероприятий. Кроме того, при ожирении увеличивается продукция в печени глобулина, связывающего половые гормоны, что приводит к снижению содержания свободного тестостерона - биологически активной фракции гормона и, соответственно, дефициту его физиологических эффектов действия [16]. У мужчин, как правило, развиваются сексуальные проблемы: снижение либидо, эректильная дисфункция, снижение репродуктивного потенциала и нарушение фертильности $[10,12]$.

С другой стороны, низкий уровень тестостерона сам по себе может быть предиктором прогрессирующего развития как ожирения, так и ассоциированных с ним метаболических нарушений $[17,18]$. Гипогонадизм может непосредственно способствовать развитию ИР и нарушению углеводного обмена, атерогенной дислипидемии, заболеваний гепатобилиарной системы, ХБП [19-21].

Важно отметить, что причиной прогрессирующего развития осложнений заболевания у мужчин является отсутствие эстетических претензий к проблеме избыточного веса, столь характерных для лиц женского пола. Долгие годы мужчины смотрят на проблему набора веса как на естественный процесс старения организма в условиях социальной востребованности и гиподинамии [19]. Поэтому при отсутствии явной угрозы для состояния здоровья, повода для обращения к врачу и проведения клинического обследования обычно не видят. Часто возникает необходимость активного вовлечения мужчин с ожирением в программы коррекции веса, формирования стойкой мотивации на модификацию образа жизни и приверженность медикаментозной терапии.

Для практического врача принципиально важно понимать необходимость своевременной диагностики гипогонадизма у лиц мужского пола на фоне избыточной массы тела и целесообразность коррекции уровня тестостерона крови в комплексном подходе к терапии. Ниже приводятся непосредственные рекомендации по диагностике, лечению и мониторингу гипогонадизма у мужчин с ожирением, рассмотрены благоприятные эффекты лечения гипогонадизма в отношении метаболизма.

\section{ДИАГНОСТИКА}

6.1. Гипогонадизм рекомендуется диагностировать при наличии клинических симптомов, ассоциированных с дефицитом андрогенов, и выявлении стойкого снижения уровня тестостерона (как минимум двукратное подтверждение) надежным методом (например, методом усиленной хемилюминесценции) $[22,23]$ (УУР В, УДД 3). 


\section{Жалобы и анамнез}

6.2. При клинической диагностике гипогонадизма рекомендуется ориентироваться на три основных признака [22, 23]:

- снижение либидо и сексуальной активности;

- снижение числа утренних эрекций;

- снижение адекватных эрекций (УУР В, УДД З).

6.3. При обследовании пациента рекомендуется выявить и/или исключить сопутствующие заболевания, а также задать вопросы относительно фармакологической терапии [24, 25] (УУР В, УДД 3).

Комментарии. Симптомы нарушений половой функции как при наличии дефицита тестостерона, так и без такового могут быть связаны с сопутствующими заболеваниями или приемом лекарственных препаратов (например, спиронолактона, неселективных бета-адреноблокаторов) [25].

\section{Физикальное обследование}

6.4. В физикальное обследование при постановке диагноза и в динамике для оценки выраженности и осложнений гипогонадизма рекомендуется включать оценку грудных желез и органов мошонки, в том числе оценку размеров и консистенции яичек, а также обследование полового члена и предстательной железы [22, 23] (УУР В, УДД 3).

\section{Лабораторная диагностика}

6.5. В качестве порогового значения, позволяющего разграничить нормальное состояние и потенциальный дефицит тестостерона, рекомендуется считать 12,1 нмоль/л для общего тестостерона сыворотки крови [26, 27] (УУР А, УДД 2).

6.6. При уровне общего тестостерона от 8 до 12 нмоль/л рекомендуется определить уровень глобулина, связывающего половые стероиды, с дальнейшим расчетом уровня свободного тестостерона, нижняя граница нормы которого, по данным различных источников, составляет 225-250 пмоль/л, но большинством исследователей предлагается величина 243 пмоль/л [26, 27] (УУР А, УДД 2).

6.7. Забор крови для определения уровня тестостерона рекомендуется производить натощак, между 7 и 11 ч утра [26, 27] (УУР А, УДД 2).

6.8. Для оценки репродуктивного прогноза, потенциальной обратимости гипогонадизма, а также выявления субклинического гипогонадизма (повышение лг при нормальном уровне тестостерона) рекомендуется определение сывороточного уровня лГ; анализ на уровень ЛГ, как и на уровень тестостерона, должен выполняться двукратно [22, 23] (УУР В, УДД 3).

6.9. Для оценки потенциальной обратимости гипогонадизма путем лечения ожирения пациентам с нормальным уровнем ЛГ рекомендуется проведение пробы с антиэстрогенами: назначается любой из препаратов кломифена в дозе 50 мг перорально ежедневно утром 10 дней, на 11-й день определяется уровень тестостерона - его нормальное значение свидетельствует о потенциальной обратимости гипогонадизма [28] (УУР В, УДД 3).

\section{Инструментальная диагностика}

6.10. При выявлении патологических изменений при осмотре рекомендуется проведение ультразвуковых исследований. При выявлении гипогонадотропного гипогонадизма рекомендуется проведение магнитно-резонансной томографии головного мозга с целью исключения аденомы гипофиза [22, 23] (УУР В, УДД З).

\section{ЛЕЧЕНИЕ}

\section{Консервативное лечение}

Необходимым и достаточным показанием к лечению гипогонадизма является доказанный дефицит тестостерона. Цель лечения - облегчение симптомов гипогонадизма путем восстановления сывороточных уровней тестостерона до нормальных физиологических значений. Выбор метода лечения определяется формой заболевания, факторами риска и репродуктивными планами пациента. Пациент должен быть полностью информирован о предполагаемой пользе лечения и побочных эффектах каждого метода лечения [15].

6.11. В случаях обратимого гипогонадизма, например, у молодых мужчин с ожирением и сохранной гонадотропной функцией гипофиза, терапия тестостероном не рекомендуется, так как физиологическое восстановление уровня тестостерона возможно при снижении массы тела на фоне лечения ожирения [14] (Уур В, УДД 3). 
6.12. При невозможности добиться целевых показателей снижения массы тела рекомендуется назначение короткодействующих препаратов тестостерона. В таких случаях андрогенная терапия проводится с подбором индивидуальной дозы тестостерона, что позволяет сохранить циркадный физиологический ритм секреции тестостерона, а также минимизировать риски подавления гонадотропной функции гипофиза и сперматогенеза [15, 29] (УУР С, УДД 5).

Комментарии. Поскольку при экзогенном введении тестостерона возможно подавление сперматогенеза путем отрицательной обратной связи в системе гипоталамус-гипофиз-гонады, при репродуктивной реабилитации пациента (мужском бесплодии) следует рассматривать возможность терапии гонадотропинами (препараты хорионического гонадотропина человека, ЛГ и ФСГ) или антиэстрогенами, а также использование методов вспомогательных репродуктивных технологий [15, 30, 31].

6.13. Коррекция дозы препаратов должна проводиться индивидуально. Информации о терапевтических и неблагоприятных эффектах долгосрочной терапии гонадотропинами или антиэстрогенами в настоящее время недостаточно, и этот вид лечения не рекомендуется для постоянного использования [15, 29] (УУР С, УДД 5).

6.14. В случаях необратимого гипогонадизма, когда нет необходимости в сохранении репродуктивной функции, рекомендуется тестостерон-заместительная терапия, которая является безопасной и эффективной [31, 32] (УУР А, УДД 1).

6.15. Существующие препараты отличаются по пути введения и фармакокинетическим особенностям, решение о выборе конкретного препарата должно приниматься врачом и пациентом совместно [33, 34]. На начальном этапе лечения рекомендуется отдать предпочтение препаратам короткого действия над препаратами длительного действия, особенно у пациентов с факторами риска. Это позволит при необходимости прекратить лечение, если возникнут любые нежелательные явления, которые могут развиться во время терапии [34] (УУР В, УДД 3).

Комментарии. Из препаратов тестостерона используются нижеприведенные.

- Смесь эфиров тестостерона.

Применение: в/м, каждые 2-4 нед. Время оценки уровня тестостерона: через 2-4 нед с момента инъекции. Преимущества: средняя продолжительность действия. Недостатки: вариабельность уровня тестостерона, описаны супрафизиологические пики тестостерона в первые дни после инъекции, у пациентов с СД существует потенциальный риск развития местных инфекционных осложнений при инъекциях масляных растворов.

- Тестостерон раствор для внутримышечного введения.

Применение: в/м, каждые 10-14 нед. Время оценки уровня тестостерона: через 10-14 нед с момента инъекции. Преимущества: редкие инъекции, равновесная концентрация тестостерона после 3-5 инъекций. Недостатки: препарат длительного действия, нельзя быстро отменить, описаны супрафизиологические пики тестостерона в течение 1-2 нед после инъекции, у пациентов с СД существует потенциальный риск развития местных инфекционных осложнений при инъекциях масляных растворов.

- Трансдермальный тестостерон в виде геля.

Применение: ежедневно накожно. Время оценки уровня тестостерона: через 2-4 ч с момента нанесения геля. Преимущества: равновесная концентрация тестостерона без колебаний, можно быстро отменить. Недостатки: раздражение кожи в месте применения, потенциальный риск воздействия тестостерона на половых партнерш или детей, находящихся в тесном контакте.

6.16. Данных об определении оптимального сывороточного уровня тестостерона на фоне заместительной терапии в настоящее время недостаточно. На фоне лечения сывороточный уровень тестостерона рекомендуется восстанавливать до средне-нормальных значений, этого обычно достаточно для нивелирования различных проявлений андрогенного дефицита. Следует избегать супрафизиологических значений тестостерона в крови, особенно у лиц пожилого и старческого возраста с сопутствующей патологией [22, 23] (УУР В, УДД 3).

6.17. Мужчинам, имеющим в анамнезе рак грудной и/или предстательной железы, терапия препаратами тестостерона противопоказана и не рекомендуется [35-37] (УУР А, УДД 2).

Комментарии. Взаимосвязь между терапией тестостероном и развитием рака грудной железы не подтверждена достоверными доказательствами [38]. Терапия тестостероном также не повышает риск развития рака предстательной железы [39].

6.18. Пациенты с серьезной застойной сердечной недостаточностью (класс III-IV по NYHA) относятся к группе риска осложнений со стороны сердечно-сосудистой системы, поэтому терапия препаратами тестостерона этим пациентам не рекомендуется до момента разрешения застойной сердечной недостаточности [40, 41] (УУР В, УДД 2).

6.19. При развитии гипергемоглобинемии с уровнем гемоглобина $>180$ г/л и/или гематокрита $>54 \%$ терапия препаратами тестостерона противопоказана и не рекомендуется [41, 42] (УУР А, УДД 2). 
Хирургическое лечение

Хирургическое лечение гипогонадизма не применяется.

\section{РЕАБИЛИТАЦИЯ}

6.20. Специальных методов реабилитации не требуется. Эффективность лечения обуславливает консервативная терапия [31, 32] (УУР А, УДД 1).

\section{ПРОФИЛАКТИКА И ДИСПАНСЕРНОЕ НАБЛЮДЕНИЕ.}

6.21. Рекомендуется проводить мониторинг динамики клинических проявлений дефицита тестостерона и маркеров безопасности лечения через 3-6 мес [22, 23, 43] (УУР С, УДД 4).

6.22. Пациентам, получающим препараты тестостерона, рекомендуется периодическое гематологическое обследование (до назначения лечения, затем через 3, 6 и 12 мес терапии, далее ежегодно) [43] (УУР C, УДД 4).

6.23. Рекомендуется проводить коррекцию терапии только при повторных значениях гематокрита $>54 \%$ и/или гемоглобина >180 г/л [44]. В случаях использования трансдермальной формы тестостерона рекомендуется снижение дозы препарата, в случаях использования инъекционных форм, рекомендуется либо их замена на трансдермальную форму, либо отмена с дальнейшей оценкой уровней гемоглобина и гематокрита через 3 мес [44, 45] (УУР С, УДД 5).

6.24. Состояние предстательной железы рекомендуется оценивать путем пальцевого или ультразвукового исследования простаты и по показателю простатспецифического антигена (ПСА) (у мужчин старше 35 лет) до начала лечения тестостероном [36, 37]. Контроль уровня ПСА рекомендуется выполнять спустя 3, 6 и 12 мес, а в последующем - ежегодно(УУР А, УДД 2).

6.25. Во время лечения применять дополнительные методы исследования предстательной железы (биопсия) рекомендуется при выявлении новых пальпируемых образований в простате при пальцевом ректальном исследовании или при вызывающем беспокойство повышении уровня ПСА, при отрицательных результатах биопсии простаты может проводиться терапия тестостероном. При выявлении рака простаты андрогенная терапия должна быть отменена [46-48] (УУР В, УДД 3).

6.26. Рекомендуется осмотр грудных желез спустя 3, 6 и 12 мес, а в последующем - ежегодно. При подозрении или выявлении рака грудных желез рекомендуется отменить андрогенную терапию [35, 38] (УУР А, УДД 2).

\section{БЛАГОПРИЯТНЫЕ ЭФФЕКТЫ ЛЕЧЕНИЯ ГИПОГОНАДИЗМА В ОТНОШЕНИИ МЕТАБОЛИЗМА}

6.27. При устранении гипогонадизма у мужчин отмечается благоприятное влияние нормализации уровня тестостерона на композиционный состав тела, углеводный и липидный обмены [49-56] (УУР А, УДД 2).

Комментарии. Устранение гипогонадизма у мужчин приводит к уменьшению жировой массы и увеличению мышечной массы тела [43]. Установлено снижение содержания висцерального жира, что сопровождалось уменьшением ОТ [49]. Имеются также доказательства, что долгосрочная терапия препаратами тестостерона может приводить к значительному и устойчивому снижению массы тела, ОТ и ИМТ у тучных мужчин с гипогонадизмом [50-51]. Метаанализ показал достоверное уменьшение массы жировой ткани у пациентов с СД2 на фоне коррекции дефицита тестостерона [52]. Терапия гипогонадизма также оказывала благоприятное влияние на углеводный и липидный спектры крови, ИР и висцеральное ожирение, нарушение толерантности к глюкозе и дислипидемию [53-55]. Установлено, что восстановление тестостерона до физиологических уровней приводит к улучшению соматических и метаболических показателей у пожилых мужчин с ожирением, возрастным гипогонадизмом и НГН [56].

\section{СПИСОК ЛИТЕРАТУРЫ | REFERENCES}

WHO. Obesity and overweight. Available from: https://www.who.int/ ru/news-room/fact-sheets/detail/obesity-and-overweight

2. Sturm R. Increases in Clinically Severe Obesity

in the United States, 1986-2000. Arch Intern Med. 2003;163(18):2146. doi: https://doi.org/10.1001/archinte.163.18.2146

3. Kontsevaya A, Shalnova S, Deev A, et al. Overweight and Obesity in the Russian Population: Prevalence in Adults and Association with Socioeconomic Parameters and Cardiovascular Risk Factors. Obes Facts. 2019;12(1):103-114. doi: https://doi.org/10.1159/000493885

4. Бутрова СА. От эпидемии ожирения к эпидемии сахарного диабета // Международный эндокринологический журнал. 2013. — T.50. — №2. - C.45-50. [Butrova SA. Ot epidemii ozhireniya k epidemii sakharnogo diabeta. Mezhdunarodnyi endokrinologicheskii zhurnal. 2013;(50)2:45-50. (In Russ.)].
5. Калинченко СЮ, Тюзиков ИА, Ворслов ЛО. Ожирение, инсулинорезистентность и репродуктивное здоровье мужчины: патогенетические взаимодействия и современная патогенетическая фармакология // Эффективная фармакотерапия. - 2015. — №27. - C.66-79. [Kalinchenko SYu, Tyuzikov IA, Vorslov LO. Ozhirenie, insulinorezistentnost' i reproduktivnoe zdorov'e muzhchiny: patogeneticheskie vzaimodeistviya i sovremennaya patogeneticheskaya farmakologiya. Effektivnaya farmakoterapiya. 2015;27:66-79. (In Russ.)].

6. Аметов АС, Демидова ТЮ, Кочергина ИИ. Эффективность препаратов метформина в лечении сахарного диабета 2 типа // Медицинский совет. — 2016. — №3. - C.30-36. [Ametov AS, Demidova TYu, Kochergina II. Effektivnost' preparatov metformina v lechenii sakharnogo diabeta 2 tipa. Meditsinskii sovet. 2016;3:30-36. (In Russ.)]. 
7. Коган МИ, Воробьев СВ, Хрипун ИА, и др. Тестостерон: от сексуальности к метаболическому контролю. М.: Феникс; 2017 [Kogan MI, Vorob'ev SV, Khripun IA, et al. Testosteron: ot seksual'nosti k metabolicheskomu kontrolyu. M.: Feniks; 2017. (In Russ.)].

8. Wu F-Z, Wu CC, Kuo P-L, Wu M-T. Differential impacts of cardiac and abdominal ectopic fat deposits on cardiometabolic risk stratification. BMC Cardiovasc Disord. 2016;16(1):20. doi: https://doi.org/10.1186/s12872-016-0195-5

9. Pandolfi JB, Ferraro AA, Sananez I, et al. ATP-Induced Inflammation Drives Tissue-Resident Th17 Cells in Metabolically Unhealthy Obesity. J Immunol. 2016;196(8):3287-3296. doi: https://doi.org/10.4049/jimmunol.1502506

10. Eckel RH, Jakicic JM, Ard JD, et al. Gonadal Steroids and Body Composition, Strength, and Sexual Function in Men. N Engl J Med. 2013;369(25):2455-2457. doi: https://doi.org/10.1056/NEJMc1313169

11. Corona G, Mannucci E, Ricca V, et al. The age-related decline of testosterone is associated with different specific symptoms and signs in patients with sexual dysfunction. Int J Androl. 2009;32(6):720-728. doi: https://doi.org/10.1111/j.1365-2605.2009.00952.x

12. Svartberg J, von Mühlen D, Sundsfiord J, Jorde R. Waist Circumference and Testosterone Levels in Community Dwelling Men. The Tromsø Study. Eur J Epidemiol. 2003;19(7):657-663. doi: https://doi.org/10.1023/B:EJEP.0000036809.30558.8f

13. Роживанов Р.В. Синдром гипогонадизма у мужчин // Ожирение и метаболизм. - 2014. - T.11. №2. - C.30-34. [Rozhivanov RV. Syndrome of hypogonadism in males. Obesity and metabolism. 2014;11(2):30-34. (In Russ.)] doi: https://doi.org/10.14341/omet2014230-34

14. Роживанов Р.В. Шурдумова Б.О., Парфенова Н.С., Савельева Л.В. Комплексный подход к лечению ожиренияи метаболического синдрома у мужчин Синдром гипогонадизма у мужчин // Ожирение и метаболизм. - 2009. - Т.6. - №4. - C.38-41. [Rozhivanov RV, Shurdumova BO, Parfenova NS, Savel'eva LV. Kompleksnyy podkhod k lecheniyu ozhireniyai metabolicheskogo sindroma u muzhchin. Obesity and metabolism. 2009;6(4):38-41. (In Russ.)] doi: https://doi.org/10.14341/2071-8713-4877

15. Роживанов РВ. Эндокринные нарушения половой функции у мужчин. В кн. Рациональная фармакотерапия заболеваний эндокринной системы и нарушений обмена веществ. Под ред. академика РАН и РАМН Дедова И.И., академика РАМН Мельниченко Г.А. Второе издание, исправленное и дополненное. Москва; 2013: 754-775. [Rozhivanov RV. Endokrinnye narusheniya polovoi funktsii u muzhchin. In: Ratsional'naya farmakoterapiya zabolevanii endokrinnoi sistemy i narushenii obmena veshchestv. Dedov II, Mel'nichenko G.A., editors. Vtoroe izdanie, ispravlennoe i dopolnennoe. Moscow; 2013: 754-775. (In Russ.)]

16. Corona G, Giagulli VA, Maseroli E, et al. Testosterone supplementation and body composition: results from a meta-analysis of observational studies. J Endocrinol Invest. 2016;39(9):967-981. doi: https://doi.org/10.1007/s40618-016-0480-2

17. Cameron $\mathrm{J}$, Jain $\mathrm{R}$, Rais $\mathrm{M}$, et al. Perpetuating effects of androgen deficiency on insulin resistance. Int J Obes. 2016;40(12):1856-1863. doi: https://doi.org/10.1038/ijo.2016.148

18. Василькова ОН, Мохорт ТВ, Рожко АВ. Возрастной андрогенный дефицит, метаболический синдром и сахарный диабет 2-го типа: есть ли взаимосвязь? // Медицинские новости. - 2008. №3. - C.14-17 [Vasil'kova ON, Mokhort TV, Rozhko AV. Vozrastnoi androgennyi defitsit, metabolicheskii sindrom i sakharnyi diabet 2-go tipa: est'li vzaimosvyaz'? Meditsinskie novosti. 2008;3:14-17. (In Russ.)]

19. Дзантиева ЕО, Гусова ЗР, Хрипун ИА, Воробьев СВ. Особенности патогенетического влияния андрогенного дефицита на формирование нарушений углеводного обмена у мужчин с ожирением // Эндокринология: Новости. Мнения. Обучение. 2017. - T.4. — №21. — C.84-98. [Dzantieva EO, Gusova ZR, Khripun IA, Vorob'ev SV. Osobennosti patogeneticheskogo vliyaniya androgennogo defitsita na formirovanie narushenii uglevodnogo obmena u muzhchin s ozhireniem. Endokrinologiya: Novosti. Mneniya. Obuchenie. 2017;4(21):84-94. (In Russ.)]

20. Мамедов МН. Эректильная дисфункция, андрогендефицитное состояние и сердечно-сосудистые заболевания: комплексный подход к проблемам мужского здоровья. Научно-методическое пособие. Москва. Мед. книга; 2008. [Mamedov MN. Erektil'naya disfunktsiya, androgendefitsitnoe sostoyanie i serdechno-sosudistye zabolevaniya: kompleksnyi podkhod k problemam muzhskogo zdorov'ya. Nauchno-metodicheskoe posobie. Moscow: Med. kniga; 2008. (In Russ.)]

21. Zhang W-J, Chen L-L, Zheng J, et al. Association of adult weight gain and nonalcoholic fatty liver in a cross-sectional study in Wan Song Community, China. Brazilian J Med Biol Res. 2014;47(2):151-156. doi: https://doi.org/10.1590/1414-431X20133058

22. Wu FCW, Tajar A, Beynon JM, et al. Identification of Late-Onset Hypogonadism in Middle-Aged and Elderly Men. N Engl J Med. 2010;363(2):123-135. doi: https://doi.org/10.1056/NEJMoa0911101

23. Tajar A, Huhtaniemi IT, O'Neill TW, et al. Characteristics of Androgen Deficiency in Late-Onset Hypogonadism: Results from the European Male Aging Study (EMAS) J Clin Endocrinol Metab. 2012;97(5):1508-1516 doi: https://doi.org/10.1210/jc.2011-2513

24. Rey RA, Grinspon RP. Normal male sexual differentiation and aetiology of disorders of sex development. Best Pract Res Clin Endocrinol Metab. 2011;25(2):221-238. doi: https://doi.org/10.1016/j.beem.2010.08.013

25. Isidori AM, Lenzi A. Risk factors for androgen decline in older males: lifestyle, chronic diseases and drugs. J Endocrinol Invest. 2005;28(3 Suppl):14-22.

26. Bhasin S, Pencina M, Jasuja GK, et al. Reference Ranges for Testosterone in Men Generated Using Liquid Chromatography Tandem Mass Spectrometry in a Community-Based Sample of Healthy Nonobese Young Men in the Framingham Heart Study and Applied to Three Geographically Distinct Cohorts. J Clin Endocrinol Metab. 2011;96(8):2430-2439. doi: https://doi.org/10.1210/jc.2010-3012

27. Vesper HW, Bhasin S, Wang C, et al. Interlaboratory comparison study of serum total testoserone measurements performed by mass spectrometry methods. Steroids. 2009;74(6):498-503. doi: https://doi.org/10.1016/j.steroids.2009.01.004

28. Роживанов Р.В., Курбатов Д.Г., Кравцова Н.С. Дифференциальнодиагностическое, прогностическое и терапевтическое значение пробы с кломифеном у мужчин с гипогонадизмом // Проблемы Эндокринологии. — 2016. - Т.62. — №1. C.35-37. [Rozhivanov R.V., Kurbatov D.G., Kravtsova N.S. Differential and diagnostic, predictive and therapeutic value of test with clomifene in men with a Hypogonadizm. Problems of Endocrinology. 2016;62(1):35-37. (In Russ.)] doi: https://doi.org/10.14341/probl201662135-37

29. Роживанов РВ. Эффективная терапия и ошибки в лечении эндокринных нарушений в андрологии. В Кн. Эндокринология. Фармакотерапия без ошибок. Под ред. академика РАН и РАМН Дедова И.И., академика РАМН Мельниченко Г. А. Москва; 2013: 615-625. [Rozhivanov RV. Effektivnaya terapiya i oshibki v lechenii endokrinnykh narushenii v andrologii. In: Endokrinologiya. Farmakoterapiya bez oshibok. Dedov II, Mel'nichenko GA, editors. Moscow; 2013: 615-625. (In Russ.)]

30. Kim ED, McCullough A, Kaminetsky J. Oral enclomiphene citrate raises testosterone and preserves sperm counts in obese hypogonadal men, unlike topical testosterone: restoration instead of replacement. BJU Int. 2016;117(4):677-685. doi: https://doi.org/10.1111/bju.13337

31. Tracz MJ, Sideras K, Boloña ER, et al. Testosterone Use in Men and Its Effects on Bone Health. A Systematic Review and Meta-Analysis of Randomized Placebo-Controlled Trials. J Clin Endocrinol Metab. 2006;91(6):2011-2016. doi: https://doi.org/10.1210/jc.2006-0036

32. Isidori AM, Giannetta E, Greco EA, et al. Effects of testosterone on body composition, bone metabolism and serum lipid profile in middle-aged men: a meta-analysis. Clin Endocrinol (Oxf). 2005;63(3):280-293. doi: https://doi.org/10.1111/j.1365-2265.2005.02339.x

33. Moon DG, Park MG, Lee SW, et al. The Efficacy and Safety of Testosterone Undecanoate $\left(\right.$ Nebido $\left.^{\circledR}\right)$ in Testosterone Deficiency Syndrome in Korean: A Multicenter Prospective Study. J Sex Med. 2010;7(6):2253-2260. doi: https://doi.org/10.1111/j.1743-6109.2010.01765.x

34. Basaria S, Lakshman KM. Safety and efficacy of testosterone gel in the treatment of male hypogonadism. Clin Interv Aging. 2009;4:397-412.

35. Johansen Taber. Male breast cancer: Risk factors, diagnosis, and management (Review). Oncol Rep. 2010;24(5):1115-1120. doi: https://doi.org/10.3892/or_00000962 
36. Shabsigh R, Crawford ED, Nehra A, Slawin KM. Testosterone therapy in hypogonadal men and potential prostate cancer risk: a systematic review. Int J Impot Res. 2009;21 (1):9-23. doi: https://doi.org/10.1038/ijir.2008.31

37. Marks LS, Mazer NA, Mostaghel E, et al. Effect of Testosterone Replacement Therapy on Prostate Tissue in Men With Late-Onset Hypogonadism. JAMA. 2006;296(19):2351. doi: https://doi.org/10.1001/jama.296.19.2351

38. Medras M, Alicja F, Pawel J, et al. Breast cancer and long-term hormonal treatment of male hypogonadism. Breast Cancer Res Treat. 2006;96(3):263-265. doi: https://doi.org/10.1007/s10549-005-9074-y

39. Fernández-Balsells MM, Murad MH, Lane M, et al. Adverse Effects of Testosterone Therapy in Adult Men: A Systematic Review and Meta-Analysis. J Clin Endocrinol Metab. 2010;95(6):2560-2575. doi: https://doi.org/10.1210/jc.2009-2575

40. Corona G, Maseroli E, Rastrelli G, et al. Cardiovascular risk associated with testosterone-boosting medications: a systematic review and meta-analysis. Expert Opin Drug Saf. 2014;13(10):1327-1351. doi: https://doi.org/10.1517/14740338.2014.950653

41. Calof OM, Singh AB, Lee ML, et al. Adverse Events Associated With Testosterone Replacement in Middle-Aged and Older Men: A Meta-Analysis of Randomized, Placebo-Controlled Trials. Journals Gerontol Ser A Biol Sci Med Sci. 2005;60(11):1451-1457. doi: https://doi.org/10.1093/gerona/60.11.1451

42. Basaria S, Coviello AD, Travison TG, et al. Adverse Events Associated with Testosterone Administration. N Engl J Med. 2010;363(2):109-122. doi: https://doi.org/10.1056/NEJMoa1000485

43. Saad F, Aversa A, Isidori AM, et al. Zafalon L, Zitzmann M, Gooren L. Onset of effects of testosterone treatment and time span until maximum effects are achieved. Eur J Endocrinol. 2011;165(5):675-685. doi: https://doi.org/10.1530/EJE-11-0221

44. McMullin MF, Bareford D, Campbell P, et al. Guidelines for the diagnosis, investigation and management of polycythaemia/ erythrocytosis. Br J Haematol. 2005;130(2):174-195. doi: https://doi.org/10.1111/j.1365-2141.2005.05535.x

45. Роживанов РВ, Курбатов ДГ. Гематологические и урологические аспекты безопасности заместительной андрогенной терапии препаратом тестостерона ундеканоата пролонгированного действия у пациентов с гипогонадизмом // Проблемы эндокринологии. - 2009. - Т.6. - №55. - С.31-35. [Rozhivanov R.V., Kurbatov D.G. Hematological and urological aspects of the safety of androgen substitution therapy using long-acting testosterone undecanoate in patients with hypogonadism. Problems of Endocrinology. 2009;55(6):31-35. (In Russ.)] doi: https://doi.org/10.14341/probl200955631-35
46. Morgentaler A, Morales A. Should Hypogonadal Men With Prostate Cancer Receive Testosterone? J Urol. 2010;184(4):1257-1260. doi: https://doi.org/10.1016/j.juro.2010.07.010

47. Kaufman JM, Graydon RJ. Androgen replacement after curative radical prostatectomy for prostate cancer in hypogonadal men. J Urol. 2004;172(3):920-922. doi: https://doi.org/10.1097/01.ju.0000136269.10161.32

48. Sarosdy MF. Testosterone replacement for hypogonadism after treatment of early prostate cancer with brachytherapy. Cancer. 2007;109(3):536-541. doi: https://doi.org/10.1002/cncr.22438

49. Haider A, Saad F, Doros G, Gooren L. Hypogonadal obese men with and without diabetes mellitus type 2 lose weight and show improvement in cardiovascular risk factors when treated with testosterone: An observational study. Obes Res Clin Pract. 2014;8(4):e339-e349. doi: https://doi.org/10.1016/j.orcp.2013.10.005

50. Saad F, Haider A, Doros G, Traish A. Long-term treatment of hypogonadal men with testosterone produces substantial and sustained weight loss. Obesity. 2013;21(10):1975-1981. doi: https://doi.org/10.1002/oby.20407

51. Yassin AA, Doros G. Testosterone therapy in hypogonadal men results in sustained and clinically meaningful weight loss. Clin Obes. 2013;3(3-4):73-83. doi: https://doi.org/10.1111/cob.12022

52. Corona $\mathrm{G}$, Monami $\mathrm{M}$, Rastrelli $\mathrm{G}$, et al. Type 2 diabetes mellitus and testosterone: a meta-analysis study. Int J Androl. 2011;34(6pt1):528-540. doi: https://doi.org/10.1111/j.1365-2605.2010.01117.x

53. Haider A, Yassin A, Doros G, Saad F. Effects of Long-Term Testosterone Therapy on Patients with "Diabesity": Results of Observational Studies of Pooled Analyses in Obese Hypogonadal Men with Type 2 Diabetes. Int J Endocrinol. 2014;2014:1-15. doi: https://doi.org/10.1155/2014/683515

54. Aversa A, Bruzziches R, Francomano D, et al. Effects of Testosterone Undecanoate on Cardiovascular Risk Factors and Atherosclerosis in Middle-Aged Men with Late-Onset Hypogonadism and Metabolic Syndrome: Results from a 24-month, Randomized, Double-Blind, Placebo-Controlled Study. J Sex Med. 2010;7(10):3495-3503. doi: https://doi.org/10.1111/j.1743-6109.2010.01931.x

55. Jones TH, Arver S, Behre HM, et al. Testosterone Replacement in Hypogonadal Men With Type 2 Diabetes and/or Metabolic Syndrome (the TIMES2 Study). Diabetes Care. 2011;34(4):828-837. doi: https://doi.org/10.2337/dc10-1233

56. Strollo F, Strollo G, Morè M, et al. Low-intermediate dose testosterone replacement therapy by different pharmaceutical preparations improves frailty score in elderly hypogonadal hyperglycaemic patients. Aging Male. 2013;16(2):33-37. doi: https://doi.org/10.3109/13685538.2013.773305 


\title{
ГЛАВА 7. ОЖИРЕНИЕ И АРТЕРИАЛЬНАЯ ГИПЕРТЕНЗИЯ
}

\author{
Недогода С.В., Остроумова О.Д., Стародубова А.В., Саласюк А.С.
}

Обнаружено, что при коррекции на возраст, образование, статус курения, потребление алкоголя и повышенную ЧСС, вероятность наличия АГ увеличивается с ростом частоты ожирения среди мужчин - от 5,5 до 12 раз, среди женщин - от 4,5 до 18 раз [1]. При этом АГ является наиболее частым фактором риска (ФР), встречающимся при ожирении, - отношение шансов (ОШ) ассоциации между ожирением и АГ среди лиц обоего пола - 2,71 и 2,52 у мужчин и женщин соответственно. Отмечено линейное увеличение с ростом массы тела распространенности АГ и средних значений систолического и диастолического АД (САД и ДАД) [2].

По данным Framingham study, прибавка в весе на 1 кг способствует повышению АД на 1 мм рт.ст. [3].

Избыточная масса тела и ожирение способствуют повышению АД, сочетание ожирения и АГ существенно увеличивает риск развития микро- и макрососудистых поражений, включая инсульт, ИБС, инфаркт миокарда (ИМ), ХСН, атеросклероз периферических артерий, и способствует увеличению сердечно-сосудистой смертности [4-6]. У лиц с ожирением уменьшение массы тела на 5-10\% от исходной приводит к достоверному снижению риска развития сердечно-сосудистых осложнений $[7,8]$.

7.1. Пациентам с ожирением в сочетании с АГ рекомендуется снижение потребления натрия (до <5 г/сут), соблюдение диеты, богатой овощами, фруктами и нежирными молочными продуктами, поскольку данные мероприятия доказанно улучшают контроль АД [9-11] (УУР А, УДД 1).

7.2. Пациентам с ожирением и АГ рекомендуется придерживаться принципов здорового питания с акцентом на потребление овощей, фруктов, бобовых, цельнозерновых продуктов и рыбы, для снижения риска сердечно-сосудистых заболеваний [12-25] (УУР А, УДД 1 (I, рандомизированные исследования)).

7.3. Пациентам с ожирением и АГ рекомендуется замена насыщенных жиров на моно- и полиненасыщенные жирные кислоты пищи, это может способствовать снижению риска сердечно-сосудистых заболеваний [12-27] (УУР В, УДД 3 (ІІа, нерандомизированные исследования)).

7.4. Пациентам с ожирением и АГ рекомендуется питание со сниженным содержанием холестерина и натрия, это может способствовать снижению риска сердечно-сосудистых заболеваний [20, 28-30] (УУР В, УДД 3 (ІІа, нерандомизированные исследования).

7.5. Пациентам с ожирением и АГ рекомендуется соблюдать принципы здорового питания и снизить потребление переработанного красного мяса, рафинированных углеводов и сладких напитков, это может способствовать снижению риска сердечно-сосудистых заболеваний [31-38] (УУР В, УДД 3 (ІІа, нерандомизированные исследования)).

7.6. Пациентам с ожирением и АГ рекомендуется соблюдать принципы здорового питания и отказаться или максимально снизить потребление транс-изомеров жирных кислот, для снижения риска сердечнососудистых заболеваний [12-23, 28, 39-41] (УУР В, УДД 3 (ІІа, нерандомизированные исследования)).

7.7. Пациентам с ожирением в сочетании с АГ рекомендуется соблюдение режима физической активности, включающей сочетание преимущественно аэробных тренировок, дополненных тренировками с динамическим сопротивлением, поскольку в результате длительного следования данному режиму тренировок наблюдается умеренное, но значительное снижение САД (на -7 мм рт. ст.) и ДАД (на -5 мм рт. ст.) АД [42] (УУР С, УДД 5).

Пациентам с морбидным ожирением в сочетании с АГ и отсутствием противопоказаний к оперативному вмешательству рекомендуется проведение бариатрической операции в связи с выраженным положительным воздействием потери массы тела на уровень АД [43-46].

Комментарии. В исследовании Look AHEAD у пациентов со снижением массы тела от 5 до $10 \%$ наблюдалось снижение САД и ДАД на 5 мм рт. ст [43]. Снижение относительного риска конверсии высоко нормального АД в АГ у пациентов с морбидным ожирением после бариатрической операции составило 48\% [43-46].

7.8. Пациентам с ожирением в сочетании с АГ рекомендуется начинать антигипертензивную терапию при значениях АД, измеренного в медицинском учреждении, $\geq 140 / 90$ мм рт. ст. [47-50] (УУР А, УДД 1).

7.9. Пациентам с ожирением в сочетании с АГ, получающим антигипертензивные препараты, в связи с доказанными преимуществами в снижении сердечно-сосудистого риска рекомендуется:

В качестве целевого уровня снижать САД у пациентов моложе 65 лет и без ХБП до значений 130 мм рт. ст. и ниже при хорошей переносимости, но не ниже 120 мм рт. ст. [47-50] (УУР А, УДД 1);

у пожилых пациентов ( $\geq 65$ лет) с СД целевой уровень САД составляет 130-139 мм рт. ст., но не ниже 130 мм рт.ст. [47-51] (УУР А, УДД 1);

У пациентов с диабетической и недиабетической ХБП рекомендуется снижать САД до значений 130-139 мм рт. ст., но не ниже 130 мм рт.ст. [52-54] (УУР А, УДД 1);

целевой уровень ДАД у всех пациентов с ожирением и АГ составляет <80 мм рт. ст., но не ниже 70 мм рт. ст. [55] (УУР А, УДД 3). 
7.10. Пациентам с ожирением в сочетании с АГ рекомендуется начинать лечение с комбинации блокатора PAAC с АК или тиазидным/тиазидоподобным диуретиком в связи с наилучшим влиянием этих комбинаций на частоту достижения целевого АД и снижение СС риска, а также органопротективным потенциалом блокаторов РААС [56-59] (УУР А, УДД 1).

Комментарии. Двойная антигипертензивная терапия рекомендуется в качестве первой линии лечения. Комбинация ингибитора ангиотензинпревращающего фермента (ИАПФ) и блокатора рецепторов ангиотензина (БРА) не рекомендуется. Пациентам с ожирением и АГ на комбинированной антигипертензивной терапии следует рекомендовать самостоятельно контролировать АД.

При выборе антигипертензивных препаратов у пациентов с ожирением необходимо учитывать их влияние на вес пациентов при длительном лечении. С этих позиций блокаторы РААС являются наиболее предпочтительными. Бета-блокаторы (за исключением небиволола) обладают антилипазным эффектом и уменьшают термогенез, что приводит к увеличению веса.

Так как при ожирении существенно повышен риск предиабета и СД, предпочтительными являются блокаторы РААС и антагонисты кальция, поскольку они не ухудшают и даже могут улучшать чувствительность к инсулину [60]. У пациентов с ожирением, АГ и предиабетом риск развития СД2 ниже при использовании блокаторов РААС, чем при использовании бета-блокаторов или диуретиков. Блокаторы РААС положительно влияют на ИР, иммунное воспаление, протромбогенный статус и фиброз [61]. Имеются данные о том, что липофильные ИАПФ (периндоприл, рамиприл) у пациентов с ожирением демонстрируют более выраженный противовоспалительный и органопротективный эффекты, но при этом не замедляют деградацию брадикинина. Отличительной чертой БРА (антагонистов рецепторов ангиотензина II, сартанов) является наилучший среди всех антигипертензивных препаратов профиль переносимости и самый высокий уровень приверженности пациентов к лечению при их применении: Выраженное снижение риска развития СД2 типа при терапии сартанами установлено в многочисленных исследованиях (LIFE [62], VALUE [63], CHARM [64], NAVIGATOR [65]). Метаанализ указывает на то, что благодаря взаимодействию с PPARү-рецепторами телмисартан в наибольшей степени уменьшает ИР и воспаление, микроальбуминурию (МАУ) и протеинурию, замедляет прогрессирование сердечной и почечной недостаточности [66]. Для лозартана доказана возможность снижения уровня мочевой кислоты [67].

Бета-блокаторы (кроме небиволола и карведилола) и ГХТЗ следует считать лишь дополнительными препаратами и назначать их преимущественно в малых дозах.

При назначении диуретиков для лечения АГ у больных с ожирением предпочтение отдается метаболически более нейтральным диуретикам - индапамиду и хлорталидону. Особенностью индапамида является то, что он обладает двойным действием - устраняет избыточное содержание натрия в сосудистой стенке и незначительно увеличивает диурез на фоне вазодилатирующего эффекта, обусловленного блокадой каналов кальциевого тока и влиянием на синтез простагландинов. Российское исследование МИНОТАВР продемонстрировало, что индапамид-ретард эффективно снижает АД, не вызывая гипокалиемии, и оказывает положительное влияние на углеводный, липидный и пуриновый обмены у пациентов с избыточной массой тела [68]. При использовании диуретиков необходимо исключить появление гипокалиемии, поскольку она ухудшает толерантность к глюкозе [69].

Агонисты имидазолиновых рецепторов представляют собой отдельный подкласс препаратов центрального действия, они могут быть использованы в комбинации на любом этапе лечения АГ, особенно у пациентов с ожирением, метаболическим синдромом и гиперсимпатикотонией. Целесообразно добавление этой группы препаратов больным с ожирением при резистентной АГ. Несмотря на отсутствие этой группы препаратов в рекомендациях ESC 2018 г., нет никаких оснований к отмене такой терапии при условии их хорошей эффективности и безопасности.

Моксонидин является агонистом І2-имидазолиновых рецепторов вентролатерального отдела продолговатого мозга, что обуславливает снижение активности симпатической нервной системы (СНС) и АД. Высокая гипотензивная эффективность моксонидина в виде монотерапии и в составе комбинированной антигипертензивной терапии у больных АГ с избыточным весом/ожирением была продемонстрирована в исследованиях CAMUS и MERSY [70, 71]. При этом отмечалось статистически значимое снижение ИМТ пациентов на 1 кг/м², улучшение показателей углеводного и липидного обмена, уменьшение инсулино- и лептинорезистентности. В исследовании АЛМАЗ [72] моксонидин при сравнении с метформином у пациентов с избыточной массой тела оказался более эффективным в достижении контроля АД, уменьшении ИР при сопоставимом положительном влиянии на вес и показатели липидного обмена.

7.11. Пациентам с ожирением в сочетании с АГ, которым назначена терапия сибутрамином, рекомендуется контролировать уровень АД и частоту пульса каждые 2 нед в первые 2 мес лечения и затем - 1 раз В месяц. У пациентов с АГ при уровне АД > 145/90 мм рт.ст. контроль должен осуществляться тщательнее и чаще, а в случае дважды зарегистрированного подъема АД > 145/90 мм рт.ст. лечение следует прекратить [73] (УУР С, УДД 5).

Комментарии. Анализ данных о лекарственных взаимодействиях препаратов для лечения АГ и лираглутида/ орлистата $[74,75]$ не показал наличия клинически значимых лекарственных взаимодействий, требующих коррекции дозы вышеперечисленных препаратов. Лекарственное взаимодействие при одновременном применении сибутрамина с препаратами, повышающими АД и ЧСС, в настоящее время недостаточно полно изучено. Эта группа препаратов включает деконгестанты, противокашлевые, противопростудные и противоаллергические препараты, в состав которых входят эфедрин или псевдоэфедрин. Поэтому в случаях одновременного приема этих препаратов с сибутрамином следует соблюдать осторожность [73]. 


\section{СПИСОК ЛИТЕРАТУРЫ | REFERENCES}

1. Шальнова С.А., Деев А.Д., Баланова Ю.А., и др. Двадцатилетние тренды ожирения и артериальной гипертонии и их ассоциации в России // Кардиоваскулярная терапия и профилактика. 2017. - T.16. - №4. - C.4-10. [Shalnova SA, Deev AD, Balanova YuA, и дp. Twenty years trends of obesity and arterial hypertension and their association in Russia. Cardiovascular Therapy and Prevention. 2017;16(4):4-10. (In Russ.)] doi: https://doi.org/10.15829/1728-8800-2017-4-4-10

2. Баланова Ю.А., Шальнова С.А., Деев А.Д., и др. Ожирение в Российской популяции - распространенность и ассоциации с факторами риска хронических неинфекционных заболеваний. Российский кардиологический журнал. 2018. — №6. - C.123-130. [Balanova YA, Shalnova SA Deev AD, et al. Obesity in russian population — prevalence and association with the non-communicable diseases risk factors. Russian Journal of Cardiology. 2018;(6):123-130. (In Russ.)] doi: https://doi.org/10.15829/1560-4071-2018-6-123-130

3. Kannel WB. The Relation of Adiposity to Blood Pressure and Development of Hypertension. Ann Intern Med. 1967;67(1):48. doi: https://doi.org/10.7326/0003-4819-67-1-48

4. Guh DP, Zhang W, Bansback N, Amarsi Z, Birmingham CL, Anis AH The incidence of co-morbidities related to obesity and overweight: A systematic review and meta-analysis. BMC Public Health 2009;9(1):88. doi: https://doi.org/10.1186/1471-2458-9-88

5. Bogers RP. Association of Overweight With Increased Risk of Coronary Heart Disease Partly Independent of Blood Pressure and Cholesterol Levels: A Meta-analysis of 21 Cohort Studies Including More Than 300000 Persons. Arch Intern Med. 2007;167(16):1720. doi: https://doi.org/10.1001/archinte.167.16.1720

6. Fan J, Song Y, Chen Y, Hui R, Zhang W. Combined effect of obesity and cardio-metabolic abnormality on the risk of cardiovascular disease: A meta-analysis of prospective cohort studies. Int J Cardiol. 2013;168(5):4761-4768. doi: https://doi.org/10.1016/j.ijcard.2013.07.230

7. Wing RR, Lang W, Wadden TA, et al. Benefits of Modest Weight Loss in Improving Cardiovascular Risk Factors in Overweight and Obese Individuals With Type 2 Diabetes. Diabetes Care. 2011;34(7):1481-1486. doi: https://doi.org/10.2337/dc10-2415

8. Harrington M, Gibson S, Cottrell RC. A review and meta-analysis of the effect of weight loss on all-cause mortality risk. Nutr Res Rev. 2009;22(1):93-108. doi: https://doi.org/10.1017/S0954422409990035

9. Saneei P, Salehi-Abargouei A, Esmaillzadeh A, Azadbakht L. Influence of Dietary Approaches to Stop Hypertension (DASH) diet on blood pressure: A systematic review and meta-analysis on randomized controlled trials. Nutr Metab Cardiovasc Dis. 2014;24(12):1253-1261. doi: https://doi.org/10.1016/j.numecd.2014.06.008

10. He FJ, Li J, MacGregor GA. Effect of longer term modest salt reduction on blood pressure: Cochrane systematic review and metaanalysis of randomised trials. BMJ. 2013;346(apr03 3):f1325-f1325. doi: https://doi.org/10.1136/bmj.f1325

11. Neter JE, Stam BE, Kok FJ, et al. Influence of Weight Reduction on Blood Pressure. Hypertension. 2003:42(5):878-884. doi: https://doi.org/10.1161/01.HYP.0000094221.86888.AE

12. Estruch R, Ros E, Salas-Salvadó J, et al. Primary Prevention of Cardiovascular Disease with a Mediterranean Diet Supplemented with Extra-Virgin Olive Oil or Nuts. N Engl J Med. 2018. doi: https://doi.org/10.1056/nejmoa1800389

13. Kim H, Caulfield LE, Rebholz CM. Healthy Plant-Based Diets Are Associated with Lower Risk of All-Cause Mortality in US Adults. J Nutr. 2018;148(4):624-631. doi: https://doi.org/10.1093/jn/nxy019

14. Satija A, Bhupathiraju SN, Spiegelman D, et al. Healthful and Unhealthful Plant-Based Diets and the Risk of Coronary Heart Disease in U.S. Adults. J Am Coll Cardiol. 2017;70(4):411-422. doi: https://doi.org/10.1016/j.jacc.2017.05.047

15. Sotos-Prieto M, Bhupathiraju SN, Mattei J, et al. Association of Changes in Diet Quality with Total and CauseSpecific Mortality. N Engl J Med. 2017;377(2):143-153. doi: https://doi.org/10.1056/NEJMoa1613502

16. Whalen KA, Judd S, McCullough ML, Flanders WD, Hartman TJ, Bostick RM. Paleolithic and Mediterranean Diet Pattern Scores Are Inversely Associated with All-Cause and CauseSpecific Mortality in Adults. J Nutr. 2017;147(4):612-620. doi: https://doi.org/10.3945/jn.116.241919
17. Bao Y, Han J, Hu FB, et al. Association of Nut Consumption with Total and Cause-Specific Mortality. N Eng/ J Med. 2013;369(21):2001-2011. doi: https://doi.org/10.1056/NEJMoa1307352

18. Bernstein AM, Sun Q, Hu FB, et al. Major Dietary Protein Sources and Risk of Coronary Heart Disease in Women. Circulation. 2010;122(9):876-883. doi: https://doi.org/10.1161/CIRCULATIONAHA.109.915165

19. Song M, Fung TT, Hu FB, et al. Association of Animal and Plant Protein Intake With All-Cause and Cause-Specific Mortality. JAMA Intern Med. 2016;176(10):1453. doi: https://doi.org/10.1001/jamainternmed.2016.4182

20. Tharrey M, Mariotti F, Mashchak A, et al. Patterns of plant and animal protein intake are strongly associated with cardiovascular mortality: the Adventist Health Study-2 cohort. Int J Epidemiol. 2018;47(5):1603-1612. doi: https://doi.org/10.1093/ije/dyy030

21. Martínez-González MA, Sánchez-Tainta A, Corella D, et al. A provegetarian food pattern and reduction in total mortality in the Prevención con Dieta Mediterránea (PREDIMED) study. Am J Clin Nutr. 2014;100(suppl_1):320S-328S. doi: https://doi.org/10.3945/ajcn.113.071431

22. Reedy J, Krebs-Smith SM, Miller PE, et al. Higher Diet Quality Is Associated with Decreased Risk of All-Cause, Cardiovascular Disease, and Cancer Mortality among Older Adults. J Nutr. 2014;144(6):881-889. doi: https://doi.org/10.3945/jn.113.189407

23. Dickinson $\mathrm{HO}$, Mason JM, Nicolson DJ, et al. Lifestyle interventions to reduce raised blood pressure: a systematic review of randomized controlled trials. J Hypertens. 2006;24(2):215-233. doi: https://doi.org/10.1097/01.hjh.0000199800.72563.26

24. Mente A, de Koning L, Shannon HS, Anand SS. A Systematic Review of the Evidence Supporting a Causal Link Between Dietary Factors and Coronary Heart Disease. Arch Intern Med. 2009;169(7):659. doi: https://doi.org/10.1001/archinternmed.2009.38

25. Sofi F, Abbate R, Gensini GF, Casini A. Accruing evidence on benefits of adherence to the Mediterranean diet on health: an updated systematic review and meta-analysis. Am J Clin Nutr. 2010;92(5):1189-1196. doi: https://doi.org/10.3945/ajcn.2010.29673

26. Wang DD, Li Y, Chiuve SE, et al. Association of Specific Dietary Fats With Total and Cause-Specific Mortality. JAMA Intern Med. 2016;176(8):1134. doi: https://doi.org/10.1001/jamainternmed.2016.2417

27. Dehghan M, Mente A, Zhang X, et al. Associations of fats and carbohydrate intake with cardiovascular disease and mortality in 18 countries from five continents (PURE): a prospective cohort study. Lancet. 2017;390(10107):2050-2062. doi: https://doi.org/10.1016/S0140-6736(17)32252-3

28. Cook NR, Cutler JA, Obarzanek E, et al. Long term effects of dietary sodium reduction on cardiovascular disease outcomes: observational follow-up of the trials of hypertension prevention (TOHP). BMJ. 2007:334(7599):885. doi: https://doi.org/10.1136/bmj.39147.604896.55

29. Micha R, Peñalvo JL, Cudhea F, et al. Association Between Dietary Factors and Mortality From Heart Disease, Stroke, and Type 2 Diabetes in the United States. JAMA. 2017;317(9):912. doi: https://doi.org/10.1001/jama.2017.0947

30. Yang Q, Zhang Z, Gregg EW, et al. Added Sugar Intake and Cardiovascular Diseases Mortality Among US Adults. JAMA Intern Med. 2014;174(4):516. doi: https://doi.org/10.1001/jamainternmed.2013.13563

31. Kiage JN, Merrill PD, Robinson CJ, et al. Intake of trans fat and all-cause mortality in the Reasons for Geographical and Racial Differences in Stroke (REGARDS) cohort. Am J Clin Nutr. 2013;97(5):1121-1128. doi: https://doi.org/10.3945/ajcn.112.049064

32. Löfvenborg JE, Andersson T, Carlsson P-O, et al. Sweetened beverage intake and risk of latent autoimmune diabetes in adults (LADA) and type 2 diabetes. Eur J Endocrinol. 2016;175(6):605-614. doi: https://doi.org/10.1530/EJE-16-0376

33. Sacks FM, Svetkey LP, Vollmer WM, et al. Effects on Blood Pressure of Reduced Dietary Sodium and the Dietary Approaches to Stop Hypertension (DASH) Diet. N Eng/ J Med. 2001;344(1):3-10. doi: https://doi.org/10.1056/NEJM200101043440101

34. Johnson RK, Lichtenstein AH, Anderson CAM, et al. Low-Calorie Sweetened Beverages and Cardiometabolic Health: A Science Advisory From the American Heart Association. Circulation. 2018;138(9). doi: https://doi.org/10.1161/CIR.0000000000000569 
35. Shikany JM, Safford MM, Newby PK, et al. Southern Dietary Pattern Is Associated With Hazard of Acute Coronary Heart Disease in the Reasons for Geographic and Racial Differences in Stroke (REGARDS) Study. Circulation. 2015;132(9):804-814. doi: https://doi.org/10.1161/CIRCULATIONAHA.114.014421

36. Seidelmann SB, Claggett B, Cheng S, et al. Dietary carbohydrate intake and mortality: a prospective cohort study and meta-analysis. Lancet Public Heal. 2018;3(9):e419-e428. doi: https://doi.org/10.1016/S2468-2667(18)30135-X

37. Trichopoulou A, Psaltopoulou T, Orfanos P, et al. Lowcarbohydrate-high-protein diet and long-term survival in a general population cohort. Eur J Clin Nutr. 2007;61 (5):575-581. doi: https://doi.org/10.1038/sj.ejcn.1602557

38. Noto H, Goto A, Tsujimoto T, Noda M. Low-Carbohydrate Diets and All-Cause Mortality: A Systematic Review and Meta-Analysis of Observational Studies. Manzoli L, ed. PLoS One. 2013;8(1):e55030. doi: https://doi.org/10.1371/journal.pone.0055030

39. Brandt EJ, Myerson R, Perraillon MC, Polonsky TS. Hospital Admissions for Myocardial Infarction and Stroke Before and After the TransFatty Acid Restrictions in New York. JAMA Cardiol. 2017;2(6):627. doi: https://doi.org/10.1001/jamacardio.2017.0491

40. Micha R, Mozaffarian D. Trans fatty acids: effects on metabolic syndrome, heart disease and diabetes. Nat Rev Endocrinol. 2009;5(6):335-344. doi: https://doi.org/10.1038/nrendo.2009.79

41. Mozaffarian D. Dietary and Policy Priorities for Cardiovascular Disease, Diabetes, and Obesity. Circulation. 2016;133(2):187-225. doi: https://doi.org/10.1161/CIRCULATIONAHA.115.018585

42. Hansen D, Niebauer J, Cornelissen V, et al. Exercise Prescription in Patients with Different Combinations of Cardiovascular Disease Risk Factors: A Consensus Statement from the EXPERT Working Group. Sport Med. 2018;48(8):1781-1797. doi: https://doi.org/10.1007/s40279-018-0930-4

43. Wing RR, Lang W, Wadden TA, et al. Benefits of Modest Weight Loss in Improving Cardiovascular Risk Factors in Overweight and Obese Individuals With Type 2 Diabetes. Diabetes Care. 2011;34(7):1481-1486. doi: https://doi.org/10.2337/dc10-2415

44. Ricci C, Gaeta M, Rausa E, et al. Long-Term Effects of Bariatric Surgery on Type II Diabetes, Hypertension and Hyperlipidemia: A MetaAnalysis and Meta-Regression Study with 5-Year Follow-Up. Obes Surg. 2015;25(3):397-405. doi: https://doi.org/10.1007/s11695-014-1442-4

45. Ricci C, Gaeta M, Rausa E, et al. Early Impact of Bariatric Surgery on Type II Diabetes, Hypertension, and Hyperlipidemia: A Systematic Review, Meta-Analysis and Meta-Regression on 6,587 Patients. Obes Surg. 2014;24(4):522-528. doi: https://doi.org/10.1007/s11695-013-1121-x

46. Buchwald $H$, Avidor $Y$, Braunwald E, et al. Bariatric Surgery. JAMA 2004;292(14):1724. doi: https://doi.org/10.1001/jama.292.14.1724

47. Böhm M, Schumacher $H$, Teo KK, et al. Achieved blood pressure and cardiovascular outcomes in high-risk patients: results from ONTARGET and TRANSCEND trials. Lancet. 2017;389(10085):2226-2237. doi: https://doi.org/10.1016/S0140-6736(17)30754-7

48. Kjeldsen SE, Berge E, Bangalore S, et al. No evidence for a J-shaped curve in treated hypertensive patients with increased cardiovascular risk: The VALUE trial. Blood Press. 2016;25(2):83-92. doi: https://doi.org/10.3109/08037051.2015.1106750

49. Mancia G, Kjeldsen SE, Zappe DH, et al. Cardiovascular outcomes at different on-treatment blood pressures in the hypertensive patients of the VALUE trial. Eur Heart J. 2016;37(12):955-964. doi: https://doi.org/10.1093/eurheartj/ehv633

50. SPRINT Research Group, et al. A Randomized Trial of Intensive versus Standard BloodPressure Control. N Engl J Med. 2015;373(22):2103-2116. doi: https://doi.org/10.1056/NEJMoa1511939

51. «Алгоритмы специализированной медицинской помощи больным сахарным диабетом» Под редакцией И.И. Дедова, М.В. Шестаковой, А.Ю. Майорова 9-й выпуск // Сахарный диабет. 2019. - T.22. — №1S1. - C.1-144. [Standards of specialized diabetes care. Edited by Dedov I.I., Shestakova M.V., Mayorov A.Yu. 9th edition. Diabetes mellitus. 2019;22(1S1):1-144. (In Russ.)] doi: https://doi.org/10.14341/DM221S1

52. Tsai W-C, Wu H-Y, Peng Y-S, et al. Association of Intensive Blood Pressure Control and Kidney Disease Progression in Nondiabetic Patients With Chronic Kidney Disease. JAMA Intern Med. 2017;177(6):792. doi: https://doi.org/10.1001/jamainternmed.2017.0197
53. Jafar TH, Stark PC, Schmid CH, et al. Progression of Chronic Kidney Disease: The Role of Blood Pressure Control, Proteinuria, and Angiotensin-Converting Enzyme Inhibition: A Patient-Level Meta-Analysis. Ann Intern Med. 2003;139(4):244. doi: https://doi.org/10.7326/0003-4819-139-4-200308190-00006

54. Sim JJ, Shi J, Kovesdy CP, et al. Impact of Achieved Blood Pressures on Mortality Risk and End-Stage Renal Disease Among a Large, Diverse Hypertension Population. J Am Coll Cardiol. 2014;64(6):588597. doi: https://doi.org/10.1016/j.jacc.2014.04.065

55. Thomopoulos C, Parati G, Zanchetti A. Effects of blood-pressure-lowering treatment on outcome incidence in hypertension. J Hypertens. 2017;35(5):922-944. doi: https://doi.org/10.1097/HJH.0000000000001276

56. Owen JG, Reisin E. Anti-hypertensive Drug Treatment of Patients with and the Metabolic Syndrome and Obesity: a Review of Evidence, Meta-Analysis, Post hoc and Guidelines Publications. Curr Hypertens Rep. 2015;17(6):46. doi: https://doi.org/10.1007/s11906-015-0558-9

57. Tocci G, Paneni F, Palano F, et al. Angiotensin-Converting Enzyme Inhibitors, Angiotensin II Receptor Blockers and Diabetes: A MetaAnalysis of Placebo-Controlled Clinical Trials. Am J Hypertens. 2011;24(5):582-590. doi: https://doi.org/10.1038/ajh.2011.8

58. Abuissa H, Jones PG, Marso SP, O'Keefe JH. Angiotensin-Converting Enzyme Inhibitors or Angiotensin Receptor Blockers for Prevention of Type 2 Diabetes. J Am Coll Cardiol. 2005;46(5):821-826. doi: https://doi.org/10.1016/j.jacc.2005.05.051

59. Yang $Y, W e i R$, Xing $Y$, et al. A meta-analysis of the effect of angiotensin receptor blockers and calcium channel blockers on blood pressure, glycemia and the HOMA-IR index in non-diabetic patients. Metabolism. 2013;62(12):1858-1866. doi: https://doi.org/10.1016/j.metabol.2013.08.008

60. Scheen A. Renin-angiotensin system inhibition prevents type 2 diabetes mellitus: Part 1. A meta-analysis of randomised clinical trials. Diabetes Metab. 2004;30(6):487-496. doi: https://doi.org/10.1016/S1262-3636(07)70146-5

61. Andraws R, Brown DL. Effect of Inhibition of the Renin-Angiotensin System on Development of Type 2 Diabetes Mellitus (MetaAnalysis of Randomized Trials). Am J Cardiol. 2007;99(7):1006-1012. doi: https://doi.org/10.1016/j.amjcard.2006.10.068

62. Dahlöf B, Devereux RB, Kjeldsen SE, et al. Cardiovascular morbidity and mortality in the Losartan Intervention For Endpoint reduction in hypertension study (LIFE): a randomised trial against atenolol. Lancet. 2002;359(9311):995-1003. doi: https://doi.org/10.1016/S0140-6736(02)08089-3

63. Julius S, Kjeldsen SE, Weber M, et al. Outcomes in hypertensive patients at high cardiovascular risk treated with regimens based on valsartan or amlodipine: the VALUE randomised trial. Lancet. 2004;363(9426):2022-2031. doi: https://doi.org/10.1016/50140-6736(04)16451-9

64. Yusuf S, Pfeffer MA, Swedberg K, et al. Effects of candesartan in patients with chronic heart failure and preserved left-ventricular ejection fraction: the CHARM-Preserved Trial. Lancet. 2003;362(9386):777-781. doi: https://doi.org/10.1016/S0140-6736(03)14285-7

65. Califf RM, Boolell M, Haffner SM, et al. Prevention of diabetes and cardiovascular disease in patients with impaired glucose tolerance: Rationale and design of the Nateglinide And Valsartan in Impaired Glucose Tolerance Outcomes Research (NAVIGATOR) Trial. Am Heart J. 2008;156(4):623-632. doi: https://doi.org/10.1016/j.ahj.2008.05.017

66. Takagi H, Niwa M, Mizuno Y, Goto S, Umemoto T. Telmisartan as a metabolic sartan: The first meta-analysis of randomized controlled trials in metabolic syndrome. J Am Soc Hypertens. 2013;7(3):229-235. doi: https://doi.org/10.1016/j.jash.2013.02.006

67. Alderman M, Aiyer KJ V. Uric acid: role in cardiovascular disease and effects of losartan. Curr Med Res Opin. 2004;20(3):369-379. doi: https://doi.org/10.1185/030079904125002982

68. Мычка В.Б., Чазова И.Е. Российская доказательная медицина программа МИНОТАВР: преимущества ретардной формы индапамида при лечении метаболического синдрома // Consilium medicum. — 2006. - T.8. — №1S1. — C.46-50. [Mychka VB, Chazova IE. Russian evidence-based medicine - MINOTAVR program: advantages of the retard form of indapamide in the treatment of metabolic syndrome. Consilium medicum. 2006;8(5):46-50. (In Russ.)] 
69. Zillich AJ, Garg J, Basu S, et al. Thiazide Diuretics, Potassium, and the Development of Diabetes. Hypertension. 2006;48(2):219-224. doi: https://doi.org/10.1161/01.HYP.0000231552.10054.aa

70. Sharma AM, Wagner T, Marsalek P. Moxonidine in the treatment of overweight and obese patients with the metabolic syndrome: a postmarketing surveillance study. J Hum Hypertens. 2004;18(9):669-675. doi: https://doi.org/10.1038/sj.jhh.1001676

71. Chazova I, Schlaich MP. Improved Hypertension Control with the Imidazoline Agonist Moxonidine in a Multinational Metabolic Syndrome Population: Principal Results of the MERSY Study. Int J Hypertens. 2013;2013:1-9. doi: https://doi.org/10.1155/2013/541689

72. Чазова И. Е., Мычка В. Б. Новые возможности в лечении больных с метаболическим синдромом (результаты исследования ALMAZ) // Системные гипертензии. - 2006. - №2. - C.14-17. [Chazova I. E., Mychka V. B. Novye vozmozhnosti v lechenii bol'nykh s metabolicheskim sindromom (rezul'taty issledovaniya ALMAZ) // Sistemnye gipertenzii. 2006;(2):14-17. (In Russ.)]

73. Инструкция по медицинскому применению лекарственного препарата для медицинского применения Сибутрамин.
Государственный реестр лекарственных средств Министерства здравоохранения РФ. [Instructions for the medical use of the medicinal product for medical use Sibutramine. State Register of Medicines of the Ministry of Health of the Russian Federation. (In Russ.)] Available at: https://grls.rosminzdrav.ru/grls.aspx

74. Инструкция по медицинскому применению лекарственного препарата для медицинского применения Лираглутид. Государственный реестр лекарственных средств Министерства здравоохранения РФ. [Instructions for the medical use of the medicinal product for medical use Liraglutide. State Register of Medicines of the Ministry of Health of the Russian Federation. (In Russ.)] Available at: https://grls.rosminzdrav.ru/grls.aspx

75. Инструкция по медицинскому применению лекарственного препарата для медицинского применения Орлистат. Государственный реестр лекарственных средств Министерства здравоохранения РФ. [Instructions for the medical use of the medicinal product for medical use Orlistat. State Register of Medicines of the Ministry of Health of the Russian Federation. (In Russ.)] Available at: https://grls.rosminzdrav.ru/grls.aspx 


\title{
ГЛАВА 8. ОЖИРЕНИЕ И ДИСЛИПИДЕМИИ
}

\author{
Недогода С.В., Стародубова А.В., Остроумова О.Д., Клепикова М.В., Саласюк А.С.
}

Нарушения липидного обмена наблюдаются у 60-70\% пациентов с ожирением и чаще всего представлены повышением уровня триглицеридов (ТГ), липопротеинов очень низкой плотности (ЛПОНП), аполипопротеина В и холестерина не-ЛПВП в сыворотке [1-3]. Уровень холестерина липопротеинов высокой плотности (ЛПВП), как правило, низок и связан с повышением уровня триглицеридов в сыворотке [4]. Уровни холестерина липопротеинов низкой плотности (ЛПНП) могут находиться в пределах нормы или быть повышены незначительно [1], однако увеличение лПНП является не просто биомаркером повышенного риска, но и патогенетическим фактором в патофизиологии атеросклеротических сердечно-сосудистых заболеваний [5].

Установлено, что уровень триглицеридов >1,7 ммоль/л является фактором повышенного сердечно-сосудистого риска, но положительный эффект от снижения триглицеридов ниже 1,7 ммоль/л не подтвержден данными доказательной медицины. Безусловно, гипертриглицеридемия - это самостоятельный независимый фактор риска сердечно-сосудистой смертности, но ее влияние все же меньше, чем у гиперхолестеринемии [6]. При этом наиболее значимое повышение сердечно-сосудистого риска имеет место при умеренной, а не тяжелой гипертриглицеридемии (>10 ммоль/л), которая является важным фактором риска развития панкреатита.

Низкий уровень ЛПВП представляет собой независимый фактор риска повышения сердечно-сосудистой смертности [7]. Особенно неблагоприятно сочетание низкого уровня ЛПВП и гиперхолестеринемии, при котором значительно повышен риск ИБС [8]. Уровень ЛПВП <1,0 ммоль/л у мужчин и <1,2 ммоль/л у женщин может расцениваться как фактор риска, однако роль снижения ЛПВП в повышении риска сердечно-сосудистой смертности требует дополнительных доказательств [9]. Сочетание повышения триглицеридов и снижения ЛПВП наиболее часто встречается при абдоминальном ожирении [1].

\section{ОСОБЕННОСТИ ДИЕТОТЕРАПИИ ПРИ ДИСЛИПИДЕМИИ}

8.1. Рекомендуется консультирование пациентов с ожирением и дислипидемией по поводу изменения образа жизни для профилактики ССЗ, включающее рекомендации по здоровому (оптимальному) питанию [10] (УУР В, УДД 2).

8.2. Пациентам с ожирением и дислипидемией рекомендуется придерживаться здорового питания и увеличить потребление овощей, фруктов, бобовых, орехов, цельнозерновых продуктов и рыбы для снижения риска ССЗ [11-24] (УУР А, УДД 1).

8.3. При диетологическом консультировании пациентов с ожирением и дислипидемией необходимо учитывать индивидуальные потребности в энергии, макро- и микронутриентах, массу тела и наличие сопутствующих заболеваний. При необходимости следует рекомендовать уменьшение калорийности рациона для снижения или стабилизации массы тела [25-28] (УУР А, УДД 3).

8.4. Пациентам с ожирением в сочетании с дислипидемией рекомендуется сократить потребление насыщенных жирных кислот и заменить их на моно- и полиненасыщенные жирные кислоты, так как это может способствовать снижению риска ССЗ [22-24, 29-30] (УУР А, УДД 1).

8.5. Пациентам с ожирением в сочетании с дислипидемией рекомендуется рацион питания с низким содержанием холестерина и натрия, так как это может способствовать снижению риска СС3 [22-24, 31-33] (УУР В, УДД 3).

8.6. Пациентам с ожирением в сочетании с дислипидемией при здоровом (оптимальном) питании целесообразно снизить потребление переработанного красного мяса, рафинированных (простых) углеводов и сладких прохладительных напитков для снижения риска СС3 [22-24, 34-41] (УУР А, УДД 1).

8.7. Пациентам с ожирением в сочетании с дислипидемией при здоровом (оптимальном) питании рекомендуется исключить потребление транс-изомеров жирных кислот для снижения риска СС3 [22-24, 29, 34, 42, 43] (УУР А, УДД 1).

8.8. Пациентам с ожирением в сочетании с дислипидемией рекомендуется отказ от потребления транс-жиров, снижение потребления насыщенных жиров и натрия (до <5 г/сут), соблюдение диеты, богатой овощами и нежирными молочными продуктами, поскольку диеты оказывают небольшое, но существенное влияние на изменения уровня липидов [22-24] (УУР А, УДД 1).

Комментарии. Пациентам с гипертриглицеридемией рекомендуется сокращать количество продуктов, содержащих фруктозу, до <10\% от общего потребления калорий [44].

8.9. Пациентам с ожирением в сочетании с дислипидемией без гипертриглицеридемии рекомендуется снижение потребления алкоголя (<10 г/сут для мужчин и женщин), поскольку это доказанно снижает риск кардиоваскулярных осложнений [45-47] (УУР А, УДД 1). 
8.10. Пациентам с ожирением в сочетании с гипертриглицеридемией рекомендуется отказ от потребления алкоголя, поскольку доказана ассоциация между употреблением алкоголя и повышением уровня ТГ сыворотки крови [48-51] (УУР А, УДД 1).

8.11. Пациентам с ожирением в сочетании с дислипидемией рекомендуется соблюдение интенсивного режима физической активности (эквивалентной потере 700-2000 ккал/нед), поскольку в результате длительного следования данному режиму наблюдается снижение уровня лПнП на 4-7\%, уровня ТГ на 4-37\% (среднее снижение на 24\%) и повышение уровня ЛПВП на 0,08-0,15 ммоль/л, даже при отсутствии значительной потери массы тела [52-60] (УУР В, УДД 3).

Комментарии. Пациентам рекомендуется тренироваться 150 мин и более в неделю (например, по 30 мин в день 5 раз в неделю). Чем интенсивнее программа упражнений, тем больше влияние на вес и уровень липидов.

8.12. Пациентам с морбидным ожирением в сочетании с дислипидемией и отсутствием противопоказаний к оперативному вмешательству рекомендуется проведение бариатрической операции в связи с заметным влиянием на уровень липидов в сыворотке [61, 62] (УУР В, УДД 2).

Комментарии. Современные бариатрические хирургические методы приводят к значительному улучшению дислипидемии, однако степень изменений широко варьируется для каждой процедуры. Эти различия могут иметь значение при выборе наиболее подходящего метода оперативного вмешательства для конкретного пациента. Часто наблюдается ремиссия гиперлипидемии при шунтировании желудка.

8.13. Пациентам с ожирением и очень высоким СС-риском для первичной и вторичной профилактики рекомендовано назначение статинов для достижения целевого ХС лПНП <1,4 ммоль/л или его снижение на $\geq 50 \%$ от исходного при уровне ХС ЛПНП 1,8-3,5 ммоль/л для снижения СС-риска [63-65] (УУР А, УДД 1).

8.14. Пациентам с ожирением и высоким СС-риском рекомендовано назначение статинов для достижения целевого ХС ЛПНП <1,8 ммоль/л или его снижение на $\geq 50 \%$ от исходного при уровне ХС лПНП 2,6-5,2 ммоль/л для снижения СС-риска [63, 64] (УУР А, УДД 1).

Комментарии. У пациентов с низким риском можно рассмотреть назначение статинов для достижения целевого ХС ЛПНП <3,0 ммоль/л, с умеренным риском - для достижения целевого ХС лПНП <2,6 ммоль/л [63, 64]

8.15. Пациентам с ожирением и повторной СС-катастрофой в течение 2 лет (не обязательно одного типа) при хорошей переносимости статинотерапии рекомендовано рассмотреть целесообразность достижения целевого ХС ЛПНП <1,0 ммоль/л для снижения СС риска [65, 66] (УУР В, УДД 2).

Комментарии. Назначение гиполипидемической терапии пациентам с ожирением имеет целью снижение СС-риска. Стратегии снижения уровня ЛПНП зависят от величины СС-риска (табл. 9).

Таблица 9. Стратегия снижения уровня липопротеинов низкой плотности в зависимости от сердечно-сосудистого риска

\begin{tabular}{|c|c|c|c|c|c|c|c|}
\hline \multirow{2}{*}{\multicolumn{2}{|c|}{$\begin{array}{c}\text { Общий CC-риск } \\
\text { (SCORE) \% } \\
<1,4 \text { ммоль/л }\end{array}$}} & \multicolumn{6}{|c|}{ Уровень ЛПНП до лечения } \\
\hline & & $\begin{array}{c}\geq 1,4 \text { до <1,8 } \\
\text { ммоль/л }\end{array}$ & $\begin{array}{c}\geq 1,8 \text { до <2,6 } \\
\text { ммоль/л }\end{array}$ & $\begin{array}{c}\geq 2,6 \text { до <3,0 } \\
\text { ммоль/л }\end{array}$ & $\begin{array}{c}\geq 3,0 \text { до <4,9 } \\
\text { ммоль/л }\end{array}$ & $\geq 1,4$ ммоль/л & \\
\hline \multirow{4}{*}{ 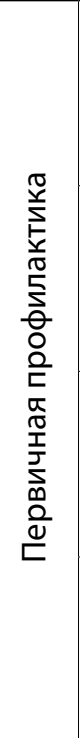 } & $\begin{array}{l}<1 \\
\text { (низкий } \\
\text { риск) }\end{array}$ & $\begin{array}{l}\text { Изменение } \\
\text { образа жизни }\end{array}$ & $\begin{array}{l}\text { Изменение } \\
\text { образа жизни }\end{array}$ & $\begin{array}{l}\text { Изменение } \\
\text { образа жизни }\end{array}$ & $\begin{array}{l}\text { Изменение } \\
\text { образа жизни }\end{array}$ & $\begin{array}{l}\text { Изменение } \\
\text { образа жизни, } \\
\text { рассмотреть } \\
\text { добавление } \\
\text { препаратов }\end{array}$ & $\begin{array}{l}\text { Изменение } \\
\text { образа жизни, } \\
\text { медикаменто- } \\
\text { зная терапия }\end{array}$ \\
\hline & $\begin{array}{l}\geq 1 \text { до <5 } \\
\text { (или } \\
\text { умеренный } \\
\text { риск) }\end{array}$ & $\begin{array}{l}\text { Изменение } \\
\text { образа жизни }\end{array}$ & $\begin{array}{l}\text { Изменение } \\
\text { образа жизни }\end{array}$ & $\begin{array}{l}\text { Изменение } \\
\text { образа жизни }\end{array}$ & $\begin{array}{l}\text { Изменение } \\
\text { образа жизни, } \\
\text { рассмотреть } \\
\text { добавление } \\
\text { препаратов }\end{array}$ & $\begin{array}{l}\text { Изменение } \\
\text { образа жизни, } \\
\text { рассмотреть } \\
\text { добавление } \\
\text { препаратов }\end{array}$ & $\begin{array}{l}\text { Изменение } \\
\text { образа жизни, } \\
\text { медикаменто- } \\
\text { зная терапия }\end{array}$ \\
\hline & $\begin{array}{l}\geq 5 \text { до <10 } \\
\text { (или } \\
\text { высокий } \\
\text { риск) }\end{array}$ & $\begin{array}{l}\text { Изменение } \\
\text { образа жизни }\end{array}$ & $\begin{array}{l}\text { Изменение } \\
\text { образа жизни }\end{array}$ & $\begin{array}{l}\text { Изменение } \\
\text { образа жизни, } \\
\text { рассмотреть } \\
\text { добавление } \\
\text { препаратов }\end{array}$ & $\begin{array}{l}\text { Изменение } \\
\text { образа жизни, } \\
\text { медикаменто- } \\
\text { зная терапия }\end{array}$ & $\begin{array}{l}\text { Изменение } \\
\text { образа жизни, } \\
\text { медикаменто- } \\
\text { зная терапия }\end{array}$ & $\begin{array}{l}\text { Изменение } \\
\text { образа жизни, } \\
\text { медикаменто- } \\
\text { зная терапия }\end{array}$ \\
\hline & $\begin{array}{l}\geq 10 \\
\text { (или очень } \\
\text { высокий } \\
\text { риск) }\end{array}$ & $\begin{array}{l}\text { Изменение } \\
\text { образа жизни }\end{array}$ & $\begin{array}{l}\text { Изменение } \\
\text { образа жизни, } \\
\text { рассмотреть } \\
\text { добавление } \\
\text { препаратов }\end{array}$ & $\begin{array}{l}\text { Изменение } \\
\text { образа жизни, } \\
\text { медикаменто- } \\
\text { зная терапия }\end{array}$ & $\begin{array}{l}\text { Изменение } \\
\text { образа жизни, } \\
\text { медикаменто- } \\
\text { зная терапия }\end{array}$ & $\begin{array}{l}\text { Изменение } \\
\text { образа жизни, } \\
\text { медикаменто- } \\
\text { зная терапия }\end{array}$ & $\begin{array}{l}\text { Изменение } \\
\text { образа жизни, } \\
\text { медикаменто- } \\
\text { зная терапия }\end{array}$ \\
\hline 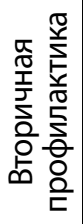 & $\begin{array}{l}\text { Очень } \\
\text { Высокий } \\
\text { риск }\end{array}$ & $\begin{array}{l}\text { Изменение } \\
\text { образа жизни, } \\
\text { рассмотреть } \\
\text { добавление } \\
\text { препаратов }\end{array}$ & $\begin{array}{l}\text { Изменение } \\
\text { образа жизни, } \\
\text { медикаменто- } \\
\text { зная терапия }\end{array}$ & $\begin{array}{l}\text { Изменение } \\
\text { образа жизни, } \\
\text { медикаменто- } \\
\text { зная терапия }\end{array}$ & $\begin{array}{l}\text { Изменение } \\
\text { образа жизни, } \\
\text { медикаменто- } \\
\text { зная терапия }\end{array}$ & $\begin{array}{l}\text { Изменение } \\
\text { образа жизни, } \\
\text { медикаменто- } \\
\text { зная терапия }\end{array}$ & $\begin{array}{l}\text { Изменение } \\
\text { образа жизни, } \\
\text { медикаменто- } \\
\text { зная терапия }\end{array}$ \\
\hline
\end{tabular}


Метаанализы применения статинов выявили наличие дозозависимого от степени снижения уровня ЛПнПуменьшения сердечно-сосудистой смертности - снижение уровня ЛПНП на каждые 1,0 ммоль/л ассоциируется с 20-25-процентным снижением сердечно-сосудистой смертности и нефатального ИМ [63]. Эффект от гиполипидемической терапии зависит от исходного уровня СС-риска: чем он исходно выше, тем больше выражен эффект его абсолютного снижения.

Гиполипидемическими препаратами первой линии являются статины. Терапия статинами сопровождается достоверным уменьшением общей смертности и смертности от ССЗ, смертельного и несмертельного ИМ, острого коронарного синдрома, периферического атеросклероза [67]. Статины остаются единственным классом гиполипидемических препаратов, который, по данным проспективных контролируемых исследований, снижает риск инсультов [68-71].

8.16. Пациентам с ожирением и дислипидемией, не достигшим целевых уровней ХС лпнП на максимально переносимой дозе статинов, рекомендовано назначение эзетимиба в дополнение к статинотерапии для снижения СС-риска [72, 73] (УУР А, УДД 1).

8.17. Пациентам с ожирением и дислипидемией с непереносимостью статинов рекомендовано назначение эзетимиба в качестве первой линии терапии для снижения СС риска [72] (УУР А, УДД 1).

Комментарии. Пациентам с ожирением и дислипидемией, не достигшим целевых уровней ХС-ЛПНП на максимально переносимой дозе статинов в комбинации с эзетимибом, рекомендовано назначение ингибиторов не-ЛПВП $[65,66]$.

8.18. Пациентам с метаболическим синдромом, СД, гипертриглицеридемией рекомендовано использовать показатель ХС не-ЛПВП, поскольку прямое измерение ХС ЛПНП имеет ограничение [74, 75] (УУР С, УДД 1).

Комментарии. В клинической практике ХС лПНП рассчитывается по формуле Фридвальда [72, 75]:

*ХС ЛПНП (мг/дл) = ОХС (мг/дл) - ХС ЛПВП (мг/дл) - ХС ЛПОНП (мг/дл);

**ХС ЛПНП (ммоль/л) = ОХС (ммоль/л) - ХС ЛПВП (ммоль/л) - ХС ЛПОНП (ммоль/л),

где количество ХС ЛПОНП рассчитывается по формуле (в зависимости от единиц измерения):

* ХС лпОНП (мг/дл) $=\frac{\text { Триглицериды }}{5}$;

** ХС лПОНП (ммоль/л) $=\frac{\text { Триглицериды }}{2,2}$.

При концентрации ТГ $\geq 2$ ммоль/л расчетный метод занижает уровень ХС ЛПНП. При высоком уровне ТГ (> 4,5 ммоль/л) данную формулу использовать нельзя [74, 75].

Показатель не-ЛПВП рассчитывается по формулам:

не-ЛПВП=ОХС-ХС ЛПВП;

не-ЛПВП=ЛПНП+ТГ/2,2.

8.19. Пациентам с ожирением и дислипидемией, не достигшим целевых уровней ТГ на максимально

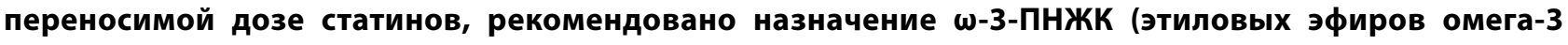
полиненасыщенных жирных кислот) в дополнение к статинотерапии для снижения СС-риска [76-78] (УУР В, УДД 2).

8.20. Пациентам с ожирением, дислипидемией и сахарным диабетом при уровне ТГ 1,5-5,6 ммоль/л, несмотря на терапию статинами, рекомендуется добавить фенофибрат; при недостаточном эффекте или при непереносимости фенофибрата добавить ш-3-ПНЖК 2 г раза в день [79-81] (УУР В, УДД 2).

\section{СПИСОК ЛИТЕРАТУРЫ | REFERENCES}

1. Klop B, Elte J, Cabezas M. Dyslipidemia in Obesity: Mechanisms and Potential Targets. Nutrients. 2013;5(4):1218-1240. doi: https://doi.org/10.3390/nu5041218

2. Björnson E, Adiels M, Taskinen M-R, Borén J. Kinetics of plasma triglycerides in abdominal obesity. Curr Opin Lipidol. November 2016:1. doi: https://doi.org/10.1097/MOL.0000000000000375

3. Mandviwala T, Khalid U, Deswal A. Obesity and Cardiovascular Disease: a Risk Factor or a Risk Marker? Curr Atheroscler Rep. 2016;18(5):21. doi: https://doi.org/10.1007/s11883-016-0575-4

4. Feingold KR. Obesity and Dyslipidemia. [Updated 2020 Nov 2]. In: Feingold KR, Anawalt B, Boyce A, et al., editors. Endotext [Internet]. South Dartmouth (MA): MDText.com, Inc. 2000. Available from: https://www.ncbi.nlm.nih.gov/books/NBK305895/

5. Ference BA, Ginsberg HN, Graham I, et al. Low-density lipoproteins cause atherosclerotic cardiovascular disease. 1. Evidence from genetic, epidemiologic, and clinical studies. A consensus statement from the European Atherosclerosis Society Consensus Panel. Eur Heart J. 2017;38(32):2459-2472. doi: https://doi.org/10.1093/eurheartj/ehx144
6. Sarwar N, Danesh J, Eiriksdottir G, et al. Triglycerides and the Risk of Coronary Heart Disease. Circulation. 2007;115(4):450-458. doi: https://doi.org/10.1161/CIRCULATIONAHA.106.637793

7. Chapman MJ, Ginsberg HN, Amarenco P, et al. Triglyceriderich lipoproteins and high-density lipoprotein cholesterol in patients at high risk of cardiovascular disease: evidence and guidance for management. Eur Heart J. 2011;32(11):1345-1361. doi: https://doi.org/10.1093/eurheartj/ehr112

8. Fruchart J-C, Sacks FM, Hermans MP, et al. The Residual Risk Reduction Initiative: a call to action to reduce residual vascular risk in dyslipidaemic patients. Diabetes Vasc Dis Res. 2008;5(4):319-335. doi: https://doi.org/10.3132/dvdr.2008.046

9. Voight BF, Peloso GM, Orho-Melander M, et al. Plasma HDL cholesterol and risk of myocardial infarction: a mendelian randomisation study. Lancet. 2012;380(9841):572-580. doi: https://doi.org/10.1016/S0140-6736(12)60312-2

10. Arnett DK, Blumenthal RS, Albert MA, et al. 2019 ACC/AHA Guideline on the Primary Prevention of Cardiovascular Disease: A Report of the American College of Cardiology/American Heart Association Task Force on Clinical Practice Guidelines. Circulation. 2019;140(11):623-632. doi: https://doi.org/10.1161/CIR.0000000000000678 
11. Estruch R, Ros E, Salas-Salvadó J, et al. Primary Prevention of Cardiovascular Disease with a Mediterranean Diet Supplemented with Extra-Virgin Olive Oil or Nuts. N Engl J Med. 2018;378(25):e34. doi: https://doi.org/10.1056/NEJMoa1800389

12. Kim H, Caulfield LE, Garcia-Larsen V, Steffen LM, Coresh J, Rebholz CM. Plant-Based Diets Are Associated With a Lower Risk of Incident Cardiovascular Disease, Cardiovascular Disease Mortality, and AllCause Mortality in a General Population of Middle-Aged Adults. J Am Heart Assoc. 2019;8(16). doi: https://doi.org/10.1161/JAHA.119.012865

13. Reedy J, Krebs-Smith SM, Miller PE, et al. Higher Diet Quality Is Associated with Decreased Risk of All-Cause, Cardiovascular Disease, and Cancer Mortality among Older Adults. J Nutr. 2014;144(6):881-889. doi: https://doi.org/10.3945/jn.113.189407

14. Satija A, Bhupathiraju SN, Spiegelman D, et al. Healthful and Unhealthful Plant-Based Diets and the Risk of Coronary Heart Disease in U.S. Adults. J Am Coll Cardiol. 2017;70(4):411-422. doi: https://doi.org/10.1016/j.jacc.2017.05.047

15. Sotos-Prieto M, Bhupathiraju SN, Mattei J, et al. Association of Changes in Diet Quality with Total and CauseSpecific Mortality. N Engl J Med. 2017;377(2):143-153. doi: https://doi.org/10.1056/NEJMoa1613502

16. Whalen KA, Judd S, McCullough ML, Flanders WD, Hartman TJ, Bostick RM. Paleolithic and Mediterranean Diet Pattern Scores Are Inversely Associated with All-Cause and CauseSpecific Mortality in Adults. J Nutr. 2017;147(4):612-620. doi: https://doi.org/10.3945/jn.116.241919

17. Bao Y, Han J, Hu FB, et al. Association of Nut Consumption with Total and Cause-Specific Mortality. N Eng/ J Med. 2013;369(21):2001-2011. doi: https://doi.org/10.1056/NEJMoa1307352

18. Bernstein AM, Sun Q, Hu FB, Stampfer MJ, Manson JE, Willett WC. Major Dietary Protein Sources and Risk of Coronary Heart Disease in Women. Circulation. 2010;122(9):876-883. doi: https://doi.org/10.1161/CIRCULATIONAHA.109.915165

19. Song M, Fung TT, Hu FB, et al. Association of Animal and Plant Protein Intake With All-Cause and Cause-Specific Mortality. JAMA Intern Med. 2016;176(10):1453. doi: https://doi.org/10.1001/jamainternmed.2016.4182

20. Tharrey M, Mariotti F, Mashchak A, et al. Patterns of plant and animal protein intake are strongly associated with cardiovascular mortality: the Adventist Health Study-2 cohort. Int J Epidemiol. 2018;47(5):1603-1612. doi: https://doi.org/10.1093/ije/dyy030

21. Martínez-González MA, Sánchez-Tainta A, Corella D, et al. A provegetarian food pattern and reduction in total mortality in the Prevención con Dieta Mediterránea (PREDIMED) study. Am J Clin Nutr. 2014;100(suppl_1):320S-328S. doi: https://doi.org/10.3945/ajcn.113.071431

22. Mensink RP, Zock PL, Kester ADM, Katan MB. Effects of dietary fatty acids and carbohydrates on the ratio of serum total to HDL cholesterol and on serum lipids and apolipoproteins: a metaanalysis of 60 controlled trials. Am J Clin Nutr. 2003;77(5):1 146-1155. doi: https://doi.org/10.1093/ajcn/77.5.1146

23. Schwingshackl L, Bogensberger B, Benčič A, et al. Effects of oils and solid fats on blood lipids: a systematic review and network meta-analysis. J Lipid Res. 2018;59(9):1771-1782. doi: https://doi.org/10.1194/jlr.P085522

24. Kastorini C-M, Milionis HJ, Esposito K, et al. The Effect of Mediterranean Diet on Metabolic Syndrome and its Components. J Am Coll Cardiol. 2011;57(11):1299-1313. doi: https://doi.org/10.1016/j.jacc.2010.09.073

25. Grundy SM, Stone NJ. 2018 Cholesterol Clinical Practice Guidelines: Synopsis of the 2018 American Heart Association/American College of Cardiology/Multisociety Cholesterol Guideline*. Ann Intern Med. 2019;170(11):779. doi: https://doi.org/10.7326/M19-0365

26. Eckel RH, Jakicic JM, Ard JD, et al. 2013 AHA/ACC Guideline on Lifestyle Management to Reduce Cardiovascular Risk. Circulation. 2014;129(25 suppl 2):S76-S99. doi: https://doi.org/10.1161/01.cir.0000437740.48606.d1

27. Jensen MD, Ryan DH, Apovian CM, et al. 2013 AHA/ACC/ TOS Guideline for the Management of Overweight and Obesity in Adults. Circulation. 2014;129(25 suppl 2):S102-S138. doi: https://doi.org/10.1161/01.cir.0000437739.71477.ee

28. Estruch R, Ros E, Salas-Salvadó J, et al. Primary Prevention of Cardiovascular Disease with a Mediterranean Diet Supplemented with Extra-Virgin Olive Oil or Nuts. N Eng/ J Med. 2018;378(25):e34. doi: https://doi.org/10.1056/NEJMoa1800389
29. Wang DD, LiY Chiuve SE, et al Association of Specific Dietary Fats With Total and CauseSpecific Mortality. JAMA Intern Med. 2016;176(8):1134. doi: https://doi.org/10.1001/jamainternmed.2016.2417

30. Dehghan M, Mente A, Zhang X, et al. Associations of fats and carbohydrate intake with cardiovascular disease and mortality in 18 countries from five continents (PURE): a prospective cohort study. Lancet. 2017;390(10107):2050-2062. doi: https://doi.org/10.1016/S0140-6736(17)32252-3

31. Sacks FM, Svetkey LP, Vollmer WM, et al. Effects on Blood Pressure of Reduced Dietary Sodium and the Dietary Approaches to Stop Hypertension (DASH) Diet. N Engl J Med. 2001;344(1):3-10. doi: https://doi.org/10.1056/NEJM200101043440101

32. Cook NR, Cutler JA, Obarzanek E, et al. Long term effects of dietary sodium reduction on cardiovascular disease outcomes: observational follow-up of the trials of hypertension prevention (TOHP). BMJ. 2007;334(7599):885. doi: https://doi.org/10.1136/bmj.39147.604896.55

33. Micha R, Peñalvo JL, Cudhea F, et al. Association Between Dietary Factors and Mortality From Heart Disease, Stroke, and Type 2 Diabetes in the United States. JAMA. 2017;317(9):912. doi: https://doi.org/10.1001/jama.2017.0947

34. Kiage JN, Merrill PD, Robinson CJ, et al. Intake of trans fat and all-cause mortality in the Reasons for Geographical and Racial Differences in Stroke (REGARDS) cohort. Am J Clin Nutr. 2013;97(5):1121-1128. doi: https://doi.org/10.3945/ajcn.112.049064

35. Löfvenborg JE, Andersson T, Carlsson P-O, et al. Sweetened beverage intake and risk of latent autoimmune diabetes in adults (LADA) and type 2 diabetes. Eur J Endocrinol. 2016;175(6):605-614. doi: https://doi.org/10.1530/EJE-16-0376

36. Yang Q, Zhang Z, Gregg EW, et al. Added Sugar Intake and Cardiovascular Diseases Mortality Among US Adults. JAMA Intern Med. 2014;174(4):516. doi: https://doi.org/10.1001/jamainternmed.2013.13563

37. Johnson RK, Lichtenstein AH, Anderson CAM, et al. Low-Calorie Sweetened Beverages and Cardiometabolic Health: A Science Advisory From the American Heart Association. Circulation. 2018;138(9). doi: https://doi.org/10.1161/CIR.0000000000000569

38. Shikany JM, Safford MM, Newby PK, et al. Southern Dietary Pattern Is Associated With Hazard of Acute Coronary Heart Disease in the Reasons for Geographic and Racial Differences in Stroke (REGARDS) Study. Circulation. 2015;132(9):804-814. doi: https://doi.org/10.1161/CIRCULATIONAHA.114.014421

39. Seidelmann SB, Claggett B, Cheng $\mathrm{S}$, et al. Dietary carbohydrate intake and mortality: a prospective cohort study and meta-analysis. Lancet Public Heal. 2018;3(9):e419-e428. doi: https://doi.org/10.1016/S2468-2667(18)30135-X

40. Trichopoulou A, Psaltopoulou T, Orfanos P, Hsieh C-C, Trichopoulos D. Low-carbohydrate-high-protein diet and long-term survival in a general population cohort. Eur J Clin Nutr. 2007;61(5):575-581. doi: https://doi.org/10.1038/sj.ejcn.1602557

41. Noto H, Goto A, Tsujimoto T, Noda M. LowCarbohydrate Diets and All-Cause Mortality: A Systematic Review and Meta-Analysis of Observational Studies. Manzoli L, ed. PLoS One. 2013;8(1):e55030. doi: https://doi.org/10.1371/journal.pone.0055030

42. Brandt EJ, Myerson R, Perraillon MC, Polonsky TS. Hospital Admissions for Myocardial Infarction and Stroke Before and After the TransFatty Acid Restrictions in New York. JAMA Cardiol. 2017;2(6):627. doi: https://doi.org/10.1001/jamacardio.2017.0491

43. Micha R, Mozaffarian D. Trans fatty acids: effects on metabolic syndrome, heart disease and diabetes. Nat Rev Endocrinol. 2009:5(6):335-344. doi: https://doi.org/10.1038/nrendo.2009.79

44. Taskinen M-R, Söderlund S, Bogl LH, et al. Adverse effects of fructose on cardiometabolic risk factors and hepatic lipid metabolism in subjects with abdominal obesity. J Intern Med. 2017;282(2):187-201. doi: https://doi.org/10.1111/joim.12632

45. Saneei P, Salehi-Abargouei A, Esmaillzadeh A, Azadbakht L. Influence of Dietary Approaches to Stop Hypertension (DASH) diet on blood pressure: A systematic review and meta-analysis on randomized controlled trials. Nutr Metab Cardiovasc Dis. 2014;24(12):1253-1261. doi: https://doi.org/10.1016/j.numecd.2014.06.008 
46. He FJ, Li J, MacGregor GA. Effect of longer-term modest salt reduction on blood pressure. Cochrane Database Syst Rev. April 2013. doi: https://doi.org/10.1002/14651858.CD004937.pub2

47. Neter JE, Stam BE, Kok FJ, et al. Influence of Weight Reduction on Blood Pressure. Hypertension. 2003:42(5):878-884 doi: https://doi.org/10.1161/01.HYP.0000094221.86888.AE

48. Rimm EB, Williams P, Fosher $\mathrm{K}$, et al. Moderate alcohol intake and lower risk of coronary heart disease: meta-analysis of effects on lipids and haemostatic factors. BMJ. 1999;319(7224):1523-1528. doi: https://doi.org/10.1136/bmj.319.7224.1523

49. Brien SE, Ronksley PE, Turner BJ, et al. Effect of alcohol consumption on biological markers associated with risk of coronary heart disease: systematic review and meta-analysis of interventional studies. BMJ. 2011;342(feb22 1):d636-d636. doi: https://doi.org/10.1136/bmj.d636

50. Griswold MG, Fullman N, Hawley C, et al. Alcohol use and burden for 195 countries and territories, 1990-2016: a systematic analysis for the Global Burden of Disease Study 2016. Lancet. 2018:392(10152):1015-1035. doi: https://doi.org/10.1016/S0140-6736(18)31310-2

51. Wood AM, Kaptoge S, Butterworth AS, et al. Risk thresholds for alcohol consumption: combined analysis of individual-participant data for 599912 current drinkers in 83 prospective studies. Lancet. 2018;391(10129):1513-1523. doi: https://doi.org/10.1016/S0140-6736(18)30134-X

52. Huffman KM, Hawk VH, Henes ST, et al. Exercise effects on lipids in persons with varying dietary patterns - does diet matter if they exercise? Responses in Studies of a Targeted Risk Reduction Intervention through Defined Exercise I. Am Heart J. 2012;164(1):117-124. doi: https://doi.org/10.1016/j.ahj.2012.04.014

53. Kraus WE, Powell KE, Haskell WL, et al. Physical Activity, AllCause and Cardiovascular Mortality, and Cardiovascular Disease. Med Sci Sport Exerc. 2019;51(6):1270-1281. doi: https://doi.org/10.1249/MSS.0000000000001939

54. Piercy KL, Troiano RP, Ballard RM, et al. The Physical Activity Guidelines for Americans. JAMA. 2018;320(19):2020. doi: https://doi.org/10.1001/jama.2018.14854

55. Shaw KA, Gennat HC, O'Rourke P, Del Mar C. Exercise for overweight or obesity. Cochrane Database Syst Rev. October 2006. doi: https://doi.org/10.1002/14651858.CD003817.pub3

56. Yu-Poth S, Zhao G, Etherton T, et al. Effects of the National Cholesterol Education Program's Step I and Step II dietary intervention programs on cardiovascular disease risk factors: a meta-analysis. Am J Clin Nutr. 1999:69(4):632-646. doi: https://doi.org/10.1093/ajcn/69.4.632

57. Kraus WE, Houmard JA, Duscha BD, et al. Effects of the Amount and Intensity of Exercise on Plasma Lipoproteins. N Engl J Med. 2002;347(19):1483-1492. doi: https://doi.org/10.1056/NEJMoa020194

58. Kodama S. Effect of Aerobic Exercise Training on Serum Levels of High-Density Lipoprotein Cholesterol. Arch Intern Med. 2007:167(10):999. doi: https://doi.org/10.1001/archinte.167.10.999

59. Kelley GA, Kelley KS. Impact of progressive resistance training on lipids and lipoproteins in adults: A meta-analysis of randomized controlled trials. Prev Med (Baltim). 2009;48(1):9-19. doi: https://doi.org/10.1016/j.ypmed.2008.10.010

60. Kelley GA, Kelley KS, Franklin B. Aerobic Exercise and Lipids and Lipoproteins in Patients With Cardiovascular Disease. J Cardiopulm Rehabil. 2006;26(3):131-139. doi: https://doi.org/10.1097/00008483-200605000-00002

61. Buchwald H, Avidor Y, Braunwald E, et al. Bariatric Surgery. JAMA. 2004;292(14):1724. doi: https://doi.org/10.1001/jama.292.14.1724

62. Heffron SP, Parikh A, Volodarskiy A, et al. Changes in Lipid Profile of Obese Patients Following Contemporary Bariatric Surgery: A Meta-Analysis. Am J Med. 2016;129(9):952-959. doi: https://doi.org/10.1016/j.amjmed.2016.02.004

63. Baigent C, Blackwell L, Emberson J, et al. Efficacy and safety of more intensive lowering of LDL cholesterol: a meta-analysis of data from 170000 participants in 26 randomised trials. Lancet. 2010;376(9753):1670-1681. doi: https://doi.org/10.1016/S0140-6736(10)61350-5

64. Fulcher J, O'Connell R, Voysey M, et al. Efficacy and safety of LDL-lowering therapy among men and women: metaanalysis of individual data from 174000 participants in 27 randomised trials. Lancet. 2015;385(9976):1397-1405. doi: https://doi.org/10.1016/S0140-6736(14)61368-4

65. Schwartz GG, Steg PG, Szarek M, et al. Alirocumab and Cardiovascular Outcomes after Acute Coronary Syndrome. N Engl J Med. 2018;379(22):2097-2107. doi: https://doi.org/10.1056/NEJMoa1801174

66. Sabatine MS, Giugliano RP, Keech AC, et al. Evolocumab and Clinical Outcomes in Patients with Cardiovascular Disease. N Engl J Med. 2017;376(18):1713-1722. doi: https://doi.org/10.1056/NEJMoa1615664

67. Cannon CP, Steinberg BA, Murphy SA, et al. Meta-Analysis of Cardiovascular Outcomes Trials Comparing Intensive Versus Moderate Statin Therapy. J Am Coll Cardiol. 2006;48(3):438-445 doi: https://doi.org/10.1016/j.jacc.2006.04.070

68. Amarenco P, Labreuche J, Lavallée P, Touboul P-J. Statins in Stroke Prevention and Carotid Atherosclerosis. Stroke. 2004;35(12):29022909. doi: https://doi.org/10.1161/01.STR.0000147965.52712.fa

69. Cholesterol Treatment Trialists' (CTT) Collaborators Efficacy of cholesterol-lowering therapy in 18686 people with diabetes in 14 randomised trials of statins: a meta-analysis. Lancet. 2008;371(9607):117-125 doi: https://doi.org/10.1016/S0140-6736(08)60104-X

70. Efficacy and safety of cholesterol-lowering treatment: prospective meta-analysis of data from 90056 participants in 14 randomised trials of statins. Lancet. 2005;366(9493):1267-1278. doi: https://doi.org/10.1016/S0140-6736(05)67394-1

71. Wang J, Chen D, Li D-B, Yu X, Shi G-B. Comparison of the efficacy and safety of intensive-dose and standard-dose statin treatment for stroke prevention. Medicine (Baltimore). 2016;95(39):e4950. doi: https://doi.org/10.1097/MD.0000000000004950

72. Pandor A, Ara RM, Tumur I, et al. Ezetimibe monotherapy for cholesterol lowering in 2,722 people: systematic review and meta-analysis of randomized controlled trials. J Intern Med. 2009;265(5):568-580. doi: https://doi.org/10.1111/j.1365-2796.2008.02062.x

73. Morrone D, Weintraub WS, Toth PP, et al. Lipid-altering efficacy of ezetimibe plus statin and statin monotherapy and identification of factors associated with treatment response: A pooled analysis of over 21,000 subjects from 27 clinical trials. Atherosclerosis. 2012;223(2):251-261. doi: https://doi.org/10.1016/j.atherosclerosis.2012.02.016

74. Mach F, Baigent C, Catapano AL, et al. 2019 ESC/EAS Guidelines for the management of dyslipidaemias: lipid modification to reduce cardiovascular risk. Eur Heart J. 2020;41(1):111-188. doi: https://doi.org/10.1093/eurheartj/ehz455

75. Диагностика и коррекция нарушений липидного обмена с челью просилактики и лечения атеросклероза. Российские рекомендачии, VII пересмотр // Атеросклероз и Дислипидемии. - 2020. - Т.38. - №1. - C.7-42. [Diagnostika i korrektsiya narushenii lipidnogo obmena s tsel'yu profilaktiki i lecheniya ateroskleroza. Rossiiskie rekomendatsii, VII peresmotr. Ateroskleroz i Dislipidemii. 2020;38(1):7-42. (in Russ.)] doi: https://doi.org/10.34687/2219-8202.JAD.2020.01.0002

76. Bhatt DL, Steg PG, Miller M, et al. Cardiovascular Risk Reduction with Icosapent Ethyl for Hypertriglyceridemia. N Engl J Med. 2019;380(1):11-22. doi: https://doi.org/10.1056/NEJMoa1812792

77. Harris WS, Ginsberg HN, Arunakul N, et al. Safety and efficacy of Omacor in severe hypertriglyceridemia. J Cardiovasc Risk. 1997:4(5):385-391. doi: https://doi.org/10.1097/00043798-199710000-00011

78. Skulas-Ray AC, Wilson PWF, Harris WS, et al. Omega-3 Fatty Acids for the Management of Hypertriglyceridemia: A Science Advisory From the American Heart Association. Circulation. 2019;140(12):111-188. doi: https://doi.org/10.1161/CIR.0000000000000709

79. Maki KC, Guyton JR, Orringer CE, Hamilton-Craig I, Alexander DD, Davidson MH. Triglyceride-lowering therapies reduce cardiovascular disease event risk in subjects with hypertriglyceridemia. J Clin Lipidol. 2016;10(4):905-914. doi: https://doi.org/10.1016/j.jacl.2016.03.008

80. Effects of long-term fenofibrate therapy on cardiovascular events in 9795 people with type 2 diabetes mellitus (the FIELD study): randomised controlled trial. Lancet. 2005;366(9500):1849-1861. doi: https://doi.org/10.1016/S0140-6736(05)67667-2

81. Kim NH, Han KH, Choi J, Lee J, Kim SG. Use of fenofibrate on cardiovascular outcomes in statin users with metabolic syndrome: propensity matched cohort study. BMJ. September 2019:15125. doi: https://doi.org/10.1136/bmj.15125 


\title{
ГЛАВА 9. ОЖИРЕНИЕ И ХРОНИЧЕСКАЯ СЕРДЕЧНАЯ НЕДОСТАТОЧНОСТЬ
}

\author{
Бондаренко И.З.
}

Согласно эпидемиологическому Фрамингемскому исследованию, избыточный вес и ожирение увеличивают риск развития всех заболеваний сердца и сосудов, однако именно хроническая сердечная недостаточность (ХСН), согласно сердечно-сосудистому континууму, в наибольшей степени определяет прогноз жизни пациента [1].

Данные последнего десятилетия свидетельствуют о том, что ожирение более чем на 50\% увеличивает риск развития XСН с сохраненной фракцией выброса левого желудочка (ЛЖ), находящейся в диапазоне 40-49\% [2].

Накопились данные и о том, что пациенты с ожирением 1-й степени могут иметь более благоприятный сердечно-сосудистый прогноз в сравнении с лицами с нормальной или недостаточной массой тела. Это явление было описано как «парадокс ожирения» в нескольких крупных исследованиях, однако механизмы, с помощью которых ожирение улучшает прогноз пациентов с XCH, до конца не ясны [3].

Известно, что ожирение включает в себя не только избыточную жировую, но и мышечную массу тела. Увеличение мышечной массы (в том числе массы миокарда) связано с улучшением работы кардиореспираторной системы, основной детерминанты формирования устойчивости к гипоксии. Увеличение ударного объема Лж и, соответственно, сердечного выброса ЛЖ создает условия для формирования компенсаторной гипертрофии миокарда и диастолической дисфункции ЛЖ [4]. Эти механизмы способны длительно компенсировать кислородный долг тканям организма. В дальнейшем развивается систолическая дисфункция миокарда с постепенным снижением фракции выброса ЛЖ [5]. В последних исследованиях «парадокс ожирения» подтвержден не только для XCH с сохраненной фракцией выброса ЛЖ, но и для более тяжелой ее формы - ХCH со сниженной насосной функцией ЛЖ [6].

9.1. Измерение пикового потребления кислорода (VO2) во время проведения спироэргометрического теста рекомендовано в качестве маркера степени гипоксии у пациентов с ожирением и ХСН (УДД 2, УУР В).

9.2. Оценка динамики показателей кардиореспираторной системы, прежде всего пиковое потребление кислорода (VO2), может использоваться в качестве маркера успешного лечения XCH у пациентов с ожирением (УДД 2, УУР В).

Комментарии. Более высокие показатели пикового потребления кислорода связаны сулучшением выживаемости пациентов с ожирением и ХCH. Однако потеря веса, вызванная ограничением калорий, также демонстрирует уменьшение тканевой гипоксии по данным спироэргометрического теста и улучшение качества жизни пациентов ССН и сохраненной фракцией выброса ЛЖ. То есть существуют и другие механизмы, не связанные с кардиореспираторной системой, но эффективно влияющие на нее [7]. Важность оценки устойчивости кардиореспираторной системы к гипоксии как маркера успешного лечения ХСН у пациентов с ожирением опубликована Американской кардиологической ассоциацией в 2016 г. Было предложено включить спироэргометрию в стандарты медицинской помощи [8].

Лица с непреднамеренной потерей веса (пациенты с терминальной ХСН), саркопеническим или морбидным ожирением при формировании необратимого изменения геометрии сердца имеют низкие показатели кардиореспираторной системы и неблагоприятный прогноз [9].

Соответственно, основные усилия клиницистов и исследователей должны быть направлены на разработку и реализацию стратегий, способных оптимизировать работу кардиореспираторной системы с использованием нефармакологических (аэробные физические нагрузки, диетология) и фармакологических вмешательств, особенно у пациентов со сниженной фракцией выброса ЛЖ [10].

9.3. Пациентам с застойной XCH для улучшения прогноза и снижения смертности не рекомендуется терапия, направленная на снижение массы тела (УДД 2, УУР В).

Комментарии. Недостаточно данных клинических исследований, подтверждающих преимущество медикаментозной потери веса в долгосрочном прогнозе пациентов С ХCH. Хотя имеются данные, свидетельствующие о том, что потеря массы тела может улучшить функцию миокарда и уменьшить симптомы застойной ХСН в краткосрочной перспективе. Трудно оценить независимость влияния потери массы тела на вероятность развития и исходы ССЗ по нескольким причинам:

а) пациенты с ожирением и XCH, как правило, получают терапию с доказанной эффективностью в отношении предотвращения кардиоваскулярных событий (статины, ингибиторы ангиотензинпревращающего фермента, гипотензивные препараты);

б) в ранее проведенных исследованиях по изучению лекарственных препаратов, снижающих массу тела, пациенты не были рандомизированы по факторам сердечно-сосудистого риска. Не очевиден и факт, что вмешательство было выполнено до начала развития заболеваний, ассоциированных с атеросклерозом.

9.4. Пациентам с подтвержденной ИБС, ожирением и ХСН рекомендуется целенаправленная потеря массы тела путем модификации образа жизни в сочетании с медикаментозным и хирургическим лечением ИБС, что может эффективно влиять на улучшение сердечно-сосудистых исходов (УДД 2, УУР В).

Комментарии. Результаты субанализов, проспективных и ретроспективных когортных исследований, включающих медикаментозное вмешательство, модификацию образа жизни и бариатрические операции, позволяют предположить, что потеря массы тела может быть связана со снижением сердечно-сосудистой смертности посредством 
оптимизации уровня АД, улучшения липидного профиля, нормализации гликемии, уменьшения объема висцерального жира. Метаанализ 12 исследований с участием 35335 пациентов с ИБС показал, что преднамеренная потеря массы тела благодаря вмешательству может эффективно влиять на улучшение сердечно-сосудистых исходов (ОР 0,67; 95\% ДИ 0,56-0,80; Р<0,001), тогда как снижение массы тела без модификации образа жизни, медикаментозного или хирургического лечения связано с ухудшением сердечно-сосудистого прогноза (ОР 1,62; 95\% ДИ 1,26-2,08; Р<0,001; взаимодействие $\mathrm{P}<0,001$ ) [11]. Ожирение повышает риск развития ХСН и вероятность структурных и функциональных изменений в миокарде $[12,13]$. Именно поэтому снижение массы тела может улучшить функцию миокарда и кратковременно повысить качество жизни. Клинические исследования необходимы для оценки отдаленных результатов, особенно с учетом «парадокса ожирения» при ХСН, который может проявиться в спланированных эпидемиологических исследованиях [14].

Современные Руководства АСС/АНА по лечению ХСН не содержат каких-либо конкретных рекомендаций по управлению ИМТ и признают отсутствие соответствующих данных [15]. Европейское общество кардиологов в своих Руководствах рекомендует, что ожирение при застойной ХСН следует лечить в соответствии с Рекомендациями «других руководств», разработанных для ведения пациентов с ожирением [16].

\section{5. Пациентам с ожирением рекомендуется такая же медикаментозная терапия ХСН, как и в общей популя- ции (УДД 1, УУР А).}

Комментарии. Кданной медикаментозной терапии относятся блокаторы ренин-ангиотензин-альдостероновой системы; антагонисты кальция; диуретики; бета-адреноблокаторы; статины и препараты ацетилсалициловой кислоты (при ИБС/высоком сердечно-сосудистом риске), прямые антикоагулянты (при наличии фибрилляции предсердий), сердечные гликозиды (по показаниям).

При ХСН и сниженной фракции выброса Лж влиянием на прогноз обладают антагонисты минералокортикоидов, препараты группы ARNI (сакубитрил/валсартан), ресинхронизирующие операции (имплантация кардиовертерадефибриллятора), реваскуляризирующие вмешательства на миокарде.

\section{6. Пациентам с СД2 и ожирением не рекомендуется целенаправленное снижение массы тела с явной и единственной целью предотвращения ССЗ и смертности (УДД1, УУР В).}

Комментарии. У пациентов с СД2 недостаточно данных, чтобы определить, снижает ли потеря веса вероятность СС3 и смертность от всех причин. Нерандомизированные когортные исследования дают противоречивые результаты [17]. Отчасти это объясняется тем, что в этих исследованиях участвовали как пациенты, преднамеренно снижающие массу тела, так и получающие медикаментозную терапию, влияющую на массу тела. Метаанализ 26 проспективных исследований с участием пациентов с СД и без СД продемонстрировал, что преднамеренная потеря массы тела не изменила смертность от всех причин (ОР 1,01; $\mathrm{P}=0,89)$, в то время как непреднамеренная - была связана с повышением сердечно-сосудистых рисков от 22 до 39\%. Большинство метаанализов рандомизированных клинических исследований (РКИ) выявило снижение смертности от всех причин, СД или онкологии [18].

РКИ, оценивающие эффекты преднамеренного снижения массы тела у пациентов с СД, достигнутого в результате интенсивной модификации образа жизни, не демонстрируют значительного снижения смертности у больных с кардиальной патологией, особенно имеющих тяжелые формы ее проявления по сравнению с контрольной группой, где существенное изменение образа жизни не проводилось [19].

\section{7. ИМТ не рекомендуется использовать в качестве маркера эффективности лечения пациентов с сердеч- но-сосудистой патологией и ХСН (УДД 2, УУР В).}

Комментарии. ИМТ связан с повышенным риском развития ССЗ главным образом благодаря его связи с другими факторами риска [20]. При поправке на ОТ или при наличии метаболического синдрома эта зависимость исчезает.

\section{СПИСОК ЛИТЕРАТУРЫ | REFERENCES}

1. Kenchaiah S, Evans JC, Levy D, et al. Obesity and the Risk of Heart Failure. N Engl J Med. 2002;347(5):305-313. doi: https://doi.org/10.1056/NEJMoa020245

2. Pandey A, LaMonte M, Klein L, et al. Relationship Between Physical Activity, Body Mass Index, and Risk of Heart Failure. J Am Coll Cardiol. 2017;69(9):1129-1142. doi: https://doi.org/10.1016/j.jacc.2016.11.081

3. Elagizi A, Kachur S, Lavie CJ, et al. An Overview and Update on Obesity and the Obesity Paradox in Cardiovascular Diseases. Prog Cardiovasc Dis. 2018;61(2):142-150. doi: https://doi.org/10.1016/.jpcad.2018.07.003

4. Obokata M, Reddy YNV, Pislaru S V. Melenovsky V, Borlaug BA. Evidence Supporting the Existence of a Distinct Obese Phenotype of Heart Failure With Preserved Ejection Fraction. Circulation. 2017;136(1):6-19. doi: https://doi.org/10.1161/CIRCULATIONAHA.116.026807

5. Packer $\mathrm{M}$. The conundrum of patients with obesity, exercise intolerance, elevated ventricular filling pressures and a measured ejection fraction in the normal range. Eur $J$ Heart Fail. 2019;21(2):156-162. doi: https://doi.org/10.1002/ejhf.1377
6. Padwal R, McAlister FA, McMurray JJ V, et al. The obesity paradox in heart failure patients with preserved versus reduced ejection fraction: a meta-analysis of individual patient data. Int J Obes. 2014;38(8):1110-1114. doi: https://doi.org/10.1038/ijo.2013.203

7. Carbone S, Canada JM, Buckley LF, et al. Obesity Contributes to Exercise Intolerance in Heart Failure With Preserved Ejection Fraction. J Am Coll Cardiol. 2016;68(22):2487-2488. doi: https://doi.org/10.1016/j.jacc.2016.08.072

8. Ross R, Blair SN, Arena R, et al. Importance of Assessing Cardiorespiratory Fitness in Clinical Practice: A Case for Fitness as a Clinical Vital Sign: A Scientific Statement From the American Heart Association. Circulation. 2016;134(24). doi: https://doi.org/10.1161/CIR.0000000000000461

9. Miller SL, Wolfe RR. The danger of weight loss in the elderly. J Nutr Heal Aging. 2008;12(7):487-491. doi: https://doi.org/10.1007/BF02982710

10. Carbone S, Canada JM, Buckley LF, et al. Dietary Fat, Sugar Consumption, and Cardiorespiratory Fitness in Patients With Heart Failure With Preserved Ejection Fraction. JACC Basic to Trans/ Sci. 2017;2(5):513-525. doi: https://doi.org/10.1016/j.jacbts.2017.06.009 
11. Pack QR, Rodriguez-Escudero JP, Thomas RJ, et al. The Prognostic Importance of Weight Loss in Coronary Artery Disease: A Systematic Review and Meta-analysis. Mayo Clin Proc. 2014;89(10):1368-1377. doi: https://doi.org/10.1016/j.mayocp.2014.04.033

12. Poirier P, Giles TD, Bray GA, et al. Obesity and Cardiovascular Disease. Arterioscler Thromb Vasc Biol. 2006;26(5):968-976. doi: https://doi.org/10.1161/01.ATV.0000216787.85457.f3

13. Kenchaiah S, Evans JC, Levy D, et al. Obesity and the Risk of Heart Failure. N Engl J Med. 2002;347(5):305-313. doi: https://doi.org/10.1056/NEJMoa020245

14. Curtis JP, Selter JG, Wang Y, et al. The Obesity Paradox. Arch Intern Med. 2005;165(1):55. doi: https://doi.org/10.1001/archinte.165.1.55

15. Yancy CW, Jessup M, Bozkurt B, et al. 2013 ACCF/AHA Guideline for the Management of Heart Failure. J Am Coll Cardiol. 2013;62(16):e147-e239. doi: https://doi.org/10.1016/j.jacc.2013.05.019

16. McMurray JJ V., Adamopoulos S, Anker SD, et al. ESC Guidelines for the diagnosis and treatment of acute and chronic heart failure 2012: The Task Force for the Diagnosis and Treatment of Acute and Chronic
Heart Failure 2012 of the European Society of Cardiology. Developed in collaboration with the Heart. Eur Heart J. 2012;33(14):1787-1847. doi: https://doi.org/10.1093/eurheartj/ehs104

17. Williamson DF. Weight loss and mortality in persons with type-2 diabetes mellitus: a review of the epidemiological evidence. Exp Clin Endocrinol Diabetes. 2009;106(S 02):14-21. doi: https://doi.org/10.1055/s-0029-1212031

18. Kritchevsky SB, Beavers KM, Miller ME, et al. Intentional Weight Loss and All-Cause Mortality: A Meta-Analysis of Randomized Clinical Trials. Wu W-CH, ed. PLoS One. 2015;10(3):e0121993. doi: https://doi.org/10.1371/journal.pone.0121993

19. Kenchaiah S, Evans JC, Levy D, et al. Cardiovascular Effects of Intensive Lifestyle Intervention in Type 2 Diabetes. N Engl J Med. 2013;369(2):145-154. doi: https://doi.org/10.1056/NEJMoa1212914

20. van Dijk SB, Takken T, Prinsen EC, Wittink H. Different anthropometric adiposity measures and their association with cardiovascular disease risk factors: a meta-analysis. Netherlands Hear J. 2012;20(5):208-218. doi: https://doi.org/10.1007/s12471-011-0237-7 


\title{
ГЛАВА 10. ОЖИРЕНИЕ И НЕАЛКОГОЛЬНАЯ ЖИРОВАЯ БОЛЕЗНЬ ПЕЧЕНИ
}

\author{
Комшилова К.А., Мазурина Н.В., Исаков В.А., Сасунова А.Н., Трошина Е.А.
}

\section{ВВЕДЕНИЕ}

Неалкогольная жировая болезнь печени (НАЖБП) — хроническое заболевание, характеризующееся избыточным накоплением в клетках печени жира в форме триглицеридов, не связанное со злоупотреблением алкоголем в гепатотоксичных дозах (более 40 г чистого этанола в сутки для мужчин и более 20 г для женщин).

При НАЖБП выделяют две клинико-морфологические формы заболевания: стеатоз печени (с накоплением жировых включений в печени ( $\geq 5 \%$ гепатоцитов) без баллонной дистрофии гепатоцитов и фиброза) и неалкогольный стеатогепатит (НАСГ) — с накоплением жировых включений в печени ( $\geq 5 \%$ гепатоцитов), воспалением, баллонной дистрофией гепатоцитов и возможным развитием фиброза.

НАЖБП на стадии стеатоза характеризуется доброкачественным, медленно прогрессирующим течением и не повышает риск смертности в общей популяции, однако потенциально опасная стадия - НАСГ во многих случаях остается нераспознанной и в отсутствие адекватного лечения может прогрессировать и приводить к развитию цирроза, печеночной недостаточности и гепатоцеллюлярной карциномы. НАСГ — наиболее вероятная причина развития криптогенных циррозов печени неясной этиологии: по данным ряда исследований, в 60-80\% случаев криптогенный цирроз формируется в исходе НАСГ. Также цирроз печени в исходе НАСГ в настоящее время является наиболее частой причиной трансплантации печени в экономически развитых странах [1-4].

НАЖБП тесно ассоциирована с ожирением и метаболическим синдромом, что значительно повышает риск СС3 и отражается на продолжительности жизни больных. По данным Всемирной гастроэнтерологической организации, у пациентов с НАЖБП и ожирением смертность намного выше, чем в общей популяции, в первую очередь за счет ССЗ [1-4]. Следует отметить, что увеличение смертности связано не с наличием у пациента НАЖБП как таковой, а со степенью фиброза печени, который сформировался в результате ее прогрессирования.

\section{ЭПИДЕМИОЛОГИЯ}

По данным эпидемиологических исследований, распространенность неалкогольного стеатоза печени у жителей экономически развитых стран мира составляет в среднем 20-35\%, НАСГ - 3\%. В США стеатоз печени имеют 34\% взрослого населения, в Японии - 29\%. Среди больных ожирением распространенность различных клинических форм НАЖБП значительно выше, чем в общей популяции, и составляет, по данным различных исследований, 75-93\%, причем НАСГ диагностируется у 18,5-26\%, фиброз - у 20-37\%, цирроз печени - у 9-10\% больных. При морбидном ожирении частота НАЖБП возрастает до 95-100\%. Среди больных СД2 НАЖБП диагностируется у 50-75\% пациентов [1-4].

\section{ЭТИОЛОГИЯ И ПАТОГЕНЕЗ НАЖБП}

Патогенез НАЖБП связан с абдоминальным ожирением и ИР: накопление избыточного количества триглицеридов в гепатоцитах, повышение синтеза эндогенных жирных кислот, оксидативный стресс, эндотелиальная дисфункция, хроническое сосудистое воспаление, изменение секреции адипоцитокинов, нарушение микрофлоры в тонкой кишке, которые нарастают по мере прогрессирования патологических изменений печени от стеатоза к НАСГ. Следует отметить, что ИР рассматривается как самостоятельный фактор, который способен определить развитие и прогрессирование НАЖБП. Гены, участвующие в метаболизме глюкозы, липидов, воспалении и развитии фиброза (например, PNPLA3, ENPP1/PC-1), определяют риск развития НАЖБП независимо от наличия ожирения и СД [5-7].

Среди множества факторов и механизмов, способствующих развитию и прогрессированию НАЖБП, первостепенная роль принадлежит ИР и ожирению, особенно висцеральному (табл. 10) [7-8].

Таблица 10. Этиологические факторы развития неалкогольной жировой болезни печени

\begin{tabular}{l|l}
\hline $\begin{array}{l}\text { Нарушения } \\
\text { питания }\end{array}$ & Ожирение (особенно абдоминальное) \\
\hline $\begin{array}{l}\text { Болезни эндокринной } \\
\text { системы, расстройств питания } \\
\text { и нарушения обмена веществ }\end{array}$ & $\begin{array}{l}\text { СД2, ИР, липодистрофия регионарная, гипертриглицеридемия, абеталипопротеи- } \\
\text { немия, гиполипопротеинемия, болезнь Вебера-Крисчена и Вильсона-Коновалова, } \\
\text { длительное парентеральное питание, быстрая потеря массы тела }\end{array}$ \\
\hline $\begin{array}{l}\text { Лекарственные } \\
\text { препараты }\end{array}$ & $\begin{array}{l}\text { Глюкокортикоиды, нестероидные противовоспалительные препараты, синтетические } \\
\text { эстрогены, тамоксифен, тетрациклины, метотрексат, зидовудин, диданозин, амиодарон, } \\
\text { вальпроевая кислота и др. }\end{array}$ \\
\hline Хирургические & $\begin{array}{l}\text { Синдром мальабсорбции вследствие: гастропластики, наложения } \\
\text { илеоеюнального анастомоза, расширенной резекции тонкой кишки и т.д. }\end{array}$ \\
\hline Генетические & Врожденные дефекты мультиферментного комплекса ß-окисления, изменения \\
факторы & $\begin{array}{l}\text { структуры митохондриальной ДНК, угнетение Љ-окисления под воздействием аммиака, } \\
\text { накапливающегося вследствие нарушения функционирования орнитинового цикла }\end{array}$ \\
\hline
\end{tabular}


Выделяют следующие группы риска развития НАЖБП.

$\checkmark$ Группы высокого риска развития НАЖБП: пациенты с ожирением, СД2, дислипидемией, метаболическим синдромом, синдромом поликистозных яичников.

$\checkmark$ Группа умеренного риска развития НАЖБП: пациенты с гипотиреозом, синдромом обструктивного апноэ сна, гипопитуитаризмом, гипогонадизмом, псориазом, пациенты, перенесшие панкреатодуоденальную резекцию, независимо от ожирения [7-9].

Существует ряд клинических и биохимических признаков, которые легко можно диагностировать в ходе регулярного профилактического осмотра пациентов, дающего возможность выявить пациентов с высоким риском развития НАСГ (табл. 11).

Таблица 11. Факторы риска развития фиброза печени у больных НАЖБП

\author{
1. Ожирение. \\ 2. Возраст старше 45 лет. \\ 3. Женский пол. \\ 5. СД2. \\ 6. АГ. \\ 7. АСТ $\geq 40$ ЕД/л. \\ 8. АСТ/АЛТ $\geq 0,8-1$. \\ 9. Низкий уровень тромбоцитов
}

\title{
КЛИНИЧЕСКАЯ ХАРАКТЕРИСТИКА, ОСНОВНЫЕ СИМПТОМЫ И ДИАГНОСТИКА НАЖБП
}

Диагноз НАСГ является в значительной мере диагнозом исключения, когда отсутствуют иные причины хронического воспаления печени, такие как злоупотребление алкоголем, вирусные и аутоиммунные заболевания печени, болезни накопления, прием гепатотоксичных препаратов.

\section{Клиническая картина}

У пациентов заболевание протекает бессимптомно. Подозрение на НАЖБП возникает в основном у большинства обследуемых с высокими уровнями АЛТ (аланинаминотрансферазы) и АСТ (аспартатаминотрансферазы) в крови или при наличии диффузного повышения эхогенности ткани печени на УЗИ, являющегося признаком стеатоза. Наиболее распространенными симптомами являются астения, слабость, утомляемость. Реже отмечается чувство тяжести, ноющие боли в правой подреберной области, не имеющие четкой связи с какими-либо провоцирующими факторами. У некоторых пациентов (50-75\%) при пальпации отмечается гепатомегалия и слегка незначительная болезненность. Диспепсические явления, кожный зуд, желтуха, «печеночные знаки», признаки печеночной недостаточности и портальной гипертензии (увеличение селезенки, асцит) выявляются редко, уже преимущественно на стадии цирроза. Проявления НАСГ неспецифичны и не коррелируют со степенью его активности [10-12].

\section{Лабораторная диагностика}

10.1. Всем пациентам с ожирением рекомендовано определение показателей, характеризующих функциональное состояние печени (АЛТ, АСТ, гамма-глутамилтранспептидаза (ГГТП), щелочная фосфатаза) (УУР В, УДД 2).

Комментарии. У пациентов с НАЖБП показатели, характеризующие функциональное состояние печени (АЛТ, АСТ, ГГТП, щелочная фосфатаза) не определяют форму НАЖБП и активность НАСГ. Повышенный уровень сывороточных трансаминаз выявляют у 20-21\% пациентов со стеатозом печени и у 50-90\% больных с НАСГ. Тем не менее нормальные показатели трансаминаз не исключают вероятность существования некротически-воспалительных изменений и фиброза печени. Вероятность наличия НАСГ выше при уровне трансаминаз, превышающем норму более чем в 2 раза. При НАСГ уровень АЛТ чаще выше уровня АСТ, а пониженный уровень АЛТ в сочетании с выраженным ожирением может свидетельствовать о наличии тяжелого фиброза и цирроза печени. Как правило, активность трансаминаз в сыворотке крови не превышает норму более чем в 4-5 раз. В ряде случаев при НАЖБП отмечается изолированное повышение активности ГГТП и щелочной фосфатазы. При развитии цирроза у больных НАЖБП могут выявляться: гипоальбуминемия, тромбоцитопения и увеличение времени свертывания крови. В ряде случаев у пациентов с НАЖБП обнаруживаются нарушения метаболизма железа (повышение уровня ферритина и насыщения трансферрина сыворотки), не связанные с наличием наследственного гемохроматоза [10-12].

10.2. В связи с отсутствием в настоящее время достоверных данных по сопоставлению фибротестов с клинико-морфологическими изменениями в печени, выявляемыми при пункционной биопсии, фибротесты не рекомендуются в качестве основного метода диагностики НАЖБП, но могут быть дополнительными методами исследования для определения наличия и стадии фиброза [10-12] (УУР С, УдД 2). 
Комментарии. Фибротесты (FIB-4, NFS) позволяют оценить степень выраженности повреждения печени на основе определения в крови биомаркеров воспаления и фиброза (таких, например, как альфа 2-макроглобулин, аполипопротеин А1, гаптоглобин, ГГТП, билирубин, гиалуроновая кислота, общий амино-терминальный пропептид проколлагена III типа, тканевой ингибитор матричной металлопротеиназы-1 и др.). Их чувствительность и специфичность составляют 70-90\%, информативность возрастает с увеличением степени стеатоза, НАСГ и фиброза. Данные тесты предназначены для первичного скрининга, целью которого является выявление лиц с возможным наличием выраженного фиброза печени и их последующего дообследования у специалиста-гепатолога (рис. 2).

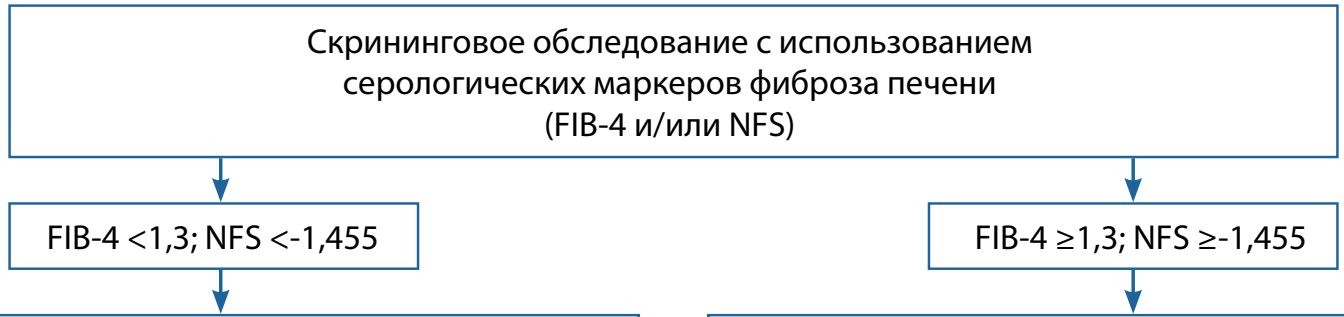

Выраженный фиброз печени маловероятен. Дальнейшее обследование не требуется. Повторная оценка через 1 год

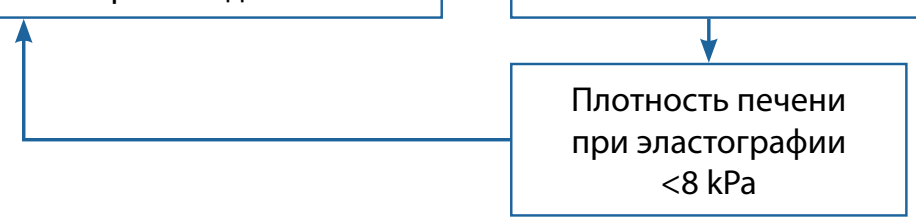

Выраженный фиброз печени высоковероятен. Требуется подтверждение результата

с использованием эластографии печени

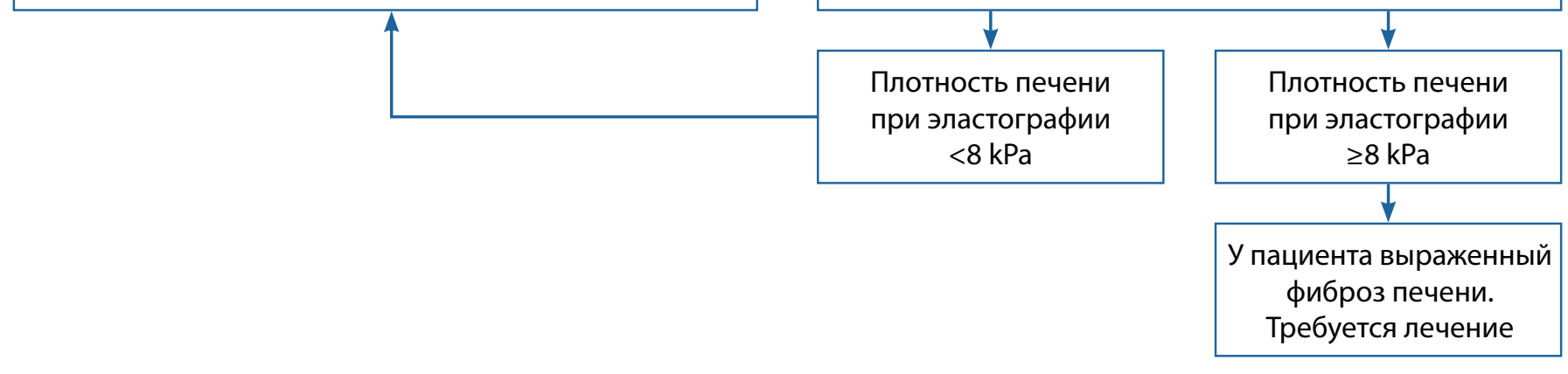

Рисунок 2. Алгоритм обследования пациента с подозрением на неалкогольную жировую болезнь печени с целью выявления стадии фиброза печени.

\section{ИMT $\geq 30 \mathrm{Kг} / \mathrm{M}^{2}$}

УЗИ ПЕЧЕНИ: жировой гепатоз

Исключение вирусных, аутоиммунных заболеваний печени, болезней накопления, приема гепатотоксических препаратов, СД 1 типа

БИОХИМИЧЕСКИЙ АНАЛИЗ КРОВИ: АЛТ, АСТ

Б/Х АНАЛИЗ КРОВИ: ОХС, ТГ, ЛПНП, ЛПВП, глюкоза, билирубин общий и прямой, общий белок, мочевая кислота

ЛЕЧЕНИЕ: снижение массы тела (назначение основного варианта стандартной диеты), регулярная физическая активность, лечение сопутствующей патологии

Б/Х АНАЛИЗ КРОВИ: ОХС, ТГ, ЛПНП, ЛПВП, глюкоза, билирубин общий и прямой, общий белок, мочевая кислота

КОНТРОЛЬ ЧЕРЕ3 1,5 МЕС: антропометрия / оценка состава тела / АЛТ, АСТ / оценка фактического питания

Рисунок 3. Алгоритм обследования и лечения пациентов с неалкогольной жировой болезнью печени для врачей общей практики 


\section{Исследование показателей липидного и углеводного обмена}

10.3. Всем пациентам с ожирением и подозрением на НАЖБП рекомендовано обязательное исследование параметров липидного и углеводного обмена как составляющих метаболического синдрома (УУР А, УДД 1).

Комментарии. У абсолютного большинства больных с ожирением и НАЖБП выявляются различные метаболические нарушения, такие как дислипидемия, гипертриглицеридемия, снижение ХС ЛПВП в крови, НГН или НТГ, гиперинсулинемия, СД2, являющиеся кардиометаболическими факторами риска. Данные нарушения, как правило, носят сочетанный характер и нарастают по частоте и выраженности по мере прогрессирования заболевания [10-12].

\section{Инструментальные методы диагностики}

10.4. Для диагностики НАЖБП всем пациентам с ожирением рекомендовано проведение ультразвукового исследования печени (первый скрининговый метод диагностики стеатоза печени) (УУР А, УДД 1).

Комментарии. Квизуальным методам диагностики НАЖБПотносят:ультразвуковое исследование, компьютерную томографию, магнитно-резонансную томографию печени и эластографию. Все инструментальные методы диагностики НАЖБП обладают определенной диагностической информативностью в качественном определении стеатоза печени, но ни один из этих методов не позволяет точно определить форму НАЖБП, выявить стеатогепатит и определить степень его активности [10-12].

Чувствительность и специфичность ультразвукового исследования составляют 60-94 и 88-95\% соответственно и снижаются по мере увеличения ИМТ и степени стеатоза до 49 и 75\%. Ультразвуковое исследование печени у больных с НАЖБП, как правило, выявляет гиперэхогенность или диффузное увеличение «яркости» печеночной паренхимы (эхогенность печени превышает эхогенность почек), нечеткость сосудистого рисунка, дистальное затухание эхосигнала [10-12]. Компьютерная томография печени и магнитно-резонансная томография с контрастированием позволяют лишь косвенно оценить форму НАЖБП [10-12].

10.5. Эластография (фиброскан) неинформативна при ИМТ более 30 кг/м² и не рекомендуется для диагностики НАЖБП при ожирении, но может быть дополнительным методом исследования для определения наличия и стадии фиброза [10-12] (УУР С, УДД 2).

Комментарии. В настоящее время фиброскан, оснащенный технологией САР (определение параметра контролируемого затухания ультразвуковой волны), позволяет надежно диагностировать стеатоз печени [13], в том числе и у пациентов с высокими значениями ИMT с использованием XL-датчика [14, 15]. Тем не менее, поскольку степень стеатоза не важна для прогноза заболевания и значимо не влияет на риск смерти от печеночных или внепеченочных причин, то основной проблемой является надежная диагностика продвинутых стадий фиброза, поскольку именно эта категория пациентов требует динамического наблюдения и медикаментозной терапии. С этой задачей фиброскан справляется успешно даже у пациентов с высокой массой тела с использованием датчика XL. OCHовное назначение фиброскана у данной категории пациентов - исключить или подтвердить наличие тяжелого фиброза (F3/F4), так как это позволяет в подавляющем большинстве случаев избежать выполнения биопсии печени.

\section{Морфологическая диагностика}

10.6. Пункционная биопсия печени, позволяющая объективно диагностировать НАЖБП и ее форму, оценить степень активности НАСГ, стадию фиброза, прогнозировать течение заболевания и контролировать эффективность лечения, рекомендуется пациентам с факторами риска развития НАСГ и цирроза печени (УУР А, УДД 1).

Критерии для проведения биопсии печени при НАЖБП:

1. пациенты с высоким риском трансформации стеатоза в НАСГ и выраженный фиброз печени;

2. пациенты (особенно при наличии метаболического синдрома) со стойким повышением АЛТ, АСТ после снижения массы тела и изменения образа жизни;

3. преобладание уровня АСТ над АЛт;

4. высокий индекс фиброза;

5. пациенты старше 45 лет, с ИМТ > 30 кг/м², СД2 и признаками цирроза печени;

6. пациенты с предполагаемой НАЖБП, у которых иная этиология стеатоза и сопутствующее хроническое заболевание печени не могут быть исключены без проведения этого исследования.

Точность диагностики морфологической формы НАЖБП с использованием неинвазивных методов составляет всего 50\% [10-12]. Данные биопсии печени позволяют подтвердить диагноз НАЖБП, исключить другую патологию и провести дифференциальную диагностику между стеатозом и стеатогепатитом. Гистологическое исследование также позволяет установить стадию заболевания, оценить выраженность фиброза печени (основной фактор прогноза заболевания). Но данный метод является инвазивным, не самым доступным, поэтому необходимо тщательно проводить отбор пациентов для биопсии. При отборе пациентов для биопсии печени врачи должны учитывать в первую очередь факторы риска развития НАСГ [10-12]. На самом деле биопсия печени в реальной клинической практике для диагностики НАЖБП используется редко, поскольку выявление стеатоза печени большой проблемы не представляет. Для этой цели успешно используются УЗИ или другие методы визуализации, позволяющие определить стеатоз печени 
полуколичественно (фиброскан, оснащенный технологией CAP) или даже количественно (MRI-PDFF). При этом в динамическом наблюдении стеатоза, например, на фоне лечения, последние выигрывают у биопсии, поскольку оценивают его наличие в значительно большем объеме печеночной ткани. Для принятия решения о том или ином терапевтическом вмешательстве у больных НАЖБП не нужно точно знать стадию фиброза, достаточно информации о наличии продвинутых его стадий (F3/F4), а это также можно выявить с помощью методов визуализации - фиброскана (Рисунок 2) или магнитно-резонансной эластографии. В связи с этим биопсия печени применяется при НАЖБП в основном в рамках клинических исследований, для оценки динамики гистологических показателей (стеатоза, воспаления и баллонной дистрофии гепатоцитов) при уменьшении фиброза на 1 балл или хотя бы отсутствии его прогрессирования. Вторым показанием для проведения биопсии печени является неясность этиологии процесса в печени, что характерно для очень небольшого числа пациентов в практике гепатолога.

\section{ЛЕЧЕНИЕ НАЖБП}

Немедикаментозная терапия

10.7. Всем пациентам с ожирением и НАЖБП рекомендуется сбалансированное антиатерогенное питание с ограничением жиров до 25-30\% от суточной калорийности, гипокалорийное (с умеренным дефицитом калорийности суточного рациона в 500-1000 ккал) на этапе снижения веса и эукалорийное на этапе его поддержания [10-12] (УУР А, УДД 1).

10.8. Всем пациентам с ожирением и НАЖБП рекомендуется обязательное увеличение физической активности - это ежедневные умеренные аэробные физические нагрузки, например, ходьба 30-40 мин в день или 150-200 мин в неделю. При сочетании физических нагрузок с рациональным питанием в большей степени улучшаются биохимические показатели и морфологические изменения печени [10-12] (УУР В, УДД 1).

10.9. Пациентам без НАСГ или фиброза рекомендованы только здоровое питание и физическая активность без фармакотерапии [10] (УУР В, УДД 2).

Комментарии. До сих пор не существует универсальных алгоритмов лечения пациентов с НАЖБП, тем не менее, очевидным является то, что подход к лечению таких пациентов должен быть комплексным. При отсутствии значимого фиброза печени основу терапии составляют диета и дозированные физические нагрузки (рис. 3). Поскольку основными причинами ожирения являются избыточная калорийность пищи в совокупности с малоподвижным образом жизни, основу лечения пациентов с ожирением и НАЖБП составляют немедикаментозные методы: модификация образа жизни, основанная на коррекции питания и расширении объема аэробных физических нагрузок [10-12].

Критерием эффективности терапии является постепенное уменьшение массы тела на 7-10\% от исходной, что сопровождается положительной динамикой метаболических показателей и морфологической картины печени, а также приводит к снижению трансаминаз и улучшению гистологической картины НАЖБП (уменьшение стеатоза, стабилизация и регрессия фиброза печени).

В то время как гиперкалорийный рацион приводит к возникновению и прогрессированию НАЖБП, коррекция питания влияет на течение заболевания. Многие исследования показали, что снижение массы тела на 5-10\% в течение 12 мес на фоне диеты и физических упражнений приводит к значительному снижению выраженности стеатоза [16]. Каждому пациенту требуется индивидуальный подход, сочетающий в себе диетотерапию и постепенное расширение физической активности. Все рекомендации по диетотерапии должны быть выполнимыми на долгосрочной основе.

Соблюдение диеты с ограничением калорийности в течение 12 мес приводит к снижению массы тела и, как следствие, снижает ИР, которая лежит в основе патогенеза НАЖБП. В сравнительных исследованиях и низкожировая, и низкоуглеводная диеты показали положительные результаты, на основании чего можно сделать вывод, что снижение калорийности рациона важнее конкретных диетических ограничений. Вместе с этим резкое ограничение калорийности и быстрое снижение массы тела может привести к прогрессированию фиброза и повышению уровня печеночных трансаминаз. Рекомендовано медленное снижение массы тела на 0,5-1 кг в месяц.

Диетические рекомендации должны включать ограничение энергетической ценности рациона и исключение консервированных пищевых продуктов, а также продуктов и напитков с высоким содержанием фруктозы. Состав макроэлементов следует скорректировать в соответствии со средиземноморской диетой. Особым фактором нерационального питания, который приводит к развитию стеатоза печени, является избыточное потребление фруктозы. Считается, что его неблагоприятное воздействие реализуется путем de novo липогенеза, увеличения количества висцерального жира и отрицательного влияния на чувствительность к инсулину. В связи с этим пациентам рекомендуется ограничение потребления сладких газированных напитков, меда, сиропов и избыточного потребления фруктов.

Пациентам с НАЖБП рекомендовано снижение суточной калорийности рациона на 750-1000 ккал или на 30\% от привычного рациона за счет снижения потребления легкоусвояемых углеводов и насыщенных жиров. Считается, что структура рациона, соответствующая «средиземноморской диете» (табл. 12), способствует меньшей вероятности формирования стеатоза печени за счет большого количества ПНЖК и пищевых волокон [10]. Увеличение доли пищевых волокон в рационе пациентов с НАЖБП сопровождается улучшением состава микробиоты, а также оказывает положительное влияние на ИР, массу тела, уровень печеночных трансаминаз, показателей углеводного и липидного обмена. Важно, что отдельные эффекты средиземноморской диеты проявляются независимо от изменения ИМТ, что делает ее предпочтительной перед другими ввиду хорошей приверженности к ней пациентов и выраженного влияния на факторы риска ССЗ $[16,17]$. 
В эпидемиологических исследованиях умеренное употребление алкоголя (безопасный уровень потребления 30 г у мужчин; 20 г у женщин) связано с более низкой распространенностью НАЖБП, НАСГ и фиброза по данным гистологии. Однако у пациентов с метаболическим синдромом избыточное употребление алкоголя чаще приводит к развитию гепатоцеллюлярной карциномы и, соответственно, значительно увеличивает риск смерти.

Таблица 12. Средиземноморская диета: макронутриентный состав

\begin{tabular}{|c|c|}
\hline Углеводы & 45-60\% общей калорийности, предпочтительно нерафинированные \\
\hline Клетчатка & 20-40 г/сут \\
\hline Жиры: & $\begin{array}{l}\text { 25-30\% общей калорийности. } \\
\text { Из них: } \\
\text { насыщенные жиры: 7\%; } \\
\text { ПНЖК: 5-10\%; } \\
\text { мононенасыщенные жиры: 15-20\%; } \\
\text { холестерин: 200-300 мг/ сут; } \\
\text { трансжиры: <1\% суточной калорийности }\end{array}$ \\
\hline Белки & 20\% суточной калорийности \\
\hline
\end{tabular}

В настоящее время проводится множество исследований по изучению влияния различных нутрицевтиков на течение НАЖБП. С нутрицевтической точки зрения относительно небольшое количество добавок можно считать клинически изученными. В настоящее время основное внимание уделяется изучению силимарина, витамина D, омега-3 полиненасыщенных жирных кислот, астаксантина, коэнзима Q10, берберина, куркумина, ресвератрола и пробиотиков. Однако до настоящего времени ни один из нутрицевтиков не доказал свою эффективность относительно влияния на выраженность фиброза печени у больных НАЖБП.

\section{Медикаментозная терапия}

10.10. При отсутствии клинически значимого снижения массы тела на фоне немедикаментозных методов, для повышения эффективности терапии ожирения рекомендовано использование фармакотерапии (лираглутид 3,0 мг/сут, орлистат, сибутрамин, сибутрамин+МКЦ, сибутрамин+метформин), которая позволяет добиться более эффективного снижения массы тела, облегчает выполнение рекомендаций по питанию, помогает в выработке новых привычек в питании, а также способствует длительному удержанию сниженной массы тела [18, 19] (УУР В, УДД 1).

10.11. Пациентам с НАЖБП и нарушениями углеводного обмена рекомендуется назначение метформина В дозе 2000 мг в сутки не менее чем на 12 мес (УУР В, УДД 1).

10.12. Пациентам с НАСГ, особенно при выраженном фиброзе, требуется медикаментозное лечение. Пациентам с менее тяжелым течением заболевания, но с высоким риском его прогрессирования (при СД, МС, устойчивом повышении уровня АЛТ, выраженном некровоспалительном процессе) также показана профилактическая терапия [10] (УУР В, УДД 1).

10.13. В лечении НАСГ можно использовать пиоглитазон (данные свидетельствуют о наибольшей эффективности препарата, однако за исключением применения при СД2 во всех остальных случаях он используется вне зарегистрированных показаний), или витамин Е (наиболее безопасный и хорошо переносимый препарат в краткосрочной перспективе), или комбинацию этих препаратов, однако достоверные рекомендации на этот счет отсутствуют [10] (УУР В, УДД 2).

10.14. Оптимальная длительность терапии не определена; у пациентов с исходно повышенным уровнем АЛт лечение нужно прекратить, если после 6 мес терапии уровень АЛТ не снижается; в отношении пациентов с нормальным уровнем АЛТ рекомендации отсутствуют [10] (УУР С, УДД 2).

10.15. Статины можно уверенно рекомендовать для снижения уровня ЛПнП и сердечно-сосудистого риска, положительное или отрицательное воздействие на печеночную патологию не установлено. ПнЖК способствуют снижению уровня жира в плазме и печени, но нет никаких данных в поддержку их использования именно при НАСГ [10] (УУР В, УДД 1).

Комментарии. До сих пор не существует универсальных алгоритмов лечения пациентов с НАЖБП, тем не менее, очевидным является то, что подход к лечению таких пациентов должен быть комплексным. При выборе метода лечения учитывают основные этиопатогенетические факторы и фоновые заболевания. Лечение должно быть направлено на снижение стеатоза печени, активности воспаления ткани печени и уменьшение фиброгенеза. Полагают, что эффективность терапии НАСГ должна соответствовать следующим критериям: уменьшение стеатоза печени и воспаления при как минимум отсутствии прогрессирования фиброза по данным парных биопсий печени (до и после лечения). Согласно этим критериям, все существующие сегодня препараты, так или иначе воздействующие на состояние гепатоцитов и долгое время применявшиеся при НАЖБП, неэффективны. К ним относятся различные «гепатопротекторы», 
урсодезоксихолевая кислота, средства для лечения диабета (в том числе метформин), статины и другие. Относительно подавляющего большинства таких препаратов опубликованы обширные метаанализы, подтверждающие их неэффективность относительно НАСГ, либо проведенные клинические исследования с их использованием малочисленны и не отвечают принципам доказательной медицины. Таким образом, в настоящее время специфической терапии НАЖБП нет [10-12, 20].

Два опубликованных к настоящему времени метаанализа свидетельствуют о положительном влиянии метформина на метаболические показатели, однако не подтверждают положительного влияния этого препарата на морфологию ткани печени при НАЖБП [20, 21].

Поскольку показатели общей смертности пациентов с НАЖБП выше по сравнению с общей популяцией, преимущественно из-за СС3 [2, 3], то первоочередной задачей терапии становится коррекция метаболических нарушений. С этой точки зрения метформин обладает доказанной эффективностью. Профилактика развития СД2 у пациентов с НАЖБП является важнейшим компонентом лечения данной категории больных, таким образом, применение метформина при НАЖБП обосновано, прежде всего с целью замедления прогрессирования нарушений углеводного обмена [22].

Многочисленные исследования, посвященные оценке эффективности метформина при НАЖБП [23-30], демонстрируют целый ряд преимуществ данной терапии по сравнению с немедикаментозным лечением: более выраженное уменьшение размеров печени, по данным УЗИ, снижение ИР, плазменных концентраций АЛТ, АСТ и улучшение метаболических показателей. Несмотря на то что во всех этих исследованиях метаболические параметры были лучше на фоне лечения метформином, результаты также подтверждают, что диетотерапия сама по себе также эффективна при НАЖБП. Улучшение гистологической картины на фоне лечения метформином было отмечено в нескольких открытых неконтролируемых исследованиях [25-27]. Положительная динамика выражалась в уменьшении воспалительной инфильтрации и дистрофии гепатоцитов. В трех рандомизированных исследованиях терапия метформином практически не оказывала эффекта на гистологическую картину заболевания [28-30].

Единственной медикаментозной терапией НАСГ с доказанной эффективностью в настоящее время является применение витамина Е в дозе 800 МЕ/сут. При длительности лечения не менее года он продемонстрировал эффективность относительно уменьшения стеатоза и отсутствие прогрессирования фиброза печени [10-12, 31-33]. Однако данный вид лечения имеет существенные недостатки: во-первых, его эффективность неизвестна у больных с СД2, поскольку обширные плацебо-контролируемые исследования выполнены на популяции пациентов с НАСГ без диабета, во-вторых, длительный прием высоких доз витамина Е ассоциирован с небольшим, но достоверным увеличением смертности от всех причин по данным обширных проспективных исследований и, наконец, в-третьих, использование высоких доз витамина Е увеличивает риск развития рака предстательной железы [34-35]. Все это существенно сужает круг пациентов с НАСГ, у которых может быть использована данная терапия.

\section{Бариатрическая хирургия}

10.16. Бариатрическая хирургия не противопоказана больным ожирением с НАЖБП или НАСГ (без верифицированного цирроза) [10-12, 36-37] (УУР А, УДД 1).

Комментарии. Проспективные данные свидетельствуют о регрессии всех неблагоприятных гистологических изменений при НАСГ, включая фиброз, у пациентов, перенесших бариатрические операции [10-12, 36-37].

10.17. У больных с НАСГ, у которых изменение образа жизни и фармакотерапия не дали улучшения, рекомендуется хирургическое лечение ожирения для снижения массы тела и коррекции метаболических осложнений с получением стабильных долгосрочных результатов [10-12, 36-37] (УУР В, УДД 1).

\section{СПИСОК ЛИТЕРАТУРЫ | REFERENCES}

1. Lazo M, Clark J. The Epidemiology of Nonalcoholic Fatty Liver Disease: A Global Perspective. Semin Liver Dis. 2008;28(04):339-350. doi: https://doi.org/10.1055/s-0028-1091978

2. Misra VL, Khashab M, Chalasani N. Nonalcoholic fatty liver disease and cardiovascular risk. Curr Gastroenterol Rep. 2009;11(1):50-55. doi: https://doi.org/10.1007/s1 1894-009-0008-4

3. Stefan N, Kantartzis K, Häring H-U. Causes and Metabolic Consequences of Fatty Liver. Endocr Rev. 2008;29(7):939-960. doi: https://doi.org/10.1210/er.2008-0009

4. Musso G, Gambino R, Cassader M. Non-alcoholic fatty liver disease from pathogenesis to management: an update. Obes Rev. 2009;1 1(6):430-445. doi: https://doi.org/10.1111/j.1467-789X.2009.00657.x

5. Dowman JK, Tomlinson JW, Newsome PN. Pathogenesis of non-alcoholic fatty liver disease. QJM. 2010;103(2):71-83. doi: https://doi.org/10.1093/ajmed/hcp158

6. Nafisa A, Gray SG, Cao Y, et al. Endothelial function and dysfunction: Impact of metformin. Pharmacol Ther. 2018;192(1):150-162. doi: https://doi.org/10.1016/j.pharmthera.2018.07.007
7. Ong JP, Younossi ZM. Epidemiology and Natural History of NAFLD and NASH. Clin Liver Dis. 2007;11(1):1-16. doi: https://doi.org/10.1016/j.cld.2007.02.009

8. Leite NC, Salles GF, Araujo ALE, Villela-Nogueira CA, Cardoso CRL. Prevalence and associated factors of non-alcoholic fatty liver disease in patients with type-2 diabetes mellitus. Liver Int. 2009;29(1):113-119. doi: https://doi.org/10.1111/j.1478-3231.2008.01718.x

9. Younossi ZM, Koenig AB, Abdelatif D, Fazel Y, Henry L, Wymer M. Global epidemiology of nonalcoholic fatty liver disease-Metaanalytic assessment of prevalence, incidence, and outcomes. Hepatology. 2016;64(1):73-84. doi: https://doi.org/10.1002/hep.28431

10. Nafisa A, Gray SG, Cao Y, et al. EASL-EASD-EASO Clinical Practice Guidelines for the management of non-alcoholic fatty liver disease. J Hepatol. 2016;64(6):1388-1402. doi: https://doi.org/10.1016/j.jhep.2015.11.004

11. Chalasani N, Younossi Z, Lavine JE, et al. The Diagnosis and Management of Non-alcoholic Fatty Liver Disease: Practice Guideline by the American Association for the Study of Liver Diseases, American College of Gastroenterology, and the American Gastroenterological Association. Am J Gastroenterol. 2012;107(6):811-826. doi: https://doi.org/10.1038/ajg.2012.128 
12. Chalasani N, Younossi Z, Lavine JE, et al. The diagnosis and management of nonalcoholic fatty liver disease: Practice guidance from the American Association for the Study of Liver Diseases. Hepatology. 2018;67(1):328-357. doi: https://doi.org/10.1002/hep.29367

13. Karlas T, Petroff D, Sasso M, et al. Individual patient data metaanalysis of controlled attenuation parameter (CAP) technology for assessing steatosis. J Hepatol. 2017;66(5):1022-1030. doi: https://doi.org/10.1016/j.jhep.2016.12.022

14. Siddiqui MS, Vuppalanchi R, Van Natta ML, et al. Vibration-Controlled Transient Elastography to Assess Fibrosis and Steatosis in Patients With Nonalcoholic Fatty Liver Disease. Clin Gastroenterol Hepatol. 2019;17(1):156-163.e2. doi: https://doi.org/10.1016/j.cgh.2018.04.043

15. Eddowes PJ, Sasso M, Allison M, et al. Accuracy of FibroScan Controlled Attenuation Parameter and Liver Stiffness Measurement in Assessing Steatosis and Fibrosis in Patients With Nonalcoholic Fatty Liver Disease. Gastroenterology. 2019;156(6):1717-1730. doi: https://doi.org/10.1053/j.gastro.2019.01.042

16. Katsagoni CN, Georgoulis M, Papatheodoridis G V., Panagiotakos $\mathrm{DB}$, Kontogianni MD. Effects of lifestyle interventions on clinical characteristics of patients with non-alcoholic fatty liver disease: A meta-analysis. Metabolism. 2017;68:119-132. doi: https://doi.org/10.1016/j.metabol.2016.12.006

17. Romero-Gómez M, Zelber-Sagi S, Trenell M. Treatment of NAFLD with diet, physical activity and exercise. J Hepatol. 2017;67(4):829-846. doi: https://doi.org/10.1016/j.jhep.2017.05.016

18. Vilsboll T, Christensen M, Junker AE, Knop FK, Gluud LL. Effects of glucagon-like peptide-1 receptor agonists on weight loss: systematic review and meta-analyses of randomised controlled trials. BMJ. 2012;344(jan10 2):d7771-d7771. doi: https://doi.org/10.1136/bmj.d7771

19. Armstrong MJ, Gaunt P, Aithal GP, et al. Liraglutide safety and efficacy in patients with non-alcoholic steatohepatitis (LEAN): a multicentre, double-blind, randomised, placebocontrolled phase 2 study. Lancet. 2016;387(10019):679-690. doi: https://doi.org/10.1016/S0140-6736(15)00803-X

20. Musso G, Gambino R, Cassader M, Pagano G. A meta-analysis of randomized trials for the treatment of nonalcoholic fatty liver disease. Hepatology. 2010;52(1):79-104 doi: https://doi.org/10.1002/hep.23623

21. Li Y, Liu L, Wang B, et al. Metformin in non-alcoholic fatty liver disease: A systematic review and meta-analysis. Biomed Reports. 2013;1 (1):57-64. doi: https://doi.org/10.3892/br.2012.18

22. Siddiqui MS, Vuppalanchi R, Van Natta ML, et al. Reduction in the Incidence of Type 2 Diabetes with Lifestyle Intervention or Metformin. N Engl J Med. 2002;346(6):393-403. doi: https://doi.org/10.1056/NEJMoa012512

23. Doycheva I, Loomba R. Effect of Metformin on Ballooning Degeneration in Nonalcoholic Steatohepatitis (NASH): When to Use Metformin in Nonalcoholic Fatty Liver Disease (NAFLD). Adv Ther. 2014;31 (1):30-43. doi: https://doi.org/10.1007/s12325-013-0084-6

24. Garinis GA, Fruci B, Mazza A, et al. Metformin versus dietary treatment in nonalcoholic hepatic steatosis: a randomized study. Int J Obes. 2010;34(8):1255-1264. doi: https://doi.org/10.1038/ijo.2010.40
25. Nair S, Diehl AM, Wiseman M, Farr GH, Perrillo RP. Metformin in the treatment of non-alcoholic steatohepatitis: a pilot open label trial. Aliment Pharmacol Ther. 2004;20(1):23-28. doi: https://doi.org/10.1111/j.1365-2036.2004.02025.x

26. Loomba R, Lutchman G, Kleiner DE, et al. Clinical trial: pilot study of metformin for the treatment of non-alcoholic steatohepatitis. Aliment Pharmacol Ther. 2009:29(2):172-182. doi: https://doi.org/10.1111/j.1365-2036.2008.03869.x

27. de Oliveira CPMS, Stefano JT, de Siqueira ERF, et al. Combination of $\mathrm{N}$-acetylcysteine and metformin improves histological steatosis and fibrosis in patients with nonalcoholic steatohepatitis. Hepatol Res. 2007;38:159-165. doi: https://doi.org/10.1111/j.1872-034X.2007.00215.x

28. Shields WW, Thompson KE, Grice GA, et al. The effect of metformin and standard therapy versus standard therapy alone in nondiabetic patients with insulin resistance and nonalcoholic steatohepatitis (NASH): a pilot trial. Therap Adv Gastroenterol. 2009;2(3):157-163. doi: https://doi.org/10.1177/1756283X09105462

29. Uygun A, Kadayifci A, Isik AT, et al. Metformin in the treatment of patients with non-alcoholic steatohepatitis. Aliment Pharmacol Ther. 2004;19(5):537-544. doi: https://doi.org/10.1111/j.1365-2036.2004.01888.x

30. Haukeland JW, Konopski Z, Eggesbø HB, et al. Metformin in patients with non-alcoholic fatty liver disease: A randomized, controlled trial. Scand J Gastroenterol. 2009;44(7):853-860. doi: https://doi.org/10.1080/00365520902845268

31. Sanyal AJ, Chalasani N, Kowdley KV., et al. Pioglitazone, Vitamin E, or Placebo for Nonalcoholic Steatohepatitis. N Eng/ J Med. 2010;362(18):1675-1685. doi: https://doi.org/10.1056/NEJMoa0907929

32. Sato K, Gosho M, Yamamoto T, et al. Vitamin E has a beneficial effect on nonalcoholic fatty liver disease: A meta-analysis of randomized controlled trials. Nutrition. 2015;31(7-8):923-930. doi: https://doi.org/10.1016/.nut.2014.11.018

33. Xu R, Tao A, Zhang S, et al. Association between vitamin E and non-alcoholic steatohepatitis: a meta-analysis. Int J Clin Exp Med. 2015;8(3):3924-3934.

34. Miller ER, Pastor-Barriuso R, Dalal D, et al. Meta-Analysis: High-Dosage Vitamin E Supplementation May Increase All-Cause Mortality. Ann Intern Med. 2005;142(1):37. doi: https://doi.org/10.7326/0003-4819-142-1-200501040-00110

35. Miller ER, Pastor-Barriuso R, Dalal D, et al. Meta-Analysis: High-Dosage Vitamin E Supplementation May Increase All-Cause Mortality. Ann Intern Med. 2005;142(1):37. doi: https://doi.org/10.7326/0003-4819-142-1-200501040-00110

36. Lassailly G, Caiazzo R, Buob D, et al. Bariatric Surgery Reduces Features of Nonalcoholic Steatohepatitis in Morbidly Obese Patients. Gastroenterology. 2015;149(2):379-388 doi: https://doi.org/10.1053/j.gastro.2015.04.014

37. Bower G, Toma T, Harling L, et al. Bariatric Surgery and NonAlcoholic Fatty Liver Disease: a Systematic Review of Liver Biochemistry and Histology. Obes Surg. 2015;25(12):2280-2289. doi: https://doi.org/10.1007/s11695-015-1691-x 


\section{ГЛАВА 11. ОЖИРЕНИЕ У ЛИЦ ПОЖИЛОГО И СТАРЧЕСКОГО ВОЗРАСТА}

\section{Стародубова А.В., Остроумова О.Д., Переверзев А.П., Ткачева О.Н.}

Число людей с ожирением неуклонно растет, считается, что от 18 до 30\% всех людей в возрасте 65 лет и старше имеют ожирение [1-3].

Группа пациентов пожилого (60-74 лет) и старческого (75 лет и старше) возраста неоднородна по своему функциональному физическому и когнитивному статусу. Несмотря на то что с возрастом распространенность ожирения увеличивается [4] и имеются основания считать, что снижение массы тела является важной мерой профилактики ряда сердечно-сосудистых, эндокринных и некоторых других заболеваний, однако имеются серьезные причины, по которым перенос стратегий коррекции повышенной массы тела, в том числе доказавших свою эффективность у людей среднего возраста, на пациентов пожилого и старческого возраста не может считаться приемлемой стратегией.

Во-первых, для пожилого возраста характерно развитие саркопенического ожирения с уменьшением мышечной массы [5]. Саркопения лежит в основе развития старческой астении - ведущего гериатрического синдрома, ассоциированного с утратой самостоятельности и развитием функциональной зависимости пациентов. Риск возникновения старческой астении особенно отчетливо увеличивается после 75 лет.

Во-вторых, эпидемиологические данные позволяют предполагать, что критерии необходимости снижения веса в пожилом и старческом возрасте могут отличаться от таковых у людей среднего возраста. Так, в отличие от людей среднего возраста, у пожилых повышение ИМТ до 25-29,9 кг/м² по сравнению с более низкими значениями ассоциировано со снижением, а не повышением риска смерти [6]. Более того, у пожилых пациентов более высокая масса тела ассоциирована с большей минеральной плотностью костной ткани, меньшим риском остеопороза и переломов бедренной кости, а снижение массы тела ассоциировано со снижением костной массы [7].

В-третьих, в клинических исследованиях по коррекции ожирения с включением людей пожилого возраста внимание, как правило, уделялось риску СД, сердечно-сосудистых осложнений, но не сохранению функциональной активности. При этом у лиц старческого возраста (75 лет и старше) любая потеря веса (намеренная или нет) может иметь потенциально опасные последствия в виде развития и/или прогрессирования саркопении, мальнутриции, потери костной массы и повышения смертности [6].

11.1. Для диагностики наличия избыточной массы тела или ожирения у пациентов пожилого и старческого возраста рекомендуется измерение роста, массы тела и расчет значения ИМТ и оценка по классификации, предложенной ВОЗ (УДД 5, УУР А) [8].

Комментарии. Диагностика ожирения у пожилых и людей среднего возраста не отличается. Независимо от возраста, согласно определению ВО3, избыточная масса тела диагностируется при значениях ИМТ от 25 до <30 кг/м², а ожирение - при значениях ИМТ, равных или более 30 кг/м² [8].

11.2. Рекомендуется индивидуальное консультирование диетологом лиц пожилого и старческого возраста с ожирением и (или) лиц, осуществляющих за ними уход, по вопросам питания, которые могут быть дополнены групповыми консультациями, беседами по телефону, письменными рекомендациями (УУД 1, УУР А) [9-11].

Комментарии. Консультирование по вопросам питания является важной частью мер по выработке необходимых пищевых привычек и повышению эффективности диетических интервенций. Консультации должны состоять из нескольких сеансов на протяжении длительного периода (не менее 8-12 нед).

11.3. Не рекомендуется назначать гипокалорийную диету лицам 65 лет и старше, имеющим избыточную массу тела, чтобы избежать потери мышечной массы и сопровождающего ее снижения функциональных возможностей (мышечной силы и физической активности) (УДД 2, УУР А) [1, 5, 12-18].

Комментарии. Большинство экспертов согласны с тем, что, как правило, пожилым людям, имеющим избыточную массу тела, не нужно ее снижать [13, 19-22], поскольку, согласно результатам метаанализов, самый низкий риск смертности у здоровых пожилых людей наблюдается при значениях ИМТ, соответствующих избыточной массе тела [23-25]. Кроме того, потеря массы тела, преднамеренная или нет, усиливает ассоциированную с возрастом потерю мышечной массы и, следовательно, повышает риск саркопении, слабости, снижения функциональных возможностей, переломов и недоедания $[13,26,27]$. Более того, в большинстве случаев повторный набор массы тела после прекращения соблюдения диеты для похудения происходит преимущественно за счет набора жировой, а не тощей массы [27]. Таким образом, циклично повторяющиеся фазы потери и набора массы тела могут способствовать развитию саркопенического ожирения (наличие недостатка мышечной массы вместе с избытком жировой массы) [27]. Поэтому, а также во избежание прогрессирующего набора массы тела и формирования ожирения, для людей старшего возраста с избыточной массой тела предпочтительным считается не снижение, а поддержание стабильной массы тела [3]. Сочетание сбалансированной диеты с высокой пищевой ценностью, обеспечивающей достаточное количество энергии и белка, и физической активности, а при возможности и выполнения физических упражнений, является разумной стратегией для поддержания стабильной массы тела и предотвращения ожирения [28]. 
11.4. Рекомендуется индивидуальная оценка риска и пользы от назначения диеты для снижения массы тела у людей 65 лет и старше, имеющих ожирение и ассоциированные с ним заболевания, перед назначением диеты (УДД 1, УУР А) [29-34].

Комментарии. Наличие ожирения у пожилых людей, особенно при значениях ИМТ 35 кг/м² и выше, сопровождается повышением риска ССЗ и метаболических нарушений, а также риска ограничения подвижности и синдрома хрупкости пожилого и старческого возраста [21, 22, 30], особенно при уже имеющемся выраженном снижении мышечной массы [27]. В настоящее время рекомендации экспертов по снижению массы тела у пожилых людей в основном относятся к случаям ожирения, ассоциированного с сопутствующими заболеваниями и неблагоприятными последствиями для здоровья, связанными с ожирением [13, 21, 22, 26]. В вышеперечисленных случаях и при сочетании диетотерапии с физическими упражнениями описывается положительное влияние преднамеренного снижения массы тела и уменьшение на этом фоне ортопедических проблем, сердечно-сосудистого и метаболического риска, хронического воспаления, функциональных ограничений, и повышение чувствительности к инсулину [3, 13, 19, 21, 30, 35].

С другой стороны, решение о снижении массы тела у пожилых людей всегда должно приниматься индивидуально, поскольку похудение может сопровождаться нежелательной потерей мышечной массы. Необходимо тщательно взвесить и оценить пользу и риски данного вмешательства с учетом функциональных возможностей, метаболического риска, наличия сопутствующих заболеваний, пожеланий самого пациента, прогноза и ожидаемого влияния на качество жизни $[19,35]$. Если принято решение отказаться от снижения массы тела, необходимо сфокусироваться на ее стабилизации и профилактике ее дальнейшего набора [3].

11.5. Рекомендуется умеренное ограничение калорийности рациона питания людям 65 лет и старше, имеющим ожирение, и в отношении которых было принято решение о необходимости медленного темпа снижения массы тела (УДД 2, УУР А) [36-38].

Комментарии. Снижать массу тела у пожилых людей с ожирением следует с большой осторожностью и только в том случае, если предполагаемая польза от вмешательства будет превосходить риски [19, 20]. Результаты, полученные при изучении тех или иных вмешательств у молодых людей, не могут быть экстраполированы на популяцию пожилых людей в связи с наличием низкой мышечной массы [26]. Чтобы предотвратить потерю мышечной массы и добиться медленного темпа снижения массы тела у пожилых людей, диетологические рекомендации должны включать сбалансированное питание с учетом возраста, умеренное ограничение калорийности рациона ( на 500 ккал/день меньше, чем оцениваемые потребности, но не ниже 1000-1200 ккал/день) с целью снижения массы тела на 0,25-1 кг/неделю ( на 5-10\% первоначальной массы тела через 6 мес и более), обеспечение потребления белка на уровне не менее 1 г/кг массы тела в сутки и соответствующее потребление микроэлементов [13, 21, 39]. Строгие ограничительные диеты, например, диеты с калорийностью ниже <1000 ккал/день, не должны назначаться пожилым людям из-за риска развития недостаточного питания (мальнутриции) и снижения функциональных возможностей $[21,27,40]$.

11.6. Рекомендуется сочетание диетотерапии и физических упражнений во всех случаях, когда это возможно, людям 65 лет и старше, имеющим ожирение, в отношении которых принято решение о необходимости снижения массы тела, для сохранения мышечной массы (УДД 2, УУР А) [41-43].

Комментарии. Диетологические вмешательства должны сочетаться со структурированными, контролируемыми физическими упражнениями во всех случаях, когда это возможно, и рекомендациями по увеличению ежедневной физической активности. Опубликованы результаты нескольких РКИ, в которых сравнивались эффекты исключительно диетологических вмешательств по снижению массы тела и сочетания того же вида диетологического вмешательства с физическими упражнениями у пожилых людей. В некоторые исследования включались только пациенты с ожирением $[44,45]$, а в другие также были включены и пациенты с избыточной массой тела. В большинстве исследований исключительно диетологические вмешательства позволяли эффективно снижать массу тела, но при этом снижалась как жировая, так и мышечная масса [45-53].

Сочетание диеты для снижения массы тела и физических упражнений было не менее, а в некоторых случаях более эффективно, чем исключительно диетологические вмешательства в отношении снижения массы тела и жировой массы, при этом часто удавалось лучше сохранять мышечную массу, чем на фоне исключительно диетотерапии [44-56]. По некоторым показателям, характеризующим силу и физическую работоспособность, результаты были лучше в группах комбинированного вмешательства по сравнению с группами с исключительно диетологическим вмешательством [44-46, 48-51, 53-55]. В этих исследованиях диетологическое вмешательство включало назначение сбалансированной диеты с ежедневным дефицитом энергии 300-1000 ккал с целью снижения массы тела на 5-10\% от исходной и/или на 0,25-1 кг в неделю [44-48, 53-55]. В исследованиях изучалось влияние частичной замены пищи на снижение массы тела, а также были включены еженедельные или два раза в месяц индивидуальные и/или групповые образовательные занятия по вопросам питания и изменения поведения и образа жизни, которые проводил диетолог [44, 46, 47, 53-55]. Тренировки выполнялись 2-5 раз в неделю, а продолжительность одного сеанса составляла от 45 до 90 мин. В большинстве исследований комбинировали упражнения на гибкость и выносливость $[44,45,47,48,54]$. В разных исследованиях оценивалась эффективность исключительно аэробной нагрузки на выносливость [49, 52], ходьбы [52], физические нагрузки на выносливость средней и высокой интенсивности $[46,50,51]$ и в одном исследовании сравнивали аэробную и анаэробную нагрузки, результаты были сопоставимы [55]. 
Прежде чем приступать к физическим упражнениям и тренировкам, необходимо оценить состояние здоровья и уровень физической подготовленности пациента, чтобы исключить наличие противопоказаний к тренировкам и определить оптимальный начальный уровень и тип упражнений для обеспечения безопасной и успешной физической нагрузки $[56,57]$.

Регулярные физические нагрузки являются важным компонентом коррекции ожирения в любом возрасте, при этом у пожилых людей физическая активность за счет поддержания мышечной массы и силы способна также отдалить развитие старческой астении и/или замедлить ее прогрессирование.

У пациентов старческого возраста, при наличии мультиморбидной патологии и ограниченной подвижности решение о снижении массы тела следует принимать с максимальной осторожностью, кроме того, необходимо тщательное мониторирование состояния здоровья пациента на фоне снижения массы тела [3, 20].

11.7. Назначение лекарственных средств для снижения массы тела рекомендуется пациентам в возрасте 60-75 лет с индексом массы тела $\geq 30$ кг/м² и наличием по крайней мере одного сопутствующего заболевания, для которого избыточная масса тела является фактором риска (например, СД2, АГ, дислипидемия), при отсутствии противопоказаний и иных причин, которые могут негативно сказаться на клиническом и гериатрическом статусе, качестве жизни и прогнозе (УДД 2, УУР А) [30, 58-81].

Комментарии. Индекс массы тела 25-27 кг/м² у пациентов пожилого возраста ассоциирован с низкой смертностью, что было показано в обсервационных исследованиях [58, 59]. В связи с этим представляется целесообразным использовать более высокие значения ИМТ ( $\left.\geq 30 \mathrm{kг} / \mathrm{m}^{2}\right)$ для принятия решения о назначении фармакотерапии для снижения веса [60].

Склонность к увеличению массы тела и развитию ожирения наблюдается в течение первых 8 декад жизни человека, после чего имеется тенденция к ее снижению, вследствие этого у многих лиц в возрасте старше 75 лет нет необходимости в проведении медицинских интервенций, направленных на коррекцию массы тела [30, 61].

В настоящее время Агентством по контролю за продуктами питания и лекарственными средствами CША (US FDA) одобрено пять лекарственных средств для длительного ( $\geq 1$ года) лечения ожирения (ИМТ $\geq 30$ кг/M²) или пациентов с ИМТ $\geq 27$ кг/м² и наличием по крайней мере одного сопутствующего заболевания, для которой избыточная масса тела является фактором риска (например, СД2, АГ, дислипидемия): орлистат, лоркасерин (не зарегистрирован в РФ), бупропион-налтрексон (не зарегистрирован в РФ), фентермин-топирамат (не зарегистрирован в РФ) и лираглутид [60].

Противопоказаниями к назначению орлистата, актуальными для пожилых пациентов, являются одновременный прием ситаглиптина и варфарина, а также реакции гиперчувствительности на орлистат и вспомогательные компоненты препарата [62].

Противопоказаниями к назначению лираглутида, актуальными для пожилых пациентов, являются реакции гиперчувствительности на лираглутид и вспомогательные компоненты препарата, медуллярный рак щитовидной железы в анамнезе (в том числе семейном), множественная эндокринная неоплазия 2 типа, тяжелая депрессия, суицидальные мысли или поведение, в том числе в анамнезе, тяжелая почечная недостаточность (клиренс креатинина менее 30 мл/мин), тяжелая печеночная недостаточность, возраст пациентов $\geq 75$ лет, XCH IV ФК (по NYHA), одновременное применение других препаратов для коррекции массы тела, применение в комбинации с другими препаратами-агонистами рецепторов ГПП-1, вторичное ожирение на фоне эндокринных заболеваний или расстройств пищевого поведения либо на фоне применения ЛС, которые могут привести к увеличению массы тела [62].

Следует индивидуализированно и максимально объективно (тщательно взвесив отношение польза/риск) подходить к принятию решения о назначении лекарственной терапии ожирения лицам пожилого возраста с определенными сопутствующими заболеваниями, часто встречающимися у лиц данной возрастной группы. Особое внимание следует уделить наличию ХСН, ИБС, прежде всего перенесенному ИМ, инсульту в анамнезе, тяжелой ХБП.

Например, наличие ожирения I степени (ИМТ 30-35 кг/м²) у пациентов с сердечной недостаточностью ассоциировано с более благоприятным прогнозом по сравнению с более худыми пациентами (так называемый «парадокс ожирения») [63-65]. Принимая во внимание высокую распространенность сердечной недостаточности улиц пожилого возраста, следует рассмотреть необходимость назначения лекарственных препаратов для снижения веса у таких пациентов начиная не с I, а с II степени (ИМТ $\geq 35$ кг/M²) ожирения.

Имеются также данные о наличии «парадокса ожирения» у пациентов в возрасте 70 лет и старше с ИМ и ИБС $[66,67]$. В систематическом обзоре и метаанализе Z.J. Wang и соавт. [67] (89 исследований >1,3 млн пациентов с ИБС) было показано, что дефицит массы тела (ИМТ <18,5кг/м²) был ассоциирован с увеличением смертности как в краткосрочной (<6 мес), так и долгосрочной (>6 мес) перспективе, в то время как у пациентов с ожирением I степени отмечался наименьший риск летального исхода. В то же время показано, что пациенты с ожирением II-III степени имели наибольший риск смерти в долгосрочной перспективе. В работе K. Keller и соавт. [68] показано, что среди пациентов ( $n=125000)$ в возрасте $\geq 70$ лет с острым ИМ наилучшая выживаемость во время их пребывания в стационаре была отмечена в группе лиц с ожирением I степени [68]. Таким образом, на основании представленных данных следует рекомендовать назначение лекарственных препаратов для снижения веса у пожилых пациентов с ИБС, с ИМ, чрескожными коронарными вмешательствами и аортокоронарным шунтированием в анамнезе, начиная со II степени (ИМТ $\geq 35$ кг/M²) ожирения.

В исследовании K.K. Andersen и T.S. Olsen [69] (29 326 пациентов, средний возраст 72,3 года) было показано, что уровень смертности ниже у пациентов с избыточной массой тела и ожирением и значительно выше у пациентов с дефицитом массы тела по сравнению с лицами с нормальной массой тела [69]. 
Данные относительно влияния «парадокса ожирения» на смертность у пациентов с перенесенным инсультом противоречивы и не позволяют сделать однозначного вывода относительно значения ИМТ, начиная с которого следует проводить интервенции по коррекции массы тела. Так, L.E. Skolarus и соавт. [70] обнаружили, что наименьший

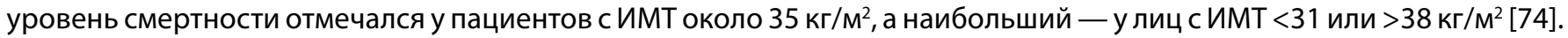
B работе L. Zhaо и соавт. [71] были показаны сходные уровни смертности у пациентов с нормальной и избыточной массой тела и повышенный - у пациентов с ИМТ $\geq 35$ и <18,5кг/м² [71]. T. Razinia и соавт. [72] продемонстрировали в своем исследовании, что пациенты с ожирением после перенесенного инсульта дольше пребывают в стационаре и выписываются из него домой [72]. Многие авторы единогласны в том, что пациенты с ожирением после перенесенного инсульта быстрее функционально восстанавливаются и имеют лучший функциональный статус через 3 мес по сравнению с лицами с нормальной массой тела $[71,73,74]$. Также рядом авторов $[69,75,76]$ выявлено снижение риска повторного инсульта у больных с ожирением $[69,75,76]$. Таким образом, у пациентов пожилого возраста, перенесших инсульт, целесообразно начало медикаментозных интервенций по коррекции массы тела, начиная со II степени (ИМТ $\geq 35$ кг/м²) ожирения.

Научные данные о влиянии «парадокса ожирения» на смертность у пациентов с тяжелым нарушением функции почек (находящихся на гемодиализе или перитонеальном диализе) противоречивы. Taк, по данным E. Fleischmann и соавт. [77] уровень выживаемости был выше у пациентов, находящихся на гемодиализе, с ИМТ $\geq 27,5$ кг/м² по срав-

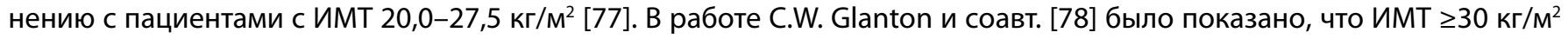
ассоциирован со снижением уровня смертности, особенно у лиц с темным цветом кожи [78].

\section{8. У пожилых пациентов с нормальной массой тела представляется нецелесообразным назначение меди- каментозных интервенций по снижению массы тела (УДД 5, УУР С).}

Комментарии. В исследовании К.С. Abbott и соавт. [79] было показано, что выживаемость у пациентов с ИМТ $\geq 30 \mathrm{kг} / \mathrm{M}^{2}$, находящихся на перитонеальном диализе, не отличалась от таковой у пациентов с другой массой тела [83]. По данным A.G. Stack и соавт. [80], риск смерти был выше у пациентов с ИМТ <20,9 кг/м², но не было отмечено более высокого уровня выживаемости у пациентов с ИМТ выше 23,5-26,1кг/м² [80].

По мнению R. de Mutsert и соавт. [81], у лиц с ожирением, находящихся на перитонеальном диализе, уровень выживаемости не хуже, чем у пациентов с нормальным ИМТ, но пациенты со сниженным ИМТ, которые получают перитонеальный диализ, имеют повышенный в 2 раза риск смерти [81].

\section{СПИСОК ЛИТЕРАТУРЫ | REFERENCES}

1. Volkert D, Beck AM, Cederholm T, et al. ESPEN guideline on clinical nutrition and hydration in geriatrics. Clin Nutr. 2019;38(1):10-47. doi: https://doi.org/10.1016/j.clnu.2018.05.024

2. Gallus S, Lugo A, Murisic B, Bosetti C, Boffetta P, La Vecchia C. Overweight and obesity in 16 European countries. Eur J Nutr 2015;54(5):679-689. doi: https://doi.org/10.1007/s00394-014-0746-4

3. Porter Starr K, McDonald S, Weidner J, Bales C. Challenges in the Management of Geriatric Obesity in High Risk Populations. Nutrients. 2016;8(5):262. doi: https://doi.org/10.3390/nu8050262

4. Kuk JL, Ardern Cl. Influence of Age on

the Association Between Various Measures of Obesity and All-Cause Mortality. J Am Geriatr Soc. 2009;57(11):2077-2084. doi: https://doi.org/10.1111/j.1532-5415.2009.02486.x

5. Roubenoff R. Sarcopenic Obesity: The Confluence of Two Epidemics. Obes Res. 2004;12(6):887-888. doi: https://doi.org/10.1038/oby.2004.107

6. Stessman J, Jacobs JM, Ein-Mor E, Bursztyn M. Normal Body Mass Index Rather than Obesity Predicts Greater Mortality in Elderly People: The Jerusalem Longitudinal Study. J Am Geriatr Soc. 2009;57(12):2232-2238. doi: https://doi.org/10.1111/j.1532-5415.2009.02567.x

7. Schott AM, Cormier C, Hans D, et al. How Hip and Whole-Body Bone Mineral Density Predict Hip Fracture in Elderly Women: The EPIDOS Prospective Study. Osteoporos Int. 1998;8(3):247-254. doi: https://doi.org/10.1007/s001980050061

8. WHO Consultation on Obesity (1997: Geneva, Switzerland), World Health Organization. Division of Noncommunicable Diseases \& World Health Organization. Programme of Nutrition, Family and Reproductive Health. (1998). Obesity: preventing and managing the global epidemic : report of a WHO Consultation on Obesity, Geneva, 3-5 June 1997. World Health Organization. Available at: https://apps.who.int/iris/handle/10665/63854

9. Stallings DT, Kraenzle Schneider J. Motivational Interviewing and Fat Consumption in Older Adults: A Meta-Analysis. J Gerontol Nurs. 2018;44(11):33-43. doi: https://doi.org/10.3928/00989134-20180817-01

10. Kriaucioniene $V$, Petkeviciene J, Raskiliene A. Nutrition and physical activity counselling by general practitioners in Lithuania, 2000-2014. BMC Fam Pract. 2019;20(1):125. doi: https://doi.org/10.1186/s12875-019-1022-8
11. Schultz TJ, Roupas P, Wiechula R, et al. Nutritional interventions for optimizing healthy body composition in older adults in the community. JBI Database Syst Rev Implement Reports. 2016;14(8):257-308. doi: https://doi.org/10.11124/JBISRIR-2016-003063

12. Normandin E, Houston DK, Nicklas BJ. Caloric Restriction for Treatment of Geriatric Obesity: Do the Benefits Outweigh the Risks? Curr Nutr Rep. 2015;4(2):143-155. doi: https://doi.org/10.1007/s13668-015-0123-9

13. Mathus-Vliegen EMH, Basdevant A, Finer N, et al. Prevalence, Pathophysiology, Health Consequences and Treatment Options of Obesity in the Elderly: A Guideline. Obes Facts. 2012;5(3):460-483. doi: https://doi.org/10.1159/000341193

14. Goisser S, Kemmler W, Porzel S, et al. Sarcopenic obesity and complex interventions with nutrition and exercise in communitydwelling older persons - A narrative review. Clin Interv Aging. 2015 doi: https://doi.org/10.2147/CIA.S82454

15. Kuk JL, Ardern Cl. Influence of Age on the Association Between Various Measures of Obesity and All-Cause Mortality. J Am Geriatr Soc. 2009;57(11):2077-2084. doi: https://doi.org/10.1111/j.1532-5415.2009.02486.x

16. Stessman J, Jacobs JM, Ein-Mor E, Bursztyn M. Normal Body Mass Index Rather than Obesity Predicts Greater Mortality in Elderly People: The Jerusalem Longitudinal Study. J Am Geriatr Soc. 2009;57(12):2232-2238. doi: https://doi.org/10.1111/j.1532-5415.2009.02567.x

17. Schott AM, Cormier C, Hans D, et al. How Hip and Whole-Body Bone Mineral Density Predict Hip Fracture in Elderly Women: The EPIDOS Prospective Study. Osteoporos Int. 1998;8(3):247-254. doi: https://doi.org/10.1007/s001980050061

18. Stenholm S, Harris TB, Rantanen T, Visser M, Kritchevsky SB, Ferrucci L. Sarcopenic obesity: definition, cause and consequences. Curr Opin Clin Nutr Metab Care. 2008;11(6):693-700. doi: https://doi.org/10.1097/MCO.0b013e328312c37d

19. Garvey WT, Mechanick Jl, Brett EM, et al. American Association of Clinical Endocrinologists and American College of Endocrinology comprehensive clinical practice guidelines for medical care of patients with obesity. Endocr Pract. 2016;22:1-203. doi: https://doi.org/10.4158/EP161365.GL 
20. Expert panel report: Guidelines (2013) for the management of overweight and obesity in adults. Obesity. 2014;22(S2):S41-S410. doi: https://doi.org/10.1002/oby.20660

21. Villareal DT, Apovian CM, Kushner RF, Klein S. Obesity in Older Adults: Technical Review and Position Statement of the American Society for Nutrition and NAASO, The Obesity Society. Obes Res. 2005;13(11):1849-1863. doi: https://doi.org/10.1038/oby.2005.228

22. Visvanathan R, Haywood C, Piantadosi C, Appleton S. Australian and New Zealand Society for Geriatric Medicine. Australas J Ageing. 2012;31(4):261-267. doi: https://doi.org/10.1111/j.1741-6612.2012.00652.x

23. Di Angelantonio E, Bhupathiraju SN, Wormser D, et al. Body-mass index and all-cause mortality: individual-participant-data meta-analysis of 239 prospective studies in four continents. Lancet. 2016;388(10046):776-786. doi: https://doi.org/10.1016/S0140-6736(16)30175-1

24. Winter JE, Maclnnis RJ, Wattanapenpaiboon N, Nowson CA. BMI and all-cause mortality in older adults: a meta-analysis. Am J Clin Nutr. 2014;99(4):875-890. doi: https://doi.org/10.3945/ajcn.113.068122

25. Flegal KM, Kit BK, Orpana H, Graubard BI. Association of All-Cause Mortality With Overweight and Obesity Using Standard Body Mass Index Categories. JAMA. 2013;309(1):71. doi: https://doi.org/10.1001/jama.2012.113905

26. Cetin DC, Nasr G. Obesity in the elderly: More complicated than you think. Cleve Clin J Med. 2014;81 (1):51-61. doi: https://doi.org/10.3949/ccjm.81a.12165

27. Parr EB, Coffey VG, Hawley JA. 'Sarcobesity': A metabolic conundrum. Maturitas. 2013;74(2):109-113. doi: https://doi.org/10.1016/j.maturitas.2012.10.014

28. Volpe SL, Sukumar D, Milliron B-J. Obesity Prevention in Older Adults. Curr Obes Rep. 2016;5(2):166-175. doi: https://doi.org/10.1007/s13679-016-0213-z

29. DiMilia PR, Mittman AC, Batsis JA. Benefit-to-Risk Balance of Weight Loss Interventions in Older Adults with Obesity. Curr Diab Rep. 2019;19(11):114. doi: https://doi.org/10.1007/s11892-019-1249-8

30. Batsis JA, Zagaria AB. Addressing Obesity

in Aging Patients. Med Clin North Am. 2018;102(1):65-85. doi: https://doi.org/10.1016/j.mcna.2017.08.007

31. Fan $\mathrm{H}, \mathrm{Li} X$, Zheng $\mathrm{L}$, et al. Abdominal obesity is strongly associated with Cardiovascular Disease and its Risk Factors in Elderly and very Elderly Community-dwelling Chinese. Sci Rep. 2016;6(1):21521. doi: https://doi.org/10.1038/srep21521

32. Tussing-Humphreys L, Lamar M, Blumenthal JA, et al. Building research in diet and cognition:The BRIDGE randomized controlled trial. Contemp Clin Trials. 2017;59:87-97. doi: https://doi.org/10.1016/j.cct.2017.06.003

33. Leavy J, Clifton P, Keogh J. The Role of Choice in Weight Loss Strategies: A Systematic Review and Meta-Analysis. Nutrients. 2018;10(9):1136. doi: https://doi.org/10.3390/nu10091136

34. Colpani V , Baena CP, Jaspers L, et al. Lifestyle factors, cardiovascular disease and all-cause mortality in middle-aged and elderly women: a systematic review and meta-analysis. Eur J Epidemiol. 2018;33(9):831-845. doi: https://doi.org/10.1007/s10654-018-0374-z

35. Gill LE, Bartels SJ, Batsis JA. Weight Management in Older Adults. Curr Obes Rep. 2015;4(3):379-388. doi: https://doi.org/10.1007/s13679-015-0161-z

36. Wojzischke J, Diekmann R, Bauer JM. Adipositas im Alter und ihre Bedeutung für Funktionalität und Frailty. Z Gerontol Geriatr. 2016;49(7):573-580. doi: https://doi.org/10.1007/s00391-016-1133-y

37. Ard JD, Gower B, Hunter G, et al. Effects of Calorie Restriction in Obese Older Adults: The CROSSROADS Randomized Controlled Trial. Journals Gerontol Ser A Biol Sci Med Sci. 2017:73(1):73-80. doi: https://doi.org/10.1093/gerona/glw237

38. Haas MC, Bodner EV., Brown CJ, et al. Calorie Restriction in Overweight Seniors: Response of Older Adults to a Dieting Study: The CROSSROADS Randomized Controlled Clinical Trial. J Nutr Gerontol Geriatr. 2014;33(4):376-400. doi: https://doi.org/10.1080/21551197.2014.965993

39. Mathus-Vliegen L, Toouli J, Fried M, et al. World Gastroenterology Organisation Global Guidelines on Obesity. J Clin Gastroenterol. 2012;46(7):555-561. doi: https://doi.org/10.1097/MCG.0b013e318259bd04

40. Zeanandin G, Molato O, Le Duff F, et al. Impact of restrictive diets on the risk of undernutrition in a free-living elderly population. Clin Nutr. 2012;31(1):69-73. doi: https://doi.org/10.1016/j.clnu.2011.08.007

41. Coker RH, Wolfe RR. Weight Loss Strategies in the Elderly: A Clinical Conundrum. Obesity. 2018;26(1):22-28. doi: https://doi.org/10.1002/oby.21961
42. Villareal DT, Aguirre L, Gurney AB, et al. Aerobic or Resistance Exercise, or Both, in Dieting Obese Older Adults. N Eng/ J Med. 2017:376(20):1943-1955. doi: https://doi.org/10.1056/NEJMoa1616338

43. Villareal DT, Aguirre L, Gurney AB, et al. Aerobic or Resistance Exercise, or Both, in Dieting Obese Older Adults. NEngl J Med. 2017;376(20):1943-1955. doi: https://doi.org/10.1056/NEJMoa1616338

44. Villareal DT, Chode S, Parimi N, et al. Weight Loss, Exercise, or Both and Physical Function in Obese Older Adults. N Eng/ J Med. 2011;364(13):1218-1229. doi: https://doi.org/10.1056/NEJMoa1008234

45. Frimel TN, Sinacore DR, Villareal DT. Exercise Attenuates the Weight-Loss-Induced Reduction in Muscle Mass in Frail Obese Older Adults. Med Sci Sport Exerc. 2008;40(7):1213-1219. doi: https://doi.org/10.1249/MSS.0b013e31816a85ce

46. Avila JJ, Gutierres JA, Sheehy ME, et al. Effect of moderate intensity resistance training during weight loss on body composition and physical performance in overweight older adults. Eur J Appl Physiol. 2010;109(3):517-525. doi: https://doi.org/10.1007/s00421-010-1387-9

47. Shah K, Stufflebam A, Hilton TN, Sinacore DR, Klein S, Villareal DT. Diet and Exercise Interventions Reduce Intrahepatic Fat Content and Improve Insulin Sensitivity in Obese Older Adults. Obesity. 2009;17(12):2162-2168. doi: https://doi.org/10.1038/oby.2009.126

48. Messier SP, Mihalko SL, Legault C, et al. Effects of Intensive Diet and Exercise on Knee Joint Loads, Inflammation, and Clinical Outcomes Among Overweight and Obese Adults With Knee Osteoarthritis. JAMA. 2013;310(12):1263. doi: https://doi.org/10.1001/jama.2013.277669

49. Chomentowski P, Dube JJ, Amati F, et al. Moderate Exercise Attenuates the Loss of Skeletal Muscle Mass That Occurs With Intentional Caloric Restriction-Induced Weight Loss in Older, Overweight to Obese Adults. Journals Gerontol Ser A Biol Sci Med Sci. 2009;64A(5):575-580. doi: https://doi.org/10.1093/gerona/glp007

50. Campbell WW, Haub MD, Wolfe RR, et al. Resistance Training Preserves Fat-free Mass Without Impacting Changes in Protein Metabolism After Weight Loss in Older Women. Obesity. 2009;17(7):1332-1339. doi: https://doi.org/10.1038/oby.2009.2

51. Dunstan DW, Daly RM, Owen N, et al. High-Intensity Resistance Training Improves Glycemic Control in Older Patients With Type 2 Diabetes. Diabetes Care. 2002;25(10):1729-1736. doi: https://doi.org/10.2337/diacare.25.10.1729

52. Kitzman DW, Brubaker P, Morgan T, et al. Effect of Caloric Restriction or Aerobic Exercise Training on Peak Oxygen Consumption and Quality of Life in Obese Older Patients With Heart Failure With Preserved Ejection Fraction. JAMA. 2016;315(1):36. doi: https://doi.org/10.1001/jama.2015.17346

53. Amati F, Dubé JJ, Shay C, Goodpaster BH. Separate and combined effects of exercise training and weight loss on exercise efficiency and substrate oxidation. J Appl Physiol. 2008;105(3):825-831. doi: https://doi.org/10.1152/japplphysiol.90384.2008

54. Messier SP, Loeser RF, Miller GD, et al. Exercise and dietary weight loss in overweight and obese older adults with knee osteoarthritis: The arthritis, diet, and activity promotion trial. Arthritis Rheum. 2004;50(5):1501-1510. doi: https://doi.org/10.1002/art.20256

55. Rejeski WJ, Ambrosius WT, Burdette JH, Walkup MP, Marsh AP. Community Weight Loss to Combat Obesity and Disability in At-Risk Older Adults. Journals Gerontol Ser A Bio/ Sci Med Sci. 2017;72(11):1547e53. doi: https://doi.org/10.1093/gerona/glw252

56. Chodzko-Zajko WJ, Proctor DN, Fiatarone Singh $M A$, et al. Exercise and Physical Activity for Older Adults. Med Sci Sport Exerc. 2009:41(7):1510-1530. doi: https://doi.org/10.1249/MSS.0b013e3181a0c95c

57. Moore G, Durstine JL, Painter P, Medicine AcoS. ACSM's exercise management for persons with chronic diseases and disabilities. 4E: Human Kinetics; 2016.

58. Janssen I, Mark AE. Elevated body mass index and mortality risk in the elderly. Obes Rev. 2007;8(1):41-59. doi: https://doi.org/10.1111/j.1467-789X.2006.00248.x

59. Adams KF, Schatzkin A, Harris TB, et al. Overweight, Obesity, and Mortality in a Large Prospective Cohort of Persons 50 to 71 Years Old. N Engl J Med. 2006;355(8):763-778. doi: https://doi.org/10.1056/NEJMoa055643

60. Carbone S, Dixon DL. Selecting appropriate weight loss pharmacotherapies in older adults to reduce cardiovascular risk. Expert Opin Pharmacother. 2018;19(13):1399-1402. doi: https://doi.org/10.1080/14656566.2018.1511704 
61. Baumgartner RN. Body Composition in Healthy Aging. Ann N Y Acad Sci. 2006;904(1):437-448 doi: https://doi.org/10.1111/j.1749-6632.2000.tb06498.x

62. Государственный реестр лекарственных средств Министерства здравоохранения РФ. [State Register of Medicines of the Ministry of Health of the Russian Federation. (In Russ.)] Available at: https://grls.rosminzdrav.ru/grls.aspx

63. Lavie CJ, Sharma A, Alpert MA, et al. Update on Obesity and Obesity Paradox in Heart Failure. Prog Cardiovasc Dis. 2016;58(4):393-400. doi: https://doi.org/10.1016/j.pcad.2015.12.003

64. Carbone S, Popovic D, Lavie CJ, Arena R. Obesity, body composition and cardiorespiratory fitness in heart failure with preserved ejection fraction. Future Cardiol. 2017;13(5):451-463. doi: https://doi.org/10.2217/fca-2017-0023

65. Carbone S, Lavie CJ, Arena R. Obesity and Heart Failure: Focus on the Obesity Paradox. Mayo Clin Proc. 2017;92(2):266-279. doi: https://doi.org/10.1016/j.mayocp.2016.11.001

66. Lavie CJ, Carbone S, Agarwal MA. An obesity paradox with myocardial infarction in the elderly. Nutrition. 2018;46:122-123. doi: https://doi.org/10.1016/..nut.2017.08.003

67. Wang ZJ, Zhou YJ, Galper BZ, et al. Association of body mass index with mortality and cardiovascular events for patients with coronary artery disease: a systematic review and meta-analysis. Heart. 2015;101(20):1631-1638. doi: https://doi.org/10.1136/heartjnl-2014-307119

68. Keller K, Münzel T, Ostad MA. Sex-specific differences in mortality and the obesity paradox of patients with myocardial infarction ages $>70$ y. Nutrition. 2018;46(4):124-130 doi: https://doi.org/10.1016/j.nut.2017.09.004

69. Andersen KK, Olsen TS. The Obesity Paradox in Stroke: Lower Mortality and Lower Risk of Readmission for Recurrent Stroke in Obese Stroke Patients. Int J Stroke. 2015;10(1):99-104. doi: https://doi.org/10.1111/ijs.12016

70. Skolarus LE, Sanchez BN, Levine DA, et al. Association of Body Mass Index and Mortality After Acute Ischemic Stroke. Circ Cardiovasc Qual Outcomes. 2014;7(1):64-69. doi: https://doi.org/10.1161/CIRCOUTCOMES.113.000129

71. Zhao L, Du W, Zhao X, et al. Favorable Functional Recovery in Overweight Ischemic Stroke Survivors: Findings from the China National Stroke Registry. J Stroke Cerebrovasc Dis. 2014;23(3):e201-e206. doi: https://doi.org/10.1016/j.jstrokecerebrovasdis.2013.10.002
72. Razinia T, Saver JL, Liebeskind DS, Ali LK, Buck B, Ovbiagele B. Body Mass Index and Hospital Discharge Outcomes After Ischemic Stroke. Arch Neurol. 2007;64(3):388. doi: https://doi.org/10.1001/archneur.64.3.388

73. Burke DT, Al-Adawi S, Bell RB, et al. Effect of Body Mass Index on Stroke Rehabilitation. Arch Phys Med Rehabil. 2014;95(6):1055-1059. doi: https://doi.org/10.1016/j.apmr.2014.01.019

74. Kim Y, Kim CK, Jung S, et al. Obesity-stroke paradox and initial neurological severity. J Neurol Neurosurg Psychiatry. 2015;86(7):743-747. doi: https://doi.org/10.1136/jnnp-2014-308664

75. Ovbiagele B, Bath PM, Cotton D, et al. Obesity and Recurrent Vascular Risk After a Recent Ischemic Stroke. Stroke. 2011;42(12):3397-3402. doi: https://doi.org/10.1161/STROKEAHA.111.624957

76. Andersen KK, Olsen TS. Body Mass Index and Stroke: Overweight and Obesity Less Often Associated with Stroke Recurrence. J Stroke Cerebrovasc Dis. 2013;22(8):e576-e581. doi: https://doi.org/10.1016/j.jstrokecerebrovasdis.2013.06.031

77. Fleischmann E, Teal N, Dudley J, May W, Bower JD, Salahudeen AK. Influence of excess weight on mortality and hospital stay in 1346 hemodialysis patients. Kidney Int. 1999;55(4):1560-1567. doi: https://doi.org/10.1046/j.1523-1755.1999.00389.x

78. Glanton CW, Hypolite IO, Hshieh PB, et al. Factors Associated with Improved Short Term Survival in Obese End Stage Renal Disease Patients. Ann Epidemiol. 2003;13(2):136-143. doi: https://doi.org/10.1016/S1047-2797(02)00251-X

79. Abbott KC, Glanton CW, Trespalacios FC, et al. Body mass index, dialysis modality, and survival: Analysis of the United States Renal Data System Dialysis Morbidity and Mortality Wave II Study. Kidney Int. 2004;65(2):597-605 doi: https://doi.org/10.1111/j.1523-1755.2004.00385.x

80. Stack AG, Murthy BVR, Molony DA. Survival differences between peritoneal dialysis and hemodialysis among "large" ESRD patients in the United States. Kidney Int. 2004;65(6):2398-2408. doi: https://doi.org/10.1111/j.1523-1755.2004.00654.x

81. de Mutsert R, Grootendorst DC, Boeschoten EW, et al. Is Obesity Associated with a Survival Advantage in Patients Starting Peritoneal Dialysis? In: Peritoneal Dialysis - From Basic Concepts to Clinical Excellence. Basel: KARGER; 2009:124-131. doi: https://doi.org/10.1159/000223790 


\title{
ГЛАВА 12. ОЖИРЕНИЕ, ГИПЕРУРИКЕМИЯ И ПОДАГРА
}

\author{
Елисеев М.С., Новикова А.М.
}

\section{ДИАГНОСТИКА ГИПЕРУРИКЕМИИ (ГУ) ПРИ ОЖИРЕНИИ}

12.1. Всем пациентам с наличием ожирения или избыточной массы тела рекомендуется определять сывороточный уровень мочевой кислоты (МК) натощак (УДД 1, УУР А).

Комментарии. Ожирение - ведущий фактор риска развития ГУ и подагры. В крупнейшем популяционном проспективном исследовании риска ГУ, рассчитанного по результатам многомерного анализа с поправкой на возраст, самые высокие отношения шансов (ОШ) наблюдались для ожирения (у мужчин - 3,00 (95\% доверительный интервал (ДИ) 2,85-3,16); у женщин 2,74 (95\% ДИ 2,60-2,88)) [1]. Раннее развитие ожирения, обусловленное алиментарными факторами, столь же сильно связано с повышенным риском подагры [2] и остается ключевой среди других причин развития подагры в развитых и развивающихся странах $[3,4]$. Когортное исследование показало, что ИМТ >27 кг/м² независимо связан с подагрой у пожилых женщин [5]. В США общая распространенность подагры варьирует от 1-2\% среди лиц с нормальным ИМТ (18,5-24,9 кг/м²) до 4-5\% с ожирением I степени и 5-7\% - с ожирением II-III степени [6]. Анализ глобальной распространенности болезней от 2017 г., рассчитанный для 195 стран или территорий в период с 1990 по 2017 гг., выделил высокий ИМТ как ведущий фактор риска подагры [7].

Среди возможных причин ассоциации ожирения и ГУ - экспрессия адипоцитами уратного транспортера URAT-1, из-за наличия которого МК может поглощаться адипоцитами и влиять на функцию жировой ткани, способствуя развитию ИР [8-10]. Пациентам с ГУ и подагрой свойственна высокая частота развития метаболического синдрома (МС): 62,8\% (95\% ДИ 51,9-73,6) при подагре vs 25,4\% (95\% ДИ 23,5-27,3) без подагры и абдоминального ожирения: 62,9\% (95\% ДИ 50,9-74,8) vs 35,3\% (95\% ДИ 33,7-36,9) соответственно [11]. При этом первый приступ подагрического артрита в $90 \%$ случаев предшествует МС [12].

Доказано, что ГУ и подагра являются факторами риска ССЗ. Повышение уровня МК на каждый 1 мг/дл приводит к возрастанию риска общей смерти на 9\% и риска развития СС3 на 20\% [13]. Глобальный метаанализ, включивший суммарно более 1 млн пациентов, продемонстрировал, что наличие ГУ повышает риск смерти от ССЗ почти в 1,5 раза: относительный риск (ОР) - 1,45 (95\% ДИ 1,33-1,58) [14].

\section{2. Уровень урикемии выше 360 мкмоль/л рекомендуется рассматривать в качестве маркера ГУ (УДД 2, УУР В).}

Комментарии. Общепризнанного значения уровня МК сыворотки, соответствующего ГУ, нет. В качестве маркера предлагается использовать значение >360 мкмоль/л, т.к., хотя плазма насыщается при уровне МК 6,8 мг/дл (405 мкмоль/л) и при $\mathrm{pH} 7,4$, in vitro показано, что снижение температуры водной среды всего на $2^{\circ} \mathrm{C}$ (с $37^{\circ} \mathrm{C}$ до $\left.35^{\circ} \mathrm{C}\right)$ достаточно для падения точки растворимости с 6,8 мг/дл до 6,0 мг/дл (примерно 360 мкмоль/л) [15]. Уровень МК сыворотки > 360 мкмоль/л отождествляется с риском подагры, непосредственно ассоциированной с ГУ, что также позволяет принимать указанный уровень МК за пороговый [16].

12.3. Обследование пациентов с ГУ и наличием в анамнезе острых приступов артрита любого периферического сустава или бурсита должно проводиться в соответствии с рекомендациями АРР с целью исключения диагноза подагры и включать методы лучевой (сонография, рентгенография) и, при возможности, инструментальной диагностики (поляризационная микроскопия) для поиска доказательств осаждения кристаллов моноурата натрия (УДД 1, УУР А).

Комментарии. Понятия ГУ и подагры не тождественны, к последней относятся пациенты с ГУ и наличием клинических проявлений подагры (острые приступы артрита, хронический артрит, наличие подкожных и внутрикостных тофусов), тогда как асимптоматическую ГУ определяют при отсутствии острых приступов артрита и подкожных тофусов, в том числе при наличии признаков отложения кристаллов моноурата натрия [17].

Диагностика подагры основана на анализе типичных симптомов: рецидивирующие атаки острого артрита, чаще моноартикулярное поражение суставов стоп (особенно I плюснефалангового сустава), характеризующиеся эритемой, быстрым развитием выраженной боли и воспаления, с пиком интенсивности в первые 24 ч и продолжительностью обычно до 2 нед при ГУ. Эти характеристики позволяют думать о подагре, но неспецифичны [18-21].

Золотым стандартом диагностики подагры является исследование синовиальной жидкости/тофусной массы в поляризационном микроскопе, что было недавно подтверждено в крупном международном исследовании по разработке классификационных критериев подагры [22].

В случае невозможности исследования синовиальной жидкости существенно увеличить вероятность постановки правильного диагноза может рутинное использование ультрасонографии, особенно на ранних стадиях заболевания, когда клиническая симптоматика может быть сомнительной [23, 24].

Рентгенография целевых суставов оправдана при дифференциальной диагностике, однако характерные для подагры рентгенологические изменения относятся к поздним проявлениям подагры [18, 24]. Перспективно применение для диагностики подагры двухэнергетической КТ [25, 26], включенной в классификационные критерии подагры Американской коллегии ревматологов и Европейской антиревматической лиги [19, 20], но метод пока не нашел широкого применения, и его возможности изучены недостаточно. 


\section{ВЫБОР ТАКТИКИ ЛЕЧЕНИЯ ПРИ ОЖИРЕНИИ И ГУ}

\section{4. Пациентам с ожирением и наличием ГУ и подагры рекомендуется достигать цели по снижению массы тела на 5-10\% от исходной (УДД 3, УУР В).}

Комментарии. В настоящее время нет достоверных данных, насколько необходимо снижать массу тела у пациентов с ГУ или подагрой, поэтому основным ориентиром могут служить рекомендации для пациентов с ожирением, согласно которым медленное, за 3-6 мес, консервативное снижение массы тела на 5-10\% и удержание результата в течение года позволяет уменьшить риски для здоровья, улучшить течение заболеваний, ассоциированных с ожирением [27]. Однако в крупном динамическом исследовании лиц с высоким сердечно-сосудистым риском по результатам мультифакторного анализа снижение массы тела только на 1-4,9 кг по сравнению с отсутствием его изменения (от -0,9 до 0,9 кг) характеризовалось ОШ достижения сывороточного уровня МК <360 мкмоль/л 1,43 (95\% ДИ 1,33-1,54), а $\geq 10$ кг - 3,90 (95\% ДИ 3,31-4,61), хотя среднее снижение уровня МК было незначительным [28]. Небольшое снижение веса, в среднем всего на 3 кг, через 6 мес терапии сопровождалось выраженным снижением МК сыворотки, но на результат могло повлиять использование метформина [29]. Однако быстрое снижение массы тела (в краткосрочной перспективе) сопряжено с увеличением сывороточного уровня МК [30], что предполагает необходимость постепенного его снижения путем уменьшения калорийности пищи (на 500-1000 ккал в сутки от расчетного) [29]. Подобный подход (ограничение калорийности до 1600 ккал/сут) у пациентов с подагрой и избыточной массой тела/ожирением ассоциировался со снижением сывороточного уровня МК (с 570 мкмоль/л до 470 мкмоль/л), ХС, ХС-ЛПНП, ТГ, частоты приступов артрита в 3,5 раза при среднем снижении массы тела через 16 нед наблюдения на 7,7 кг [31]. Однако снижение сывороточного уровня МК происходило раньше, чем массы тела, и частично могло быль связано с влиянием на уратный обмен компонентов пищи.

\section{ОБРАЗ ЖИЗНИ И ОСОБЕННОСТИ ДИЕТЫ ПРИ ОЖИРЕНИИ И ГУ}

\section{5. При ГУ снижение массы тела рекомендуется всем пациентам с ожирением или избыточной массой тела} (УДД 2, УУР В).

Комментарии. Снижение массы тела как за счет диеты, так и дозированных физических нагрузок связано с нормализацией уровня МК [32]. Детальный анализ 10 ключевых исследований, не подлежащих метаанализу в силу их неоднородности, также подтвердил, что потеря веса у пациентов с избыточной массой тела и подагрой при среднесрочном/долгосрочном наблюдении приводит к снижению сывороточного уровня МК и частоты приступов артрита [33].

Систематический обзор и метаанализ исследований по применению низкоуглеводной диеты у пациентов с ожирением показали, что снижение массы тела коррелировало со снижением сывороточного уровня МК в среднем на -0,43 (95\% ДИ -0,47--0.39) мг/дл, а также нормализацией САД и ДАД, уровня ТГ плазмы крови, а также сывороточных уровней глюкозы, инсулина, гликированного гемоглобина и С-реактивного белка (СРБ) [34]. Хотя конкретная диета для пациентов с ГУ и подагрой при ожирении не разработана, предполагается, что стандартная гипокалорийная диета может быть столь же эффективной, как низкопуриновая [35].

По данным крупного 7-летнего проспективного когортного исследования с участием 11816 лиц с ГУ, динамика ИМТ связана как с риском развития подагры, так и с влиянием на частоту приступов: увеличение ИМТ на >5\% характеризовалось возрастанием риска у развивших подагру в процессе наблюдения острых приступов артрита в 1,6 раза, снижение показателя >5\% - уменьшением риска в 1,4 раза по сравнению с теми, у кого ИМТ существенно не менялся (в интервале $\pm 3,5 \%$ ) [36].

12.6. Пациентам с ожирением и ГУ рекомендуется ограничение потребления любых алкогольных напитков (УДД 1, УУР А).

Комментарии. Несколько крупныхпроспективных исследований показали прямую корреляцию между приемом алкоголя и риском развития ГУ и подагры [37, 38], причем риск развития подагры увеличивается пропорционально количеству потребляемого алкоголя [39]. Прием 1 г алкоголя сопровождается образованием 7 ккал энергии, что является достаточно высоким показателем и при хроническом употреблении может вносить значимый вклад в развитие ожирения и жирового поражения печени [40].

\section{7. Пациентам с ожирением и ГУ рекомендуется ограничение потребления фруктозосодержащих напит- ков и соков (УДД 1, УУР А).}

Комментарии. Помимо увеличения риска развития СД2 и высокой калорийности [41], потребление фруктозы всего 1 г/кг массы тела увеличивает концентрацию МК сыворотки на 60-120 мкмоль/л на протяжении 2 ч после приема у пациентов с подагрой, их детей и здоровых добровольцев [42]. По результатам крупнейшего популяционного исследования NHANES, ОШ развития ГУ (>7,0 мг/дл у мужчин и >5,7 мг/дл у женщин) увеличивалось прямо пропорционально количеству потребляемых подслащенных безалкогольных напитков с 1,01 при приеме $<0,5$ порций в день до 1,82 у потребляющих $\geq 4$ порций в день, в последнем случае сывороточный уровень МК был выше на 0,42 мг/дл, чем у тех, кто не употреблял подслащенные напитки. [44]. 
12.8. Пациентам с ожирением и ГУ рекомендуется ограничение потребления пуринсодержащих продуктов животного происхождения, особенно мяса красных сортов и субпродуктов (УДД 1, УУР А).

Комментарии. Основным экзогенным источником пуринов являются высокобелковые продукты животного происхождения, богатые нуклеопротеинами. В крупном исследовании ( $\mathrm{n=51} 529$ ) отмечено, что потребление мяса и морепродуктов увеличивает риск подагры в 1,5 раза [39]. Ассоциация между количеством потребляемого мяса, и морепродуктов и уровнем МК была выявлена и в исследовании NHANES III [45]. Потребление богатых пуринами продуктов преимущественно животного происхождения увеличивает риск приступов артрита у пациентов с подагрой почти в 5 раз [46].

В крупном исследовании показано, что у профессиональных спортсменов с ГУ (46\%) по сравнению с группой без нее, обнаружена прямая корреляция между сывороточным уровнем МК и потреблением белка, содержащегося в жировых продуктах ( $\mathrm{R}=0,37 ; \mathrm{p}<0,05)$, белка, содержащегося в алкоголе $(\mathrm{R}<0,05 ; \mathrm{p}=0,32)$, а также общим потреблением белка животного происхождения (исключая молочный белок) $(R=0,35 ; p<0,49)$ [47]. Диета с низким содержанием липидов и пуринов у 300 пациентов с бессимптомной ГУ в течение 4 нед сопровождалась снижением массы тела, уровня ХС, ТГ и МК [48].

Пациенты с недавно развившейся подагрой и умеренным повышением сывороточного уровня МК и использовавшие калькулятор для расчета потребления пуринов (не более 200 мг/сут) снизили сывороточный уровень МК на 7\%

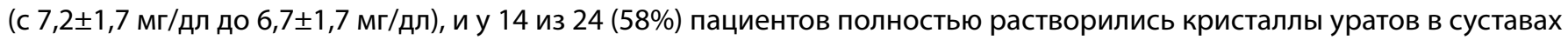
и мягких тканях стоп (определялись при помощи двухэнергетической КТ) [49]. Однако пациентам рекомендовали избегать потребления фруктозы, алкоголя, а не только богатых пуринами мяса и морепродуктов, что также могло благоприятно повлиять на результат.

\section{9. Пациентам с ожирением и ГУ рекомендуется дозированная физическая нагрузка (УДД 2, УУР В).}

Комментарии. Схемы физической нагрузки при ГУ не разработаны, и отсутствуют данные РКИ. По результатам единичных работ среди пациентов с ГУ показано, что осуществляющие физическую активность более 150 мин/нед имели риск общей смертности на 11\% ниже [OР 0,89 (95\% ДИ 0,82-0,97)] в сравнении с теми, кто имел низкую физическую активность [50]. Регулярная, дозированная физическая нагрузка ассоциируется с более низким уровнем MK [51].

\section{ОСОБЕННОСТИ МЕДИКАМЕНТОЗНОЙ ТЕРАПИИ ПАЦИЕНТОВ С ОЖИРЕНИЕМ И ГУ}

12.10. Медикаментозное лечение ожирения у пациентов с ГУ и подагрой способствует снижению сывороточного уровня МК (УДД 4, УУР С).

Комментарии. Сравнительных исследований по эффективности снижающих массу тела препаратов и диетотерапии в отношении влияния на уровень МК сыворотки нет. Данные слепого исследования Sibutramine Cardiovascular OUTcomes (SCOUT) свидетельствовали о параллельном снижении веса и небольшом снижении сывороточного уровня МК при приеме сибутрамина у пациентов с СС3 и/или СД2, при этом уратснижающий эффект препарата сохранялся при отсутствии снижения массы тела [52]. У женщин с ИМТ >30 кг/м² применение сибутрамина 10 мг 2 р/д снижало сывороточный уровень МК на 12\%, орлистата 120 мг 3 р/д - на 8,6\% [53]. Подобный эффект предполагается и для лираглутида [54].

12.11. У пациентов с ожирением в сочетании с ГУ или подагрой рекомендуется применение метформина (УДД 3, УУР В).

Комментарии. В сравнении с лекарственными препаратами, применяемыми для лечения ожирения (сибутрамин, орлистат), применение метформина в дозе 850 мг 2 р/д приводит к максимальному уменьшению сывороточного уровня MK (на 13,4\%) [53]. По результатам 6-месячного применения у пациентов с подагрой метформина в суточной дозе 1500 мг, более чем у половины которых отмечался ИМТ >30 кг/м², снижение сывороточного уровня МК составило

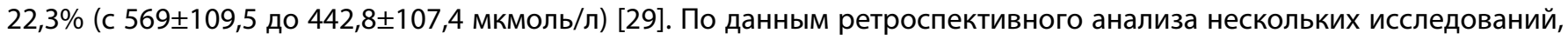
комбинированный прием аллопуринола и метформина у пациентов с подагрой ассоциируется с в 2 раза более редкими приступами артрита в сравнении с монотерапией аллопуринолом, что связано с противовоспалительным эффектом метформина благодаря ингибиции mTOR [55].

12.12.У пациентов с подагрой при назначении симптоматической (противовоспалительной) терапии купирования или профилактики приступов артрита не рекомендуется применение ГК, предпочтение должно отдаваться колхицину или НПВП (УДД 3 УУР С).

Комментарии. Одним из возможных методов купирования приступа артрита или профилактики обострений при подагре является назначение ГК, причем если для купирования обострения препараты могут быть назначены однократно (в виде локальной терапии) или коротким курсом (30-35 мг преднизолона в сутки в течение 3-5 дней), то профилактика предполагает длительный прием низких доз ( $\leq 7,5$ мг/сут) [56, 57]. Применение любых форм препаратов чревато развитием синдрома «рикошета», повышением АД, уровня гликемии, может сопровождаться снижением плотности костной ткани, увеличением массы тела, и развитием метаболического синдрома [58-60].

Есть данные, что применение колхицина снижает риски сердечно-сосудистых осложнений. По результатам исследования COLCOT, 3-летний прием колхицина (0,5 мг 1 раз в день) в сравнении с плацебо после острого ИМ снижает 
риск сердечно-сосудистой смерти, реанимационной остановки сердца, инфаркта миокарда, инсульта или срочной госпитализации по поводу стенокардии, приводящей к коронарной реваскуляризации, на 27\% $(5,5 \%$ vs 7,1\%, p=0,02) [61]. У пациентов с подагрой 16,5-месячная терапия колхицином снижала риск первичного ИМ, инсульта или транзиторной ишемической атаки в 2,9 раза [62].

\section{ХИРУРГИЧЕСКИЕ МЕТОДЫ ЛЕЧЕНИЯ ОЖИРЕНИЯ У ПАЦИЕНТОВ С ГУ И ПОДАГРОЙ}

\subsection{3. Хирургические методы лечения ожирения при ГУ и подагре способствуют снижению сывороточного уровня МК в отдаленной перспективе, но должны назначаться с осторожностью, т.к. в первые месяцы после оперативного лечения увеличивается риск развития приступа подагрического артрита (УДД 3, уУР В).}

Комментарии. Хотя проведение бариатрического лечения способствует снижению МК по отдаленным результатам [30, 63, 64], при ГУ и подагре оно должно назначаться с особой осторожностью, т.к. в первые месяцы после оперативного лечения увеличивается риск развития острого подагрического артрита/бурсита, это связано в первую очередь со стремительным снижением массы тела, что приводит к значительному повышению уровня МК и может быть фактором обострения или дебюта подагры [65].

\section{СПИСОК ЛИТЕРАТУРЫ | REFERENCES}

1. Zitt E, Fischer A, Lhotta K, Concin H, Nagel G. Sex-and age-specific variations, temporal trends and metabolic determinants of serum uric acid concentrations in a large population-based Austrian cohort. Sci Rep. 2020;10(1):7578. doi: https://doi.org/10.1038/s41598-020-64587-z

2. Maynard JW, McAdams DeMarco MA, Baer AN, et al. Incident Gout in Women and Association with Obesity in the Atherosclerosis Risk in Communities (ARIC) Study. Am J Med. 2012;125(7):717.e9-717.e17. doi: https://doi.org/10.1016/j.amjmed.2011.11.018

3. Stanaway JD, Afshin A, Gakidou E, et al. Global, regional, and national comparative risk assessment of 84 behavioural, environmental and occupational, and metabolic risks or clusters of risks for 195 countries and territories, 1990-2017: a systematic analysis for the Global Burden of Disease Stu. Lancet. 2018;392(10159):1923-1994. doi: https://doi.org/10.1016/S0140-6736(18)32225-6

4. Gakidou E, Afshin A, Abajobir AA, et al. Global, regional, and national comparative risk assessment of 84 behavioural, environmental and occupational, and metabolic risks or clusters of risks, 1990-2016: a systematic analysis for the Global Burden of Disease Study 2016. Lancet. 2017;390(10100):1345-1422. doi: https://doi.org/10.1016/S0140-6736(17)32366-8

5. Chen J-H, Pan W-H, Hsu C-C, et al. Impact of obesity and hypertriglyceridemia on gout development with or without hyperuricemia: A prospective study. Arthritis Care Res (Hoboken). 2013;65(1):133-140. doi: https://doi.org/10.1002/acr.21824

6. Juraschek SP, Miller ER, Gelber AC. Body mass index, obesity, and prevalent gout in the United States in 1988-1994 and 2007-2010. Arthritis Care Res (Hoboken). 2013;65(1):127-132 doi: https://doi.org/10.1002/acr.21791

7. Xia Y, Wu Q, Wang $H$, et al. Global, regional and national burden of gout, 1990-2017: a systematic analysis of the Global Burden of Disease Study. Rheumatology. 2020;59(7):1529-1538. doi: https://doi.org/10.1093/rheumatology/kez476

8. Choi Y-J, Shin H-S, Choi HS, et al. Uric acid induces fat accumulation via generation of endoplasmic reticulum stress and SREBP-1C activation in hepatocytes. Lab Investig. 2014;94(10):1114-1125. doi: https://doi.org/10.1038/labinvest.2014.98

9. Vuorinen-Markkola H, Yki-Järvinen H. Hyperuricemia and insulin resistance. J Clin Endocrinol Metab. 1994;78(1):25-29. doi: https://doi.org/10.1210/jcem.78.1.8288709

10. Han T, Lan L, Qu R, et al. Temporal Relationship Between Hyperuricemia and Insulin Resistance and Its Impact on Future Risk of Hypertension. Hypertension. 2017;70(4):703-711. doi: https://doi.org/10.1161/HYPERTENSIONAHA.117.09508

11. Choi HK, Ford ES, Li C, Curhan G. Prevalence of the metabolic syndrome in patients with gout: The Third National Health and Nutrition Examination Survey. Arthritis Rheum. 2007;57(1):109-115. doi: https://doi.org/10.1002/art.22466

12. Hernández-Cuevas CB, Roque LH, Huerta-Sil G, et al First Acute Gout Attacks Commonly Precede Features of the Metabolic Syndrome. JCR J Clin Rheumatol. 2009;15(2):65-67. doi: https://doi.org/10.1097/RHU.0b013e31819c0dba
13. White J, Sofat R, Hemani G, et al. Plasma urate concentration and risk of coronary heart disease: a Mendelian randomisation analysis. Lancet Diabetes Endocrinol. 2016;4(4):327-336. doi: https://doi.org/10.1016/S2213-8587(15)00386-1

14. Rahimi-Sakak F, Maroofi M, Rahmani J, et al. Serum uric acid and risk of cardiovascular mortality: a systematic review and dose-response meta-analysis of cohort studies of over a million participants. BMC Cardiovasc Disord. 2019;19(1):218. doi: https://doi.org/10.1186/s12872-019-1215-z

15. Loeb JN. The influence of temperature on the solubility of monosodium urate. Arthritis Rheum. 1972;15(2):189-192. doi: https://doi.org/10.1002/art.1780150209

16. Roddy E, Doherty M. Gout. Epidemiology of gout. Arthritis Res Ther. 2010;12(6):223. doi: https://doi.org/10.1186/ar3199

17. Bursill D, Taylor WJ, Terkeltaub R, et al. Gout, Hyperuricaemia and Crystal-Associated Disease Network (G-CAN) consensus statement regarding labels and definitions of disease states of gout. Ann Rheum Dis. 2019;78(11):1592-1600. doi: https://doi.org/10.1136/annrheumdis-2019-215933

18. Елисеев МС. Подагра. В кн.: Насонов ЕЛ, редактор. Ревматология. Российские клинические рекомендации. Москва: ГЭОТАРМедиа; 2017. С. 253-64. [Eliseev MS. Podagra. In: Nasonov EL, editor. Revmatologiya. Rossiiskie klinicheskie rekomendatsii. Moskva: GEOTAR-Media; 2017. S. 253-64. (In Russ.)]

19. Neogi T, Jansen TLTA, Dalbeth N, et al. 2015 Gout classification criteria: an American College of Rheumatology/ European League Against Rheumatism collaborative initiative. Ann Rheum Dis. 2015;74(10):1789-1798. doi: https://doi.org/10.1136/annrheumdis-2015-208237

20. Richette P, Doherty M, Pascual E, et al. 2018 updated European League Against Rheumatism evidence-based recommendations for the diagnosis of gout. Ann Rheum Dis. 2020;79(1):31-38. doi: https://doi.org/10.1136/annrheumdis-2019-215315

21. Елисеев М.С., Владимиров С.А. Распространенность и клинические особенности подагры и болезни депонирования пирофосфата кальция у пациентов с острым артритом // Научнопрактическая ревматология. - 2015. — №4. — С. 375-378. [Eliseev MS, Vladimirov SA. Rasprostranennost'i klinicheskie osobennosti podagry i bolezni deponirovaniya pirofosfata kal'tsiya u patsientov s ostrym artritom // Nauchno-prakticheskaya revmatologiya. 2015;(4):375-378. (In Russ.)]

22. Dalbeth N, Schumacher HR, Fransen J, et al. Survey Definitions of Gout for Epidemiologic Studies: Comparison With Crystal Identification as the Gold Standard. Arthritis Care Res (Hoboken). 2016;68(12):1894-1898. doi: https://doi.org/10.1002/acr.22896

23. Christiansen SN, Østergaard M, Slot O, et al. Ultrasound for the diagnosis of gout-the value of gout lesions as defined by the Outcome Measures in Rheumatology ultrasound group. Rheumatology. 2021;60(1):239-249. doi: https://doi.org/10.1093/rheumatology/keaa366 
24. Taylor WJ, Fransen J, Dalbeth N, et al. Performance of classification criteria for gout in early and established disease. Ann Rheum Dis. 2016;75(1):178-182. doi: https://doi.org/10.1136/annrheumdis-2014-206364

25. Gamala M, Jacobs JWG, Linn-Rasker SF, et al. The performance of dual-energy $\mathrm{CT}$ in the classification criteria of gout: a prospective study in subjects with unclassified arthritis. Rheumatology. 2020;59(4):845-851. doi: https://doi.org/10.1093/rheumatology/kez391

26. Filippou G, Pascart T, lagnocco A. Utility of Ultrasound and Dual Energy CT in Crystal Disease Diagnosis and Management. Curr Rheumatol Rep. 2020;22(5):15. doi: https://doi.org/10.1007/s11926-020-0890-1

27. Дедов И.И., Мельниченко Г.А., Шестакова М.В., и др. Лечение морбидного ожирения у взрослых // Ожирение и метаболизм. 2018. - T.15. — №1. — C. 53-70. [Dedov II, Mel'nichenko GA, Shestakova M V., et al. Russian national clinical recommendations for morbid obesity treatment in adults. 3rd revision (Morbid obesity treatment in adults). Obesity and Metabolism. 2018;15(1):53-70. (In Russ.)] doi: https://doi.org/10.14341/omet2018153-70

28. Zhu Y, Zhang Y, Choi HK. The serum urate-lowering impact of weight loss among men with a high cardiovascular risk profile: the Multiple Risk Factor Intervention Trial. Rheumatology. 2010;49(12):2391-2399. doi: https://doi.org/10.1093/rheumatology/keq256

29. Барскова В.Г., Елисеев М.С., Кудаева Ф.М., и др. Влияние метформина на течение подагры и инсулинорезистентность // Клиническая медицина. — 2009. — Т.87. — №7. — С. 41-46. [Barskova VG, Eliseev MS, Kudaeva FM, et al. Vliyanie metformina na techenie podagry i insulinorezistentnost'. Klinicheskaya meditsina. 2009;87(7):41-46. (In Russ.)]

30. Dalbeth $N$, Chen $P$, White $M$, et al. Impact of bariatric surgery on serum urate targets in people with morbid obesity and diabetes: a prospective longitudinal study. Ann Rheum Dis. 2014;73(5):797-802. doi: https://doi.org/10.1136/annrheumdis-2013-203970

31. Dessein PH. Beneficial effects of weight loss associated with moderate calorie/carbohydrate restriction, and increased proportional intake of protein and unsaturated fat on serum urate and lipoprotein levels in gout: a pilot study. Ann Rheum Dis. 2000;59(7):539-543. doi: https://doi.org/10.1136/ard.59.7.539

32. Zhou J, Wang Y, Lian F, et al. Physical exercises and weight loss in obese patients help to improve uric acid. Oncotarget. 2017;8(55):94893-94899. doi: https://doi.org/10.18632/oncotarget.22046

33. Nielsen SM, Bartels EM, Henriksen M, et al. Weight loss for overweight and obese individuals with gout: a systematic review of longitudinal studies. Ann Rheum Dis. 2017;76(11):1870-1882. doi: https://doi.org/10.1136/annrheumdis-2017-211472

34. Santos FL, Esteves SS, da Costa Pereira A, Yancy Jr WS, Nunes JPL. Systematic review and meta-analysis of clinical trials of the effects of low carbohydrate diets on cardiovascular risk factors. Obes Rev. 2012;13(11):1048-1066. doi: https://doi.org/10.1111/j.1467-789X.2012.01021.x

35. Khanna D, Fitzgerald JD, Khanna PP, et al. 2012 American College of Rheumatology guidelines for management of gout. Part 1: Systematic nonpharmacologic and pharmacologic therapeutic approaches to hyperuricemia. Arthritis Care Res (Hoboken). 2012;64(10):1431-1446. doi: https://doi.org/10.1002/acr.21772

36. Nguyen UDT, Zhang Y, Louie-Gao Q, et al. Obesity Paradox in Recurrent Attacks of Gout in Observational Studies: Clarification and Remedy. Arthritis Care Res (Hoboken). 2017;69(4):561-566. doi: https://doi.org/10.1002/acr.22954

37. Bhole V, de Vera M, Rahman MM, et al. Epidemiology of gout in women: Fifty-two-year followup of a prospective cohort. Arthritis Rheum. 2010;62(4):1069-1076. doi: https://doi.org/10.1002/art.27338

38. Gaffo AL, Roseman JM, Jacobs DR, et al. Serum urate and its relationship with alcoholic beverage intake in men and women: findings from the Coronary Artery Risk Development in Young Adults (CARDIA) cohort. Ann Rheum Dis. 2010;69(11):1965-1970. doi: https://doi.org/10.1136/ard.2010.129429

39. Choi HK, Atkinson K, Karlson EW, et al. Alcohol intake and risk of incident gout in men: a prospective study. Lancet. 2004;363(9417):1277-1281. doi: https://doi.org/10.1016/S0140-6736(04)16000-5

40. Tumwesigye NM, Mutungi G, Bahendeka S, et al. Alcohol consumption, hypertension and obesity: Relationship patterns along different age groups in Uganda. Prev Med Reports. 2020;19:101141. doi: https://doi.org/10.1016/j.pmedr.2020.101141
41. Tsilas CS, de Souza RJ, Mejia SB, et al. Relation of total sugars, fructose and sucrose with incident type 2 diabetes: a systematic review and meta-analysis of prospective cohort studies. Can Med Assoc J. 2017;189(20):E711-E720. doi: https://doi.org/10.1503/cmaj.160706

42. Stirpe F, Della Corte E, Bonetti E, et al. Fructose-induced hyperuricæmia. Lancet. 1970;296(7686):1310-1311. doi: https://doi.org/10.1016/S0140-6736(70)92269-5

43. Choi HK, Curhan G. Soft drinks, fructose consumption, and the risk of gout in men: prospective cohort study. BMJ. 2008;336(7639):309-312. doi: https://doi.org/10.1136/bmj.39449.819271.BE

44. Choi HK, Willett W, Curhan G. Fructose-Rich Beverages and Risk of Gout in Women. JAMA. 2010;304(20):2270. doi: https://doi.org/10.1001/jama.2010.1638

45. Choi HK, Liu S, Curhan G. Intake of purine-rich foods, protein, and dairy products and relationship to serum levels of uric acid: The Third National Health and Nutrition Examination Survey. Arthritis Rheum. 2005;52(1):283-289. doi: https://doi.org/10.1002/art.20761

46. Zhang Y, Chen $\mathrm{C}$, Choi $\mathrm{H}$, et al. Purine-rich foods intake and recurrent gout attacks. Ann Rheum Dis. 2012;71(9):1448-1453. doi: https://doi.org/10.1136/annrheumdis-2011-201215

47. Елисеев М.С., Чикина М.Н., Кобелькова И.В., и др. Определение группы риска по белковому и пуриновому дисбалансу у высококвалифицированных спортсменов в различных видах спорта // Лечебная физкультура и спортивная медицина. 2019. - T.152. - №2. - C. 6-13. [Eliseev MS, Chikina MN, Kobel'kova IV, et al. Opredelenie gruppy riska po belkovomu i purinovomu disbalansu u vysokokvalifitsirovannykh sportsmenov $v$ razlichnykh vidakh sporta. Lechebnaya fizkul'tura i sportivnaya meditsina.2019;152(2):6-13. (In Russ.)]

48. Kullich W, Ulreich A, Klein G. Changes in uric acid and blood lipids in patients with asymptomatic hyperuricemia treated with diet therapy in a rehabilitation procedure. Rehabilitation (Stuttg). 1989;28(3):134-137.

49. Ellmann H, Bayat S, Araujo E, et al. Effects of Conventional Uric AcidLowering Therapy on Monosodium Urate Crystal Deposits. Arthritis Rheumatol. 2020;72(1):150-156. doi: https://doi.org/10.1002/art.41063

50. Chen J-H, Wen CP, Wu SB, et al. Attenuating the mortality risk of high serum uric acid: the role of physical activity underused. Ann Rheum Dis. 2015;74(11):2034-2042. doi: https://doi.org/10.1136/annrheumdis-2014-205312

51. Park DY, Kim YS, Ryu SH, Jin YS. The association between sedentary behavior, physical activity and hyperuricemia. Vasc Health Risk Manag. 2019;15:291-299. doi: https://doi.org/10.2147/NHRM.S200278

52. Andersson C, Weeke P, Brendorp B, et al. Differential changes in serum uric acid concentrations in sibutramine promoted weight loss in diabetes: results from four weeks of the lead-in period of the SCOUT trial. Nutr Metab (Lond). 2009;6(1):42. doi: https://doi.org/10.1186/1743-7075-6-42

53. Gokcel A, Gumurdulu Y, Karakose $H$, et al. Evaluation of the safety and efficacy of sibutramine, orlistat and metformin in the treatment of obesity. Diabetes, Obes Metab. 2002;4(1):49-55. doi: https://doi.org/10.1046/j.1463-1326.2002.00181.x

54. Tonneijck L, Muskiet MHA, Smits MM, et al. Effect of immediate and prolonged GLP-1 receptor agonist administration on uric acid and kidney clearance: Post-hoc analyses of four clinical trials. Diabetes, Obes Metab. 2018;20(5):1235-1245. doi: https://doi.org/10.1111/dom.13223

55. Vazirpanah N, Ottria A, van der Linden M, et al. mTOR inhibition by metformin impacts monosodium urate crystalinduced inflammation and cell death in gout: a prelude to a new add-on therapy? Ann Rheum Dis. 2019;78(5):663-671. doi: https://doi.org/10.1136/annrheumdis-2018-214656

56. Yu J, Lu H, Zhou J, et al. Oral prednisolone versus nonsteroidal anti-inflammatory drugs in the treatment of acute gout: a meta-analysis of randomized controlled trials. Inflammopharmacology. 2018;26(3):717-723. doi: https://doi.org/10.1007/s10787-018-0442-8

57. FitzGerald JD, Dalbeth N, Mikuls T, et al. 2020 American College of Rheumatology Guideline for the Management of Gout. Arthritis Care Res (Hoboken). 2020;72(6):744-760. doi: https://doi.org/10.1002/acr.24180

58. Oray M, Abu Samra K, Ebrahimiadib N, et al. Long-term side effects of glucocorticoids. Expert Opin Drug Saf. 2016;15(4):457465. doi: https://doi.org/10.1517/14740338.2016.1140743 
59. Федорова А.А., Барскова В.Г., Якунина И.А., Насонова В.А. Кратковременное применение глюкокортикоидов у больных с затяжным и хроническим подагрическим артритом, (часть II - сравнение эффективности различных лекарственных форм). Научно-практическая ревматология. 2008;46(5):72-75. [Fedorova AA, Barskova VG, Yakunina L, Nasonova VA. Short-term glucocorticoid administration in patients with protracted and chronic gout arthritis. Part 2 - comparison of different medication forms efficacy. Rheumatol Sci Pract. 2008;46(5):72-75. (In Russ.)] doi: https://doi.org/10.14412/1995-4484-2008-418

60. Федорова А.А., Барскова В.Г., Якунина И.А., Насонова В.А. Кратковременное применение глюкокортикоидов у больных затяжным и хроническим подагрическим артритом. Часть III частота развития нежелательных реакций. Научно-практическая ревматология. 2009;62(2):38-42. [Fedorova AA, Barskova VG, Yakunina IA, Nasonova VA. Short term administration of glucocorticoids in patients with protracted and chronic gout arthritis. Part III frequency of adverse events. Rheumatol Sci Pract. 2009;62(2):38-42. (In Russ.)] doi: https://doi.org/10.14412/1995-4484-2009-457
61. Tardif J-C, Kouz S, Waters DD, et al. Efficacy and Safety of Low-Dose Colchicine after Myocardial Infarction. N Engl J Med. 2019;381(26):2497-2505. doi: https://doi.org/10.1056/NEJMoa1912388

62. Solomon DH, Liu C-C, KuO I-H, et al. Effects of colchicine on risk of cardiovascular events and mortality among patients with gout: a cohort study using electronic medical records linked with Medicare claims. Ann Rheum Dis. 2016;75(9):1674-1679. doi: https://doi.org/10.1136/annrheumdis-2015-207984

63. Friedman JE, Dallal RM, Lord JL. Gouty attacks occur frequently in postoperative gastric bypass patients. Surg Obes Relat Dis. 2008;4(1):11-13. doi: https://doi.org/10.1016/j.soard.2007.09.012

64. Romero-Talamás H, Daigle $\mathrm{CR}$, Aminian A, et al. The effect of bariatric surgery on gout: a comparative study. Surg Obes Relat Dis. 2014;10(6):1161-1165. doi: https://doi.org/10.1016/j.soard.2014.02.025

65. Yeo C, Kaushal S, Lim B, et al. Impact of bariatric surgery on serum uric acid levels and the incidence of gout-A meta-analysis. Obes Rev. 2019;20(12):1759-1770. doi: https://doi.org/10.1111/obr.12940. 


\title{
ГЛАВА 13. ВЗАИМОДЕЙСТВИЕ ЛЕКАРСТВЕННЫХ СРЕДСТВ ПРИ ЛЕЧЕНИИ ОЖИРЕНИЯ И КОМОРБИДНЫХ ЗАБОЛЕВАНИЙ
}

\author{
Журавлева М.В., Крысанова В.С.
}

\section{ЛИРАГЛУТИД}

13.1. Пациентам, принимающим лекарственный препарат лираглутид, не требуется коррекции дозы сопутствующих пероральных лекарственных препаратов (УДД 2, УУР А).

Комментарии. Препарат лираглутид показал очень низкую способность к лекарственному фармакокинетическому взаимодействию, обусловленную метаболизмом в системе цитохрома Р-450(СҮР), а также связыванием с белками плазмы. Небольшая задержка опорожнения желудка на фоне приема препарата МНН лираглутид может оказывать влияние на всасывание сопутствующих пероральных лекарственных препаратов, у некоторых пациентов отмечалось как минимум по одному эпизоду острой диареи [1-5]. В рамках рандомизированного двойного слепого плацебо-контролируемого исследования на здоровых добровольцах была проведена оценка влияния препарата лираглутид на скорость и степень гастроинтестинальной абсорбции препаратов различных классов согласно биофармацевтической классификационной системе (II (аторвастатин), III (лизиноприл) и IV (дигоксин)), в том числе влияние на уровень кислотности в желудке в течение 24 ч после применения препарата. Результаты продемонстрировали, что незначительное замедление абсорбции пероральных препаратов на фоне применения лираглутида соответствует их биофармацевтическим свойствам, не было выявлено клинически значимых фармакокинетических отклонений, которые соответствовали ожидаемым при условии небольшой задержки опорожнения желудка натощак при нормальных значениях уровня внутрижелудочной кислотности [5].

13.2. У пациентов, принимающих варфарин или другие производные кумарина, нельзя исключить клинически значимого взаимодействия (УДД 5, УУР С).

Комментарии. У пациентов, принимающих варфарин и другие производные кумарина, после начала терапии препаратом лираглутид следует чаще проводить мониторинг Международного нормализованного отношения (МНО) $[1,6]$.

13.3. Пациентам, принимающим дигоксин, на фоне приема препарата лираглутид не требуется коррекции дозы сердечного гликозида (УДД 2, УУР А).

Комментарии. При совместном применении дигоксина и лираглутида отмечалось уменьшение площади

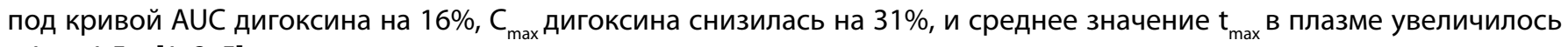
с 1 до 1,5 ч $[1,2,5]$.

\section{ОРЛИСТАТ}

13.4. Пациентам, принимающим циклоспорин, не следует назначать лекарственную терапию орлистатом В связи с риском развития отторжения трансплантата на фоне снижения иммуносупрессивной эффективности циклоспорина [7-10] (УДД 2, УУР В).

Комментарии. При необходимости одновременного назначения циклоспорина и орлистата следует разносить по времени прием данных препаратов как минимум на 2 ч с целью снижения риска возможного взаимодействия. При одновременном применении препаратов пациентам следует строго придерживаться диеты со сниженным количеством жиров и проводить более частый мониторинг концентрации циклоспорина в плазме крови [9].

13.5. Пациентам, получающим варфарин или другие антикоагулянты, при назначении терапии орлистатом рекомендовано проводить контроль МНО [11, 12] (УДД 2, УУР В).

Комментарии. Может наблюдаться снижение концентрации протромбина и повышение показателя МНО. В опубликованных данных имеется упоминание клинического случая - у 66-летнего пациента с фибрилляцией предсердий, получающего терапию варфарином, на фоне приема орлистата возросло значение показателя МНО [12]. Точный механизм неизвестен, возможно, на фоне приема орлистата снижается всасывание жирорастворимого витамина К, приводя к снижению необходимой дозы варфарина. Это может быть также связано с диетой с низким содержанием жиров, приводящей к снижению потребляемого количества витамина К и/или всасыванием витамина К [12].

13.6. Пациентам, принимающим амиодарон, следует проводить контроль ЭКГ [13] (УДД 3, УУР В).

Комментарии. На фоне приема орлистата отмечается снижение системной экспозиции амиодарона и дезэтиламиодарона (на 25-30\%), так как он обладает липофильными свойствами [13].

\section{7. Следует избегать одновременного назначения орлистата и акарбозы [1] (УДД 5, УУР С).}

Комментарии. В настоящее время имеются данные единичных клинических исследований о совместном применении препаратов в лекарственной форме с модифицированным высвобождением. В рамках пилотного контролируемого рандомизированного исследования Ila фазы в параллельных группах было показано, что применение 
орлистата и акарбозы в лекарственной форме с модифицированным высвобождением не приводит к ухудшению переносимости терапии пациентами [14].

13.8. Пациентам, принимающим противоэпилептические препараты, при одновременном применении с орлистатом следует мониторировать состояние на предмет возможных изменений в частоте и/или тяжести судорожного синдрома [15] (УДД 4, УУР С).

Комментарии. При одновременном применении орлистата и противоэпилептических препаратов наблюдались случаи развития судорог. Орлистат, снижая абсорбцию жиров, может приводить к изменению всасывания липофильных препаратов, в т.ч. противоэпилептических [15].

13.9. На фоне приема орлистата может отмечаться снижение эффективности пероральных контрацептивов [16, 17] (УДД 4, УУР С).

Комментарии. В отдельных случаях совместное применение препаратов может привести к наступлению незапланированной беременности [16]. Пациентам рекомендовано применять дополнительные методы контрацепции.

13.10. Совместное применение орлистата и левотироксина натрия может привести к развитию гипотиреоза и/или снижению контроля гипотиреоза [18] (УДД 4, УУР С).

Комментарии. На фоне приема орлистата у пациентов с папиллярным раком щитовидной железы отмечалось снижение всасывания неорганического йода и/или левотироксина натрия [18].

13.11. Орлистат может незначительно снижать всасывание жирорастворимых витаминов (A, D, E, бетакаротина) [19-24] (УДД 2, УУР А).

Комментарии. В ряде работ было показано, что у здоровых добровольцев на фоне короткого приема орлистата значительно снижалось всасывание бета-каротина и витамина Е, но при этом не отмечалось изменений со стороны всасывания витамина $A[19,20]$. В ходе 2-летнего клинического исследования было показано, что уровень концентрации жирорастворимых витаминов в плазме крови (A, D, Е и бета-каротина) снижался среди пациентов, принимавших орлистат, но при этом показатели не выходили за пределы референсных значений [21, 22]. B исследовании XENDOS [23] установлено статистически значимое снижение уровня жирорастворимых витаминов в плазме крови в группе пациентов, принимавших орлистат в течение 4 лет, по сравнению с группой плацебо. При этом среднее значение уровня каждого из анализируемых витаминов не выходило за пределы референсных значений в обеих группах в течение всего периода исследования.

\subsection{2. На фоне приема орлистата следует мониторировать концентрацию витамина D [24, 25] (УДД 4, УУР B).}

Комментарии. В ряде исследований показано, что у пациентов с ожирением, получающих одновременно орлистат и витамин D, отмечается значительное снижение концентрации витамина D в сыворотке крови [24, 25].

\section{СИБУТРАМИН}

13.13. Совместное применение сибутрамина и ингибиторов микросомального окисления, в т.ч. ингибиторов изофермента СYР3А4 и СРР2В6 (кетоконазол, эритромицин, кларитромицин, клопидогрел и т.д.), приводит к повышению в плазме крови метаболитов сибутрамина [1, 26, 27] (УДД 4, УУР В).

Комментарии. На фоне совместного приема препаратов у пациентов может отмечаться повышение частоты сердечных сокращений, клинически несущественное увеличение интервала $Q-T$ [1].

13.14. Пациентам, принимающим одновременно циклоспорин и сибутрамин, следует проводить более тщательный мониторинг концентрации циклоспорина в плазме крови [28] (УДД 4, УУР В).

Комментарии. При одновременном применении препаратов у пациентов может наблюдаться значительное повышение уровня циклоспорина, что приводит к необходимости снижения получаемой дозы [28].

13.15. Совместное применение сибутрамина и рифампицина, антибиотиков из группы макролидов, фенитоина, карбамазепина, фенобарбитала и дексаметазона приводит к ускорению метаболизма сибутрамина [1] (УДД 5, УУР С).

13.16. Одновременное применение сибутрамина и препаратов, повышающих содержание серотонина в плазме крови (селективные ингибиторы обратного захвата серотонина, препараты для лечения мигрени, сильнодействующие анальгетики, противокашлевые препараты), может приводить к развитию серотонинового синдрома [29-33] (УДД 4, УУР В).

Комментарии. Серотониновый синдром развивается в редких случаях, однако является потенциально смертельным состоянием. К клиническим проявлениям серотонинового синдрома относятся симптомы 3 групп: психические, вегетативные и нервно-мышечные. Со стороны психических симптомов отмечают ажитацию, тревогу, делирий, эйфорию, маниакальный синдром, гипоманию, повышенную восприимчивость, дисфорию, летаргию, бессонницу, галлюцинации, спутанность сознания, мутизм, кому. Со стороны вегетативных симптомов - боли в животе, понос, гипертермию (от $37-38^{\circ} \mathrm{C}$ до $42^{\circ} \mathrm{C}$ и выше), головные боли, слезотечение, расширенные зрачки, тахикардию, тахипноэ, колебания артериального давления, тошноту, рвоту, усиление кишечных шумов, слюнотечение, приливы, озноб, повышенное 
потоотделение. Со стороны нервно-мышечных симптомов - акатизию, двусторонний симптом Бабинского, эпилептиформные припадки, гиперрефлексию, нарушения координации, миоклонус, горизонтальный и вертикальный нистагм, окулогирные кризы, опистотонус, парестезии, мышечную ригидность, тризм, иногда дизартрию [29-33].

13.17. Одновременное применение сибутрамина и препаратов, влияющих на гемостаз или функцию тромбоцитов, может увеличивать риск развития кровотечений [34, 35] (УДД 3, УУР В).

13.18. При назначении сибутрамина в качестве монотерапии, а также совместно с препаратами, увеличивающими интервал Q-T, пациентам следует проводить мониторинг ЭКГ [1, 36, 37] (УДД 4, УУР В).

Комментарии. К препаратам, увеличивающим интервал Q-T, относятся $\mathrm{H}_{1}$-гистаминоблокаторы (астемизол, терфенадин), антиаритмические препараты, такие как амиодарон, хинидин, флекаинид, мексилетин, пропафенон, соталол, стимулятор моторики желудочно-кишечного тракта цизаприд, пимозид, сертиндол и трициклические антидепрессанты, а также такие состояния, как гипокалиемия и гипомагниемия [1].

Значимые лекарственные взаимодействия представлены в таблице 13.

Таблица 13. Значимые лекарственные взаимодействия на фоне приема лекарственных препаратов для лечения ожирения и коморбидных заболеваний

\begin{tabular}{|c|c|c|}
\hline $\begin{array}{l}\text { Лекарственный } \\
\text { препарат }\end{array}$ & Лекарственный препарат & Проявления \\
\hline Лираглутид & Гатифлоксацин & $\begin{array}{l}\text { Совместное применение препаратов может привести } \\
\text { к развитию гипогликемии, вплоть до развития комы }\end{array}$ \\
\hline \multirow{3}{*}{ Орлистат } & Циклоспорин & $\begin{array}{l}\text { Лекарственный препарат МНН орлистат может приводить } \\
\text { к снижению биодоступности циклоспорина при пероральном } \\
\text { приеме. Снижение абсорбции жиров на фоне приема орлистата } \\
\text { может приводить к снижению всасывания циклоспорина, так } \\
\text { как последний обладает высокой липофильностью }\end{array}$ \\
\hline & Лефлуномид & $\begin{array}{l}\text { При совместном применении риск развития гепатотоксических } \\
\text { реакций }\end{array}$ \\
\hline & Терифлуномид & $\begin{array}{l}\text { При совместном применении риск развития гепатотоксических } \\
\text { реакций }\end{array}$ \\
\hline \multirow[t]{10}{*}{ Сибутрамин } & Амитриптилин & $\begin{array}{l}\text { Совместное применение препаратов может привести к риску } \\
\text { развития серотонинового синдрома }\end{array}$ \\
\hline & Буспирон & $\begin{array}{l}\text { Совместное применение препаратов может привести к риску } \\
\text { развития серотонинового синдрома }\end{array}$ \\
\hline & Циталопрам & $\begin{array}{l}\text { Совместное применение препаратов может привести к риску } \\
\text { развития серотонинового синдрома }\end{array}$ \\
\hline & Кломипрамин & $\begin{array}{l}\text { Совместное применение препаратов может привести к риску } \\
\text { развития серотонинового синдрома }\end{array}$ \\
\hline & Декстрометорфан & $\begin{array}{l}\text { Совместное применение препаратов может привести к риску } \\
\text { развития серотонинового синдрома }\end{array}$ \\
\hline & Дулоксетин & $\begin{array}{l}\text { Совместное применение препаратов может привести к риску } \\
\text { развития серотонинового синдрома }\end{array}$ \\
\hline & Элетриптан & $\begin{array}{l}\text { Совместное применение препаратов может привести к риску } \\
\text { развития серотонинового синдрома }\end{array}$ \\
\hline & Эфедрин & $\begin{array}{l}\text { Сибутрамин является мощным ингибитором обратного захвата } \\
\text { норэпинефрина и серотонина и менее мощным ингибитором } \\
\text { обратного захвата дофамина. Совместное применение } \\
\text { препаратов может привести к риску развития серотонинового } \\
\text { синдрома }\end{array}$ \\
\hline & Эрготамин & $\begin{array}{l}\text { Совместное применение препаратов может привести к риску } \\
\text { развития серотонинового синдрома }\end{array}$ \\
\hline & Эсциталопрам & $\begin{array}{l}\text { Совместное применение препаратов может привести к риску } \\
\text { развития серотонинового синдрома }\end{array}$ \\
\hline
\end{tabular}




\begin{tabular}{|c|c|c|}
\hline $\begin{array}{l}\text { Лекарственный } \\
\text { препарат }\end{array}$ & Лекарственный препарат & Проявления \\
\hline & Фентанил & $\begin{array}{l}\text { Совместное применение препаратов может привести к риску } \\
\text { развития серотонинового синдрома }\end{array}$ \\
\hline & Флуоксетин & $\begin{array}{l}\text { Совместное применение препаратов может привести к риску } \\
\text { развития серотонинового синдрома }\end{array}$ \\
\hline & Флувоксамин & $\begin{array}{l}\text { Совместное применение препаратов может привести к риску } \\
\text { развития серотонинового синдрома }\end{array}$ \\
\hline & Фуразолидон & $\begin{array}{l}\text { Совместное применение препаратов может привести к риску } \\
\text { развития серотонинового синдрома }\end{array}$ \\
\hline & Гранисетрон & $\begin{array}{l}\text { Совместное применение препаратов может привести к риску } \\
\text { развития серотонинового синдрома }\end{array}$ \\
\hline & Имипрамин & $\begin{array}{l}\text { Совместное применение препаратов может привести к риску } \\
\text { развития серотонинового синдрома }\end{array}$ \\
\hline & Йогексол & $\begin{array}{l}\text { На фоне применения йодсодержащих контрастных веществ } \\
\text { могут возникать судороги. Совместное применение препаратов } \\
\text { может приводить к увеличению риска развития судорожного } \\
\text { синдрома }\end{array}$ \\
\hline & Йопамидол & $\begin{array}{l}\text { На фоне применения йодсодержащих контрастных веществ } \\
\text { могут возникать судороги. Совместное применение препаратов } \\
\text { может приводить к увеличению риска развития судорожного } \\
\text { синдрома. }\end{array}$ \\
\hline & Линезолид & $\begin{array}{l}\text { Линезолид является неселективным обратимым ингибитором } \\
\text { моноаминоксидазы. Совместное применение препаратов } \\
\text { может привести к риску развития серотонинового синдрома }\end{array}$ \\
\hline & Лития карбонат & $\begin{array}{l}\text { Совместное применение препаратов может привести к риску } \\
\text { развития серотонинового синдрома }\end{array}$ \\
\hline & Метиленовый синий & $\begin{array}{l}\text { Совместное применение препаратов может привести к риску } \\
\text { развития серотонинового синдрома }\end{array}$ \\
\hline & Метризамид & $\begin{array}{l}\text { На фоне применения йодсодержащих контрастных веществ } \\
\text { могут возникать судороги. Совместное применение препаратов } \\
\text { может приводить к увеличению риска развития судорожного } \\
\text { синдрома. }\end{array}$ \\
\hline & Милнаципран & $\begin{array}{l}\text { Совместное применение препаратов может привести к риску } \\
\text { развития серотонинового синдрома }\end{array}$ \\
\hline & Миртазапин & $\begin{array}{l}\text { Совместное применение препаратов может привести к риску } \\
\text { развития серотонинового синдрома }\end{array}$ \\
\hline & Ондансетрон & $\begin{array}{l}\text { Совместное применение препаратов может привести к риску } \\
\text { развития серотонинового синдрома }\end{array}$ \\
\hline & Палоносетрон & $\begin{array}{l}\text { Совместное применение препаратов может привести к риску } \\
\text { развития серотонинового синдрома }\end{array}$ \\
\hline & Пароксетин & $\begin{array}{l}\text { Совместное применение препаратов может привести к риску } \\
\text { развития серотонинового синдрома }\end{array}$ \\
\hline & Прокарбазин & $\begin{array}{l}\text { Совместное применение препаратов может привести к риску } \\
\text { развития серотонинового синдрома }\end{array}$ \\
\hline & Разагилин & $\begin{array}{l}\text { Совместное применение препаратов может привести к риску } \\
\text { развития серотонинового синдрома }\end{array}$ \\
\hline & Селегилин & $\begin{array}{l}\text { Совместное применение препаратов может привести к риску } \\
\text { развития серотонинового синдрома }\end{array}$ \\
\hline & Сертралин & $\begin{array}{l}\text { Совместное применение препаратов может привести к риску } \\
\text { развития серотонинового синдрома }\end{array}$ \\
\hline
\end{tabular}




\begin{tabular}{|c|c|c|}
\hline $\begin{array}{l}\text { Лекарственный } \\
\text { препарат }\end{array}$ & Лекарственный препарат & Проявления \\
\hline & Натрия оксибутират & $\begin{array}{l}\text { Совместное применение препаратов может приводить } \\
\text { к усилению эффектов натрия оксибутирата, связанных } \\
\text { с угнетением центральной нервной и дыхательной систем, } \\
\text { приводя к повышению риска возникновения следующих } \\
\text { побочных реакций: угнетение дыхания, гипотензия, глубокая } \\
\text { седация, синкопе, кома и смерть }\end{array}$ \\
\hline & $\begin{array}{l}\text { Зверобоя продырявленного } \\
\text { трава }\end{array}$ & $\begin{array}{l}\text { Совместное применение препаратов может привести к риску } \\
\text { развития серотонинового синдрома }\end{array}$ \\
\hline & Суматриптан & $\begin{array}{l}\text { Совместное применение препаратов может привести к риску } \\
\text { развития серотонинового синдрома }\end{array}$ \\
\hline & Тапентадол & $\begin{array}{l}\text { Совместное применение препаратов может привести к риску } \\
\text { развития серотонинового синдрома }\end{array}$ \\
\hline & Трамадол & $\begin{array}{l}\text { Совместное применение препаратов может привести к риску } \\
\text { развития серотонинового синдрома }\end{array}$ \\
\hline & Тразодон & $\begin{array}{l}\text { Совместное применение препаратов может привести к риску } \\
\text { развития серотонинового синдрома }\end{array}$ \\
\hline & Триптофан & $\begin{array}{l}\text { Совместное применение препаратов может привести к риску } \\
\text { развития серотонинового синдрома }\end{array}$ \\
\hline & Венлафаксин & $\begin{array}{l}\text { Совместное применение препаратов может привести к риску } \\
\text { развития серотонинового синдрома }\end{array}$ \\
\hline & Вортиоксетин & $\begin{array}{l}\text { Совместное применение препаратов может привести к риску } \\
\text { развития серотонинового синдрома }\end{array}$ \\
\hline & Золмитриптан & $\begin{array}{l}\text { Совместное применение препаратов может привести к риску } \\
\text { развития серотонинового синдрома }\end{array}$ \\
\hline
\end{tabular}

\section{СПИСОК ЛИТЕРАТУРЫ | REFERENCES}

1. Государственный реестр лекарственных средств. ГЭлектронный ресурс]. Доступно по ссылке: https://grls.rosminzdrav.ru/grls.aspx. Ссылка действительна на 10.08.2020 г.

2. Malm-Erjefalt $M$, Ekblom M, Brondsted $L$, et al. A randomised, doubleblind, cross-over trial investigating the effects of liraglutide on the absorption pharmacokinetics of concomitantly administered oral drugs in healthy subjects. Diabetes. 2008;56:434.

3. Jacobsen LV, Brondsted L, Vouis J, Zdaravkovic M. A randomized, double-blind, cross-over trial investigating the effect of liraglutide on the absorption of an oral contraceptive drug. Diabetes. 2008;57:2047-PO

4. Kapitza C, Zdravkovic M, Hindsberger C, Flint A. The effect of the once-daily human glucagon-like peptide 1 analog liraglutide on the pharmacokinetics of acetaminophen. Adv Ther. 2011;28(8):650-660. doi: https://doi.org/10.1007/s12325-011-0044-y

5. Malm-Erjefält M, Ekblom M, Vouis J, et al. Effect on the Gastrointestinal Absorption of Drugs from Different Classes in the Biopharmaceutics Classification System, When Treating with Liraglutide. Mol Pharm. 2015;12(11):4166-4173. doi: https://doi.org/10.1021/acs.molpharmaceut.5b00278

6. Novo Nordisk A/S. Victoza: EU summary of product characteristics. 2014. Available from: http://www.ema.europa.eu/docs/en_GB/ document_library/EPAR___Product_Information/human/001026/ WC500050017.pdf.

7. Colman E, Fossler M. Reduction in Blood Cyclosporine Concentrations by Orlistat. N Engl J Med. 2000;342(15):1141-1142. doi: https://doi.org/10.1056/NEJM200004133421518

8. Nägele $H$, Petersen B, Bonacker U, Rödiger W. Effect of orlistat on blood cyclosporin concentration in an obese heart transplant patient. Eur J Clin Pharmacol. 1999;55(9):667-669. doi: https://doi.org/10.1007/s002280050690
9. Barbaro D, Orsini P, Pallini S, et al. Obesity in Transplant Patients: Case Report Showing Interference of Orlistat with Absorption of Cyclosporine and Review of Literature. Endocr Pract. 2002;8(2):124-126. doi: https://doi.org/10.4158/EP.8.2.124

10. Zhi J, Moore R, Kanitra L, Mulligan TE. Pharmacokinetic Evaluation of the Possible Interaction between Selected Concomitant Medications and Orlistat at Steady State in Healthy Subjects. J Clin Pharmacol. 2002;42(9):1011-1019. doi: https://doi.org/10.1177/0091270002042009008

11. Zhi J, Melia AT, Guerciolini R, et al. The Effect of Orlistat on the Pharmacokinetics and Pharmacodynamics of Warfarin in Healthy Volunteers. J Clin Pharmacol. 1996;36(7):659-666. doi: https://doi.org/10.1002/j.1552-4604.1996.tb04232.x

12. MacWalter RS, Fraser HW, Armstrong KM. Orlistat Enhances Warfarin Effect. Ann Pharmacother. 2003;37(4):510-512. doi: https://doi.org/10.1345/aph.1C122

13. Zhi J, Moore R, Kanitra L, Mulligan TE. Effects of Orlistat, a Lipase Inhibitor, on the Pharmacokinetics of Three Highly Lipophilic Drugs (Amiodarone, Fluoxetine, and Simvastatin) in Healthy Volunteers. J Clin Pharmacol. 2003;43(4):428-435. doi: https://doi.org/10.1177/0091270003252236

14. Holmbäck U, Forslund A, Grudén S, et al. Effects of a novel combination of orlistat and acarbose on tolerability, appetite, and glucose metabolism in persons with obesity. Obes Sci Pract. 2020;6(3):313-323. doi: https://doi.org/10.1002/osp4.405

15. Bigham S, McGuigan C, MacDonald BK. Reduced absorption of lipophilic anti-epileptic medications when used concomitantly with the anti-obesity drug orlistat [letter]. Epilepsia. 2006;47(12):2207-2207. doi: https://doi.org/10.1111/j.1528-1167.2006.00945_1.x

16. Peleg R. Caution when using oral contraceptive pills with Orlistat [letter]. Isr Med Assoc J. 2000;2(9):712 
17. Hartmann D, Güzelhan C, Zuiderwijk PBM, Odink J. Lack of interaction between orlistat and oral contraceptives. Eur J Clin Pharmacol. 1996;50(5):421-424. doi: https://doi.org/10.1007/s002280050134

18. Madhava K, Hartley A. Hypothyroidism in Thyroid Carcinoma Follow-up: Orlistat May Inhibit the Absorption of Thyroxine [letter]. Clin Oncol. 2005;17(6):492. doi: https://doi.org/10.1016/j.clon.2005.05.00

19. Melia AT, Koss-Twardy SG, Zhi J. The Effect of Orlistat, an Inhibitor of Dietary Fat Absorption, on the Absorption of Vitamins A and E in Healthy Volunteers. J Clin Pharmacol. 1996;36(7):647-653. doi: https://doi.org/10.1002/j.1552-4604.1996.tb04230.x
20. Zhi J, Melia AT, Koss-Twardy SG, et al. The Effect of Orlistat, an Inhibitor of Dietary Fat Absorption, on the Pharmacokinetics of $\beta$-Carotene in Healthy Volunteers. J Clin Pharmacol. 1996;36(2):152-159. doi: https://doi.org/10.1002/j.1552-4604.1996.tb04180.x

21. Davidson MH, Hauptman J, DiGirolamo M, et al. Weight Control and Risk Factor Reduction in Obese Subjects Treated for 2 Years With Orlistat. JAMA. 1999;281(3):235. doi: https://doi.org/10.1001/jama.281.3.235

22. Sjöström L, Rissanen A, Andersen T, et al. Randomised placebocontrolled trial of orlistat for weight loss and prevention 


\title{
ГЛАВА 14. ПСИХОСОМАТИЧЕСКИЕ АСПЕКТЫ ОЖИРЕНИЯ
}

\author{
Зеленкова-Захарчук Т.А.
}

Ожирение формируется в результате патогенетических и клинических взаимодействий между психопатологическими и эндокринными нарушениями [1]. В связи с чем для эффективного ведения больных с ожирением необходим мультидисциплинарный подход.

К ожирению приводит избыточное потребление энергетических ресурсов в виде переедания, относящегося к проявлениям нарушений пищевого поведения $[2,3]$. Поэтому ожирение можно рассматривать как эндокринное заболевание, спровоцированное (обусловленное) психопатологией.

Степень выраженности психических расстройств коррелирует с тяжестью ожирения. Отмечается взаимосвязь между тяжестью депрессивных расстройств, интенсивностью пищевых нарушений и увеличением степени ожирения [4].

Считается, что расстройства приема пищи являются независимым фактором, увеличивающим риск суицида даже при купировании сопутствующих депрессивных проявлений [5].

Попытки удерживаться от переедания или соблюдать строгую диету, которые можно расценивать как ограничительное пищевое поведение, сопровождаются актуализацией психопатологических проявлений («диетическая депрессия» по A. J. Stunkard, 1953), которые скрывались за фасадом пищевых нарушений. На передний план в клинической картине выступают пониженное настроение с удрученностью, повышенной раздражительностью, слезливостью, агрессивностью, чувством внутреннего напряжения, тревожностью [6]. В результате чего возобновляется переедание более интенсивного характера, ведущее к еще большему набору веса (рикошетный эффект), что способствует в конечном итоге формированию пессимистического отношения к возможности выздоровления [7].

Примерно 30\% больных ожирением не осознают у себя наличие нарушений пищевого поведения, интерпретируя приемы пищи как пристрастие к вкусной еде. При этом возникают трудности вовремя остановить трапезу, теряется контроль над объемом принимаемых порций. Чувство насыщения или не возникает, или не останавливает от продолжения переедания. В других случаях постоянно ощущается чувство голода, которое подкрепляет желание переедать.

\section{ОПРЕДЕЛЕНИЕ}

Расстройства приема пищи (РПП) отличаются сложной полисиндромальной структурой и представляют собой гетерогенные психопатологические образования, включающие проявления аффективных, поведенческих (девиантных), аддиктивных, когнитивных нарушений [8] и характеризуются неконтролируемым употреблением большего количества пищи (гиперфагией), с нарушением регуляции чувства голода и насыщения.

1. Аффективные (депрессивные) проявления характеризуются неустойчивым настроением со склонностью к раздражительности, аутоагрессивности, самоистязанию, заниженной самооценке, идеями вины, негативным отношением к себе.

2. Под девиантными проявлениями понимается отклоняющееся поведение от общепринятых норм приема пищи в ущерб собственному здоровью.

3. Аддиктивные проявления представляют собой зависимость с невозможностью самостоятельно справиться с непреодолимым стремлением переедать.

4. Когнитивные нарушения включают неполное осознание наличия переедания, частичное снижение памяти в период приема пищи, фиксацию мышления на еде, потерю когнитивного контроля.

Таким образом, ожирение, развивающееся вследствие РПП, представляет собой психосоматическое заболевание, формирующееся в результате двунаправленного взаимодействия психических/характерологических расстройств с эндокринными/соматическими нарушениями [9]. С одной стороны, РПП, приводящие к увеличению веса, способствуют развитию ожирения, с другой - ухудшение течения эндокринного заболевания, в свою очередь, утяжеляет психическое состояние, запуская тем самым взаимоутяжеляющие психосоматические соотношения.

\section{ЭПИДЕМИОЛОГИЯ}

Ожирение приобретает характер пандемии, ассоциированной со значительно возрастающим риском заболеваемости и смертности [10]. Так, в 95\% случаев ожирение представлено первичным (экзогенно-конституциональным) вариантом.

По данным эпидемиологических исследований [11], показатели распространенности компульсивного переедания (КП) разнятся от 4,8 до 28,8\%. Среди всех пациентов с ожирением, распространенность КП составляет 8\%, а частота КП у пациетов в стационарах, специализирующихся на снижении веса может достигать 50\% [12]. Женщины страдают КП в полтора раза чаще, чем мужчины. Синдром ночной еды встречается от 8,9-19,8\% [13, 14] до 50\% у больных с ожирением [15]. Такая разница, возможно, связана с тем, что синдром ночной еды часто сочетается с другими видами переедания и иногда носит непостоянный характер. 


\section{КОДИРОВАНИЕ ПО МКБ-10}

По МКБ-10 РПП, приводящие к увеличению веса, относятся к поведенческим синдромам, связанным с физиологическими нарушениями, и физическим факторам (F50-59).

В РПП (F50) выделяется:

F50.4 - переедание, связанное с другими психологическими расстройствами (вследствие стрессовых событий, таких как тяжелая утрата, несчастный случай, рождение ребенка и т.д.), - психогенное переедание;

- F50.9 - расстройство приема пищи неуточненное, к которому некоторые авторы относят приступообразное или компульсивное переедание.

\section{РЕКОМЕНДАЦИИ ДЛЯ БОЛЬНЫХ С РПП, СТРАДАЮЩИХ ОЖИРЕНИЕМ.}

Междисциплинарное сотрудничество с психиатром-психотерапевтом, специализирующимся в общесоматической сети.

14.1. Всем больным ожирением при исключении вторичных причин увеличения веса, показана консультация врача психиатра-психотерапевта, специализирующего в общесоматической сети (УДД 2, УУР А).

\section{ДИАГНОСТИКА РПП}

14.2. Необходимо диагностировать РПП, приводящие к развитию ожирения, по синдромальной структуре (УДД 2, УУР А).

Комментарии. Синдромальная классификация РПП:

1. психогенное, или синдром стрессовой еды:

- приступы переедания в условиях эмоционального напряжения на фоне психосоциальных стрессов (гиперфагические реакции на стресс);

2. синдром гедонической еды:

- переедание с целью поддержания хорошего настроения;

- большие объемы пищи являются главным источником эмоционального комфорта и удовольствия;

3. компульсивное, или синдром пищевых эксцессов:

- приступы переедания в большем объеме и быстром темпе с невозможностью прекратить даже при появлении дискомфорта от ощущения перенасыщения;

- выраженное тяготение проявлениями компульсивных приемов пищи с последующими идеями вины за невозможность самостоятельно справиться с зависимостью;

4. перманентное, или синдром постоянной еды:

- постоянные приемы пищи без разграничений по кратности и порционности;

- переедание как источник постоянной эмоциональной поддержки, сопровождающий различные события обыденной жизни;

5. вечернее переедание:

- нарушение ритма приема пищи с наибольшим количеством в вечернее время, перед сном;

- еда носит успокаивающий характер - снятие напряжения, накопившегося за рабочий день;

- утром может отсутствовать аппетит с пропусками приема пищи;

6. приемы пищи в ночное время:

- нарушения сна с пробуждениями;

- тесная связь со стрессами в личной жизни;

7. полисиндромальное переедание:

- эпизоды переедания, различающиеся по синдромальной классификации, иногда с булимическими реакциями и продолжающимся перееданием.

\section{ДИАГНОСТИКА СОПУТСТВУЮЩИХ ПСИХИЧЕСКИХ РАССТРОЙСТВ}

14.3. Рекомендуется выставлять два психиатрических диагноза [16]: «расстройство приема пищи по синдрому переедания» и «коморбидное психическое расстройство» (УДД 2, УУР А).

Комментарии. Расстройства приема пищи в целом имеют высокую степень коморбидности с другими психопатологическими нарушениями [17].

В большинстве случаев «другое психиатрическое расстройство» представлено аффективными (рекуррентное депрессивное расстройство, биполярное аффективное расстройство, циклотимия), тревожно-фобическими (с/без панических атак, социальные фобии, генерализованное тревожное расстройство), обсессивно-компульсивными расстройствами, а также расстройствами, связанными с употреблением психоактивных веществ [16].

Наиболее часто КП проявляется с расстройствами аффективного (22\%) и тревожного (13\%) круга, синдромы ночной еды - большим депрессивным расстройством (51\%), биполярным (13,5\%), генерализованным тревожным $(10,4 \%)$, паническим (8,1\%), обсессивно-компульсивным (7,8\%) расстройствами и социальной фобией (4,2\%) [18].

Кроме того, предпринимаются попытки выделить определенный фенотип, специфичный для расстройств личности больных с КП, характеризующийся повышенной импульсивностью [19, 20, 21$].$ 
Таким образом, важно учитывать, что набору лишнего веса предшествуют длительно развивающиеся РПП и другие психические расстройства $[16,22]$.

\section{КЛИНИЧЕСКИЙ АНАЛИЗ ФОРМИРОВАНИЯ ПАТОЛОГИЧЕСКОГО СТЕРЕОТИПА ПИЩЕВОГО ПОВЕДЕНИЯ}

14.4. Рекомендуется оценивать пищевое поведение на протяжении всей жизни, начиная с формирования в детском возрасте (УДД 2, УУР А).

Комментарии. На этиологию и патогенез РПП оказывает влияние:

1. эпигенетическое воздействие, фетальное программирование:

- приучение к употреблению больших объемов пищи в режиме обыденности вплоть до отсутствия разграничений питания по кратности и порционности;

- доминирование роли пищи по значимости (культ еды с детства), ассоциирующейся с главным источником удовольствия, в ущерб формированию других сфер развития (эстетические, интеллектуальные, духовные);

2. подкрепление негативных эмоций приемами пищи:

- эмоциональное успокоение с помощью еды в условиях стрессов в родительской семье (конфликты между родителями, физическое насилие);

3. дефекты воспитания в отношении становления пищевого поведения:

- еда используется как поощрение и/или наказание;

- насильственное кормление.

Выявление взаимосвязей дебюта/экзацербации РПП с различными факторами (возрастные кризы, психотравмирующие ситуации)

14.5. Рекомендуется применять психопатологический метод оценки психического статуса, клинический анализ жалоб и анамнестических сведений в отношении переедания (УДД 2, УУР А).

При сборе анамнеза учитывается:

возраст начала переедания (часто ранний подростковый и ранний зрелый) [23];

выявление связи переедания с субъективно значимыми стрессовыми событиями.

Комментарии. На фоне психотравмирующих ситуаций запускается патологическая форма приспособления, во время которой не происходит адекватной (эмоционально зрелой) переработки содержания конфликта, психическое напряжение снимается с помощью упрощенных поведенческих реакций, которые сформировались на более ранних этапах развития с мнимым ощущением защиты и безопасности (регрессивный невроз).

В динамике развития РПП на начальных этапах характерны проявления расстройств невротического (тревожного, депрессивного) регистра, обусловленные психотравмирующими ситуациями. В последующем присоединяются гиперфагические реакции, которые становятся доминирующими в клинической картине психопатологических проявлений и зачастую маскируют истинную структуру симптомокомплекса. Запускается стереотипное компенсирующее реагирование гиперфагией на ситуации психоэмоционального напряжения, которое носит характер нарушения влечений для кратковременного облегчения психического состояния. Вследствие появления избыточной массы тела развиваются вторичные депрессивные расстройства с негативным восприятием внешнего образа тела, переживаниями невозможности самостоятельно справиться с неконтролируемым пищевым поведением [24].

\section{ЛЕЧЕНИЕ РПП У БОЛЬНЫХ ОЖИРЕНИЕМ}

14.6. Рекомендуется при лечении РПП при ожирении применять комбинацию психофармакотерапии и психотерапии [25] (УДД 1, УУР А).

Комментарии. Комбинированное лечение является наиболее эффективным [13-15, 26-37] и, самое главное, щадящим для пациентов лечебным подходом. Сначала психофармакотерапией купируется актуальная психопатология, уменьшается интенсивность эпизодов переедания, восстанавливаются адаптационные ресурсы, что способствует более плодотворной психотерапевтической работе.

\section{ПСИХОФАРМАКОТЕРАПИЯ РПП У БОЛЬНЫХ ОЖИРЕНИЕМ}

14.7. Рекомендуется в качестве препаратов выбора для применения психофармакотерапии переедания и сопутствующей психопатологии у больных ожирением использовать лекарства, преимущественно представленные антидепрессантами, относящиеся к трем основным группам (УДД 2, УУР В).

Классификация тимоаналептиков, применяемых для лечения РПП у больных ожирением

1. Группа селективных ингибиторов обратного захвата серотонина (СИОЗС) - флуоксетин [38, 39], флувоксамин [40], сертралин [41], эсциталопрам [42].

2. Группа селективных ингибиторов обратного захвата серотонина и норадреналина (СИОЗСиН) - дулоксетин [43].

3. Группа трициклических антидепрессантов (ТЦА) - дезипрамин, имипрамин [44]. 
Комментарии. Подбор психофармакотерапии осуществляется с целью уменьшения интенсивности переедания, купирования сопутствующей психопатологии (депрессивные, тревожные, обсессивно-компульсивные, соматоформные расстройства), нормализации сна.

Однако эффективность долговременного применения антидепрессантов до сих пор не изучена.

\section{ПСИХОТЕРАПИЯ РПП У БОЛЬНЫХ ОЖИРЕНИЕМ}

14.8. Рекомендуется из психотерапевтических методик использовать основные модальности, представленные когнитивно-поведенческой, интерперсональной, психодинамической психотерапией с различными модификациями (УДД 1, УУР А) [23].

Комментарии. Классификация психотерапевтических методик, применяемых для лечения РПП у больных ожирением.

1. Когнитивно-поведенческая психотерапия (Cognitive Behavioral Therapy - CВТ, КПП) [23].

1. кПП с участием психотерапевта (therapist-led CBT):

является базовой стратегией с применением методов когнитивного переструктурирования и формирования адаптивного поведения в условиях стрессов.

Изучаются паттерны поведения до, во время и после эпизодов переедания с целью осознания их искаженности и изменения на здоровые приемы пищи.

При этом подключается поведенческая интервенция - функциональный анализ и оценка девиантного поведения.

Кроме того, используются техники поведенческой активации, способствующие изменению пассивных негативных мыслей (паттернов) на противоположные - позитивные и преодолевающие.

2. кПП - в режиме самотренинга (self-help CBT) - рекомендована в качестве дополнения к основному лечению для самостоятельной проработки вне работы с психотерапевтом.

КПП помогает лучше контролировать свое поведение в отношении режима питания, справиться с проблемами, которые выступают в роли триггеров к перееданию (депрессивное настроение, негативные чувства в отношении своего тела).

3. Диалектическая поведенческая психотерапия (Dialectical behavior therapy/DBT, ДПП).

Направлена на обучение управлению негативными эмоциями путем рассмотрения разнообразных точек зрения на ситуации напряжения, что способствует уменьшению импульсивного реагирования на стрессы.

Особенно рекомендуется для пациентов с расстройствами личности с импульсивным реагированием, страдающих компульсивным перееданием.

При необходимости к КПП рекомендовано подключать другие виды психотерапии.

2. Интерперсональная (межличностная) психотерапия (Interpersonal psychotherapy).

Прорабатывает актуальные проблемные отношения (на работе, в личной жизни) для улучшения навыков межличностного общения.

Может помочь уменьшить число эпизодов переедания, когда они являются следствием проблем в общении, а также «нездоровых» коммуникативных привычек.

3. Психодинамическая психотерапия (Psychodynamic psychotherapy).

Психоаналитически-ориентированная психотерапия направлена на анализ глубинных психологических конфликтов, послуживших причиной развития пищевых расстройств.

4. Групповая психотерапия РПП у больных ожирением

14.9. Кроме того, при создании определенных условий рекомендуется организовывать группы поддержки (Support groups) или групповую психотерапию (ГП) для больных с РПП и ожирением (УДД 2, УУР В).

Комментарии. В группах поддержки пациенты делятся своим опытом и историями. Чувство принадлежности к социальной группе мотивирует не бросать лечение, а также не чувствовать себя одинокими в болезни.

\section{ПРОФИЛАКТИКА РАЗВИТИЯ РПП У БОЛЬНЫХ ОЖИРЕНИЕМ}

14.10. Для осуществления профилактики ожирения рекомендуется диагностировать признаки РПП, приводящие к увеличению веса на начальных этапах их проявлений, и подключать как можно раньше оказание психиатрической - психотерапевтической помощи при возникновении РПП (УДД 2, УУР В) [23].

Комментарии. Проявления РПП развиваются намного раньше выявления ожирения. Оказание адекватной психиатрической - психотерапевтической помощи поможет предотвратить развитие лишнего веса. 
СПИСОК ЛИТЕРАТУРЫ | REFERENCES

1. Kushner RF. Clinical Assessment and Management of Adult Obesity. Circulation. 2012;126(24):2870-2877. doi: https://doi.org/10.1161/CIRCULATIONAHA.111.075424

2. Вахмистров А.В. Нарушения пищевого поведения при церебральном ожирении: Дис. ... канд. мед. наук. - М.; 2001. [Vakhmistrov AV. Narusheniya pishchevogo povedeniya pri tserebral'nom ozhirenii. [dissertation] Moscow; 2001. (In Russ.)].

3. Дедов И.И. Ожирение. - М.: МИА; 2004. 456 c. [Dedov II. Ozhirenie. Moscow: MIA; 2004. 456 p. (In Russ.)].

4. Mason TB, Lewis RJ. Profiles of Binge Eating: The Interaction of Depressive Symptoms, Eating Styles, and Body Mass Index. Eat Disord. 2014;22(5):450-460. doi: https://doi.org/10.1080/10640266.2014.931766

5. Pisetsky EM, Thornton LM, Lichtenstein P, et al. Suicide attempts in women with eating disorders. J Abnorm Psychol. 2013;122(4):1042-1056. doi: https://doi.org/10.1037/a0034902

6. Stunkard AJ, Costello Allison K. Two forms of disordered eating in obesity: binge eating and night eating. Int J Obes. 2003;27(1):1-12 doi: https://doi.org/10.1038/sj.jij.0802186

7. Giannini J. The Eating Disorders ed. Slaby AE. editor. SpringerVerlag; New York Inc; 1993.

8. Малкина-Пых И.Г. Терапия пищевого поведения. Психология. M.: Эксмо; 2007. [Malkina-Pykh IG. Terapiya pishchevogo povedeniya. Psikhologiya. Moscow: Eksmo; 2007. (In Russ.)].

9. Смулевич А.Б. Психические расстройства в клинической практике. - M.: 2011. [Smulevich A.B. Psikhicheskie rasstroistva $\checkmark$ klinicheskoi praktike. Moscow: 2011. (In Russ.)].

10. Дедов И.И., Мельниченко Г.А., Шестакова М.В., и др. Национальные клинические рекомендации по лечению морбидного ожирения у взрослых. 3-й пересмотр (Лечение морбидного ожирения у взрослых) // Ожирение и метаболизм. - 2018. - Т. 15. №1 - C. 53-70. [Dedov II, Mel'nichenko GA, Shestakova MV, et al. Natsional'nye klinicheskie rekomendatsii po lecheniyu morbidnogo ozhireniya u vzroslykh. 3-ii peresmotr (Lechenie morbidnogo ozhireniya u vzroslykh). Ozhirenie i metabolizm. 2018;15(1):53-70. (In Russ.)]. doi: https://doi.org/10.14341/OMET2018153-70

11. Lowe MR, Caputo GC. Binge eating in obesity: Toward the specification of predictors. Int J Eat Disord. 1991;10(1):49-55. doi: https://doi.org/10.1002/1098-108X(199101)10:1<49::AIDEAT2260100106>3.0.CO;2-X

12. Walsh BT. Eating Disorders: Progress and Problems. Science (80-). 1998;280(5368):1387-1390. doi: https://doi.org/10.1126/science.280.5368.1387

13. Cengiz $Y$, Karamustafalioglu $O$, Toker $S$. Prevalence of night eating syndrome and comorbidity with other psychiatric disorders in Psychiatric Outpatient Population. Yeni Symposium Journal. 2011;49(2):83-88.

14. Miján A. Eating disorders in obesity. Revista Espanola de Obesidad. 2006:4(6):317-327.

15. Brownley KA, Peat CM, La Via M, Bulik CM. Pharmacological Approaches to the Management of Binge Eating Disorder. Drugs. 2015;75(1):9-32. doi: https://doi.org/10.1007/s40265-014-0327-0

16. Schag K, Schönleber J, Teufel M, et al. Food-related impulsivity in obesity and Binge Eating Disorder - a systematic review. Obes Rev. 2013;14(6):477-495. doi: https://doi.org/10.1111/obr.12017

17. Wilfley DE, Friedman MA, Dounchis JZ, et al. Comorbid psychopathology in binge eating disorder: Relation to eating disorder severity at baseline and following treatment. J Consult Clin Psychol. 2000;68(4):641-649. doi: https://doi.org/10.1037/0022-006X.68.4.641

18. Cleator J, Abbott J, Judd P, Sutton C, Wilding JPH. Night eating syndrome: implications for severe obesity. Nutr Diabetes. 2012;2(9):e44-e44. doi: https://doi.org/10.1038/nutd.2012.16

19. Gerlach $\mathrm{G}$, Herpertz S, Loeber S. Personality traits and obesity: a systematic review. Obes Rev. 2015;16(1):32-63. doi: https://doi.org/10.1111/obr.12235

20. Kessler RM, Hutson PH, Herman BK, Potenza MN. The neurobiological basis of binge-eating disorder. Neurosci Biobehav Rev. 2016;63(1):223-238. doi: https://doi.org/10.1016/j.neubiorev.2016.01.013

21. Вознесенская Т.Г., Вахмистров А.В. Клинико-психологический анализ нарушений пищевого поведения при ожирении // Журн. неврол. и психиатр. — 2001. — №12. — С. 19-24. [Voznesenskaya TG, Vakhmistrov AV. Kliniko-psikhologicheskii analiz narushenii pishchevogo povedeniya pri ozhirenii. Zhurn. nevrol. ipsikhiatr. 2001;(12):19-24. (In Russ.)].
22. Welch E, Jangmo A, Thornton LM, et al. Treatment-seeking patients with binge-eating disorder in the Swedish national registers: clinical course and psychiatric comorbidity. BMC Psychiatry. 2016;16(1):163. doi: https://doi.org/10.1186/s12888-016-0840-7

23. The Eating Disorders. Ed. by Giannini J, Andrew E. SpringerVerlag New York Inc.; 1993. 283 p.

24. Гетманчук Е.И. Клинико-психопатологическая и медикопсихологическая характеристика больных с психогенной гиперфагией // Архів психіатрії. - 2012. - Т. 3. — №70. C. 19-25. [Getmanchuk El. Kliniko-psikhopatologicheskaya i mediko-psikhologicheskaya kharakteristika bol'nykh s psikhogennoi giperfagiei. Arkhiv psikhiatriï. 2012;3:(70):19-25. (In Russ.)].

25. Palavras M, Hay P, Filho CAet al. The Efficacy of Psychological Therapies in Reducing Weight and Binge Eating in People with Bulimia Nervosa and Binge Eating Disorder Who Are Overweight or Obese - A Critical Synthesis and Meta-Analyses. Nutrients. 2017;9(3):299. doi: https://doi.org/10.3390/nu9030299

26. Melendez G, Serralde-Zúñiga AE, Gonzalez Garay AG, et al. Fluoxetine for adult overweight or obese people. Cochrane Database Syst Rev. May 2015. doi: https://doi.org/10.1002/14651858.CD011688

27. Ghaderi A, Odeberg J, Gustafsson S, et al. Psychological, pharmacological, and combined treatments for binge eating disorder: a systematic review and meta-analysis. PeerJ. 2018;6:e5113. doi: https://doi.org/10.7717/peerj.5113

28. Alfonsson S, Parling T, Ghaderi A. Group Behavioral Activation for Patients With Severe Obesity and Binge Eating Disorder. Behav Modif. 2015;39(2):270-294. doi: https://doi.org/10.1177/0145445514553093

29. Brownley KA, Berkman ND, Peat CM, et al. Binge-Eating Disorder in Adults. Ann Intern Med. 2016;165(6):409. doi: https://doi.org/10.7326/M15-2455

30. Peat CM, Berkman ND, Lohr KN, et al. Comparative Effectiveness of Treatments for Binge-Eating Disorder: Systematic Review and Network Meta-Analysis. Eur Eat Disord Rev. 2017;25(5):317-328. doi: https://doi.org/10.1002/erv.2517

31. Becker DF, Grilo CM. Comorbidity of mood and substance use disorders in patients with binge-eating disorder: Associations with personality disorder and eating disorder pathology. J Psychosom Res. 2015;79(2):159-64. doi: https://doi.org/10.1016/j.jpsychores.2015.01.016.

32. Fontenelle LF, VItor Mendlowicz M, de Menezes GB, et al. Psychiatric comorbidity in a Brazilian sample of patients with binge-eating disorder. Psychiatry Res. 2003;119(1-2):189-94. doi: https://doi.org/10.1016/S0165-1781(03)00127-6.

33. Grilo C, White M, Barnes R, Masheb R. Psychiatric disorder co-morbidity and correlates in an ethnically diverse sample of obese patients with binge eating disorder in primary care settings. Comp Psychiatry. 2013;54:209-16. doi: https://doi.org/10.1016/j.comppsych.2012.07.012

34. Grucza RA, Przybeck TR, Cloninger CR. Prevalence and correlates of binge eating disorder in a community sample. Comp Psychiatry. 2007:48(2):124-31. doi: https://doi.org/10.1016/j.comppsych.2006.08.002.

35. Hudson Jl, Hiripi E, Pope HG, Kessler RC. The prevalence and correlates of eating disorders in the National Comorbidity Survey Replication. Biol Psychiatry. 2007;61 (3):348-58. doi: https://doi.org/10.1016/j.biopsych.2006.03.040.

36. Javaras KN, Pope HG, Lalonde JK, et al. Co-occurrence of binge eating disorder with psychiatric and medical disorders. J Clin Psychiatry. 2008;69(2):266-73. doi: https://doi.org/10.4088/JCP.v69n0213.Y.

37. Bernstein BE, Bienenfeld D. Binge Eating Disorder (BED) Treatment \& Management. Mar 30, 2020. Available from: https://emedicine.medscape.com/article/2221362-treatment.

38. Arnold LM, McElroy SL, Hudson Jl, et al. A placebocontrolled, randomized trial of fluoxetine in the treatment of binge-eating disorder. J Clin Psychiatry. 2002;63:1028-33. doi: https://doi.org/10.4088/JCP.v63n1113

39. Grilo CM, Masheb RM, Wilson GT. Efficacy of cognitive behavioral therapy and fluoxetine for the treatment of binge eating disorder: a randomized double-blind placebo-controlled comparison. Biol Psychiatry. 2005;57:301-9. doi: https://doi.org/10.1016/j.biopsych.2004.11.002 
40. Hudson Jl, MCElroy SL, Raymond NC, et al. Fluvoxamine in the Treatment of Binge-Eating Disorder: A Multicenter PlaceboControlled, Double-Blind Trial. Am J Psychiatry. 1998;155(12):17561762. doi: https://doi.org/10.1176/ajp.155.12.1756

41. Guerdjikova Al, McElroy SL, Kotwal R, et al. High-dose escitalopram in the treatment of binge-eating disorder with obesity: a placebo-controlled monotherapy trial. Hum Psychopharmacol. 2008;23:1-11. doi: https://doi.org/10.1002/hup.899

42. McElroy SL, Casuto LS, Nelson EB, et al. Placebocontrolled trial of sertraline in the treatment of binge eating disorder. Am J Psychiatry. 2000;157:1004-6. doi: https://doi.org/10.1176/appi.ajp.157.6.1004

43. Guerdjikova Al, McElroy SL, Winstanley EL, et al. Duloxetine in the treatment of binge eating disorder with depressive disorders: A placebo-controlled trial. Int J Eat Disord. 2012;45(2):281-289. doi: https://doi.org/10.1002/eat.20946

44. Laederach-Hofmann K, Graf C, Horber F, et al. Imipramine and diet counseling with psychological support in the treatment of obese binge eaters: A randomized, placebo-controlled double-blind study. Int J Eat Disord. 1999;26(3):231-244. doi: https://doi.org/10.1002/ (SICI) 1098-108X(199911)26:3<231::AID-EAT1>3.0.CO;2-6

\section{ИНФОРМАЦИЯ ОБ АВТОРАХ [AUTHORS INFO]:}

Дедов Иван Иванович, д.м.н., профессор, академик PAH [Ivan I. Dedov, MD, PhD, Professor, academician of RAS]; ORCID: https://orcid.org/0000-0002-8175-7886; ResearcherID: D-3729-2014; Scopus Author ID: 7101843976; eLibrary SPIN: 5873-2280; e-mail: dedov@endocrincentr.ru

Шестакова Марина Владимировна, д.м.н., профессор, академик РАН [Marina V. Shestakova, MD, PhD, Professor, academician of RAS]; ORCID: http://orcid.org/0000-0003-3893-9972; eLibrary SPIN: 7584-7015; e-mail:nephro@endocrincentr.ru

Мельниченко Галина Афанасьевна, д.м.н., профессор, академик PAH [Galina A. Melnichenko, MD, PhD, Professor, academician of RAS]; ORCID: http://orcid.org/0000-0002-5634-7877; eLibrary SPIN: 8615-0038; e-mail: teofrast2000@mail.ru

Мазурина Наталия Валентиновна, к.M.н. [Natalya V. Mazurina, MD, PhD]; ORCID: https://orcid.org/0000-0001-8077-9381; eLibrary SPIN: 9067-3062; e-mail: natalyamazurina@mail.ru

Андреева Елена Николаевна, д.м.Н., профессор [Elena N. Andreeva, MD, PhD, Professor]; ORCID: https://orcid.org/0000-0001-8425-0020; eLibrary SPIN: 1239-2937; e-mail: endogin@mail.ru

Бондаренко Ирина Зиятовна, д.м.н. [Irina Z. Bondarenko, MD, PhD]; ORCID: https://orcid.org/0000-0002-5178-6029; eLibrary SPIN: 4524-4803; e-mail: iz_bondarenko@mail.ru

Гусова Залина Руслановна, K.M.H. [Zalina R. Gusova, MD, PhD]; ORCID: https://orcid.org/0000-0002-2516-2570; eLibrary SPIN: 7295-5053; e-mail: docgzr@yandex.ru

Дзгоева Фатима Хаджимуратовна, К.м.н. [Fatima K. Dzgoeva, MD, PhD]; ORCID: https://orcid.org/0000-0002-0327-4619; eLibrary SPIN: 9315-0722; e-mail: fatima.dzgoeva@gmail.ru

Елисеев Максим Сергеевич, к.м.н. [Maxim S. Eliseev, MD, PhD]; ORCID: https://orcid.org/0000-0003-1191-5831; eLibrary SPIN: 2524-7320; e-mail: elicmax@rambler.ru

Ершова Екатерина Владимировна, к.м.н. [Ekaterina V. Ershova, MD, PhD]; ORCID: https://orcid.org/0000-0002-6220-4397; eLibrary SPIN: 6728-3764; e-mail: yu99pol06@rambler.ru

Журавлева Марина Владимировна, д.м.н., профессор [Marina V. Zhuravleva, MD, PhD, Professor]; ORCID: https://orcid.org/0000-0002-9198-8661; eLibrary SPIN: 6267-9901; e-mail: mvzhuravleva@mail.ru

Захарчук Татьяна Анатольевна, К.M.н. [Tatyana A. Zakharchuk, MD, PhD]; elibrary SPIN: 6632-7230

Исаков Василий Андреевич, д.М.Н., профессор [Vasilii A. Isakov, MD, PhD, Professor];

ORCID: https://orcid.org/0000-0002-4417-8076; eLibrary SPIN: 1182-1646; e-mail: morosoffsv@mail.ru

Клепикова Мария Викторовна, к.м.н. [Mariya V. Klepikova, MD, PhD]; ORCID: https://orcid.org/0000-0003-4258-1889; eLibrary SPIN: 1718-1030; e-mail: pelageam@yandex.ru

Комшилова Ксения Андреевна, К.м.н. [Kseniya A. Komshilova, MD, PhD]; ORCID: https://orcid.org/0000-0002-6220-4397; eLibrary SPIN: 2880-9644; e-mail: kom-ksusha@rambler.ru

Крысанова Вера Сергеевна [Vera S. Krysanova, MD]; ORCID: https://orcid.org/0000-0002-0547-2088; eLibrary SPIN: 6433-2420

Недогода Сергей Владимирович, д.м.н., профессор [Sergei V. Nedogoda, MD, PhD, Professor]; ORCID: https://orcid.org/0000-0001-5981-1754; eLibrary SPIN: 7005-7846; e-mail: nedogodasv@rambler.ru

Новикова Александра Михайловна [Aleksandra M. Novikova, MD]; ORCID: https://orcid.org/0000-0002-3667-722X; eLibrary SPIN: 3821-1050; e-mail: aleksandra.novicova@yandex.ru 
Остроумова Ольга Дмитриевна, К.м.н. [Olga D. Ostroumova, MD, PhD, Professor];

ORCID: https://orcid.org/0000-0002-0795-8225; eLibrary SPIN: 3910-6585; e-mail: ostroumova.olga@mail.ru

Переверзев Антон Павлович, К.M.H. [Anton P. Pereverzev, MD, PhD]; ORCID: https://orcid.org/0000-0001-7168-3636; eLibrary SPIN: 4842-3770; e-mail: acchirurg@mail.ru

Роживанов Роман Викторович, д.м.н. [Roman V. Rozhivanov, MD, PhD]; ORCID: https://orcid.org/0000-0002-53864289; eLibrary SPIN: 8052-3310; e-mail: rrozhivanov@mail.ru

Романцова Татьяна Ивановна, д.м.н., профессор [Tatiana R. Romantsova, MD, PhD, Professor];

ORCID: https://orcid.org/0000-0003-3870-6394; eLibrary SPIN: 3855-5410; e-mail: romantsovatatiana@rambler.ru

Руяткина Людмила Александровна, д.м.н., профессор [Lyudmila A. Ruyatkina, PhD, Professor]; ORCID: https://orcid.org/0000-0002-6762-5238; eLibrary SPIN: 1895-7664; e-mail: larut@list.ru

Саласюк Алла Сергеевна, К.м.н. [Alla S. Salasyuk, MD, PhD]; ORCID: https://orcid.org/0000-0002-6611-9165; eLibrary SPIN: 2651-2916

Сасунова Армида Нисановна [Armida N. Sasunova, MD]; ORCID: https://orcid.org/0000-0001-8896-5285; eLibrary SPIN: 6237-1310; e-mail: pilipenkowork@rambler.ru

Сметанина Светлана Андреевна, д.м.н., професcop [Svetlana A. Smetanina, MD, PhD];

ORCID http://orcid.org/0000-0003-3525-9891; eLibrary SPIN: 3842-6394; e-mail: dr.smetanina@gmail.com

Стародубова Антонина Владимировна, д.м.н., професcop [Antonina V. Starodubova, MD, PhD, Professor]; ORCID: https://orcid.org/0000-0001-9262-9233; e-mail: mailbox@ion.ru

Суплотова Людмила Александровна, д.м.н., профессор [Lyudmila A. Suplotova, MD, PhD, professor]; ORCID http://orcid.org/0000-0001-9253-8075; eLibrary SPIN: 1212-5397; e-mail: dr.suplotova@yahoo.com

Ткачева Ольга Николаевна, д.м.Н., профессор [Olga N. Tkacheva, MD, PhD, Professor]; ORCID http://orcid.org/0000-0002-4193-688X; eLibrary SPIN: 6129-5809

Трошина Екатерина Анатольевна, д.м.н., профессор, член-корреспондент PAH [Ekaterina A. Troshina, MD, PhD, corresponding member of RAS]; ORCID: https://orcid.org/0000-0002-8520-8702; eLibrary SPIN: 8821-8990; e-mail: troshina@inbox.ru

Хамошина Марина Борисовна, д.М.н., профессор [Marina B. Khamoshina, MD, PhD, Professor]; ORCID: https://orcid.org/0000-0003-1940-4534; eLibrary SPIN: 6790-4499

Чечельницкая Серафима Моисеевна, д.м.н., профессор, член-корреспондент РАН [Serafima M. Chechelnitskaya, MD, PhD, Professor]; ORCID: https://orcid.org/0000-0003-0808-2605; eLibrary SPIN: 8847-8731; e-mail: dar-2006@bk.ru

Шестакова Екатерина Алексеевна, к.М.н. [Ekaterina A. Shestakova, MD, PhD]; ORCID: http://orcid.org/0000-0001-6612-6851; eLibrary SPIN: 1124-7600; e-mail: katiashestakova@mail.ru

Шереметьева Екатерина Викторовна, к.м.н. [Ekaterina V. Sheremetyeva, MD, PhD]; ORCID: https://orcid.org/0000-0001-7177-0254; eLibrary SPIN: 9413-5136; e-mail: s1981k@yandex.ru 